Research article

urn:1sid:zoobank.org:pub:C445E95B-446A-4601-AAA3-C1CCBAB627F9

\title{
Systematic revision of the Plectopylinae (Gastropoda, Pulmonata, Plectopylidae)
}

\author{
Barna PÁLL-GERGELY \\ Centre for Agricultural Research, Hungarian Academy of Sciences (MTA), \\ Herman Ottó Street 15, Budapest, H-1022, Hungary. \\ Email: pall-gergely.barna@agrar.mta.hu
}

urn:1sid:zoobank.org:author:31E196E9-5A51-4295-9A36-D5DA689502B7

\begin{abstract}
The family Plectopylidae is divided into two subfamilies: Sinicolinae subfam. nov. (included extant genera: Gudeodiscus Páll-Gergely, 2013, Endothyrella Zilch, 1959, Halongella Páll-Gergely, 2015, Sicradiscus Páll-Gergely, 2013, Sinicola Gude, 1899) and Plectopylinae Möllendorff, 1898 (included genera: Chersaecia Gude, 1899, Hunyadiscus Páll-Gergely, 2016, Naggsia Páll-Gergely \& Muratov, 2016, Plectopylis Benson, 1860). The Eocene fossil Plectopyloides Yen, 1969 is classified into the Sinicolinae. The Plectopylinae are revised mainly based on historical type and non-type material, and the material of the Florida Museum of Natural History, collected in Thailand in the 1980s. The following species-group taxa are described as new: Chersaecia auffenbergi sp. nov., Chersaecia densegyrata sp. nov., Chersaecia mogokensis sp. nov., Chersaecia reversalis sp. nov., Chersaecia scabra sp. nov., Chersaecia shiroiensis subnagaensis subsp. nov., Hunyadiscus tigrina sp. nov., Naggsia oligogyra sp. nov., Plectopylis crassilabris sp. nov., Plectopylis malayana sp. nov. and Plectopylis thompsoni sp. nov. The genus Endoplon Gude, 1899 is treated as a synonym of Chersaecia. Consequently, the two species classified in Endoplon are members of Chersaecia: Chersaecia brachyplecta (Benson, 1863) comb. nov. and Chersaecia smithiana (Gude, 1897) comb. nov. The genus Plectopylis is redefined, and includes only species with fused anterior and posterior lamellae. Thus, the following species are moved from Plectopylis to Chersaecia: Chersaecia feddeni (Blanford, 1865) comb. nov., Chersaecia goniobathmos (Ehrmann, 1922) comb. nov., Chersaecia leucochila (Gude, 1897) comb. nov., Chersaecia magna (Gude, 1897) comb. nov. and Chersaecia woodthorpei (Gude, 1899) comb. nov. Altogether thirteen species and varieties are moved to the synonymy of valid species: Helix (Plectopylis) brachydiscus Godwin-Austen, 1879 syn. nov., Helix (Plectopylis) ponsonbyi Godwin-Austen, 1888 syn. nov., Plectopylis (Chersaecia) kengtungensis Gude, 1914 syn. nov., Plectopylis (Chersaecia) degerbolae Solem, 1966 syn. nov., Plectopylis lissochlamys Gude, 1897 syn. nov., Helix repercussa Gould, 1856 syn. nov., Plectopylis achatina var. obesa Gude, 1898 syn. nov., Plectopylis achatina var. infrafasciata Gude, 1898 syn. nov., Plectopylis achatina var. venusta Gude, 1898 syn. nov., Plectopylis achatina var. castanea Gude, 1898 syn. nov., Plectopylis achatina var. breviplica Gude, 1898 syn. nov., Plectopylis achatina var. repercussoides Gude, 1899 syn. nov., Plectopylis linterae var. fusca Gude, 1898 syn. nov. Plectopylis (Chersaecia) simplex Solem, 1966 is a subspecies of Chersaecia perarcta (Blanford, 1865), whereas Plectopylis muspratti Gude, 1897 is a subspecies of Chersaecia nagaensis (Godwin-Austen, 1875).
\end{abstract}

Keywords. Systematics, taxonomy, new species, anatomy, radula. 
Páll-Gergely B. 2018. Systematic revision of the Plectopylinae (Gastropoda, Pulmonata, Plectopylidae). European Journal of Taxonomy 455: 1-114. https://doi.org/10.5852/ejt.2018.455

\section{Introduction}

The Plectopylidae Möllendorff, 1898 are distributed in Asia from Nepal to southern Japan and from the Chinese provinces of Sichuan, Chongqing and Hubei to the southern edge of northern Vietnam (Gude 1899e; Páll-Gergely \& Hunyadi 2013). Members of this family usually have globular to planispiral shells with a width of 5-35 $\mathrm{mm}$ and an internal armature situated approximately a quarter whorl behind the aperture, which consists of plicae and lamellae on both the palatal and parietal walls. The parietal wall bears one or two vertical (= perpendicular to the suture) lamellae, and usually some horizontal (= parallel with the suture) plicae. The palatal wall usually bears six plicae, which are normally horizontal, but can curve or undulate, and which can divide from or unite with each other.

The Plectopylidae were most intensively studied by Gerard K. Gude of the British Museum. Gude (1899d) subdivided the genus Plectopylis into seven subgenera ("sections"): Endothyra Gude, 1899 (replaced by Endothyrella by Zilch 1959), Chersaecia Gude, 1899, Endoplon Gude, 1899, Plectopylis, Sinicola Gude, 1899, Enteroplax Gude, 1899 and Sykesia Gude, 1897 (described in Gude 1897e). Subsequent research has shown that the latter two do not belong to the family Plectopylidae; Enteroplax belongs to Strobilopsidae Pilsbry, 1918 (Schileyko 1998; Solem 1968; Páll-Gergely et al. 2015a), and Ruthvenia Gude 1911 (which replaced the name Sykesia Gude, 1897) belongs to the family Endodontidae Pilsbry, 1895 (Schileyko 2001).

Recently, 32 species-group taxa and six genera and subgenera were described in the revision of the species of China (Páll-Gergely \& Hunyadi 2013; Páll-Gergely \& Asami 2014, 2016), Vietnam (PállGergely et al. 2015b), and Laos (Páll-Gergely et al. 2016). A separate paper dealing with the genus Endothyrella Zilch, 1960 was also published in the same period (Páll-Gergely et al. 2015c). These studies demonstrated how most genera were insufficiently defined and that new genus-group taxa needed to be introduced. The genus Chersaecia served as a garbage-bin taxon, including species that Gude (1899d) could not place elsewhere. During the revision of Endothyrella (Páll-Gergely et al. 2015c), five species were transferred from Chersaecia to Endothyrella, and both genera were redefined. In the present paper I subdivide the family into two subfamilies (Plectopylinae and Sinicolinae subfam. nov.), and revise the genera assigned to the former subfamily.

\section{Material and methods}

Lists of examined samples for each taxon are separated into types and additional material examined. Locality data presented within the material sections are cited verbatim from the specimen labels and locality codes for the samples are indicated by the mention "loc.". These codes are referred to in tables, figure captions and descriptions. The codes consisting of "PL" and a three-digit number correspond with the database of specimens used for molecular study.

Shell whorls $( \pm 0.25)$ were counted according to Kerney \& Cameron (1979: 13). Differences in size are indicated in the diagnosis using the following terms: very small $(5-10 \mathrm{~mm})$, small $(10-15 \mathrm{~mm})$, medium-sized $(15-20 \mathrm{~mm})$, large $(20-25 \mathrm{~mm})$, very large $(25-35 \mathrm{~mm})$. The dorsal shell side refers to the apical, whereas the ventral refers to the umbilical side.

The palatal plicae can be observed from the interior and exterior of the shell. If enough material was available, a shell fragment with the palatal plicae was broken out and the lamellae were observed directly (interior view). If shell material was limited, the plicae are figured as they were visible through the shell wall (external view). Therefore, the direction of the aperture is indicated under the letters of each 
armature drawing. For nomenclature of lamellae (vertical parietal folds) and plicae (horizontal parietal folds and palatal folds) see Fig. 1.

Ethanol-preserved specimens were dissected under a Leica stereo microscope with a camera attached to provide photographs of the external genital structure, from which drawings were produced. The inner structure of reproductive organs was illustrated from photographs. The terms 'distal' and 'proximal' are used in relation to the gonads. For nomenclature of the reproductive organs and radular teeth, see Fig. 2.

The buccal mass was removed and soaked in 2 molar KOH solution for 5 hours before extracting the radula, which was preserved in $70 \%$ ethanol. Radulae and shells were directly observed without coating under a low vacuum SEM (Miniscope TM-1000, Hitachi High-Technologies, Tokyo).

\section{Morphological characters examined}

\section{Shell characters}

Coiling direction (sinistral or dextral); shell colour; shell size; spire height (this trait is not independent from the depth/width of the umbilicus); whorl shape in dorsal view (bulging or flat; this trait is connected
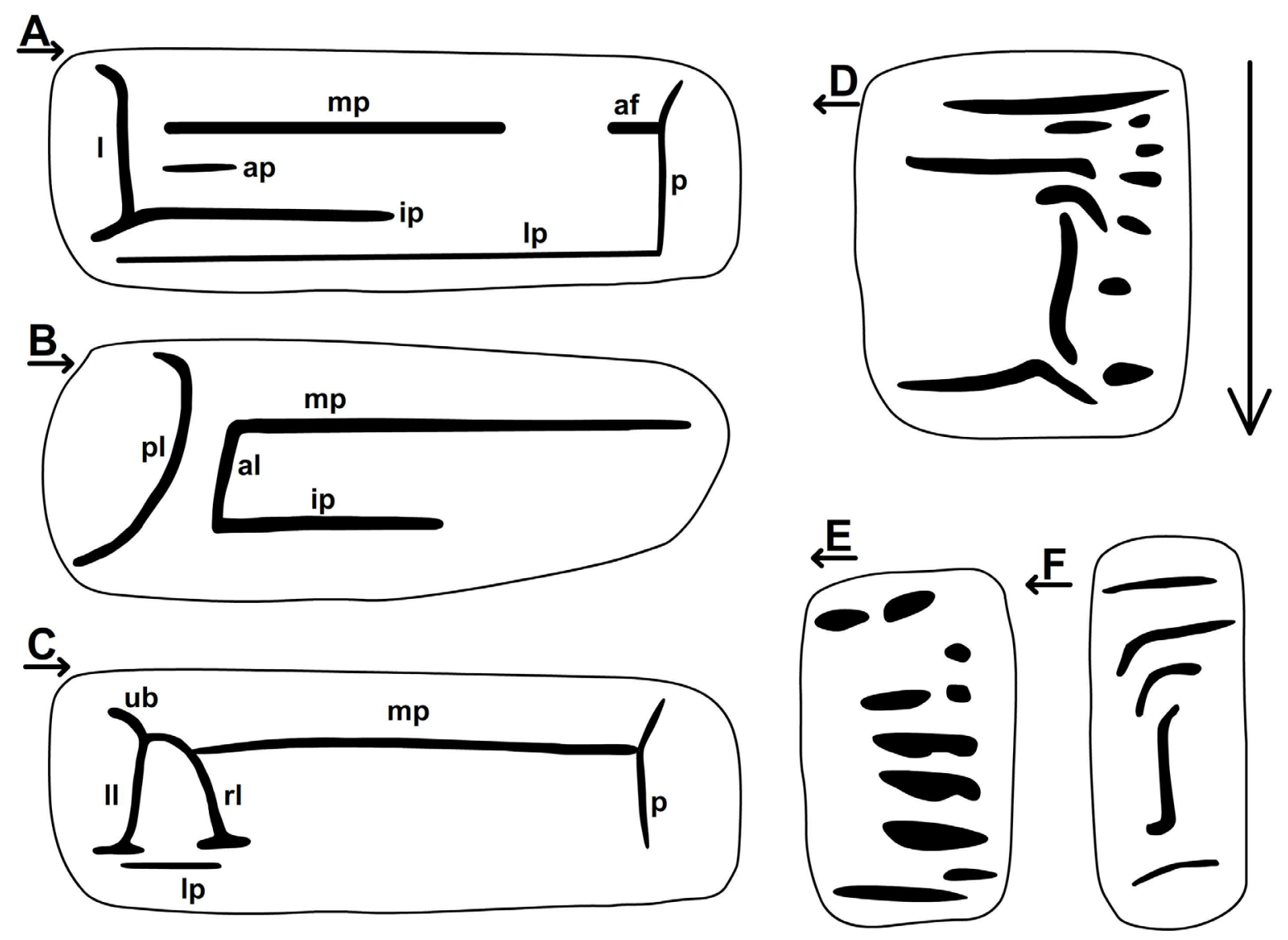

Fig. 1. Nomenclature of parietal (A-C) and palatal (D-F) lamellae and plicae of plectopylids. A. Chersaecia Gude, $1899 \mathrm{sp}$. with a single lamella. B. Chersaecia sp. with two lamellae. C. Plectopylis Benson, 1860 sp. D-E. Chersaecia spp. F. Plectopylis sp. The long arrow shows the order of counting of the plicae. Abbreviations: $a f=$ apertural fold; $\mathrm{al}=$ anterior lamella; $\mathrm{ap}=$ additional $\mathrm{plica}$; $\mathrm{ip}=$ intermediate plica; 1 = lamella; 11 = left leg; lp = lower plica; $\mathrm{mp}=$ main plica; $\mathrm{p}=$ peristome; $\mathrm{pl}=$ posterior lamella; $\mathrm{rl}=$ right leg; $\mathrm{ub}=$ upper branch. Arrows under the numbers indicate the direction of the aperture. 


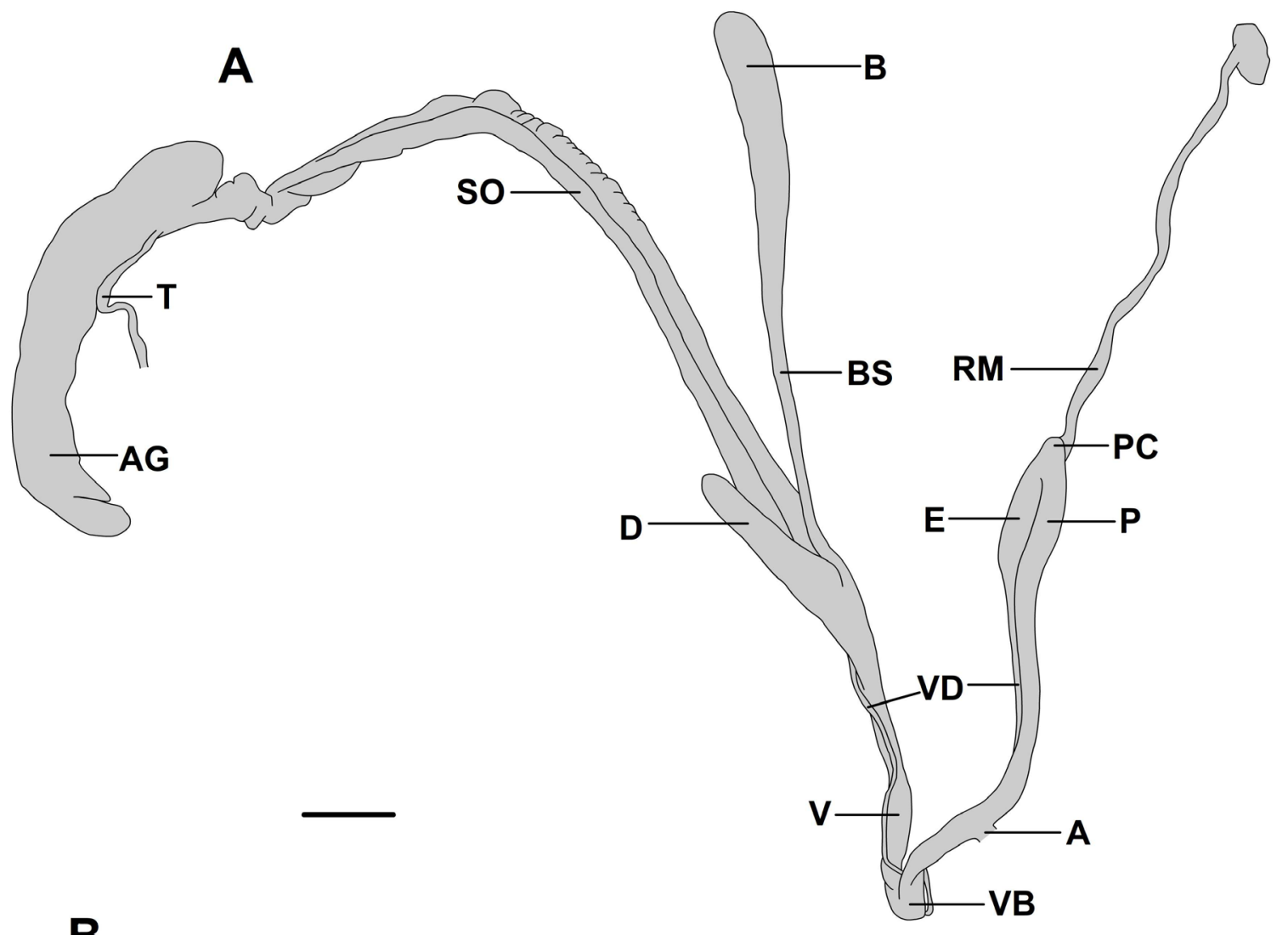

B
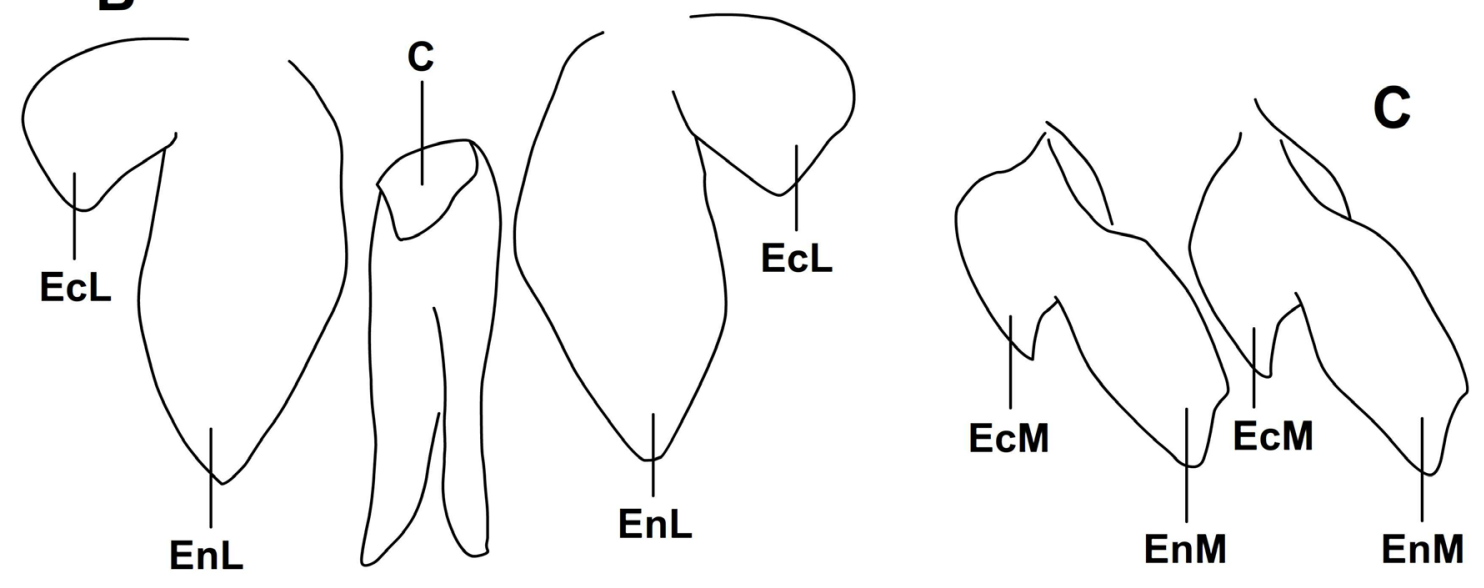

Fig. 2. A. Nomenclature of the genital system of the Plectopylinae (Plectopylis bensoni Gude, 1914: 20091014A, OP7). B. Central and first lateral teeth. C. Marginal teeth. Abbreviations: A = atrium; $\mathrm{AG}=$ albumen gland; $\mathrm{B}=$ bursa of the bursa copulatrix; $\mathrm{BS}=$ stalk of the bursa copulatrix; $\mathrm{C}=$ central tooth; $\mathrm{D}=$ diverticulum; $\mathrm{E}=$ epiphallus; $\mathrm{EcL}=$ ectocone of a lateral tooth; $\mathrm{EcM}=$ ectocone of a marginal tooth; $\mathrm{EnL}=$ endocone of a lateral tooth; $\mathrm{EnM}=$ endocone of a marginal tooth divided slightly in the middle; $\mathrm{P}=$ penis; $\mathrm{PC}=$ penial caecum; $\mathrm{RM}=$ retractor muscle of the penis; $\mathrm{SO}=$ spermoviduct; $\mathrm{T}=$ talon; $\mathrm{V}=$ vagina; $\mathrm{VB}=$ vaginal bulb; $\mathrm{VD}=$ vas deferens. Scale bar: $\mathrm{A}=2 \mathrm{~mm} ; \mathrm{B}-\mathrm{C}$ not to scale. 
to the depth of the suture); whorl shape in apertural view (rounded, keeled, shouldered); number of protoconch and teleoconch whorls; protoconch sculpture; teleoconch sculpture of both dorsal, ventral surfaces; presence/absence/morphology of periostracal folds or hairs; peristome morphology (how strongly thickened, expanded and reflected; shape, height and sharpness of the parietal callus); apertural folds (presence/absence ); connection of parietal callus to apertural folds (parietal callus free/not free); palatal plicae morphology; parietal plicae and lamellae morphology. Note that the modification of the fourth and fifth palatal plicae into a single, vertical plate is not an independent character, but usually associated with the presence of two lamellae (the vertical plate is situated between the two lamellae).

\section{Anatomical characters}

Outer morphology of the penis (reduced or normally developed); surface structure of the inner penial wall; presence/absence/morphology of the calcareous granules inside the penis; presence/absence of the epiphallus and its outer morphology; surface structure of the inner wall of the epiphallus; morphology of the vas deferens; presence/absence/morphology of the penial caecum; length and thickness of the retractor muscle; morphology of the vagina; surface structure of the inner wall of the vagina; presence/ absence/morphology of the diverticulum; morphology of the bursa copulatrix; morphology of the spermatophore.

\section{Radula characters}

Size of the central tooth compared to the ectocones of the first laterals; morphology of the endocone of the laterals; morphology of the marginals: number of cusps, their sharpness and the depth of the incision between the cusps.

\section{Taxonomic treatment}

The taxonomic revision is based on morphology by examination of type and non-type specimens and literature. All taxa are defined based on unique morphological traits, or a unique combination of characters. Some of the characters are discrete (e.g., presence or absence of periostracal filaments) or continuous, but with distinct gaps (e.g., shape of the parietal callus). In some cases I found distinguishable populations in terms of shell size, thickness of the peristome, etc., or minor differences in the plication, collected from georeferenced sites. I refrained from naming these as distinct subspecies in order to avoid oversplitting. Thus, I tried to apply a lumper approach throughout the revision.

Generally, outer shell shape was important in recognizing species. In some cases I did not find diagnosable differences in shell shape in allopatric populations, but did find stable differences in the morphology of lamellae. In those cases, depending on the degree of the differences, I treated them as different species or subspecies. In the case of minor differences I treated these as intraspecific variation and did not apply taxonomic distinctions.

Specimens examined in this study were distinguished using the following notions:

(1) Major differences in the morphology of the plicae, together with those of the protoconch sculpture, resulted in the distinction at the species level (Chersaecia shanensis vs C. mogokensis sp. nov.).

(2) Presence of one vs two lamellae also resulted in the distinction on the species level (C. goniobathmos vs "pseudophis"-like shells of C. leiophis).

(3) Major differences in the morphology of plicae resulted in the differentiation on the subspecific level:

- Presence or absence of the main plica (C. perarcta perarcta vs C. perarcta simplex; C. nagaensis nagaensis vs $C$. nagaensis muspratti).

- Presence or absence of the intermediate plica (C. shiroiensis shiroiensis vs C. shiroiensis subnagaensis subsp. nov.). 
(4) Minor differences in the plication did not result in distinction at any taxonomic level.

- Main plica connected to the apertural fold or not (C. dextrorsa, C. perarcta perarcta; P. bensoni, P. cairnsi, P. malayana sp. nov.).

- Apertural fold connected to the main plica or not (C. dextrorsa).

- Intermediate plica connected to the lamella or not (C. leiophis).

- Additional minor plicae present or absent (C. dextrorsa, C. nagaensis).

- Lower plica short or long (C. feddeni, C. magna).

- Intermediate plica short or long (C. shanensis).

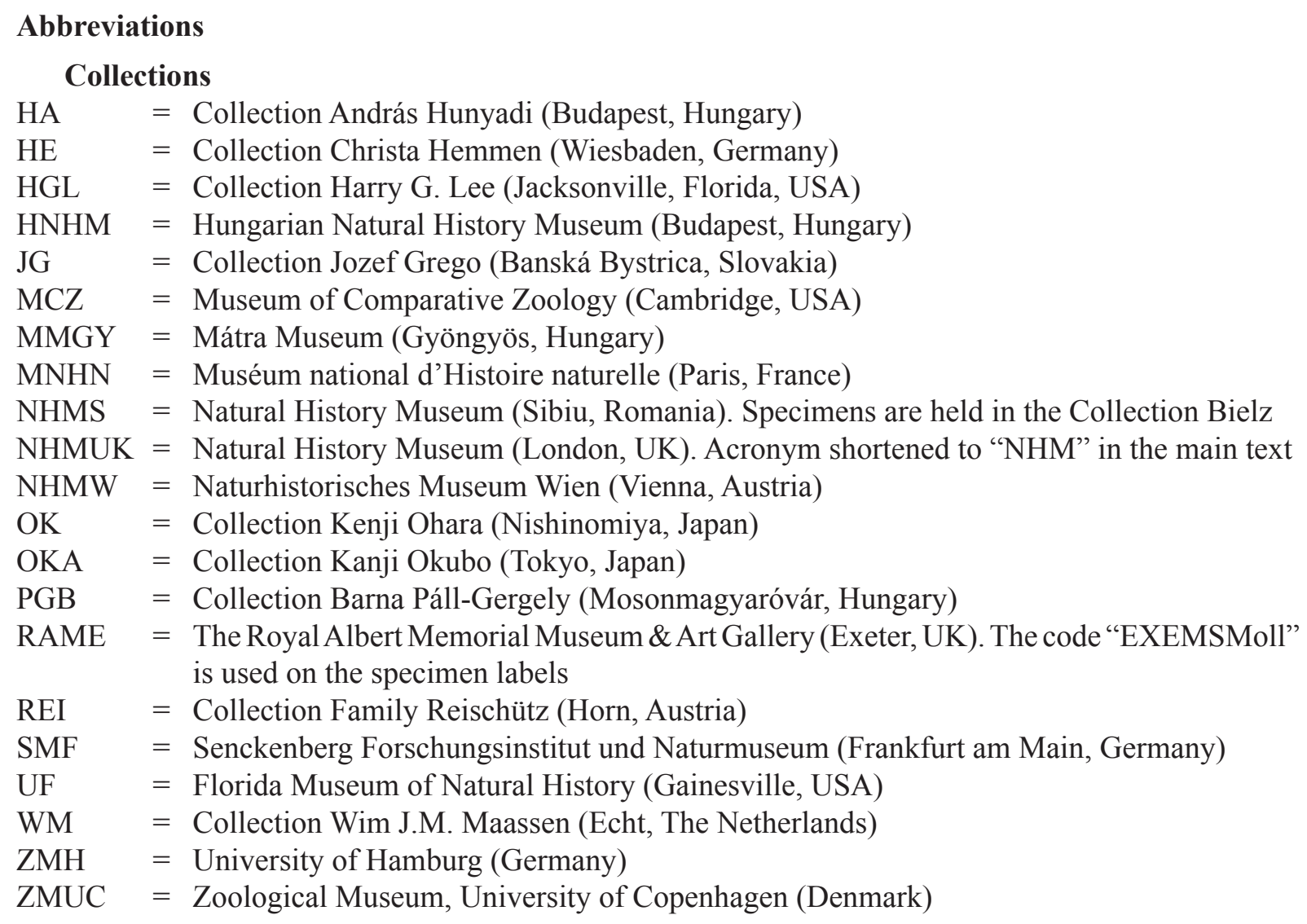

\section{Measurements}

$\mathrm{D}=$ shell diameter

$\mathrm{H}=$ shell height 
PÁLL-GERGELY B., Systematic revision of the Plectopylinae

\section{Results}

Class Gastropoda Cuvier, 1795

Order Stylommatophora Schmidt, 1855

Superfamily Plectopyloidea Möllendorff, 1898

\section{Content}

Plectopylidae Möllendorff, 1898.

\section{Remarks}

Plectopylidae, Corillidae Pilsbry, 1905 and Sculptariidae Degner, 1923 have been assigned to the superfamily Plectopyloidea by Bouchet et al. (2005, 2017). However, Schileyko (1999) had previously moved Sculptariidae to the superfamily Acavoidea Pilsbry, 1894. Schileyko also treated Corillidae as the closest relative of Plectopylidae (both Plectopyloidea). Although only limited molecular data is available, the conchologically very similar Corillidae are probably not closely related to Plectopylidae (Raheem et al. 2017). Therefore, the Corillidae and the similar Sculptaridae are excluded from the superfamily Plectopyloidea herein.

Family Plectopylidae Möllendorff, 1898

Plectopylidae Möllendorff, 1898: 147.

\section{Type genus}

Plectopylis Benson, 1860.

\section{Diagnosis}

Shell sinistral or dextral, small to very large (5-35 mm); flat, depressed-conical or conical; dorsal surface concave, flat (even in those cases the protoconch usually protrudes above surface), conical or domed; protoconch sculpture variable between genera (ribbed, wrinkled, reticulated, tuberculated); dorsal surface usually with reticulated structure (consisting of spiral and radial lines); ventral surface usually with less prominent sculpture; deciduous periostracal folds might be present on the periphery of body whorl; aperture oblique to shell axis; peristome expanded, sometimes reflected; parietal callus present, V- or slightly S-shaped, apertural fold present or absent; multiple armatures formed during growth, the last one $0.25-0.75$ whorls behind aperture; parietal wall with one or two vertical lamellae, usually with additional horizontal plicae above and below the lamellae or anterior to them; palatal wall with 6-7 plicae, which are variable in morphology: straight and horizontal, depressed Z-shaped, sometimes divided in the middle (most often when there is a single parietal lamella), or the fourth and fifth fuse to each other, forming a vertical plate (most often where there are two parietal lamellae).

Ommatophoral retractor (in sinistral specimens the left, in dextral specimens the right retractor) runs between the penis and vagina; atrium short; penis very short, vestigial to well-developed, without verge, usually with parallel folds internally; calcareous crystals may be present between folds; epiphallus usually present, bound to penis by weak fibres; penial caecum short or absent, retractor muscle inserts on penial caecum or, if caecum is absent, at the penis-epiphallus transition; vas deferens long, usually thickened before entering spermoviduct; vagina well-developed, usually U-shaped, sometimes with thickened 'vaginal bulb' formed at turning point of ' $U$ ', attached to body wall with multiple, short muscle fibres; vagina internally with longitudinal folds; spermoviduct long; bursa copulatrix with slender stalk of variable length and usually an ovoid bursa; diverticulum usually present, short ovoid to very long, 
slender, usually originates near originating point of bursa copulatrix; all species ovoviviparous, embryo sac with several small calcareous crystals on its surface; talon normally developed, elongated, albumen gland of variable length.

Radula elongated, but not very slender; teeth arranged in rows; laterals in straight rows perpendicular to central column; marginals in anteriorly pointed, slightly oblique rows, central tooth with a single, small to medium-sized cusp (sometimes absent), which is smaller or larger than ectocones of first laterals, but always smaller than endocones of first laterals; first laterals with a large endocone and a small ectocone; transition between laterals and marginals is gradual with endocone being gradually divided into two cusps, ectocones usually remain undivided.

\section{Distribution}

The family Plectopylidae extends from the southern Himalayan region (Nepal and northeastern India) throughout Myanmar, the Malay Peninsula, southern and northern Thailand, northern Laos, northern Vietnam, central, southern and eastern China (Yunnan, Sichuan, Guizhou, Chongqing, Hubei, Hunan, Guangxi, Guangdong, Jiangxi, Zhejiang and Fujian Provinces) to Taiwan and southern Japan (Miyako Island) (Fig. 3).

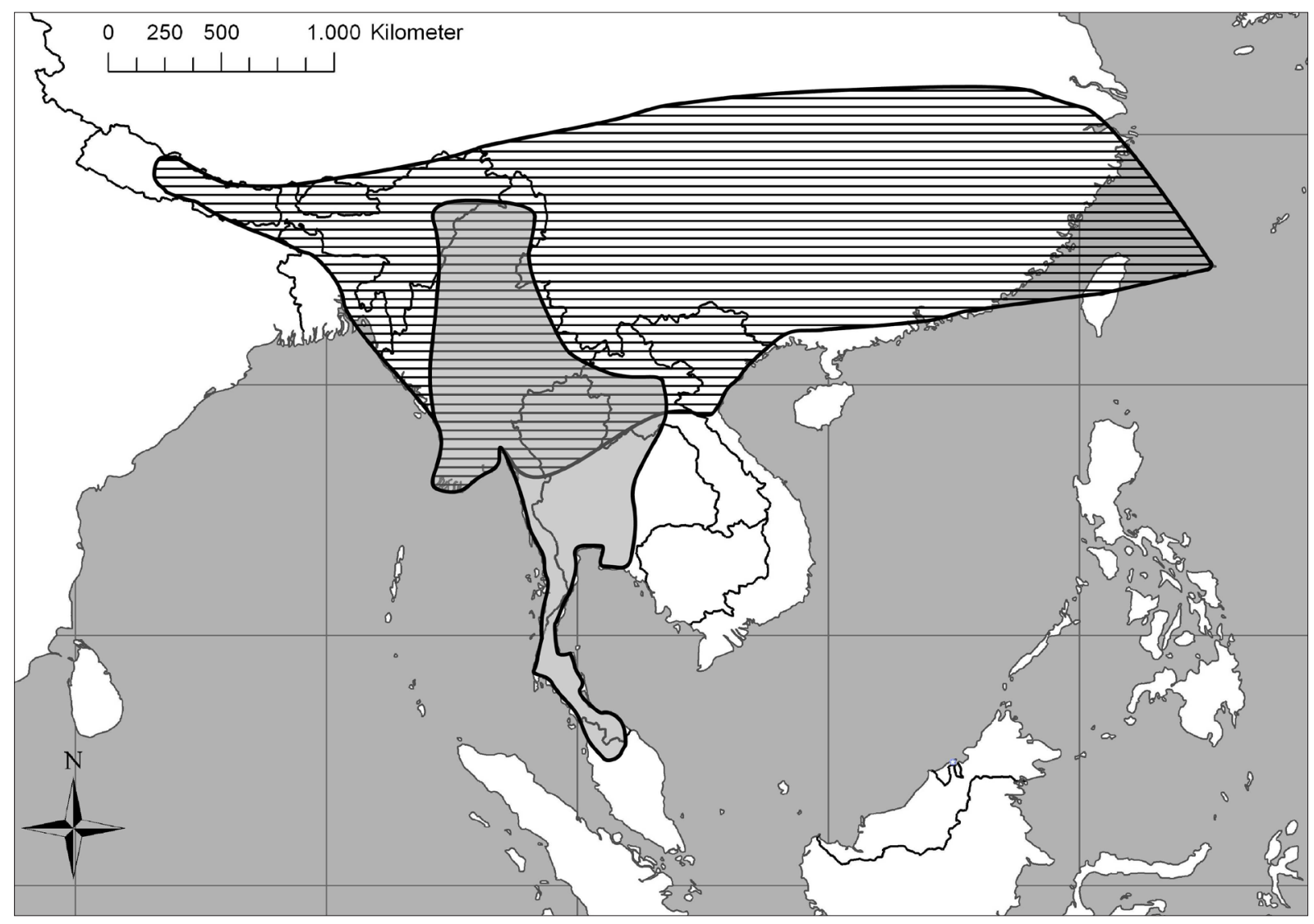

Fig. 3. Distribution of the extant Sinicolinae subfam. nov. (ruled area) and Plectopylinae Möllendorff, 1898 (grey shaded area). Mainly after Páll-Gergely \& Hunyadi (2013) and Páll-Gergely et al. (2015b, 2015c, 2016). 


\section{Subfamily Sinicolinae subfam. nov. urn:Isid:zoobank.org:act:7AA09CFF-D5FD-4DB1-98BE-9DB9E41F6B82}

\section{Type genus}

Sinicola Gude, 1899.

\section{Included genera}

Gudeodiscus Páll-Gergely, 2013 (with the subgenus Veludiscus Páll-Gergely, 2015), Endothyrella, Halongella Páll-Gergely, 2015, Sicradiscus Páll-Gergely, 2013, Sinicola.

The Eocene fossil genus Plectopyloides Yen, 1969 (type species: P. cretaceous Yen, 1969; synonyms: Henanspirus Li, 1986, Menyinspirus Li, 1986, Yenellus Li, 1986) is also classified in this subfamily, because it is most similar to Gudeodiscus (see Páll-Gergely \& Asami 2014).

\section{Diagnosis}

Shell usually dextral (although most species of Endothyrella are sinistral), flat to conical-globular; umbilicus wide to narrow; protoconch regularly ribbed without any additional sculptural elements (very rarely smooth, see Páll-Gergely et al. 2015b, 2015c); apertural fold present or absent; main plica usually absent (present only in Gudeodiscus longiplica Páll-Gergely \& Asami, 2016). Penis well-developed; penial caecum well-developed to absent; epiphallus present; diverticulum as long as bursa copulatrix (absent in some species, although possibly overlooked during dissection).

\section{Distribution}

Same as in the family Plectopylidae, except Thailand and the Malay Peninsula (Fig. 3).

\section{Remarks}

The subdivision of the family into two reciprocally monophyletic groups is supported by molecular phylogenetic analysis, which included nearly all genera. Discussion of the phylogenetic results is beyond the scope of the present revision, and will be discussed in a separate paper.

\section{Subfamily Plectopylinae Möllendorff, 1898}

\section{Type genus}

Plectopylis Benson, 1860.

\section{Included genera}

Chersaecia Gude, 1899 (synonym: Endoplon Gude, 1899), Hunyadiscus Páll-Gergely, 2016, Naggsia Páll-Gergely \& Muratov, 2016, Plectopylis Benson, 1860.

\section{Diagnosis}

Shell usually sinistral, flat to depressed conical; umbilicus wide to moderately wide; protoconch with variable sculptural elements (finely granulated, spirally striated, irregularly wrinkled/ribbed); apertural fold usually present, main plica usually present. Penis well-developed or reduced; penial caecum absent or small, epiphallus present or absent; diverticulum usually present, shorter than bursa copulatrix.

\section{Distribution}

Southeastern Himalaya (Nagaland and Manipur in northeastern India), Myanmar and the neighbouring Chinese border region (Yunnan Province), Thailand (with the exception of the lowlands in the central and northeastern regions), northern Laos (Fig. 3). 
Genus Chersaecia Gude, 1899

Chersaecia Gude, 1899d: 148.

Endoplon Gude, 1899d: 148. Syn. nov.

Chersaecia - Páll-Gergely et al. 2015c: 9.

\section{Type species}

Helix (Plectopylis) leiophis Benson, 1860 by original designation.

\section{Included species and subspecies}

Chersaecia auffenbergi sp. nov., C. brachyplecta (Benson, 1863) comb. nov., C. dextrorsa (Benson, 1860), C. feddeni (Blanford, 1865) comb. nov., C. goniobathmos (Ehrmann, 1922) comb. nov., C. leiophis (Benson, 1860), C. leucochila (Gude, 1897) comb. nov., C. magna (Gude, 1897) comb. nov., C. mogokensis sp. nov., C. nagaensis nagaensis (Godwin-Austen, 1875), C. nagaensis muspratti (Gude, 1897), C. perarcta perarcta (Blanford, 1865), C. perarcta simplex (Solem, 1966), C. perrierae (Gude, 1898), C. refuga (Gould, 1846), C. reversalis sp. nov., C. shanensis (Stoliczka, 1873), C. shiroiensis shiroiensis (Godwin-Austen, 1875), C. shiroiensis subnagaensis subsp. nov., C. smithiana (Gude, 1897) comb. nov., C. woodthorpei (Gude, 1899) comb. nov.

\section{Diagnosis}

Shell sinistral or dextral, flat, widely umbilicated; in most cases protoconch seemingly 'smooth', but never glossy, matt or with tubercles of various size; aperture always with fold; parietal wall with one or two vertical lamellae and usually one or two long horizontal plicae reaching the parietal callus (main and lower plica); all palatal plicae horizontal, sometimes divided in the middle, in some species with several additional denticles posteriorly, in some species three horizontal plicae above and one below the vertical plate formed by the accretion of two plicae (similar to that of Plectopylis).

Penis long, cylindrical to very short (reduced), internally with irregular longitudinal folds; penial caecum usually absent (rudimentary caecum rarely discernible); epiphallus present or absent; retractor muscle inserts on penis-epiphallus transition (or at the proximal end of penis); vas deferens slender, with thickened proximal part (or entire vas deferens thickened); vagina slender, usually long, with weak fibre muscles; bursa copulatrix long, with slightly or moderately thickened bursa; diverticulum conical to elongated, cylindrical, shorter than bursa (note that in C. perarcta simplex no diverticulum was reported).

\section{Differential diagnosis}

Chersaecia differs from Endothyrella, Gudeodiscus, Halongella, Sicradiscus and Sinicola by the usually tuberculated (not regularly ribbed) protoconch and the presence of long palatal plica extending to the parietal callus (the only exception is Gudeodiscus longiplica). For the delimitation of Chersaecia from Plectopylis, see Remarks.

\section{Distribution}

The genus Chersaecia is known from northeastern India, Myanmar and northern Thailand (Fig. 4).

\section{Remarks}

Gude (1899d) diagnosed Chersaecia: "Sinistral or dextral. Umbilicus wide. Palatal folds horizontal or oblique. Sometimes with one or oblique or vertical plate", whereas the diagnosis of Plectopylis s.s. was given as follows: "Sinistral. Shell flattened. Palatal armature: one vertical plate with three horizontal folds above, one below". However, the fusion of the fourth and fifth palatal plicae into a vertical plate, which is very characteristic in Plectopylis, is also present in two species (perrierae, 
shiroiensis) assigned to Chersaecia by Gude (1899d). Therefore this character-state cannot be used as a distinguishing character between the two genera. The peculiarity of Gude's division is that all species of Plectopylis have two lamellae (sometimes connecting at their upper end), whereas all Chersaecia have only one lamella. These character-states, however, were mentioned by Benson (1860), but not Gude (1899d). Gude (1914b) referred to Plectopylis woodthorpei as the transitional form between Plectopylis and Chersaecia, probably because of the small size of the species, which is similar to Chersaecia, but with two lamellae, which is characteristic of Plectopylis sensu Gude (1899d). Some specimens of Chersaecia perrierae show an intermediate character-state between the one and two lamellae types (see

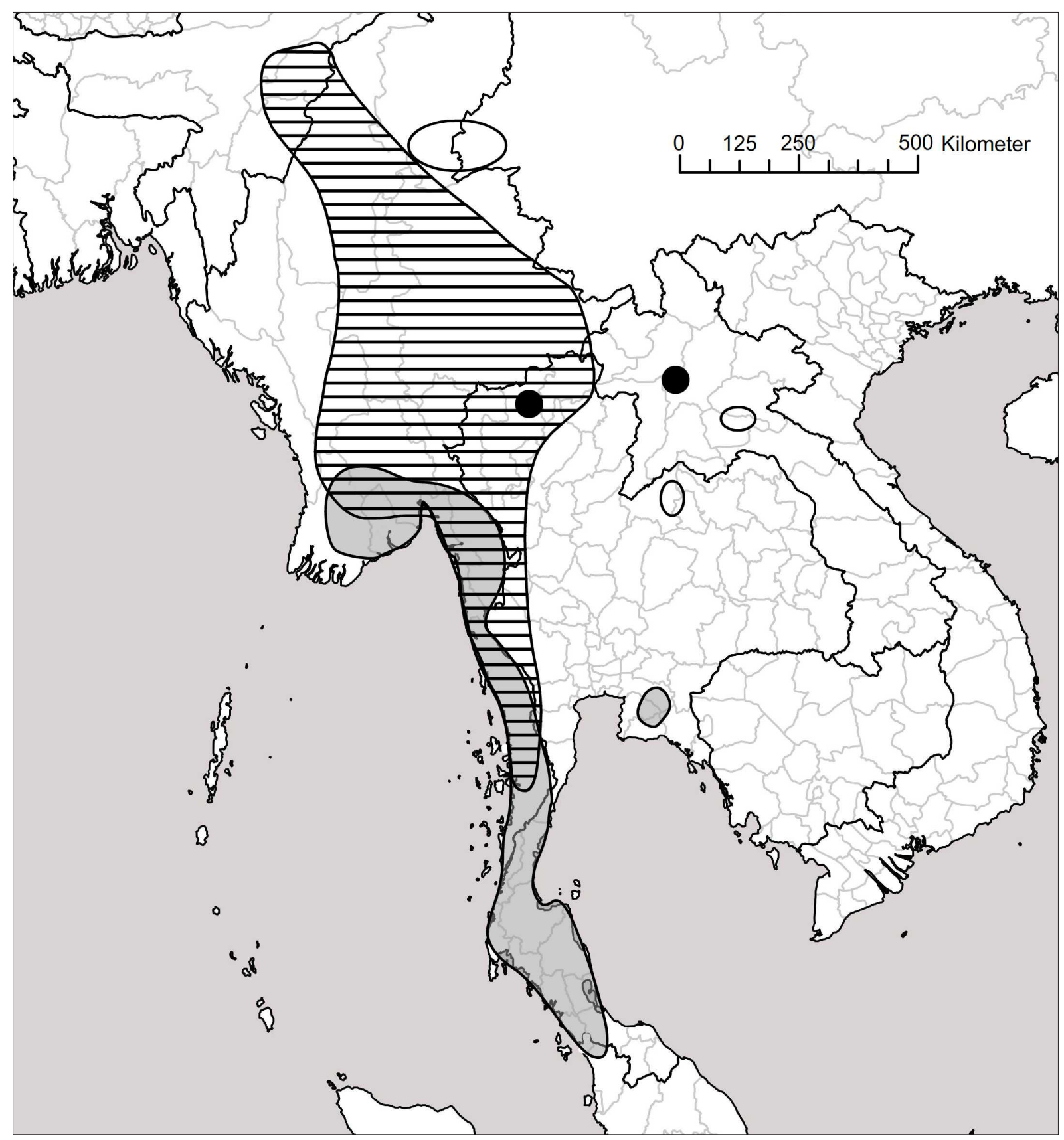

Fig. 4. Distribution of the genera Chersaecia Gude, 1899 (ruled area), Hunyadiscus Páll-Gergely, 2016 (white area), Naggsia Páll-Gergely \& Muratov, 2016 (black circles) and Plectopylis Benson, 1860 (grey shaded area). 
under that species). Moreover, the main difference between typical Chersaecia leiophis and Plectopylis goniobathmos is the absence (leiophis) and presence (goniobathmos) of an anterior lamella. These data suggest that the distinguishing mark between Plectopylis and Chersaecia cannot be the number of lamellae, because it shows clinal variability between species, or even between different specimens of the same sample (Fig. 5). I therefore retain all species that are characterized by two lamellae fused at their upper ends, forming a structure which resembles the Greek letter lambda, in the genus Plectopylis. All other former species of Plectopylis, which possess two independent lamellae, are henceforth assigned to the genus Chersaecia.

The two species classified in the genus Endoplon Gude, 1899 (type species: Helix (Plectopylis) brachyplecta Benson, 1863, by original designation) do not differ from some species of Chersaecia (e.g., C. magna) in any notable shell characters, only by the coiling direction, which is insufficient to maintain the generic distinction. Therefore, Endoplon is moved to the synonymy of Chersaecia.

Gude (1899d) classified all Vietnamese species in Endoplon. The revision of the Chinese species, however, revealed that the western (Burmese) and eastern (Chinese and Vietnamese) species are only distantly related (see Páll-Gergely \& Hunyadi 2013). The genus Gudeodiscus was erected for the Vietnamese and Chinese taxa formerly placed in Endoplon.

Chersaecia is very diverse in terms of anatomical characters, especially the length of the penis and the presence or absence of the epiphallus. So far, the limited information on the genitalia is not in agreement with conchological characters. For example, the epiphallus is absent in C. perrierae, but present in the conchologically similar $C$. shanensis. In contrast, the conchologically different $C$. scabra sp. nov. is very similar to $C$. dextrorsa in the genital anatomy (especially the absence of the epiphallus and the vestigial penis). The species classified in this genus should be placed in at least two different genera based on the presence/absence of the epiphallus. However, I here refrain from describing any new genera, because the anatomy of the type species (C. leiophis), and the majority of the other species are unknown.

Table 1 summarizes the key characters of species of Chersaecia.
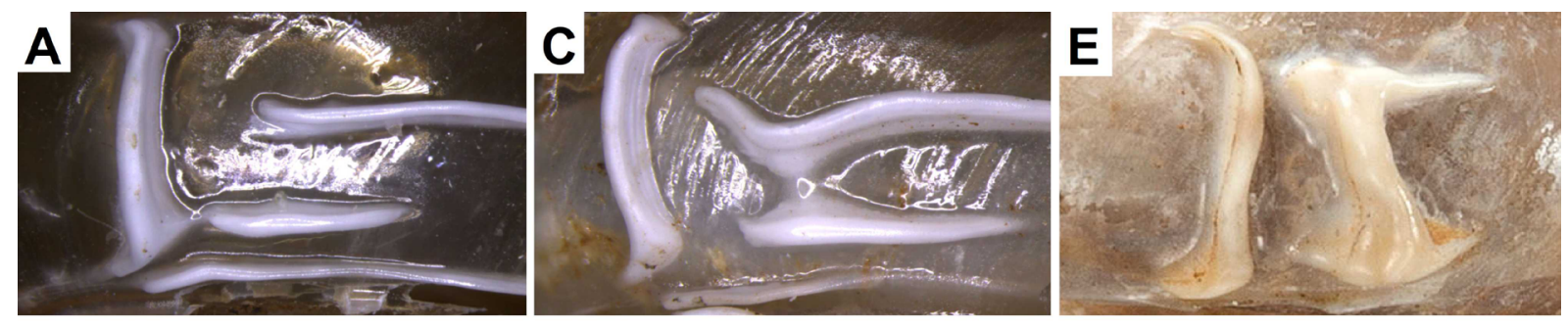

B

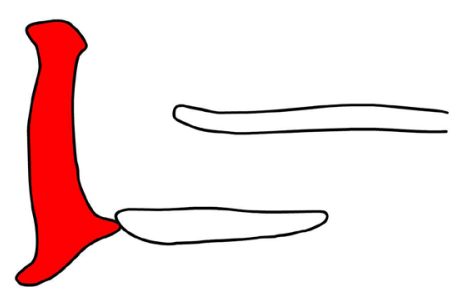

D

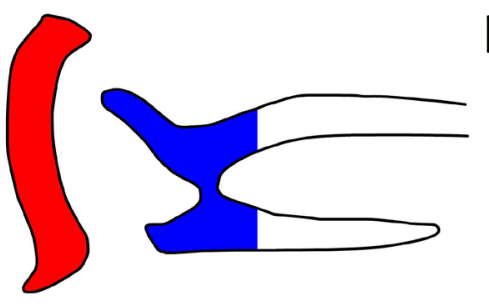

$\mathbf{F}$

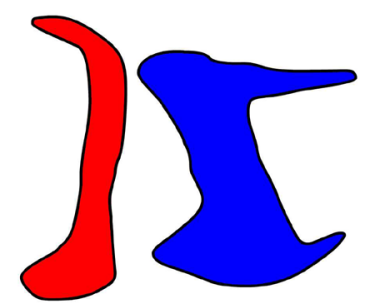

Fig. 5. Photos (A, C, E) and schematic drawings (B, D, F) of parietal plicae and lamellae of Plectopylinae Möllendorff, 1898. A-B. Chersaecia shanensis (Stoliczka, 1873), loc. 20091018C (PGB, ex coll. Ohara). C-D. Chersaecia perrierae (Gude, 1898), loc. 20091019A (PGB). E-F. Chersaecia magna (Gude, 1897) comb. nov., holotype (NHMUK 1922.8.29.37). Posterior lamella indicated with red colour, anterior lamella and homologous structures indicated with blue. Not to scale. Photos: B. Páll-Gergely (A, C) and H. Taylor (E). 
Table 1 (continued on next page). Key characters, most similar species and distribution of species of Chersaecia Gude, 1899, Hunyadiscus Páll-Gergely, 2016 and Naggsia Páll-Gergely \& Muratov, 2016.

\begin{tabular}{|c|c|c|c|}
\hline Taxon & Key traits & Most similar species & Distribution \\
\hline C. auffenbergi sp. nov. & $\begin{array}{l}\text { sinistral, concave dorsal side, two } \\
\text { lamellae, Y-shaped palatal plicae }\end{array}$ & - & $\begin{array}{l}\text { northern Thailand } \\
\text { (Chiang Mai Province) }\end{array}$ \\
\hline C. austeni & $\begin{array}{l}\text { dextral, yellowish, dorsal side } \\
\text { concave }\end{array}$ & - & northeast India \\
\hline C. brachyplecta & dextral, thick shell, two lamellae & C. smithiana & $\begin{array}{l}\text { Myanmar } \\
\text { (Mawlamyine) }\end{array}$ \\
\hline C. densegyrata sp. nov. & dextral, flat, closely coiled & C. dextrorsa & northern Thailand \\
\hline C. dextrorsa & $\begin{array}{l}\text { dextral, protoconch with cellular } \\
\text { structure, ventral side reticulated }\end{array}$ & $\begin{array}{l}\text { C. densegyrata } \mathrm{sp} . \text { nov., } \\
\text { C. reversalis sp. nov. }\end{array}$ & $\begin{array}{l}\text { Thai-Myanmarese } \\
\text { border region }\end{array}$ \\
\hline C. feddeni & sinistral, flat, fragile, two lamellae & - & southern Myanmar \\
\hline C. goniobathmos & $\begin{array}{l}\text { sinistral, brown, spire elevated, two } \\
\text { lamellae }\end{array}$ & C. nagaensis nagaensis & $\begin{array}{l}\text { Myanmar (southern } \\
\text { Shan State) }\end{array}$ \\
\hline C. leiophis & $\begin{array}{l}\text { sinistral, single lamella, base } \\
\text { reticulated, body whorl shouldered, } \\
\text { intermediate plica long }\end{array}$ & $\begin{array}{l}\text { C. leiophis, C. nagaensis, } \\
\text { C. refuga }\end{array}$ & $\begin{array}{l}\text { Myanmar (Bago, Pyay, } \\
\text { Thayet, Shan States, } \\
\text { etc.) and northern } \\
\text { Thailand. }\end{array}$ \\
\hline C. leucochila & $\begin{array}{l}\text { sinistral, spire elevated, two } \\
\text { lamellae, main plica long }\end{array}$ & C. magna & Myanmar \\
\hline C. magna & $\begin{array}{l}\text { sinistral, large, flat, two lamellae, } \\
\text { main plica short }\end{array}$ & C. leucochila & southern Myanmar \\
\hline C. mogokensis sp. nov. & $\begin{array}{l}\text { sinistral, large, reddish shell, single } \\
\text { lamella without additional plicae }\end{array}$ & C. shanensis & $\begin{array}{l}\text { Myanmar (northern } \\
\text { Mandalay Province) }\end{array}$ \\
\hline C. nagaensis nagaensis & $\begin{array}{l}\text { sinistral, single lamella, body whorl } \\
\text { rounded, main plica present }\end{array}$ & $\begin{array}{l}\text { C. nagaensis muspratti, } \\
\text { C. shiroiensis spp., } \\
\text { C. goniobathmos }\end{array}$ & $\begin{array}{l}\text { northeast India } \\
\text { (Naga Hills) }\end{array}$ \\
\hline C. nagaensis muspratti & $\begin{array}{l}\text { sinistral, single lamella, body whorl } \\
\text { rounded, main plica absent }\end{array}$ & C. nagaensis nagaensis & $\begin{array}{l}\text { northeast India (Naga } \\
\text { Hills) }\end{array}$ \\
\hline C. perarcta perarcta & $\begin{array}{l}\text { sinistral, small, flat, single lamella, } \\
\text { main plica long, palatal plicae } \\
\text { horizontal }\end{array}$ & $\begin{array}{l}\text { C. perarcta simplex, } \\
\text { C. perrierae }\end{array}$ & $\begin{array}{l}\text { Myanmar (Mandalay } \\
\text { Province) and northern } \\
\text { Thailand (Chiang Rai } \\
\text { Province) }\end{array}$ \\
\hline C. perarcta simplex & $\begin{array}{l}\text { sinistral, small, flat, single lamella, } \\
\text { main plica absent, palatal plicae } \\
\text { horizontal }\end{array}$ & C. perarcta perarcta & $\begin{array}{l}\text { northern Thailand } \\
\text { (Chiang Mai Province) }\end{array}$ \\
\hline C. perrierae & $\begin{array}{l}\text { sinistral, single lamella (with } \\
\text { sometimes indication of a second), } \\
\text { 4th and 5th parietal plicae form a } \\
\text { vertical plate }\end{array}$ & C. perarcta perarcta & middle Myanmar \\
\hline C. refuga & $\begin{array}{l}\text { sinistral, single lamella, base } \\
\text { glossy, intermediate plica short }\end{array}$ & C. leiophis & southern Myanmar \\
\hline
\end{tabular}


Table 1 (continued). Key characters, most similar species and distribution of species of Chersaecia Gude, 1899, Hunyadiscus Páll-Gergely, 2016 and Naggsia Páll-Gergely \& Muratov, 2016.

\begin{tabular}{|c|c|c|c|}
\hline Taxon & Key traits & Most similar species & Distribution \\
\hline C. reversalis sp. nov. & dextral, glossy ventral side & C. dextrorsa & $\begin{array}{l}\text { eastern Thailand } \\
\text { (Tak Province) }\end{array}$ \\
\hline C. scabra sp. nov. & $\begin{array}{l}\text { sinistral, two lamellae, rounded } \\
\text { body whorl }\end{array}$ & C. woodthorpei & $\begin{array}{l}\text { northern Thailand } \\
\text { (Chiang Rai Province) }\end{array}$ \\
\hline C. shanensis & $\begin{array}{l}\text { sinistral, reddish, large shell, single } \\
\text { lamella, middle parietal plica long }\end{array}$ & C. mogokensis sp. nov. & $\begin{array}{l}\text { Myanmar (Shan and } \\
\text { Mandalay States) }\end{array}$ \\
\hline C. shiroiensis shiroiensis & $\begin{array}{l}\text { sinistral, small, umbilicus with } \\
\text { keel, single lamella, intermediate } \\
\text { plica present }\end{array}$ & $\begin{array}{l}\text { C. nagaensis, } \\
\text { C. shiroiensis subnagaensis } \\
\text { subsp. nov. }\end{array}$ & $\begin{array}{l}\text { northeastern India } \\
\text { (Naga Hills and } \\
\text { Manipur) }\end{array}$ \\
\hline $\begin{array}{l}\text { C. shiroiensis subnagaensis } \\
\text { subsp. nov. }\end{array}$ & $\begin{array}{l}\text { sinistral, small, umbilicus with } \\
\text { keel, single lamella, intermediate } \\
\text { plica absent }\end{array}$ & $\begin{array}{l}\text { C. nagaensis, } \\
\text { C. shiroiensis shiroiensis }\end{array}$ & $\begin{array}{l}\text { northeastern India } \\
\text { (Naga Hills) }\end{array}$ \\
\hline C. smithiana & dextral, thick shell, single lamella & C. brachyplecta & $\begin{array}{l}\text { Myanmar } \\
\text { (Mawlamyine) }\end{array}$ \\
\hline C. woodthorpei & $\begin{array}{l}\text { sinistral, two lamellae, angled body } \\
\text { whorl, three additional horizontal } \\
\text { parietal plica }\end{array}$ & C. scabra sp. nov. & Myanmar (Shan States) \\
\hline H. andersoni & $\begin{array}{l}\text { dextral, large, lenticular shell, } \\
\text { strong spiral striation on } \\
\text { protoconch }\end{array}$ & - & $\begin{array}{l}\text { northern Myanmar and } \\
\text { western Yunnan }\end{array}$ \\
\hline H. saurini & $\begin{array}{l}\text { dextral, protoconch spirally } \\
\text { striated, body whorl angled, lower } \\
\text { parietal plica present }\end{array}$ & H. tigrina sp. nov. & northern Laos \\
\hline H. tigrina sp. nov. & $\begin{array}{l}\text { dextral, protoconch spirally } \\
\text { striated, body whorl keeled, lower } \\
\text { parietal plica absent }\end{array}$ & H. saurini & $\begin{array}{l}\text { northern Thailand } \\
\text { (Udon Thani and Loei } \\
\text { provinces) }\end{array}$ \\
\hline N. laomontana & $\begin{array}{l}\text { dextral, few whorls, main plica } \\
\text { absent }\end{array}$ & N. oligogyra sp. nov. & $\begin{array}{l}\text { northern Laos } \\
\text { (Louangphabang } \\
\text { Province) }\end{array}$ \\
\hline N. oligogyra sp. nov. & $\begin{array}{l}\text { dextral, few whorls, main plica } \\
\text { present }\end{array}$ & N. laomontana & $\begin{array}{l}\text { northern Thailand } \\
\text { (Chiang Mai Province) }\end{array}$ \\
\hline
\end{tabular}

\section{Dextral species}

For simplicity, I list the species according to coiling direction of their shells, which probably does not indicate phylogenetic relationships.

Chersaecia austeni (Gude, 1899)

Figs $6 \mathrm{~A}-\mathrm{B}, 7 \mathrm{~A}-\mathrm{B}$

Plectopylis austeni Gude, 1899b: 15, fig. 97a-f [“Diyung Valley, Singpho, Assam”].

Plectopylis (Chersaecia) austeni - Gude 1899d: 148; 1899e: 175; 1914b: 90-91, fig. 38.

Chersaecia austeni - Páll-Gergely et al. 2015c: 10. 


\section{Diagnosis}

A medium-sized, flat, dextral, yellowish species with very coarse reticulated sculpture, an elevated parietal callus, strong apertural fold, a single lamella on the parietal wall with a short main plica free from the apertural fold, and an even shorter intermediate plica, situated under the main plica.

\section{Material examined}

Lectotype (here designated)

INDIA: 1 shell, Diyung Valley, Singpho Hills, Assam, Ogle leg. (NHMUK 1903.06.01.1014.1).

Paralectotypes (here designated)

INDIA: 1 juv. shell, 1 adult shell, same data as for lectotype (NHMUK 1903.06.01.1014.2)

\section{Lectotype designation}

The type lot (NHMUK 1903.06.01.1014) contains one juvenile and two adult shells of Plectopylis austeni. Additionally, it contains a sinistral shell, identical to the holotype of Plectopylis leucochila, which probably got there accidently. Because of the mixed sample and in order to avoid future confusion, one of the adult shells of Plectopylis austeni $(\mathrm{D}=19.5 \mathrm{~mm})$ is selected as lectotype (NHMUK 1903.06.01.1014.1).

\section{Description of the type series}

SHELL. Dextral, flat, dorsal surface concave (spire sunken), colour yellowish; whorls 6.25-6.75 $(\mathrm{n}=2)$, separated by a very deep suture (first whorl suture shallower); protoconch consists of 2.75 whorls, matt, almost smooth, irregularly wrinkled; teleoconch roughly reticulated, on dorsal side, inside umbilicus spiral lines dominant, whereas on the periphery of last whorl radial lines stronger; fine periostracal filaments attached to ribs (one filament per rib), which remain mainly inside suture; dorsal and ventral sides of all whorls flat, boundary between the rounded periphery of body whorl and the flat dorsal side indicated with a shallow groove; aperture oval, peristome thickened and slightly reflected; parietal callus well-developed, elevated, highest at its middle; apertural fold low, free from parietal callus; approximately as long as parietal callus.

The type lot contained three shells: two adult shells (one paralectotype had been opened), and an opened juvenile. Parietal wall with a curved lamella having a main plica in the middle line of the lamella; main plica slightly longer than lamella; there is an additional lower, short plica (denticle) under posterior end of main plica; the juvenile shell had only the main plica anterior to the lamella. Palatal plicae six; first and last straight and free, others oblique, short, and connected by a ridge.

Measurements (in mm). $\mathrm{D}=17-19.5, \mathrm{H}=5-6(\mathrm{n}=2)$.

\section{Differential diagnosis}

Chersaecia austeni is most similar to $C$. dextrorsa, which is darker, has longer main and middle parietal plicae, and its palatal plicae are usually divided in the middle and not connected by a ridge.

\section{Distribution}

Chersaecia austeni is known from the type locality only. 


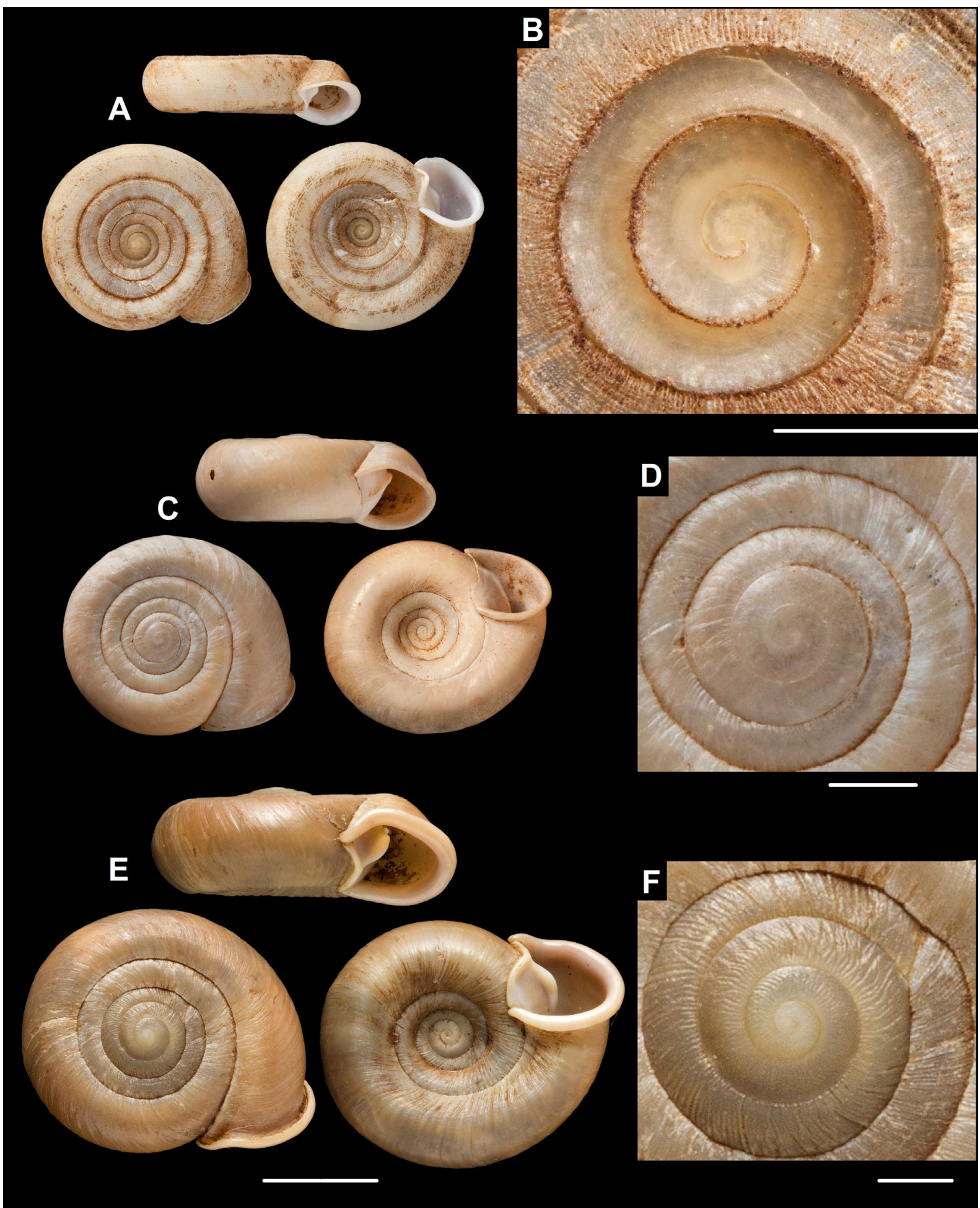

Fig. 6. Shells and protoconchs of Chersaecia Gude, 1899. A-B. C. austeni (Gude, 1899), lectotype (NHMUK 1903.06.01.1014.1). C-D. C. brachyplecta (Benson, 1863) comb. nov., syntype (NHMUK 1954.6.2.282). E-F. C. smithiana (Gude, 1897) comb. nov., syntype (NHMUK 1888.12.4.1555). Scale bars: A, C, E = $10 \mathrm{~mm}$; B, D, F = $2 \mathrm{~mm}$. All photos: H. Taylor. 
Chersaecia brachyplecta (Benson, 1863) comb. nov.

Figs $6 \mathrm{C}-\mathrm{D}, 7 \mathrm{I}-\mathrm{J}$

Helix (Plectopylis) brachyplecta Benson, 1863: 319 [“ad ripas fluvii Attaran prope Moulmein”].

Helix brachyplecta - Pfeiffer 1868: 396-397.

Helix (Plectopylis) brachyplecta - Hanley \& Theobald 1872: 26, pl. 57, figs 7, 10. - Godwin-Austen 1875b: 613, pl. 74, fig. 8-8a. - Nevill 1878: 72. — Tryon 1887: 163, pl. 35, figs 76-77, 82-83.

Plectopylis brachyplecta - Gude 1897b: 246, fig. 37a-f.

Plectopylis (Endoplon) brachyplecta - Gude 1899d: 148; 1899e: 175; 1914b: 117-119, fig. 57a-f; 1920: 62.

\section{Diagnosis}

A large, dextral, robust, flat species (protoconch elevated) with two lamellae and a long main plica extending to the parietal callus.
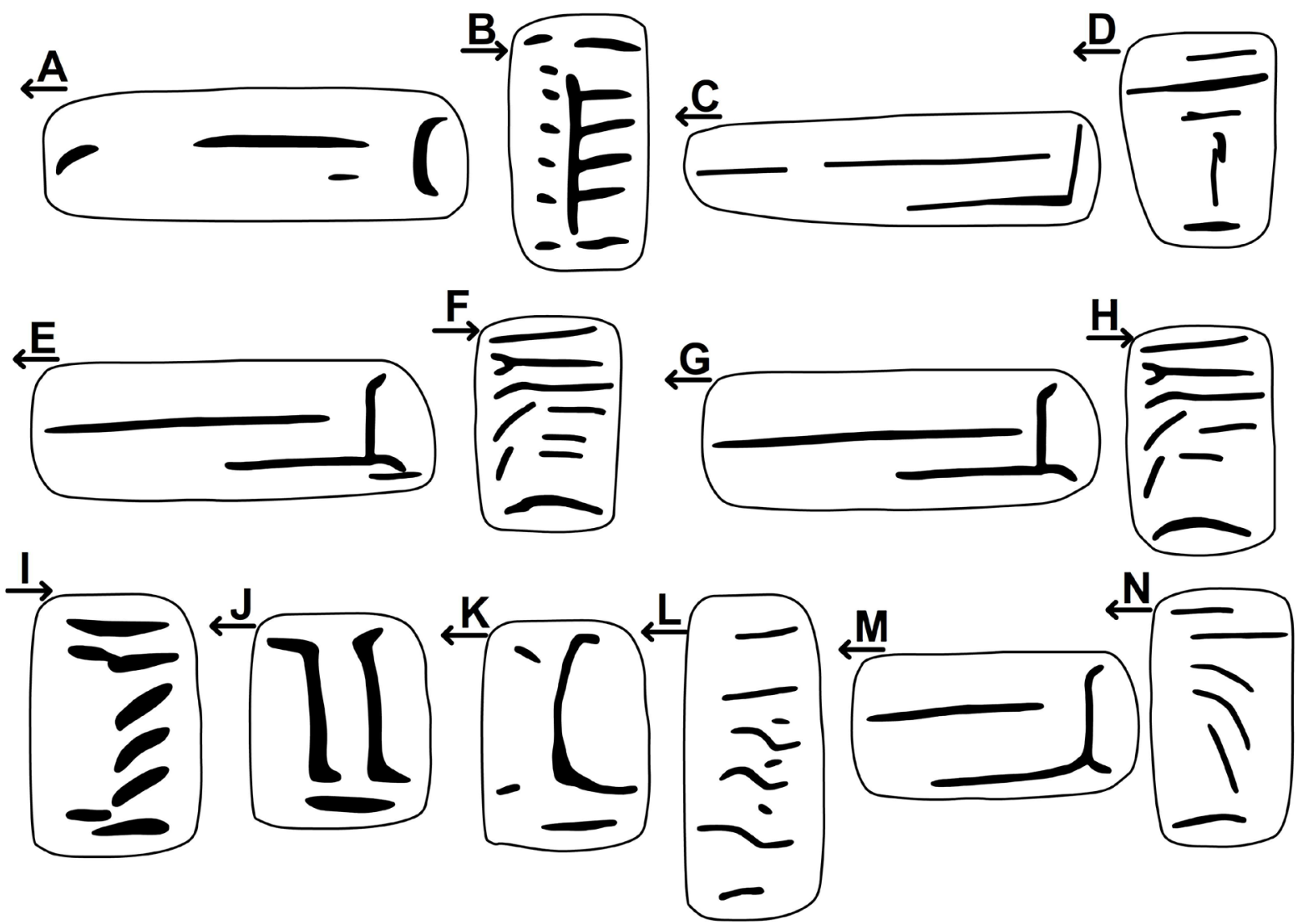

Fig. 7. Parietal (A, C, E, G, J, K, M) and palatal (B, D, F, H, I, L, N) plication in species of Chersaecia Gude, 1899. A-B. C. austeni (Gude, 1899) (1903.06.01.1014.1). C-D. C. densegyrata sp. nov. (UF 347223). E-F. C. dextrorsa (Benson, 1860) (UF 346181). G-H. Chersaecia dextrorsa (UF 76507). I-J. C. brachyplecta (Benson, 1863) comb. nov. (after Gude 1914b). K-L. C. smithiana (Gude, 1897) comb. nov. (NHMUK 1888.12.4.1555-1556, two different specimens). M-N. C. reversalis sp. nov., paratype from type locality (UF 347046). Arrows below the letters indicate the direction of the aperture. Not to scale. 


\section{Material examined}

Syntype

MYANMAR: 1 shell, “Ad ripas fluvii Attaran prope Moulmein”, coll. Benson (NHMUK 1954.6.2.282).

\section{Additional material}

MYANMAR: 1 shell, Moulmein (NHMUK); 2 shells (figured in Godwin-Austen 1875b), Moulmein, Tenasserim, coll. Godwin-Austen (NHMUK 1903.7.1.749).

\section{Description}

SHELL. Dextral, robust, flat, brownish, although the available specimens are largely eroded; protoconch large, consists of 3.5 whorls, matt, finely, densely, irregularly wrinkled; whorls 6-6.25 $(n=2)$, separated by deep suture; teleoconch finely, irregularly wrinkled; dorsal side with some reticulated sculpture, ventral surface smoother; aperture with widened sinulus; peristome strongly thickened and slightly reflected; parietal callus low, blunt, slightly S-shaped; apertural fold very long, connected to parietal callus.

One opened shell was observed. Parietal wall with two lamellae, upper end of anterior lamella curves anteriorly, whereas lower end slightly elongated in both anterior and posterior directions; posterior lamella slightly reversed S-shaped. The shell fragment having the palatal plicae was attached to the shell, but was somewhat damaged, therefore only 5 plicae were visible; all middle plicae oblique and depressed Z-shaped, or wavy; the last plica horizontal, straight.

Measurements (in mm). $\mathrm{D}=21.5-21.7, \mathrm{H}=7.6-7.8(\mathrm{n}=2$, type series).

\section{Differential diagnosis}

Chersaecia smithiana is larger, has a shallower umbilicus, a stronger and sharper parietal callus and, most importantly, only a single lamella.

\section{Distribution}

Chersaecia brachyplecta is known from the type locality only.

Chersaecia densegyrata sp. nov. urn:1sid:zoobank.org:act:9468E60C-F711-46B3-8BD5-E7983BC2E36F

Figs $7 \mathrm{C}-\mathrm{D}, 8 \mathrm{~A}$

\section{Diagnosis}

A small, dextral, flat species with 6.5 slowly increasing whorls. Parietal wall with a single lamella, main plica free from lamella and apertural fold; intermediate plica attached to lower end of lamella. On the palatal wall there are two vertical plicae, with one horizontal plica below and three above.

\section{Etymology}

The name "densegyrata" refers to the rapidly increasing whorls of the new species.

\section{Material examined}

\section{Holotype}

THAILAND: 1 shell, Chiang Mae Province, 20 km SSW of Ban Mae Khi, 19³4'40" N, 99 4'52" E, 700 m a.s.1., 22 Jun. 1987, F.G. Thompson leg. (UF 347223). 


\section{Description}

SHELL. Dextral, white and light-brown striped; concave above, only protoconch protrudes above dorsal surface; protoconch consists of 2.5 whorls, first ca 1.5 whorls almost smooth with very small tubercles, remaining ones irregularly ribbed; entire shell with 6.5 whorls, slowly increasing, separated by rather deep suture, but dorsal surface of whorls flat; teleoconch finely decussated with low riblets and spiral lines; aperture relatively small; peristome strongly thickened and slightly reflected; parietal callus elevated, sharp, in contact with apertural fold, which is free from main plica; periumbilical area (ventral shell side around funnel-shaped umbilicus) nearly smooth.

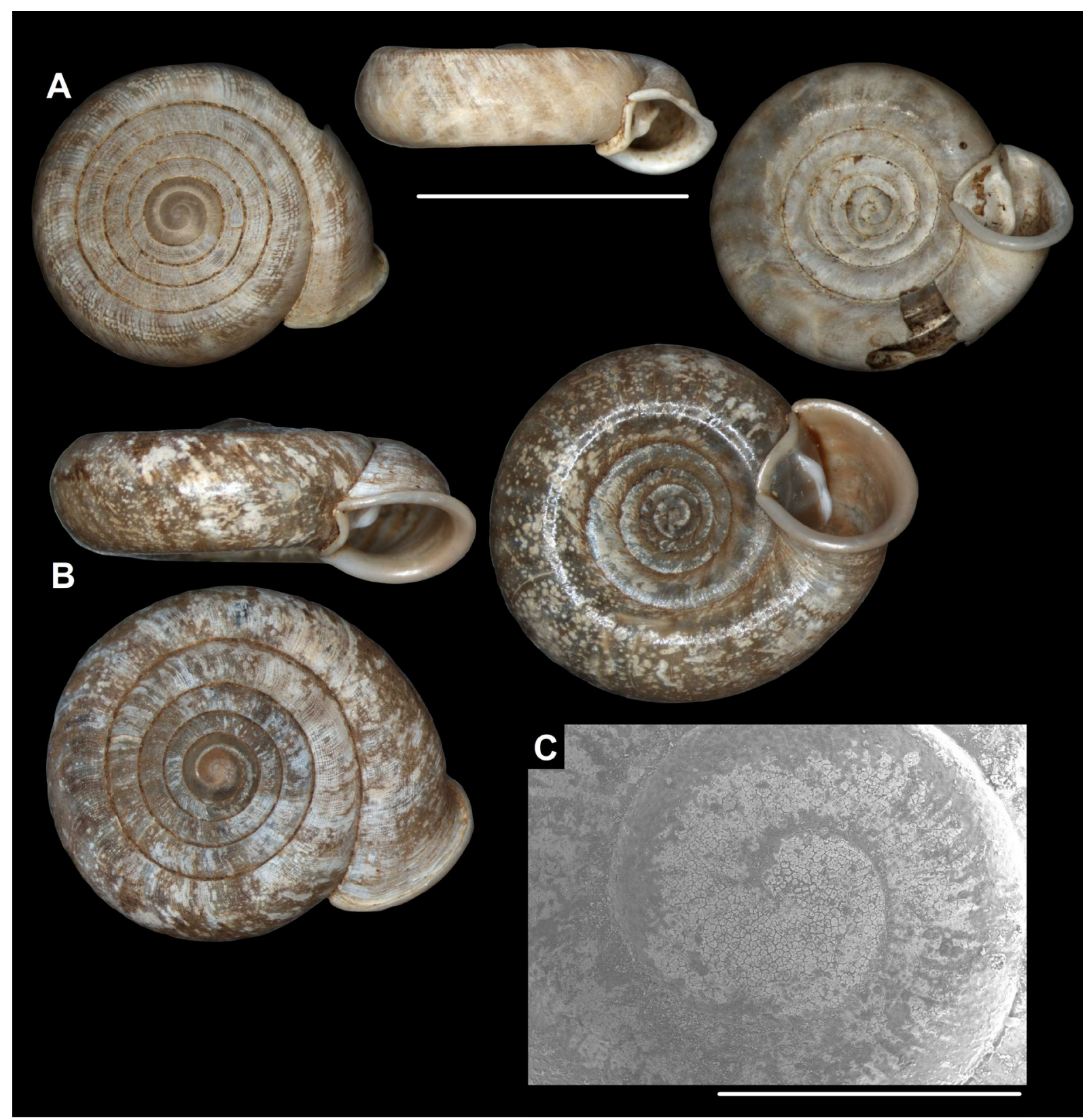

Fig. 8. A. Shell of Chersaecia densegyrata sp. nov., holotype (UF 347223). B-C. Shell and protoconch of $C$. reversalis sp. nov., holotype (UF 347046). Scale bars: A-B $=10 \mathrm{~mm} ; \mathrm{C}=1 \mathrm{~mm}$. Images: T. Deli (A-B) and B. Páll-Gergely (C). 
Parietal wall with short vertical lamella, and intermediate plica, connected to lower end of lamella; main plica long, free from lamella and apertural fold. Palatal wall with six plicae, with second being longest; first, second, third and last plicae straight and horizontal; fourth and fifth vertical.

Measurements (in mm). $\mathrm{D}=13.5, \mathrm{H}=5$ (holotype).

\section{Differential diagnosis}

Chersaecia densegyrata sp. nov. is similar to $C$. dextrorsa and C. reversalis sp. nov. in terms of coiling direction, but it is smaller and much flatter than the latter two species, and has rapidly-increasing whorls. There are also differences in the plication: the intermediate plica of $C$. dextrorsa and $C$. reversalis sp. nov. extends beyond the lamella in posterior direction, whereas it stops when reaching the lamella in the new species. Furthermore, the fourth and fifth palatal plicae of $C$. densegyrata sp. nov. are vertical.

\section{Distribution}

The new species is known from the type locality only.

\section{Chersaecia dextrorsa (Benson, 1860)}

Figs 7E-H, 9-10, 11A-B

Helix (Plectopylis) refuga var. dextrorsa Benson, 1860: 246-247 [“Phye-thán in the Tenasserim Valley"]. Helix (Plectopylis) brachydiscus Godwin-Austen, 1879a: 1-3, pl. 1, fig. 1-1e ["Mulé-it, east of Moulmein, Tenasserim"]. Syn. nov.

Helix (Plectopylis) refuga var. dextrorsa - Hanley \& Theobald 1870: 7, pl. 13, fig 9. — Godwin-Austen 1875b: 613.

Helix (Plectopylis) dextrorsa - Godwin-Austen 1875a: 44 ["Phié Thaw"]. — Nevill 1878: 70.

Helix (Plectopylis) brachydiscus - Tryon 1887: 162, pl. 36, figs 32-34.

Helix (Plectopylis) refuga var. dextrorsa - Tryon 1887: 164, pl. 35, fig. 2 [“Austen”].

Plectopylis dextrorsa - Gude 1896a: 156, fig. 21a-c.

Plectopylis brachydiscus - Gude 1896a: 154-155, fig. 18a-c.

Plectopylis (Chersaecia) dextrorsa - Gude 1899d: 148; 1899e: 175; 1914b: 110-111, fig. 52.

Plectopylis (Chersaecia) brachydiscus - Gude 1899d: 148; 1899e: 175; 1914b: 108-110, fig. 51.

Chersaecia brachydiscus - Páll-Gergely et al. 2015c: 10.

Chersaecia dextrorsa - Páll-Gergely et al. 2015c: 10.

\section{Diagnosis}

A medium-sized, dextral, more or less flat species, usually with periostracal folds on the upper periphery of the body whorl, parietal callus strongly developed, apertural fold present, main plica short (not reaching apertural fold) or long (in contact with apertural fold); parietal wall with a single lamella and an intermediate plica attached to its lower end; palatal plicae free, most of them divided in the middle.

\section{Material examined}

Holotype

MYANMAR: 1 shell, holotype of $P$. dextrorsa $(\mathrm{D}=16 \mathrm{~mm}$ ), Tenasserim Valley (NHMUK 1906.2.2.144).

\section{Syntypes}

MYANMAR: 12 shells, syntypes of P. brachydiscus, Tianoba, Mulé-it Range, Tenasserim, Limborg leg. (NHMUK 1903.7.1.752). 
Additional material

MYANMAR: 2 shells, Moulmein, coll. Möllendorff (SMF 150118); 7 shells, Tavoy, Tenasserim, coll. Möllendorff (SMF 150119); 3 shells, Tenasserim (NHMUK 1888.12.4.1557-1559); many eroded, whitish shells, Tenasserim, Limborg leg. (NHMUK); 2 juvenile shells, Tenasserim (NHMUK 1893.4.7.1-2); 7 shells, Tavoy, Tenasserim (SMF 150119).

THAILAND: 4 shells, Siam, Ponsekai (SMF 150120); 4 shells, Siam, Ponsekai, coll. Möllendorff (SMF 150120); 31 shells, Kanchanaburi Province, Erawan National Park, Erawan Falls, 14²2'27.91" N, 99 $8^{\circ} 45.43 "$ E, 150 m a.s.1., 14 Sep. 1985, F.G. Thompson leg. (UF 76507); 17 specimens (preserved in ethanol; 4 specimens in separate vials; 2 specimens, PL003 and PL004, used for molecular study), same data as for preceding (UF 76385); 8 shells, Kanchanaburi Province, $15.3 \mathrm{~km} \mathrm{NW}$ of Sangkhla Buri, 660 m, 9 May 1988, K. Auffenberg leg. (UF 346181).

\section{Description}

SHeLl (based on the type series of brachydiscus). Dextral, flat or almost flat, light to dark brown; whorls 6-6.75 ( $n=5)$, separated by a deep suture; in face of deep suture, upper surface seems to be flat due to flat whorls; protoconch irregularly wrinkled with extremely fine granular structure which is sometimes not visible, or visible only on a small part of the protoconch; teleoconch ribbed and spirally striated, giving the sculpture a reticulated appearance; the riblets may be covered by deciduous folds of the periostracum on fresh shells; on dorsal surface of whorls there are 8-9 spiral lines, and much denser riblets; sculpture also visible on ventral side and inside umbilicus; periostracal filaments longer near the sutures, whereas juvenile/subadult specimens possess long periostracal filaments on periphery of body whorl; peristome white, conspicuously thickened and slightly reflected; parietal callus slightly S-shaped; apertural fold prominent, approximately half as long as parietal callus, free from main plica.

Five shells were opened. Parietal wall with a short vertical lamella, connected to intermediate plica, which extends beyond lamella in posterior direction; intermediate plica ca half as long as main plica; main plica free from lamella and usually from apertural fold, although almost reaching each other in old specimens; two opened shells had a short lower plica under lamella. Palatal wall with six plicae, first three more or less straight, sometimes with additional posterior small denticles; second usually with a dichotomously divided posterior end; fourth and fifth divided, their posterior portions descending downwards; anterior portion of the fifth plica can be missing; sixth curved.

Measurements (in mm). $\mathrm{D}=16, \mathrm{H}=5.8$ (holotype); $\mathrm{D}=16.8-19.7, \mathrm{H}=5.9-7.2$ (type series of brachydiscus, $\mathrm{n}=4$ ); $\mathrm{D}=14.8-19.3, \mathrm{H}=5.7-7.6$ (Thai specimens, $\mathrm{n}=5$ ).

Characters of the genital system. Three specimens from sample UF 76385 were dissected. Right ommatophoral retractor passes between penis and vagina-vas deferens; penis reduced, very small, ovoid, internally with parallel, serrate folds; retractor muscle inserts on proximal end of penis; vas deferens extremely long, cylindrical and cable-like, internally with parallel, oblique folds; vagina internally slightly serrate longitudinal folds, very long, as thick as vas deferens; weak fibres attach vagina to body wall; bursa copulatrix about as long as vagina; diverticulum of two specimens contain spermatophores; end of spermatophores were found in stalk of bursa copulatrix; spermatophores formed by irregularly packed slender, reddish thread; inner wall of diverticulum with parallel folds.

RADULA. Centrals with small, triangular cusps; endocones of laterals rhomboid; ectocones of first laterals larger than centrals; ectocones of marginals undivided, endocones of marginals divided by shallow incision. 


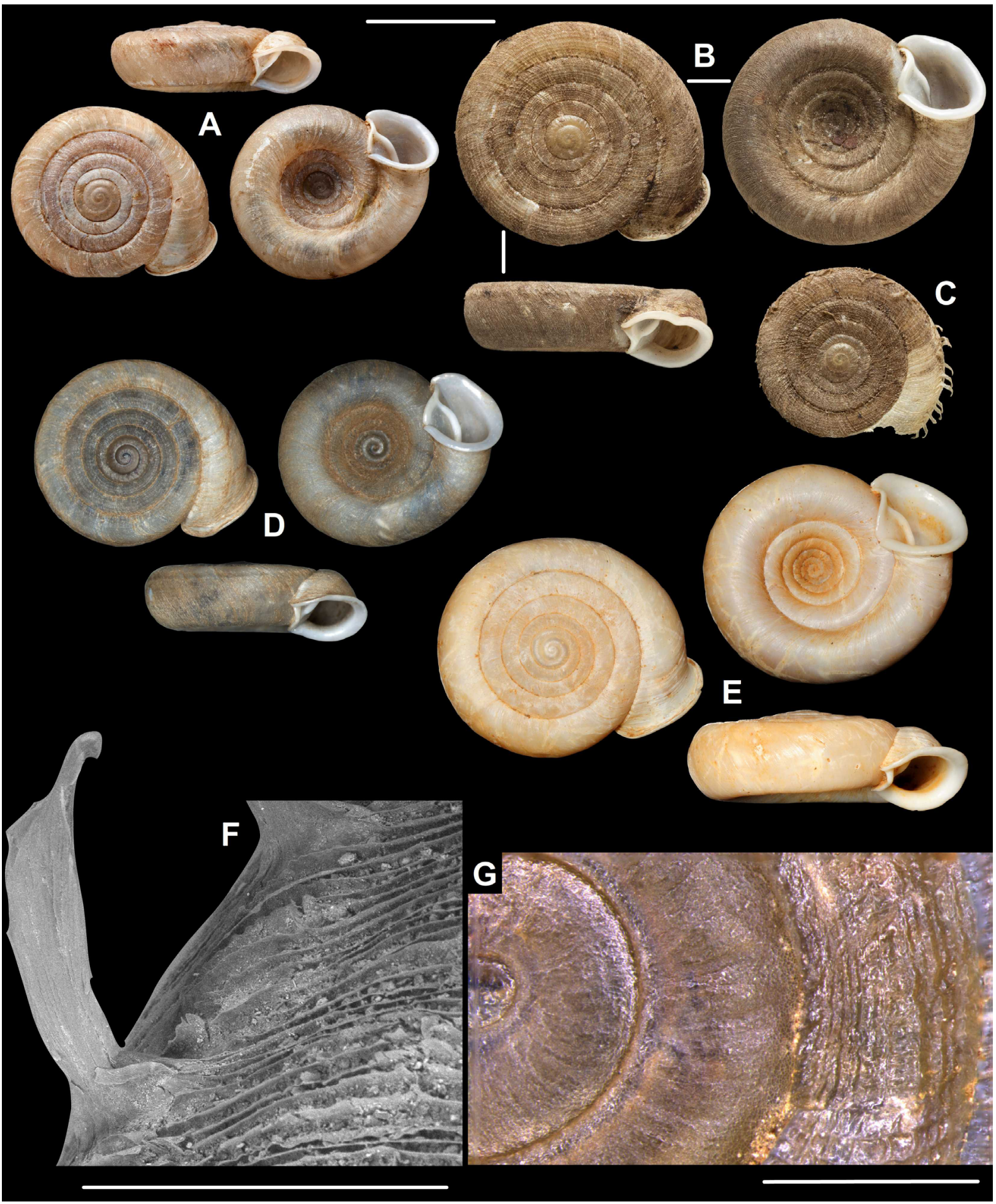

Fig. 9. Shells of Chersaecia dextrorsa (Benson, 1860). A. Holotype (NHMUK 1906.2.2.144). B-C. Adult and juvenile syntypes of Helix (Plectopylis) brachydiscus Godwin-Austen, 1879 syn. nov. (NHMUK 1903.7.1.752). D. Shell from Thailand (UF 76507). E. Shell from Thailand (UF 346181). F. Deciduous periostracal fold (UF 76385). G. Protoconch (same specimen as D). Scale bars: A-E = $10 \mathrm{~mm} ; \mathrm{F}-\mathrm{G}=1 \mathrm{~mm}$. Images: H. Taylor (A-C), T. Deli (D-E) and B. Páll-Gergely (F-G). 


\section{Differential diagnosis}

The most similar species in terms of shell characters is Chersaecia reversalis sp. nov., which is, nevertheless, strikingly different in terms of genital anatomy. Some populations of $C$. dextrorsa have a long parietal main plica that is continuous with the apertural fold, whereas in C. reversalis sp. nov. the apertural fold is always separate from the parietal plica. Chersaecia reversalis sp. nov. has a sculpture characterized by a smooth basal surface and fine, reticulated dorsal surface with small periostracal filaments. In contrast, $C$. dextrorsa has a strong sculpture all over the shell and elevated periostracal ribs with long filaments on the periphery of the body whorl of fresh, usually subadult specimens. Chersaecia densegyrata sp. nov. has a flatter shell, denser whorls, and two vertical plicae on the palatal wall (with a horizontal plica below and three above). See also under Chersaecia austeni.

\section{Distribution}

The species is distributed in western Thailand (Kanchanaburi and southern Tak Provinces) and eastern Burma (Fig. 12).

\section{Remarks}

The populations discussed here under the name Chersaecia dextrorsa show a variability in the following traits: (1) distance of the apertural fold from the parietal callus; (2) relationship of the apertural fold to the main plica (connected or separated); (3) shell shape (flat or slightly elevated spire); (4) shape of the body whorl (rounded or bluntly shouldered); (5) presence of absence of periostracal folds.

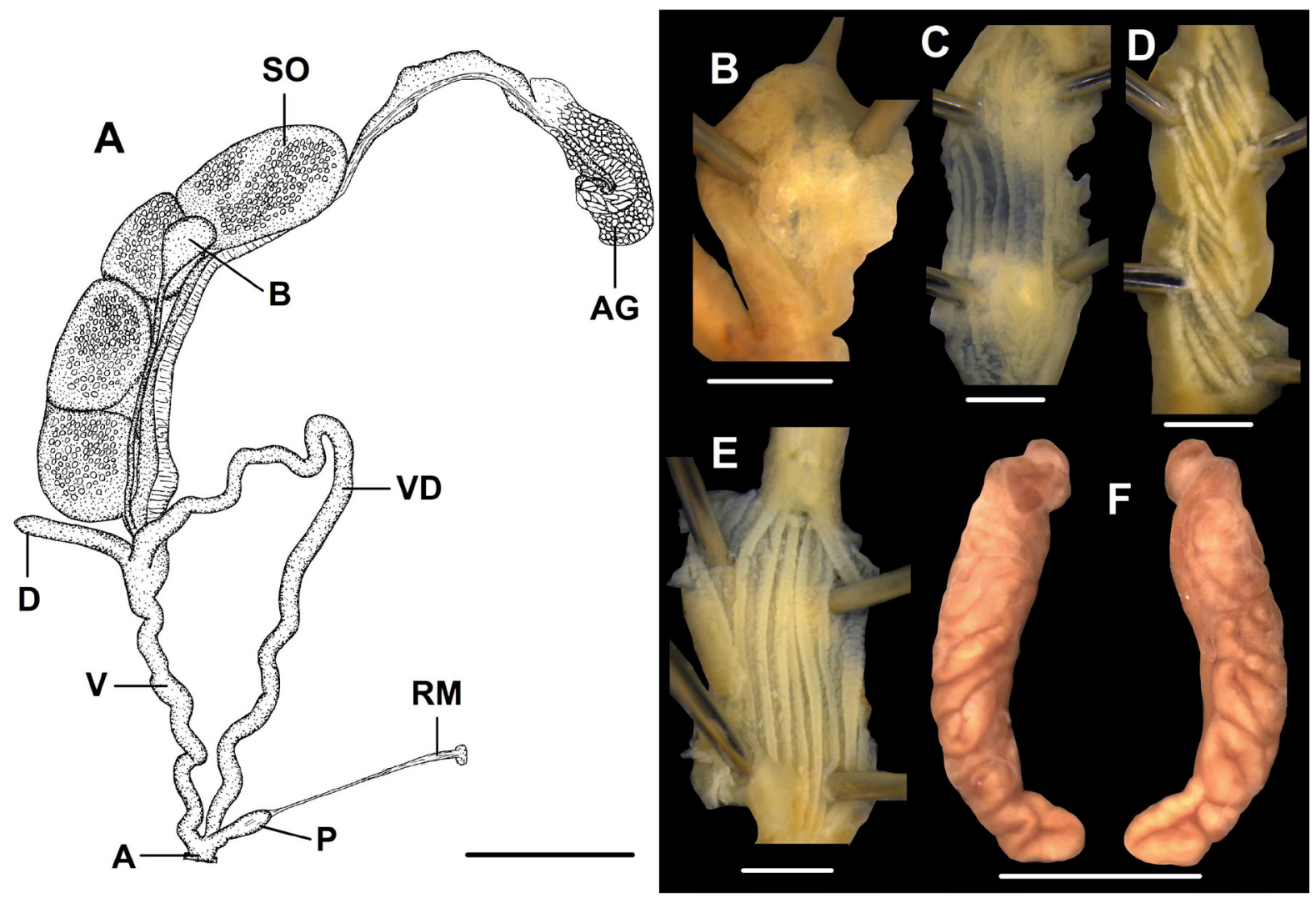

Fig. 10. Genitalia of Chersaecia dextrorsa (Benson, 1860) (FLMNH 76385). A. Whole genitalia. B-E. Inner structure of genital organs $(\mathrm{B}=$ penis, $\mathrm{C}=$ vagina, $\mathrm{D}=$ vas deferens, $\mathrm{E}=$ diverticulum). $\mathbf{F}$. Both sides of a spermatophore. Scale bars: $A=5 \mathrm{~mm} ; \mathrm{B}-\mathrm{E}=0.5 \mathrm{~mm} ; \mathrm{F}=2 \mathrm{~mm}$. For abbreviations see Fig. 2. All photos: B. Páll-Gergely. 
Table 2. Variable shell traits of populations of Chersaecia dextrorsa (Benson, 1860).

\begin{tabular}{llllll}
\hline Sample & Apertural fold & $\begin{array}{l}\text { Apertural fold } \\
\text { and main plica }\end{array}$ & Spire & Body whorl & $\begin{array}{l}\text { Periostracal } \\
\text { folds }\end{array}$ \\
\hline $\begin{array}{l}\text { brachydiscus } \\
\text { syntypes }\end{array}$ & $\begin{array}{l}\text { weakly connected or } \\
\text { separated from callus }\end{array}$ & separated & flat & $\begin{array}{l}\text { bluntly angled, } \\
\text { periphery rounded }\end{array}$ & present \\
$\begin{array}{l}\text { dextrorsa } \\
\text { holotype }\end{array}$ & connected to callus & connected & $\begin{array}{l}\text { slightly } \\
\text { elevated }\end{array}$ & $\begin{array}{l}\text { bluntly angled, } \\
\text { periphery reverse } \\
\text { trapezoid }\end{array}$ & $\begin{array}{l}\text { absent, but not } \\
\text { fresh shell }\end{array}$ \\
FLMNH & $\begin{array}{l}\text { weakly connected to, or } \\
\text { separated from callus }\end{array}$ & connected & $\begin{array}{l}\text { nearly flat/ } \\
\text { bluntly angled, } \\
\text { periphery rounded }\end{array}$ & $?$ \\
$\begin{array}{l}\text { FLMNH } \\
\text { 346181 }\end{array}$ & $\begin{array}{l}\text { weakly connected to, or } \\
\text { separated from callus }\end{array}$ & connected & $\begin{array}{l}\text { nearly flat// } \\
\text { bluntly angled, } \\
\text { periphery rounded }\end{array}$ & $?$ \\
\hline
\end{tabular}

Table 2 summarizes the differences between the examined populations. None of these differences are sufficient for species- or subspecies-level distinction. Moreover, the first two traits are probably agedependent. Namely, mature specimens (i.e., shells with strongly thickened peristome) of the type series of Plectopylis brachydiscus have the apertural fold and the main plica almost reaching each other, and those of sample UF 76507 have the apertural fold and the parietal callus connected. I therefore synonymize $P$. brachydiscus with $P$. dextrorsa.

Only the holotype of Helix (Plectopylis) refuga var. dextrorsa was found in the NHM. This specimen is an intact shell but I was not able to observe the parietal wall. More material was probably examined by previous authors because the inner plicae and lamellae have already been described (Gude 1914b).

The shells from Sangkhla Buri are larger than other Thai specimens and have an additional short plica (probably homologous with the lower plica) below the lamella. In the type series of P. dextrorsa, the additional short plica is present in some shells only.

The spermatophores of $C$. dextrorsa are formed by an irregularly folded thread-like structure, whereas the threads in species of Plectopylis are regularly, longitudinally packed.

Chersaecia reversalis sp. nov.

urn:1sid:zoobank.org:act:F0E2F58C-B7DD-484E-9B6D-CEFF434FD035

Figs $7 \mathrm{M}-\mathrm{N}, 8 \mathrm{~B}-\mathrm{C}, 11 \mathrm{C}-\mathrm{D}, 13$

\section{Diagnosis}

Shell small to medium-sized, dextral, parietal wall with a lamella connected to a relatively long intermediate plica, and a long main plica that is free from the lamella and the apertural fold; middle palatal plicae mostly curved, descending posteriorly.

\section{Etymology}

The specific epithet refers to the dextral coiling direction, which is unusual in this genus.

\section{Material examined}

Holotype

THAILAND: holotype ( $\mathrm{D}=16.7 \mathrm{~mm}$ ), Tak Province, Tham Mae Usu (cave), $14 \mathrm{~km} \mathrm{NNW,} 2 \mathrm{~km} \mathrm{~W}$ of Tha Song Yang, $17^{\circ} 17^{\prime} 58^{\prime \prime}$ N, 98 9 9'52" E, 200 m a.s.l., 3 May 1988, F.G. Thompson leg. (UF 347046). 
PÁLL-GERGELY B., Systematic revision of the Plectopylinae

\section{Paratypes}

THAILAND: 11 shells, same data as for holotype (UF 448580); 2 specimens (preserved in separate vials of ethanol: PL024 and PL025 used for molecular study), same data as for holotype (UF 347047); 1 shell, Tak Province, $9.3 \mathrm{~km}$ ENE of Ban Huei Hin Fong (ca $19 \mathrm{~km}$ ENE of Mae Sot), $15^{\circ} 48^{\prime} 8^{\prime \prime} \mathrm{N}$, 98 41'54" E, 660 m a.s.1., 26 Apr. 1988, F.G. Thompson leg. (UF 347296); 3 specimens (preserved in ethanol: adult specimen PL082 used for molecular study; 2 specimens remain intact), same data as for preceding (UF 347297); 20 shells, Tak Province, $5.5 \mathrm{~km} \mathrm{NNW}$ of Tha Song Yang, 17 $16^{\prime} 13^{\prime \prime} \mathrm{N}$, 98 12'15" E, 180 m a.s.1., 3 May 1988, F.G. Thompson leg. (UF 347028); 6 specimens (preserved in ethanol), same data as for preceding (UF 347029); 3 shells, same data as for preceding (HNHM 97472); 2 shells, Tak Province, 16 km NNW of Mae Ramat, 17³'30" N, 98 26'41" E, 220 m a.s.1., 3 May 1988, F.G. Thompson leg. (UF 347425); 3 specimens (preserved in ethanol), same data as for preceding (UF 347014); 57 shells, Tak Province, 6 km NNW of Tha Song Yang (road 105), loc. 2015/23, 17 15.361' N, 98 12.654' E, 140 m a.s.l., 13 Feb. 2015, A. Hunyadi leg. (coll. HA); 2 specimens (preserved in ethanol), same data as for preceding (coll. PGB); 18 shells, Tak Province, $14+2 \mathrm{~km}$ NNW of Tha Song Yang,

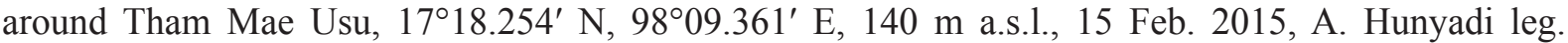

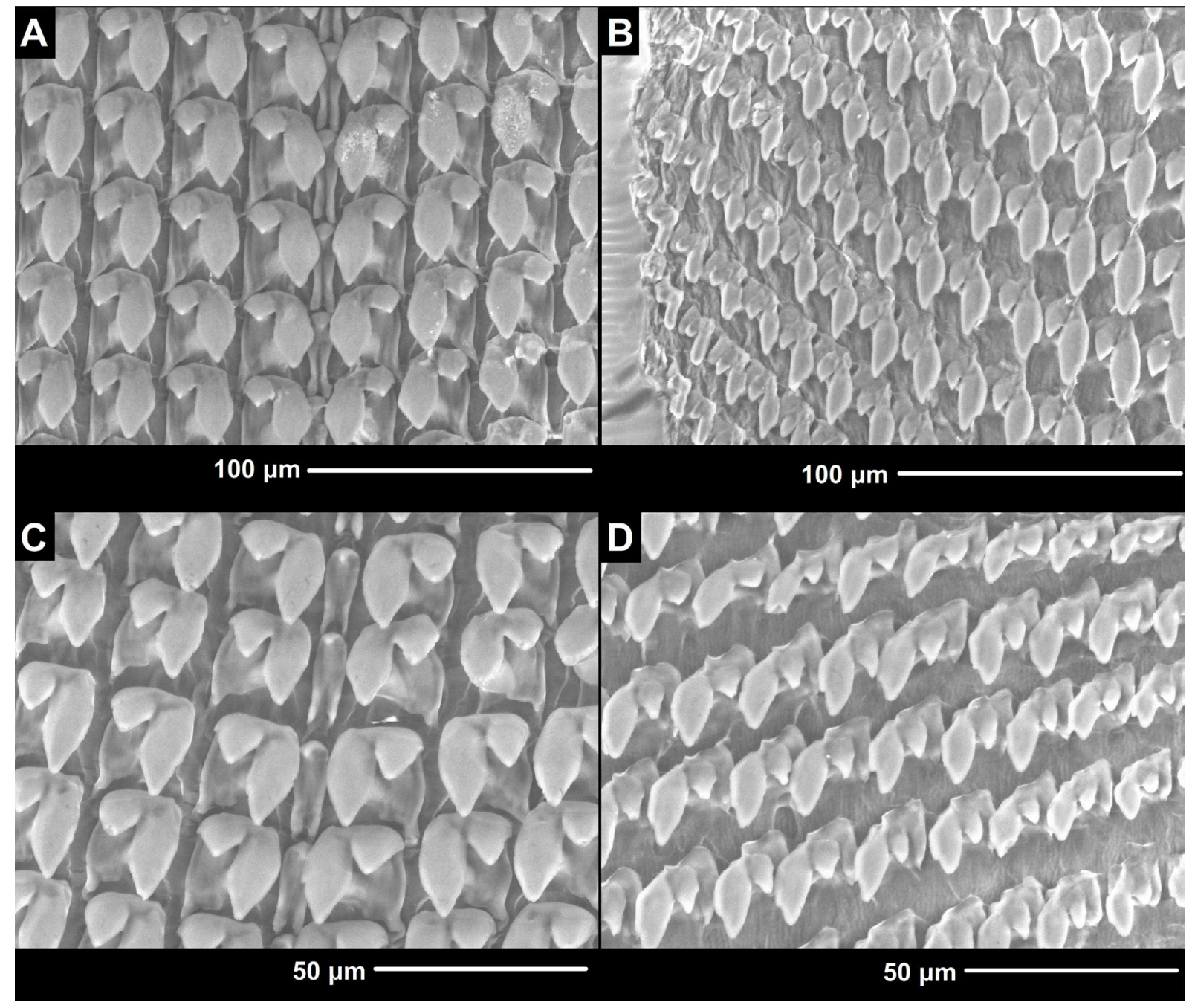

Fig. 11. Radula of Chersaecia Gude, 1899. A, C. Central and first lateral teeth. B, D. Marginal teeth. A-B. C. dextrorsa (Benson, 1860) (UF 76385). C-D. C. reversalis sp. nov. (UF 347047). All images: B. Páll-Gergely. 
(coll. HA); 6 shells, Tak Province, ca 5 km ENE Huai Hin Fon, rock wall above Chao Por Phawo, $16^{\circ} 46.330^{\prime} \mathrm{N}, 98^{\circ} 41.172^{\prime}$ E, $700 \mathrm{~m}$ a.s.1., 16 Feb. 2015, A. Hunyadi leg. (coll. HA); 40 shells, Tak Province, ca $5 \mathrm{~km}$ ENE of Ban Huai Hin Fon, rock wall opposing Chao Por Phawo, 16 Feb. 2015, A. Hunyadi leg. (coll. HA); 6 shells, Tak Province, ca 4 km ENE of Ban Huai Hin Fon, $800 \mathrm{~m}$ NW of Chao Por Phawo, 16²6.732' N, 98 40.723' E, 660 m a.s.l., 16 Feb. 2015, A. Hunyadi leg. (coll. HA); 4 shells, Tak Province, ca 3.5 km ENE of Ban Huai Hin Fon, left side of road no. 12, 1646.790' N, 98 $39.937^{\prime}$ E, 590 m a.s.l., 16 Feb. 2015, A. Hunyadi leg. (coll. HA); 2 shells, Tak Province, Wat Who Bai Huai Hin Fon, K. Okubo leg. (coll. OKA).

\section{Additional material}

THAILAND: 2 juv. specimens (preserved in ethanol), Tak Province, $9.3 \mathrm{~km}$ ENE of Ban Huei Hin Fong

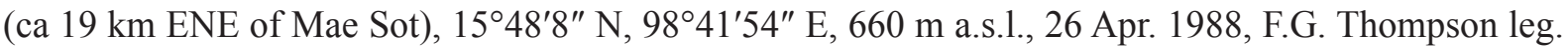

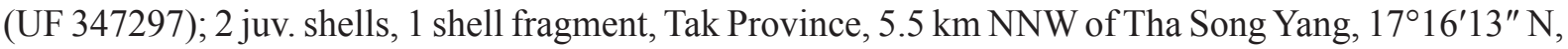
98 12'15" E, 180 m a.s.l., 3 May 1988, F.G. Thompson leg. (UF 347028); 4 juv. shells, Tak Province,

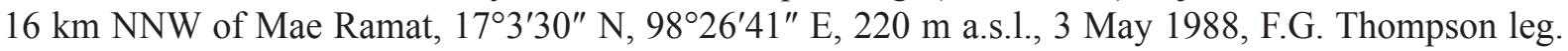
(UF 347425); 23 juv./broken shells, 2 juv. specimens (preserved in ethanol: PL118 and PL119 used for molecular study), Tak Province, 6 km NNW of Tha Song Yang (road 105), 17 $15.361^{\prime} \mathrm{N}, 98^{\circ} 12.654^{\prime} \mathrm{E}$, 140 m a.s.1., 13 Feb. 2015, A. Hunyadi leg. (coll. HA); 18 juvenile/broken shells, Tak Province, $14+$

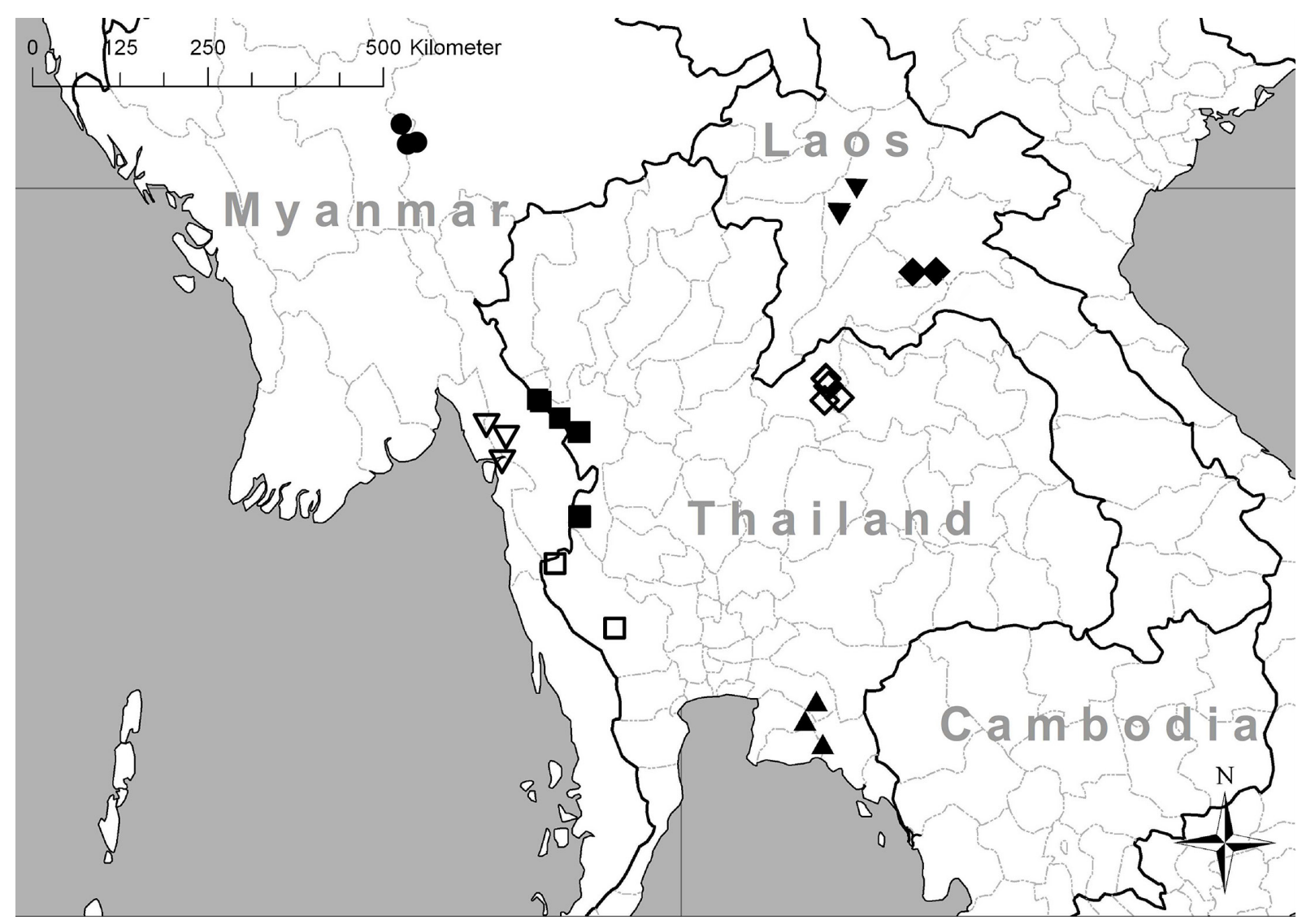

Fig. 12. Distribution of plectopylid species in Thailand, Laos and Myanmar. Legends: circle $=$ Chersaecia shanensis (Stoliczka, 1873); filled square $=$ Chersaecia reversalis sp. nov.; empty square $=$ Chersaecia dextrorsa (Benson, 1860); empty rhomb $=$ Hunyadiscus tigrina sp. nov.; filled rhomb $=$ Hunyadiscus saurini Páll-Gergely, 2016; triangle, top up = Plectopylis crassilabris sp. nov.; triangle, top down= Naggsia laomontana (L. Pfeiffer, 1862); empty triangle, top down = Plectopylis bensoni Gude, 1914. 


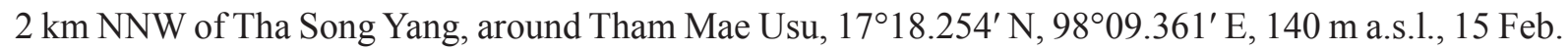
2015, A. Hunyadi leg. (coll. HA); 2 juv./broken shells, Tak Province, ca 5 km ENE of Ban Huai Hin Fon, rock wall opposing Chao Por Phawo, 16 Feb. 2015, A. Hunyadi leg. (coll. HA).

\section{Description of the type series}

SHELL. Dextral, spire slightly elevated, fresh shells have alternating and somewhat variegated reddish and yellowish radial stripes; whorls 6.25-6.5 $(n=5)$; protoconch finely, irregularly wrinkled with extremely fine granular structure, protoconch whorls separated by a shallow suture, whereas teleoconch whorls separated by deeper sutures; teleoconch sculptured with ribs and spiral striations, giving a reticulated appearance; riblets may have small lamellar periostracal projections within and adjacent to the sutures of each whorl; dorsal surface of whorls with 9-10 spiral lines; spiral striation clearly visible from the beginning of the teleoconch but fading in the final 1-1.5 whorls; reticulated sculpture visible inside umbilicus, periumbilical region smooth, glossy; reticulated upper and smooth lower sculpture change abruptly at middle line of body whorl; peristome white, conspicuously thickened and slightly reflected; parietal callus slightly S-shaped; apertural fold prominent and continuous with main plica.

Five shells were opened. Parietal wall with a short lamella, in contact with intermediate plica; intermediate plica almost twice as long as lamella; main plica long, free from both lamella and apertural fold. Palatal wall with six plicae; first two more or less straight; middle ones oblique, or slightly undulated; posterior end of all middle (second to fifth) plicae descending downwards; last plica slightly curved.

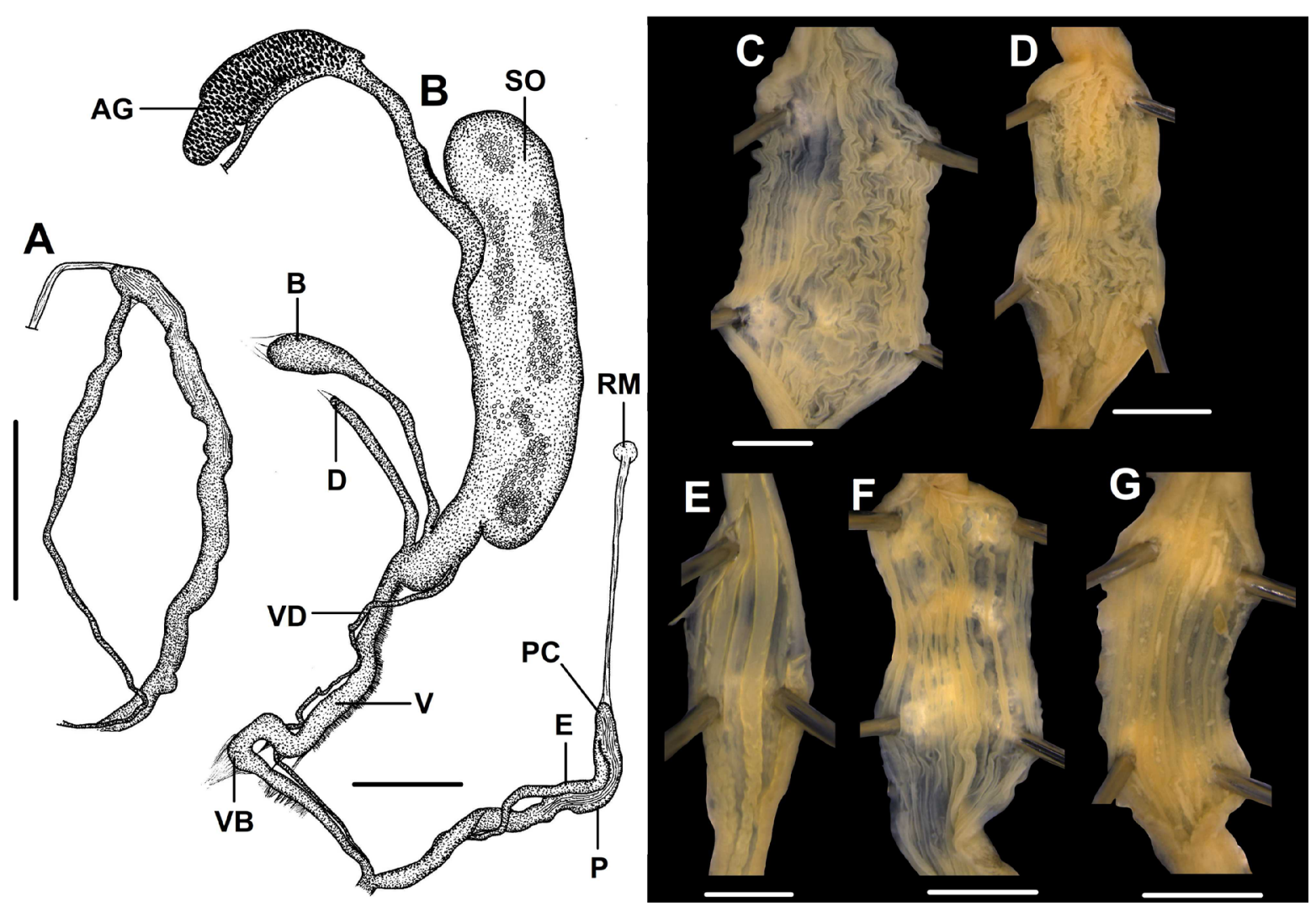

Fig. 13. Genitalia of Chersaecia reversalis sp. nov. (UF 347047). A. Male genitalia (penis, epiphallus, vas deferens). B. Whole genitalia. $\mathbf{C}-\mathbf{G}$. Inner structure of genital organs $(\mathrm{C}=$ proximal part of penis; $\mathrm{D}=$ distal part of penis; $\mathrm{E}=$ epiphallus; $\mathrm{F}=$ vagina; $\mathrm{G}=$ diverticulum). Scale bars: $\mathrm{A}-\mathrm{B}=5 \mathrm{~mm} ; \mathrm{C}-\mathrm{G}=$ $0.5 \mathrm{~mm}$. For abbreviations see Fig. 2. All photos: B. Páll-Gergely. 
Measurements (in mm). $\mathrm{D}=18.9, \mathrm{H}=6.5$ (holotype); $\mathrm{D}=14-16.4, \mathrm{H}=5.9-6.3$ (UF 347046, $\mathrm{n}=3$ ).

Characters of THE GENITAL SYSTEM. One specimen was dissected. Right ommatophoral retractor runs between penis and vagina; penis consists of two portions, a proximal thicker, and a distal slightly longer and slimmer; penis internally with longitudinal, dense, wavy folds; a vestigial penial caecum discernible at junction of penis with epiphallus; retractor muscle very long and inserts on caecum; epiphallus short and tapering to poorly defined junction with the vas deferens, internally with thick, straight longitudinal folds; vas deferens slender; vagina longer, and slightly thinner than penis, connected to body wall with short muscle fibres; vagina internally with slightly wavy longitudinal folds; bursa copulatrix about as long as vagina, with ovoid bursa; diverticulum also originates from base of spermoviduct, shorter and slimmer than bursa copulatrix; inner wall of diverticulum with straight longitudinal folds; 4-5 developing embryos having calcareous crystals on their capsule have been found in uterus.

RADULA. Centrals with small, triangular cusps; endocones of laterals rhomboid; ectocones of first laterals much larger than centrals; ectocones of marginals undivided, endocones of marginals divided by shallow incision.

\section{Differential diagnosis}

Chersaecia reversalis sp. nov. differs from Chersaecia dextrorsa by the apertural fold, which is free from the main plica (although in some specimens of dextrorsa these are sometimes connected, see under that species), by the overall weaker sculpture with smooth basal surface, and the mosaic colouration. The anatomy of the two species is strikingly different.

\section{Distribution}

The new species is known from several localities in Tak Province, western Thailand (Fig. 12).

Chersaecia smithiana (Gude, 1897) comb. nov.

Figs $6 \mathrm{E}-\mathrm{F}, 7 \mathrm{~K}-\mathrm{L}$

Plectopylis smithiana Gude, 1897c: 274, fig. 38a-d [“Attaram, Burma”].

Plectopylis smithiana - Gude 1897j: 44-45, fig. 1a-d.

Plectopylis (Endoplon) smithiana - Gude 1899d: 148; 1899e: 175; 1914b: 115-117, fig. 56a-d.

\section{Diagnosis}

A large, dextral, robust, flat species (only protoconch protrudes over dorsal surface) with one lamella, two short plicae anterior to the lamella, and a long apertural fold connected to the elevated parietal callus.

\section{Material examined}

\section{Syntypes}

MYANMAR: 2 shells, Attaram valley, Theobald leg. (NHMUK 1888.12.4.1555-6).

\section{Description}

SHELL. Dextral, strongly built, greyish-corneous, flat, but protoconch conspicuously protrudes above dorsal surface; protoconch conspicuously large (3.25-3.5 whorls, $\mathrm{n}=2)$, matt, with dense, irregular, wavy wrinkles; teleoconch finely, irregularly wrinkled; dorsal side and inside umbilicus with some reticulated sculpture; whorls 5.5-5.75 $(\mathrm{n}=2)$; teleoconch whorls separated by a deep suture, embryonic whorls by a shallow suture; periphery of body whorl seemingly smooth (but very finely wrinkled under 
higher magnification); aperture rounded, sinulus widened; peristome expanded, strongly reflected and strongly thickened; parietal callus blunt but elevated, strongly S-shaped; apertural fold connected to parietal callus, very long, its end not even visible by oblique view into aperture.

The parietal plicae were observed in one opened shell, whereas the palatal ones in the other, intact shell. Parietal wall with one curved lamella, which has both the upper and lower ends elongated posteriorly, two small denticles anterior to the lamella (one above, one below), and a short lower plica under the lamella. Palatal plicae six; first and sixth straight, second very long and straight, remaining ones depressed Z-shaped, with an additional denticle above posterior ends of each plica.

Measurements (in mm). $\mathrm{D}=26.3-26.8, \mathrm{H}=10.6-11.1$ (NHMUK 1888.12.4.1555-1556, $\mathrm{n}=2$ ).

\title{
Differential diagnosis
}

See under Chersaecia brachyplecta.

\section{Distribution}

Chersaecia smithiana is known from the type locality only.

\section{Remarks}

In the original description, Gude (1897c) mentioned that he examined two shells in the British Museum, one of which was opened by him. Furthermore, Gude examined an additional shell, which was also collected by Theobald, but received from Miss Linter. I examined the two shells in the NHM. According to the original description, Gude's drawing of the parietal plication (Gude 1897c: fig. 38d) illustrates the opened shell in the NHM. However, the lower plica is absent in the drawing, whereas the specimen itself shows a prominent lower plica. The reason for this discrepancy is unknown.

\section{Sinistral species}

\author{
Chersaecia auffenbergi sp. nov. \\ urn:1sid:zoobank.org:act:D15B11F6-EB4F-4699-B795-AD260B043E1B
}

Figs $14 \mathrm{~A}-\mathrm{B}, 15 \mathrm{~A}-\mathrm{B}, 16 \mathrm{~A}-\mathrm{B}$

\section{Diagnosis}

A medium-sized, sinistral, flat species with a concave dorsal surface (only the roughly wrinkled protoconch protrudes above the dorsal surface), rounded body whorl, dichotomous middle palatal plicae (the first and last are straight and simple) and two vertical lamellae on the parietal wall. Two horizontal plicae connect to the anterior lamella; the upper one is continuous with the apertural fold.

\section{Etymology}

The new species is named after Kurt Auffenberg, formerly of the Florida Museum of Natural History, who collected one of the samples and has assisted me with discussions in numerous publications.

\section{Material examined}

\section{Holotype}

THAILAND: 1 shell $(\mathrm{D}=16 \mathrm{~mm})$, Mae Hong Song Province, $6.2 \mathrm{~km} \mathrm{~N}$ of Soppong, along the road to Tham Lod Village, $19^{\circ} 34^{\prime}$ N, 98 ${ }^{\circ} 9^{\prime}$ E, 20 Mar. 1988, Auffenberg, K. leg. (UF 345566). 


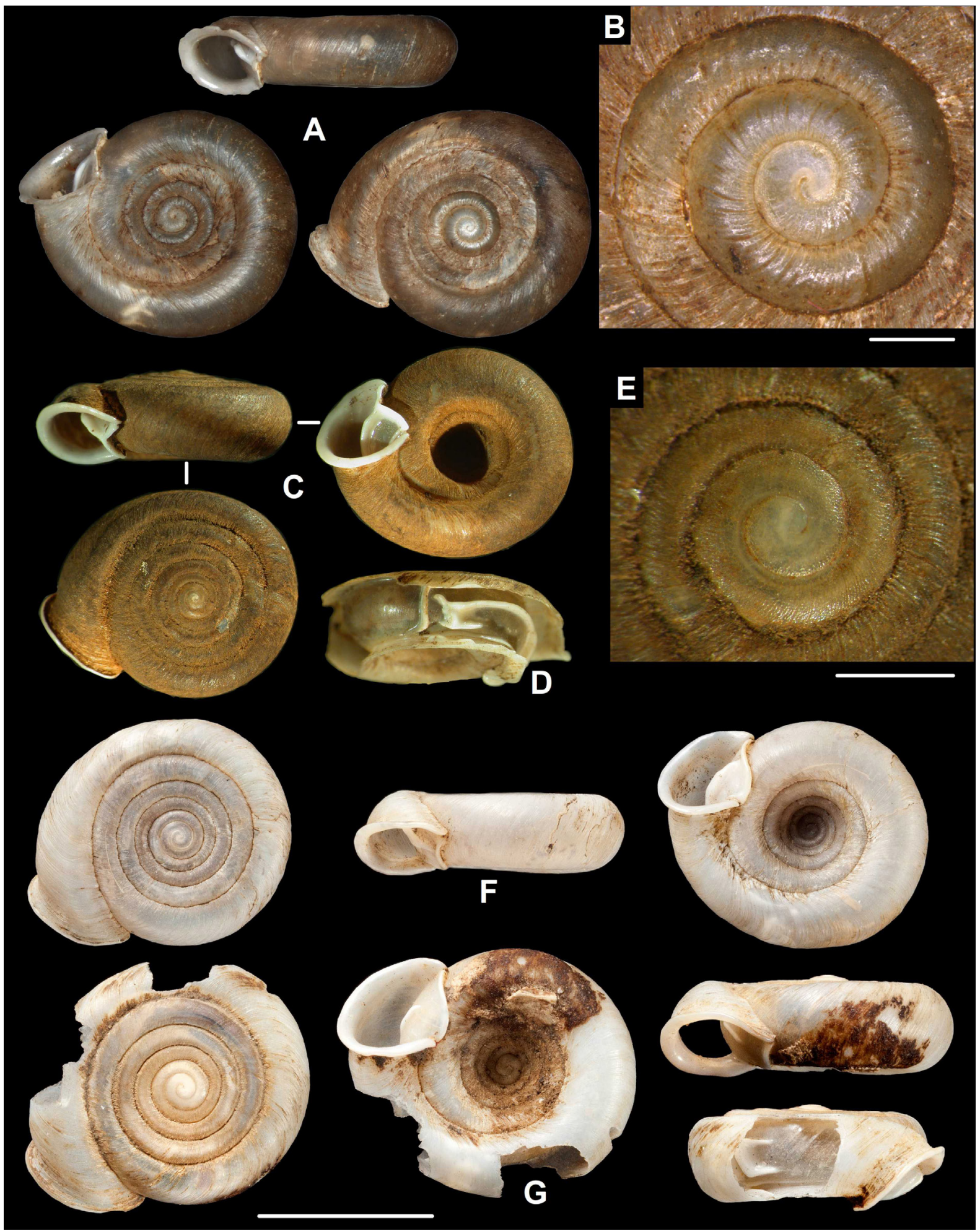

Fig. 14. Shells and protoconchs of species of Chersaecia Gude, 1899. A-B. C. auffenbergi sp. nov., holotype (UF 345566). C. C. goniobathmos (Ehrmann, 1922) comb. nov., lectotype (SMF 150100a). D-E. C. goniobathmos, paralectotype (SMF 150100c). F. C. feddeni (Blanford, 1865) comb. nov., syntype (NHMUK 1906.1.1.730). G. C. feddeni, holotype of P. ponsonbyi (Godwin-Austen, 1888) syn. nov. (NHMUK 1913.3.14.9). Scale bars: A, C-D, F-G = 10 mm; B, E = 1 mm. Photos: T. Deli (A), B. Páll-Gergely (B-E), H. Taylor (F-G). 

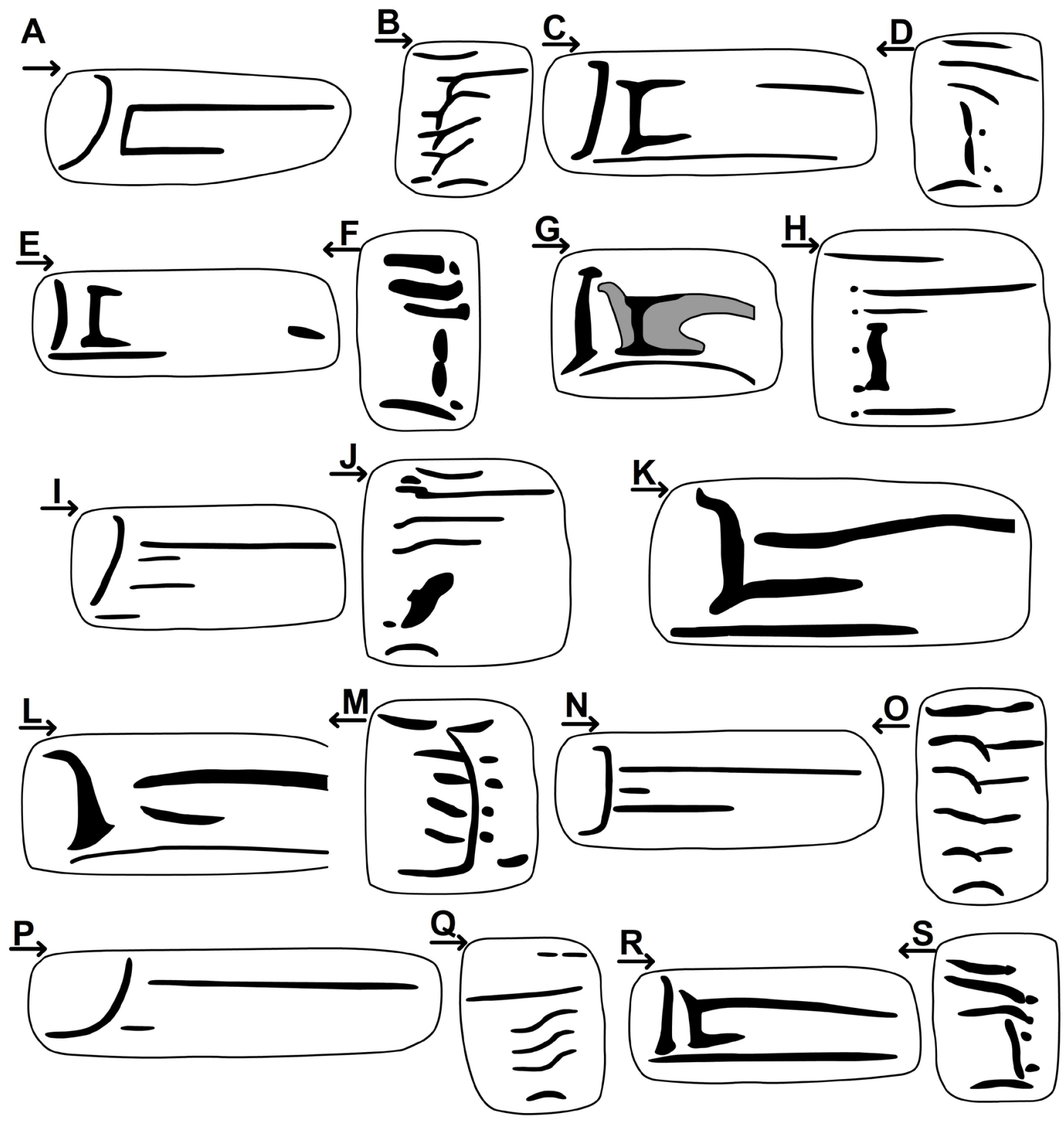

Fig. 15. Parietal (A, C, E, G, I, K, L, N, P, R) and palatal (B, D, F, H, J, M, O, Q, S) plication of species of Chersaecia Gude, 1899. A-B. C. auffenbergi sp. nov. (UF 448572). C-D. C. feddeni (Blanford, 1865) comb. nov. (after Gude 1914b). E-F. C. feddeni ("Plectopylis ponsonbyi", after Gude 1896b). G-H. C. goniobathmos (Ehrmann, 1922) comb. nov. (SMF 150100c). I-J. C. leiophis (Benson, 1860) (NHMUK 1902.02.02.145). K. C. leiophis ("pseudophis", after Gude 1914b). L-M. C. leiophis ("kengtungensis", after Gude 1914b). N-O. C. leiophis (UF 446988). P-Q. C. leiophis, holotype of Plectopylis degerbolae Solem, 1966 (ZMUC-GAS-485). R-S. C. leucochila (Gude, 1897) comb. nov. (NHMUK 1922.8.29.39). Arrows below the letters indicate the direction of the aperture. Not to scale. 


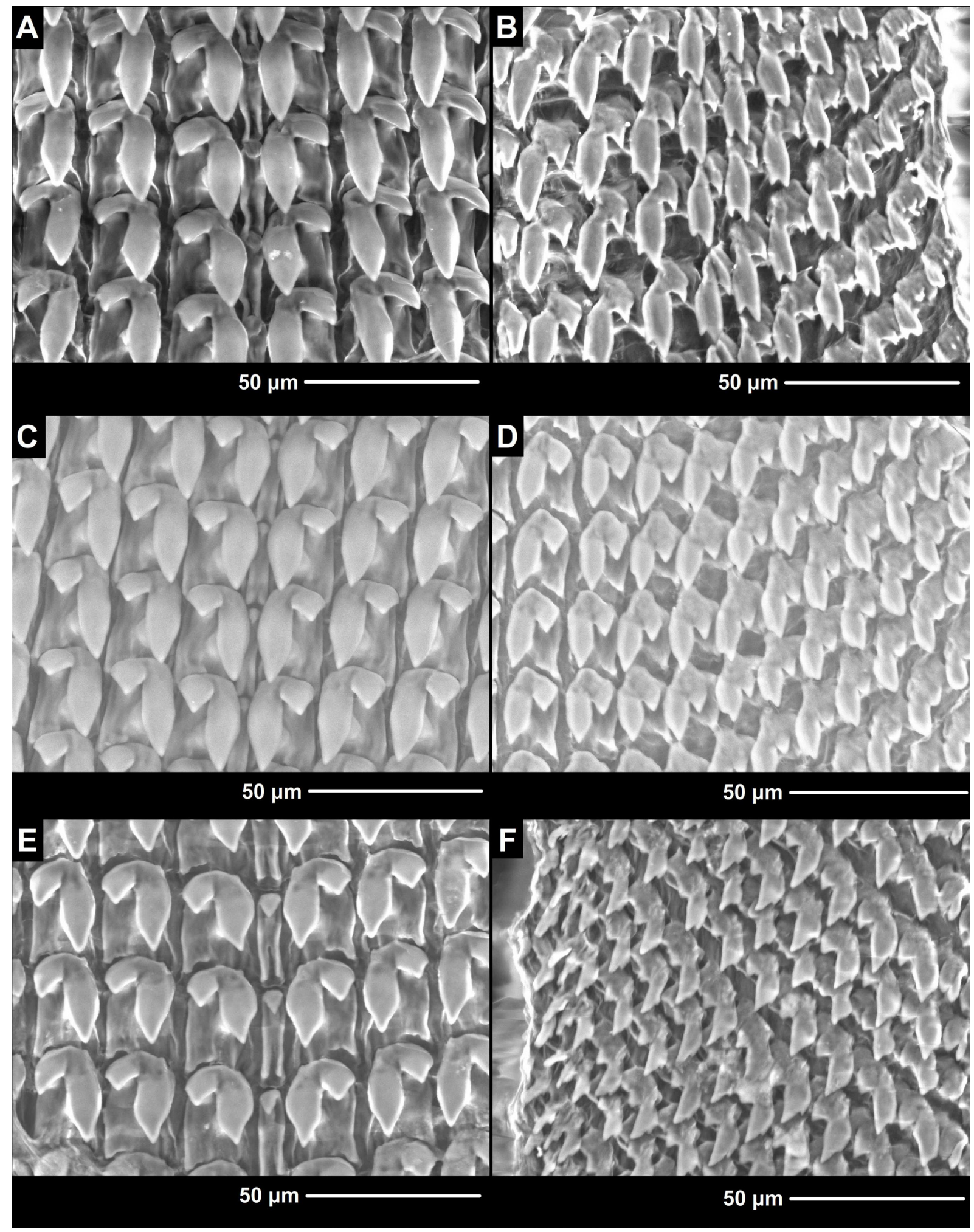

Fig. 16. Radula of species of Chersaecia Gude, 1899. A, C, E. Central and first lateral teeth. B, D, F. Marginal teeth. A-B. C. auffenbergi sp. nov. (NHMW MO-112 221) C-D. C. perrierae (Gude, 1898) (NHMUK 20170148). E-F. C. scabra sp. nov. (NHMUK 20170149). All images: B. Páll-Gergely. 
PÁLL-GERGELY B., Systematic revision of the Plectopylinae

Paratypes

THAILAND: 3 shells, same data as for holotype (UF 448572); 1 shell, same data as for holotype (HNHM 97464); 1 shell, Mae Hong Son Province, 10 km NW of Ban Soppong, 19³3'11" N, 98¹1'32" E, 24 May 1987, F.G. Thompson leg. (UF 347263); 2 shells, Soppong, NE of Mae Hong Son, 27 May 2002, W. Proester leg., ex coll. W. Maassen (coll. PGB); 4 shells, same data as for preceding (coll. WM); 26 shells, Mae Hong Son Province, 8.9 km from Ban Sop Pong toward Mae Hong Son (road 1095), $19^{\circ} 33.075^{\prime} \mathrm{N}, 98^{\circ} 11.925^{\prime} \mathrm{E}, 810 \mathrm{~m}$ a.s.1., 10 Feb. 2015, A. Hunyadi leg. (coll. HA); 3 shells, Mae Hong

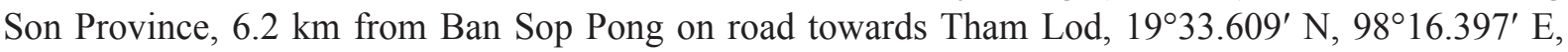
720 m a.s.1., 9 Feb. 2015, A. Hunyadi leg. (coll. HA); 18 shells, Mae Hong Son Province, 9.1 km from Ban Sop Pong towards Mae Hong Son, left side of road no. 1095, 19³3.123' N, 98¹1.694' E, 785 m a.s.1., 9 Feb. 2015, A. Hunyadi leg. (coll. HA).

\section{Additional material}

THAILAND: 3 juv. shells, Mae Hong Son Province, 8.9 km from Ban Sop Pong, on road towards Mae Hong Son (road 1095), 19³3.075' N, 98 $11.925^{\prime}$ E, 810 m a.s.l., 10 Feb. 2015, A. Hunyadi leg. (coll. HA); 2 juv. specimens (preserved in ethanol: PL050 and PL051 used for molecular study and radula examined), same data as for preceding (NHMW MO-112 221); 2 juv. shells, Mae Hong Son Province, $6.2 \mathrm{~km}$ from Ban Sop Pong on road towards Tham Lod, 19³3.609' N, 98¹6.397' E, 720 m a.s.1., 9 Feb. 2015, A. Hunyadi leg. (coll. HA); 9 juv./broken shells, Mae Hong Son Province, 9.1 km from Ban Sop Pong towards Mae Hong Son, left side of road no. 1095, 19³3.123' N, 98¹1.694' E, 785 m a.s.1., 9 Feb. 2015, A. Hunyadi leg. (coll. HA).

\section{Description}

SHELL. Sinistral, brownish corneous, flat, only protoconch protrudes above dorsal surface; protoconch consists of 2.5-2.75 whorls, with fine granular surface, roughly, irregularly ribbed; dorsal side of teleoconch finely reticulated, sculpture on umbilical side weaker; ribs stronger than spiral lines on both dorsal and ventral surfaces; whorls 5.5-5.75, separated by a rather deep suture; aperture oval; peristome thickened and slightly reflected; parietal callus weaker than peristome; apertural fold in contact with parietal callus, gradually weakens towards parietal callus.

Two shells were opened. Parietal wall with two vertical lamellae; both ends of posterior lamella slightly elongated posteriorly; anterior lamella shorter and thicker than posterior lamella, connected to main and intermediate plicae; intermediate plica slightly longer than posterior lamella; main plica runs to apertural fold. Palatal wall with six plicae; first plica straight, longest and situated near suture; last plica curved downwards very slightly; middle plicae Y-shaped, with arms of Y pointing posteriorly.

MeAsurements (in mm). $\mathrm{D}=15.2-18.2, \mathrm{H}=4.8-5.2(\mathrm{n}=4)$.

RaDULA. Centrals with very small, triangular cusps; endocones of laterals subovoid; ectocones of first laterals larger than centrals; ectocones of marginals undivided; endocones of marginals divided at their middle by rather deep incision.

\section{Differential diagnosis}

Chersaecia auffenbergi sp. nov. can easily be distinguished by its Y-shaped palatal plicae, roughly ribbed protoconch and concave spire.

\section{Distribution}

The new species is only known from five localities across three sites, which are all situated in close proximity to one another in the northern part of Mae Hong Son Province, Thailand (Fig. 17). 
Chersaecia feddeni (Blanford, 1865) comb. nov.

Figs $14 \mathrm{~F}-\mathrm{G}, 15 \mathrm{C}-\mathrm{F}$

Helix (Plectopylis) feddeni Blanford, 1865: 75-76, 94 ["Prome", "Prome, close to the Pagoda"].

Helix (Plectopylis) ponsonbyi Godwin-Austen, 1888: 243 ["Hlindet, Upper Burmah, 1500 feet"]. Syn. nov.

Helix feddeni - Pfeiffer 1868: 398.

Helix (Plectopylis) feddeni - Godwin-Austen 1875b: 613, pl. 74, fig. 7. - Hanley \& Theobald 1875:

52, pl. 131, figs 1-3. — Tryon 1887: 163, pl. 35, figs 84-87. — Tapparone Canefri 1889: 323 (=47)

["Prome"].

Helix (Plectopylis) fedden (Sic!) - Nevill 1878: 71.

Plectopylis ponsonbyi - Pilsbry 1894: 145, pl. 40, figs 9-12. — Gude 1896b: 178, fig. 22a-e; 1898c:

17, fig. 77a-b.

Plectopylis feddeni - Gude 1897i: 171, fig. 64a-d; 1899c: 75-77, fig. 104a-b.

Plectopylis (Plectopylis) feddeni - Gude 1899d: 148; 1899e: 175; 1914b: 128-129, fig. 63a-f.

Plectopylis (Plectopylis) ponsonbyi - Gude 1899d: 148. —1899e: 175; 1914b: 119-120, fig. 58a-e.

\section{Diagnosis}

A medium-sized, sinistral, flat species with Plectopylis-type palatal plicae, and two lamellae on the parietal wall with a main and a lower plica.

\section{Material examined}

Types

MYANMAR: 3 shells, syntypes of feddeni ( 2 broken, 1 complete shell with $\mathrm{D}=16.1 \mathrm{~mm}$ ), PromePegu (NHMUK 1906.1.1.730); holotype of P. ponsonbyi $(\mathrm{D}=17.8 \mathrm{~mm})$, Burmah, Hlindet (NHMUK 1913.3.14.9).

\section{Additional material}

MYANMAR: 1 shell, Moulmein, coll. Möllendorff ("ponsonbyi”) (SMF 150095); 1 shell ("feddeni”), Barma, Prome, coll. Möllendorff (SMF 150099).

\section{Description}

SHELl. Sinistral, whitish, fragile, flat, widely umbilicated; protoconch consists of 2.25-2.5 whorls with shallow suture; protoconch finely granular, after first whorl with rather rough wrinkles, which increase in strength towards end of protoconch; whorls 6.25-6.5, teleoconch whorls separated by a deep suture; dorsal surface with rather irregular, rough, dense ribs; ventral surface with lower ribs; fine spiral striation, weaker than radial lines, also discernible on entire shell; area near suture with some fine periostracal folds; body whorl rounded; aperture strongly oblique to shell axis, rounded; peristome whitish, expanded and reflected; parietal callus as strongly developed as peristome, slightly S-shaped; apertural fold rather strong, free from parietal callus; umbilicus wide, shallow.

Two syntypes of feddeni had been opened; one of them possessed three lamellae which is a teratological condition, therefore not included in the description (see Remarks). The holotype of ponsonbyi had also been opened. Parietal wall with two vertical lamellae; posterior lamella slender, elevated, with posteriorly elongated ends; anterior lamella shorter, more robust, with posteriorly, slightly elongated upper end, whereas both ends are strongly elongated anteriorly (upper one: main plica, lower one: basal plica); apertural fold connected to main plica in the intact syntype of feddeni, and free in the other two syntypes of feddeni and the holotype of ponsonbyi (these are probably subadult shells); lower plica slender, reaches peristome. Palatal plicae six; upper one close to suture, of normal size; second strongly 
elongated anteriorly; third short, depressed S-shape; fourth and fifth connected and form a vertical plate; sixth curved and of normal length; there can be additional denticles on the posterior ends of the plicae.

Measurements (in mm). $\mathrm{D}=16.1, \mathrm{H}=5.1$ (syntype of feddeni); $\mathrm{D}=17.8, \mathrm{H}=6$ (holotype of ponsonbyi).

\section{Differential diagnosis}

Chersaecia feddeni differs from C. magna in the smaller, more fragile shell, stronger sculpture, and the main plica, which is connected to the apertural fold. Chersaecia leucochila has a more elevated spire, domed dorsal side and a narrower umbilicus, and although the known specimens are somewhat weathered, the sculpture of C. leucochila is weaker than that of C. feddeni. See also under C. goniobathmos.

\section{Distribution}

Chersaecia feddeni is known from southern Myanmar only.

\section{Remarks}

The shell shape of Plectopylis feddeni is identical to that of P. ponsonbyi. The only difference between the types of the two taxa is the short main and lower plicae in the latter. The holotype of $P$. ponsonbyi

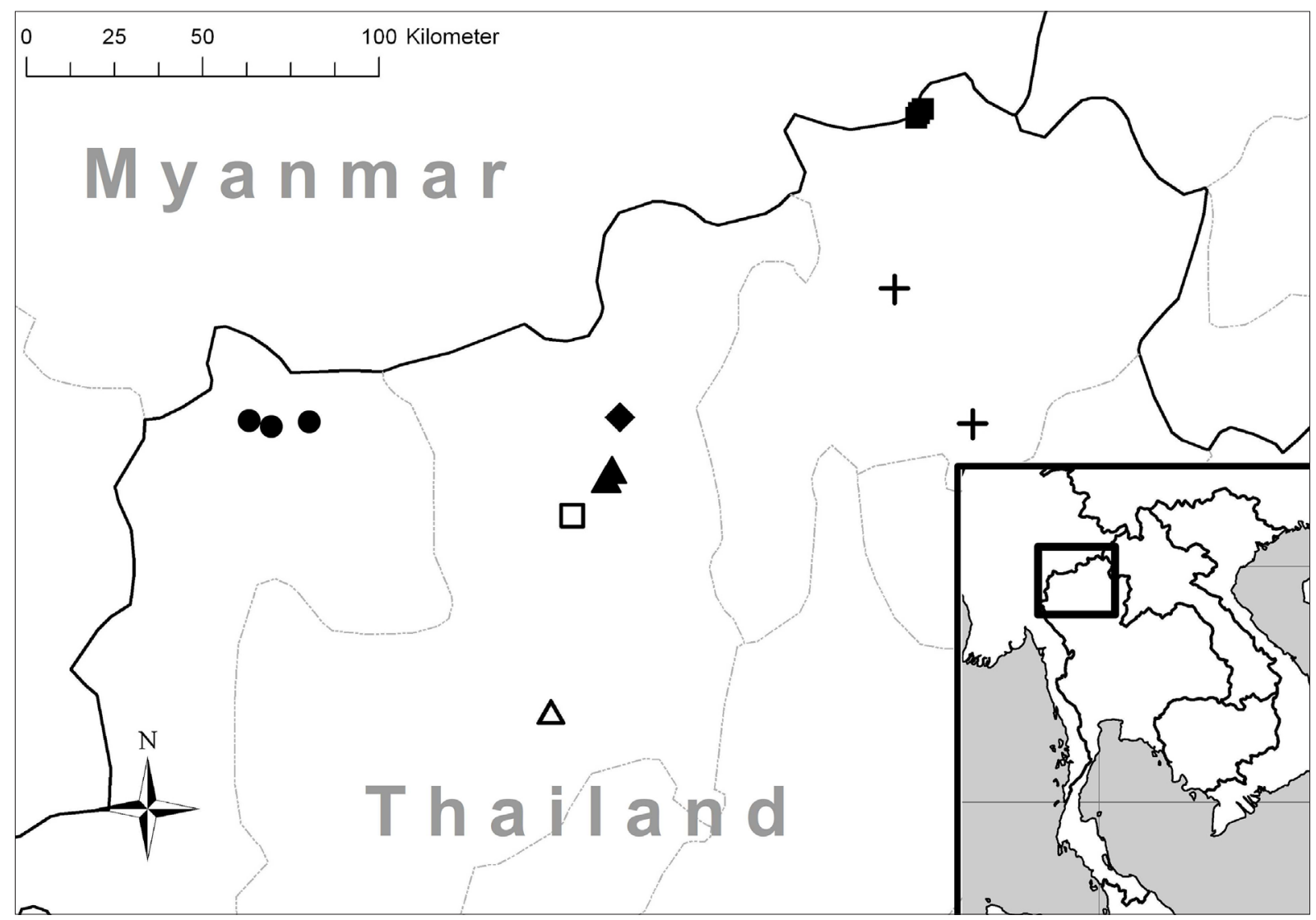

Fig. 17. Distribution of plectopylid species in Northern Thailand. Legends: circle $=$ Chersaecia auffenbergi sp. nov.; triangle $=$ Chersaecia leiophis (Benson, 1860) (empty triangle shows the type locality of Plectopylis degerbolae Solem, 1966); empty square = Chersaecia perarcta simplex (Solem, 1966); cross = Chersaecia perarcta perarcta (Blanford, 1865); filled square $=$ Chersaecia scabra sp. nov.; rhomb = Chersaecia densegyrata sp. nov.; the upper filled triangle also shows the locality of Naggsia oligogyra sp. nov. 
seems to be a subadult specimen because it has a relatively thin peristome and parietal callus. Therefore, the shorter plicae that differentiates $P$. feddeni, from $P$. ponsonbyi may be the result of ontogenetic variation and not a species-level difference.

Godwin-Austen (1875b) published a drawing of a specimen of Chersaecia feddeni with three lamellae. Gude (1914b) even produced his identification key stating that feddeni has "three transverse parietal plates". Both other specimens of the same sample had only two lamellae, which is usual in the genus. Consequently, the three lamellae may be the result of a teratological condition of the normal two lamellae with no taxonomic value.

Chersaecia goniobathmos (Ehrmann, 1922) comb. nov.

Figs $14 \mathrm{C}-\mathrm{E}, 15 \mathrm{G}-\mathrm{H}$

Plectopylis (Plectopylis) goniobathmos Ehrmann, 1922: 10-12, figs a-b, unnumbered plate, fig. 3a-c ["Pekon, südliche Shan-Staaten, in ca. 1000 m Höhe"].

\section{Diagnosis}

A small to medium-sized, sinistral, brownish species with two lamellae, long main and lower plicae reaching the aperture, and Plectopylis-type palatal plicae.

\section{Material examined}

Types

MYANMAR: 1 shell, lectotype ( $\mathrm{D}=14.7 \mathrm{~mm}$ ), Süd. Schan-Staaten: Pekor, $1000 \mathrm{~m}, \mathrm{~W}$. Micholitz leg., coll. Ehrmann (SMF 150100a); 1 shell, paralectotype, same data as for preceding (SMF 150100b); 1 paralectotype, same data as for preceding (SMF 150100c); 2 paralectotypes, same data as preceding (SMF 150100d-e).

\section{Description}

SHELL. Sinistral, flat or with slightly elevated spire; colour dark to light brown; protoconch very finely tuberculated, tubercles arranged in radial lines; teleoconch with reticulated sculpture; radial lines dominant on dorsal side; on ventral side spiral and radial sculptural elements of comparable strength; whorls $6.25-6.75(\mathrm{n}=2)$, separated by rather shallow suture; whorls slightly angled, flat above; peristome reflected and slightly thickened; parietal callus elevated, rather sharp and V-shaped; apertural fold connected to parietal callus.

Two opened shells were examined. Parietal wall with a rather straight posterior lamella having posteriorly elongated lower, and posteriorly as well as anteriorly elongated upper ends, and a shorter, straight anterior lamella with posteriorly elongated upper and lower ends; upper elongation of anterior lamella does not reach posterior lamella; main plica long, reaches apertural fold; intermediate plica short, lower plica very long, starts below posterior lamella and reaches peristome. Palatal plicae similar to that of Plectopylis; first three plicae horizontal, straight, fourth and fifth form a vertical plate, last plica also straight, horizontal, and strongly elongated anteriorly.

Measurements (in mm). $\mathrm{D}=14.7-16.4, \mathrm{H}=5.6-6.2$ (lectotype and syntypes, $\mathrm{n}=3$ ).

\section{Differential diagnosis}

Shell shape Chersaecia goniobathmos is generally similar to C. leiophis (especially the pseudophis-like shells). There are, however, considerable differences in the plication, namely (1) Chersaecia leiophis has only a single lamella (the anterior one is missing), whereas C. goniobathmos has two; (2) Chersaecia 
goniobathmos has a very long lower parietal plica, which is short in C. leiophis; (3) the palatal plicae of $C$. goniobathmos are typical of that of the genus Plectopylis, but in the case of $C$. leiophis the fourth and fifth plicae do not form a vertical plate, but are oblique. Chersaecia goniobathmos differs from C. feddeni in the more elevated spire, the apertural fold, which is connected to the parietal callus, and the main plica, which is connected to the apertural fold.

\section{Distribution}

Chersaecia goniobathmos is known from the type locality only.

\section{Chersaecia leiophis (Benson, 1860)}

Figs 15I-Q, 18, 19A-B

Helix (Plectopylis) leiophis Benson, 1860: 244, 246 ["ad Kwadouk, prope Thyet Mio"].

Helix (Plectopylis) pseudophis Godwin-Austen, 1875b: 610-613, pl. 74, fig. 3.

Plectopylis (Chersaecia) kengtungensis Gude, 1914a: 53, figs a-c (+ unnumbered figures) [“E. Burma: Kengtung"]. Syn. nov.

Plectopylis (Chersaecia) degerbolae Solem, 1966: 95-97, fig. 23a-b., pl. 2 figs F-H ["Doi Sutep, North Thailand at 1,000 meters elevation (number 1173)"]. Syn. nov.

Helix (Plectopylis) leiophis - Blanford 1865: 94 ["Thyet Myo", “Akoutoung”]. - Hanley \& Theobald 1870: 7, pl. 13, fig. 8. - Godwin-Austen 1875a: 44 (as a synonym of refuga); 1875b: 613, pl. 74, fig. 2. - Tryon 1887: 163, pl. 35, figs 88-89.

Helix leiophis - Pfeiffer 1868: 396.

Plectopylis pseudophis - Godwin-Austen 1875a: 44 ["Thayatmyo, in Pegu"]. - Gude 1897i: 170, fig. 62a-c; 1899b: 17, fig. 77a-g; 1908: 88-89 (synonym of leiophis).

Helix (Plectopylis) pseudophis - Tryon 1887: 162, pl. 35, figs 80-81.

Plectopylis leiophis - Gude 1898c: 16, fig. 76a-c; 1908: 88-89.

Plectopylis (Chersaecia) pseudophis - Gude 1899d: 148; 1899e: 175.

Plectopylis (Chersaecia) leiophis - Gude 1899d: 148; 1899e: 175; 1914b: 99-102, figs 44-46. — Zilch 1960: 595, fig. 2093.

Plectopylis (Chersaecia) kengtungensis - Gude 1914b: 97-98, fig. 43a-c + unnumbered figs.

Chersaecia leiophis - Páll-Gergely et al. 2015c: 10.

Chersaecia kengtungensis - Páll-Gergely et al. 2015c: 10.

Chersaecia degerbolae - Páll-Gergely et al. 2015c: 10.

\section{Diagnosis}

A small to medium-sized, sinistral species with a single lamella and a main plica on the parietal wall, and parallel plicae on the palatal wall.

\section{Material examined}

Types

MYANMAR: 3 shells, syntypes of kengtungensis $(\mathrm{D}=11.4-11.8 \mathrm{~mm})$, Burmah, Shan States (NHMUK 1903.7.1.750); 4 shells, probably syntypes of pseudophis, Burmah, coll. Godwin-Austen (NHMUK 1903.7.1.754).

THAILAND: 1 shell, holotype of $P$. degerbolae (preserved in ethanol: PL123 used for molecular study) (D = 16.2), N. Thailand, Doi Sutep, O.H., 1000 m a.s.l., 1 Jul. 1960, Degerbøl leg. (nr. 1173) (ZMUCGAS-485). 


\section{Additional material}

LOCALITY UNKNOWN: 1 shell ("refuga"), ex-exhibition coll. "alte Schau-Slg." (SMF 150116); 1 shell, ex-exhibition coll. "alte Schau-Slg." (SMF 150114); 67 shells, coll. Blanford (NHMUK); 3 shells, coll. Blanford (NHMUK); 1 shell, "from author" (NHMUK 1888.12.4.1532).
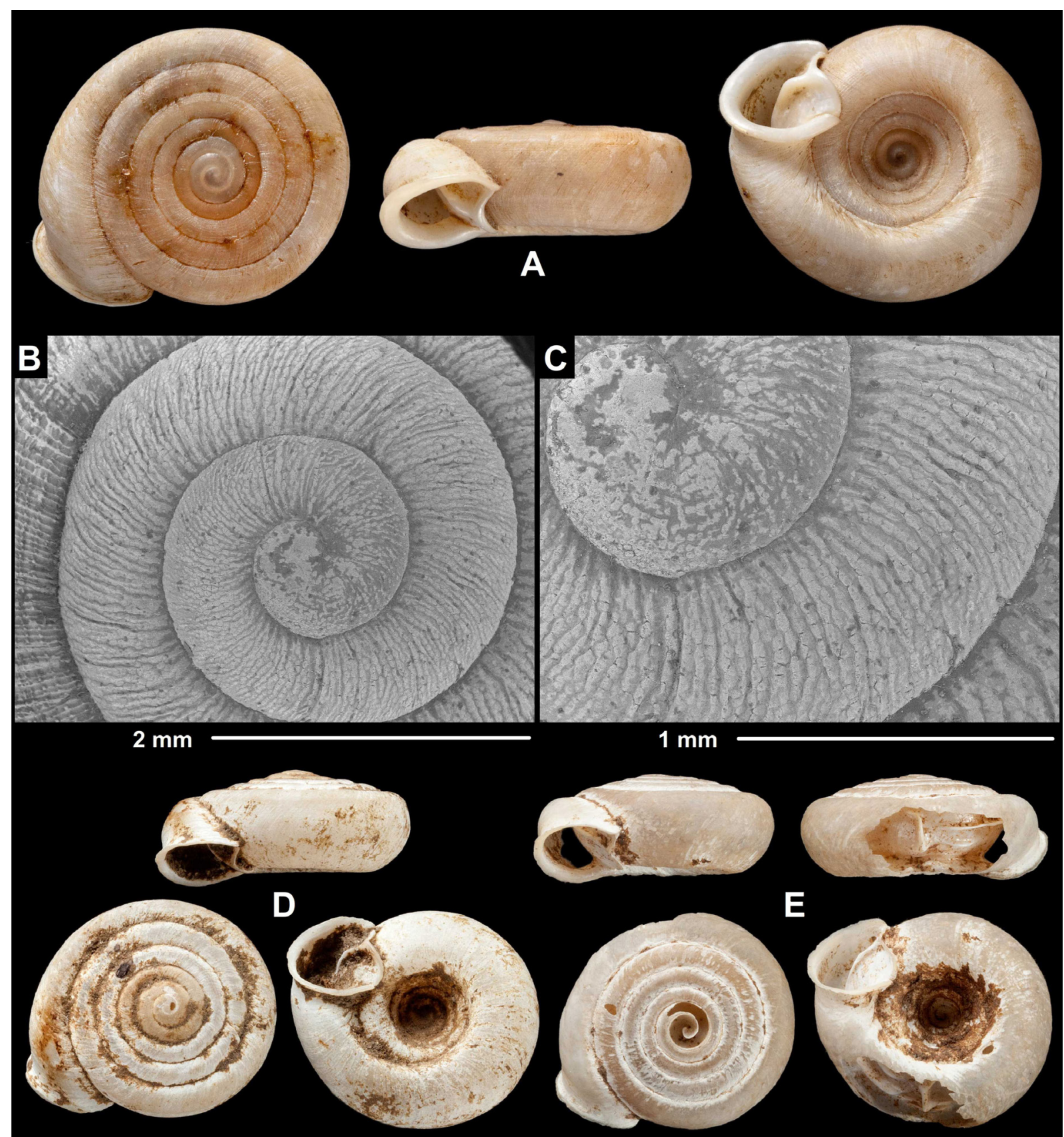

E

Fig. 18. Shells and protoconch of species of Chersaecia leiophis (Benson, 1860). A-C. Shells from Myanmar (NHMUK 1888.12.4.1526-1528, two different shells). D. Probable syntype of P. pseudophis Godwin-Austen, 1875 (NHMUK 1903.7.1.754). E. Syntype of P. kengtungensis Gude, 1914 syn. nov. (NHMUK 1903.7.1.750). Scale of shells $=10 \mathrm{~mm}$. Images: B. Páll-Gergely (B-C) and H. Taylor (A, D-E). 
MYANMAR: 1 shell, Pegu, (NHMS 122178); 3 shells, Barma, coll. Möllendorff (photographed for Zilch 1960) (SMF 150115); 1 shell, Brit. Indien, coll. Bosch ex Rolle (Schlüter) (SMF 172055); 3 shells, Akouktoung (NHMUK 1888.12.4.1526-1528); 2 shells (mixed sample with C. refuga) (NHMUK 20170160); 1 shell, Burma, ex Museum Cuming (NHMUK 20150360); 1 shell (mixed sample with C. refuga) (NHMUK 20170162); 1 shell, India, Thyet Myo (NHMUK 20170161); 3 shells, Burmah (donated by Prof. Kenneth D. Thomas), 16 Oct. 2012 (NHMUK); 3 shells, Prome(?) (NHMUK/13); 1 shell, Ava(?) (NHMUK); 4 shells, Arakan Coast, Nioung jo (NHMUK 1888.12.4.1544-1547); 1 shell, Pegu, Lower Burma, coll. Salisbury ex Beddome (NHMUK); 3 shells, India, Burmah, (NHMUK 1871.9.23.205); 6 shells, Burmah (NHMUK); 3 shells, Burmah, coll. Kennard ex Leipner ex Bullen (NHMUK); 5 shells, Akouktoung (NHMUK); 5 shells, Pegu, Thayet Myo?, coll. Blanford (NHMUK 1906.1.1.742); 3 shells, Upper Irawadi (NHMUK 1888.12.04.1533-1535); \pm 15 shells, Prome, coll. Blanford (NHMUK).

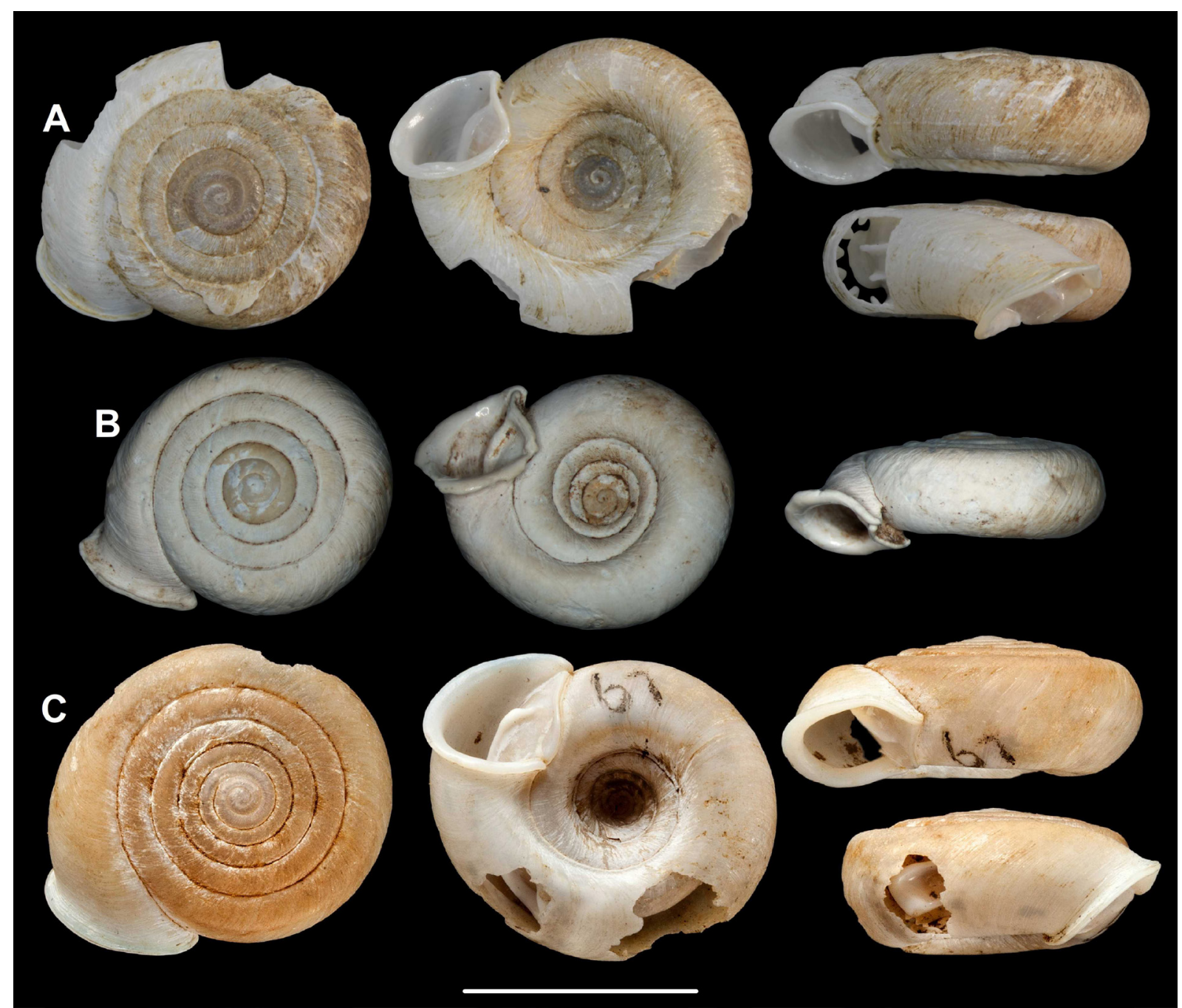

Fig. 19. Shells of species of Chersaecia Gude, 1899. A. C. leiophis (Benson, 1860), holotype of P. degerbolae Solem, 1966 (ZMUC-GAS-485). B. C. leiophis from Thailand (UF 346988). C. C. leucochila (Gude, 1897) comb. nov., holotype (NHMUK 1922.8.29.39). Scale bar $=10 \mathrm{~mm}$. Photos: B. Páll-Gergely (A), T. Deli (B), H. Taylor (C). 
THAILAND: 1 shell (Fig. 19B), Chiang Mae Province, NW side of Doi Pha Sam Sao, 19²4'27" N, 99 $2^{\prime} 56^{\prime \prime}$ E, 20 May 1988, F.G. Thompson leg. (UF 346988); 3 shells, same data as for preceding (UF 448573); 1 shell, same data as for preceding (HNHM 97456); 1 shell, Chiang Mae Province, Doi Pha San Sao Mountain, $1 \mathrm{~km} \mathrm{~W}$ of Ban Prang Ma-o, 19²5'58.26" N, 99 $4^{\prime} 14.02^{\prime \prime}$ E, 500 m a.s.1., 19 Jun. 1987, F.G. Thompson leg. (UF 346677); 1 shell, Chiang Mai Province, Ban Pang Mao, 1.1 km NW of Wat Suwan Khiri, $19^{\circ} 25.981^{\prime}$ N, 9904.335' E, 510 m a.s.1., 8 Feb. 2015, A. Hunyadi leg. (coll. HA).

\section{Description of typical leiophis}

SHELL. Sinistral, flat above or with very slightly elevated spire; colour light brown to yellowish and white; protoconch consists of 2.5-2.75 whorls, very finely tuberculated, with fine wrinkles over the entire surface; teleoconch with reticular structure, only periphery of body whorl dominated by radial riblets, rest of shell surface sculptured with spiral and radial elements of ca equal strength; whorls 5.75-6.25 $(\mathrm{n}=3)$, separated by rather shallow suture; whorls angled, flat above; peristome expanded and slightly thickened; parietal callus elevated, rather sharp and V-shaped; apertural fold connected to parietal callus.

Three opened shells of typical leiophis were examined. Parietal wall with a single curved lamella; main plica long, reaches apertural fold; lower plica short, situated under lamella; intermediate plica short; all horizontal parietal plicae free from lamella or connected to it. Palatal plicae six or seven; first and last plicae straight, middle ones straight, horizontal or oblique, or sometimes fourth and fifth vertical; sometimes the plicae have a posterior denticle.

Measurements (in mm). $\mathrm{D}=14.55-15.3, \mathrm{H}=6.1-6.9(\mathrm{n}=3$, NHMUK 1888.12.4.1526-28, typical leiophis); $\mathrm{D}=16.2, \mathrm{H}=6.2$ (holotype of degerbolae, ZMUC-GAS-485); $\mathrm{D}=13.6-15.6, \mathrm{H}=5.5-5.9$ (Thai specimens, $\mathrm{n}=3$ ).

\section{Differential diagnosis}

Chersaecia perarcta is smaller and flatter, usually with concave surface. See under C. nagaensis and C. refuga.

\section{Distribution}

Chersaecia leiophis is known from Myanmar (states of Bago, Pyay, Thayet, Shan, etc.) and northern Thailand (see Fig. 17 for localities in Thailand).

\section{Remarks}

The relationship between Plectopylis pseudophis and P. leiophis was discussed by Gude (1908). According to him, the typical forms differ in the following characters: toothed outline of the lamella, elevated spire, and the absence of a short additional plica between the main and intermediate plicae in pseudophis; smooth lamella, flat spire and the presence of an additional plica between the main and intermediate plicae in leiophis. Based on the specimens examined by Gude (1908), all these characters are variable across populations and do not allow for the separation of these two species. Therefore, Plectopylis pseudophis was assigned as a synonym of $P$. leiophis. I confirmed Gude's observations by examining the same specimens, and agree with his conclusion.

Plectopylis kengtungensis was compared with P. nagaensis and P. muspratti in the original description, but not with P. leiophis (Gude 1914a). According to the original description of P. kengtungensis, it has the palatal plicae united with a "low transverse ridge", whereas this was not mentioned in the case of P. leiophis. This character, however, varies considerably between specimens within the same populations, probably depending on their age. Older shells tend to have stronger calcareous layers built on both the 
parietal and palatal sides of the armature. Regardless of the ridge, the morphology of palatal plicae of typical kengtungensis and leiophis are similar (usually long plicae with small denticles posteriorly, and the $5^{\text {th }}$ plica is oblique). The plication of the parietal side is also similar in the two forms. The shell shape of typical leiophis is quite flat, whereas the spire of $P$. kengtungensis is slightly elevated. This character also does not differentiate the two species, because typical pseudophis (= synonym of leiophis) shells have similar shell shape to that of $P$. kengtungensis. Because of the above-mentioned information, I assign $P$. kengtungensis as a synonym of $P$. leiophis.

Plectopylis (Chersaecia) degerbolae does not differ in shape from typical P. leiophis specimens. Solem (1966) mentioned the following differences: (1) both horizontal plicae are free from the lamella in degerbolae, and at least one of them is fused to the lamella as in leiophis; (2) the denticles posterior to the palatal plicae are absent in degerbolae and present in leiophis; (3) the larger shell size of degerbolae. The first is not true, because the lamella and the horizontal plicae are separate in some leiophis samples, for example in typical ones (NHMUK 1906.02.02.145). The second might be true (in some leiophis samples only 1-2 additional denticles found), although this character appears too variable to be useful. The same prudence should be applied with regard to the slight differences in shell size. Therefore, I treat P. degerbolae as a synonym of Chersaecia leiophis.

The shells collected in Thailand on the Doi Pha San Sao Mountain differ from typical C. leiophis by the strongly descending aperture and the strongly expanded and reflected peristome. This form may deserve subspecific differentiation.

According to the original descriptions of $P$. degerbolae and $P$. simplex, their protoconchs have "irregular growth wrinkles" and are "smooth", respectively (Solem 1966). I examined type specimens of both species and found that both have finely tuberculated protoconchs, which is a characteristic trait of the genus. In addition to the tubercles, the second whorl of the protoconch is irregularly wrinkled in the paratype of $P$. degerbolae, but no wrinkles were found on the protoconch of the paratype of $P$. simplex.

Chersaecia leucochila (Gude, 1897) comb. nov. Figs 15R-S, 19C

Plectopylis leucochilus Gude, 1898a: 231, fig. 66a-e [“Burma"].

Plectopylis leucochila - Gude 1898b: 264 (erratum).

Plectopylis leucochilus - Gude 1898h: 13-14, fig. 9a-e.

Plectopylis (Plectopylis) leucochila - Gude 1899d: 148; 1899e: 175; 1914b: 126-127, fig. 62a-e.

\section{Diagnosis}

Shell medium-sized, domed, parietal wall with two lamellae and long lower and main plicae, palatal wall with typical Plectopylis-like plicae.

\section{Material examined}

Holotype

MYANMAR: 1 shell, holotype ( $\mathrm{D}=16 \mathrm{~mm}$ ), Burma (NHMUK 1922.8.29.39).

\section{Additional material}

INDIA: 1 shell (from type sample of Chersaecia austeni), Diyung valley, Singpho Hills, Assam, Ogle leg. (NHMUK 1903.06.01.1014.1). 
In the type sample of Chersaecia austeni (NHMUK 1903.06.01.1014), a sinistral shell was found which is identical to the holotype of C. leucochila. A lectotype of the sample of C. austeni was therefore selected (see under that species).

\section{Description}

SHELL. Sinistral, medium-sized, light grey; spire slightly elevated; protoconch consists of 2.75 whorls, extremely finely granular, with rough, rather regular radial ribs; whorls 7.5 , separated by shallow (protoconch) and deep (teleoconch) suture; teleoconch weathered, but the rough, rather irregular radial ribs, the much weaker spiral striation and the remains of periostracal folds near the suture still visible; aperture rounded; peristome expanded and slightly reflected; parietal callus slightly S-shaped, rather blunt; apertural fold free from parietal callus; umbilicus funnel-shaped, narrow compared to other members of the genus.

The holotype had been opened by Gude. Parietal wall with two vertical lamellae; posterior lamella thin, oblique to suture, with short elongations in both directions at its lower end; anterior lamella shorter, thicker, both ends elongated anteriorly; upper elongation continuous with main plica; main plica connected to apertural fold; lower elongation represents short intermediate plica; posterior elongations of anterior lamella not visible through opaque shell. Palatal plicae six; first slender, situated close to the suture; second strongly elongated anteriorly; third shorter, posterior end curved downwards; fourth and fifth form a slightly S-shaped, vertical plate; sixth curved, situated close to lower suture.

MeAsurements (in mm). $\mathrm{D}=16, \mathrm{H}=6.7$ (holotype of leucochila).

\section{Differential diagnosis}

See under C. feddeni and C. magna.

\section{Distribution}

This species is known from Burma (Myanmar) only. A single shell found in the type sample of C. austeni from Assam, India, was probably misplaced.

Chersaecia magna (Gude, 1897) comb. nov.

Figs 5E-F, 20A-B, 21A-D

Plectopylis magna Gude, 1897h: 70, fig. 52a-f ["Burma"].

Plectopylis lissochlamys Gude, 1897h: 70-71, fig. 53a-f ["Burma"]. Syn. nov.

Plectopylis magna - Gude 1898h: 9-11, fig. 7a-f; 1900b: 91.

Plectopylis lissochlamys - Gude 1898h: 11-13, fig. 8a-f.

Plectopylis (Plectopylis) magna - Gude 1899d: 148; 1899e: 175; 1914b: 122-124, fig. 60a-f.

Plectopylis (Plectopylis) lissochlamys - Gude 1899d: 148; 1899e: 175; 1914b: 121-122, fig. 59a-f.

\section{Diagnosis}

A medium-sized to large, flat species with two lamellae on the parietal wall, and a main plica free from the apertural fold; palatal wall with typical Plectopylis-like plicae.

\section{Material examined}

Types

MYANMAR: 1 shell, holotype of lissochlamys $(\mathrm{D}=19 \mathrm{~mm})$, Burma (NHMUK 1922.8.29.38); 1 shell, holotype of magna $(\mathrm{D}=25.4 \mathrm{~mm})$, Burma (NHMUK 1922.8.29.37). 


\section{Additional material}

MYANMAR: 1 shell ("magna"), Burma, Mergui, coll. Bosch ex Rolle (SMF 172064); 2 shells ("lissochlamys"), Moulmein, coll. Möllendorff (SMF 150098); 1 shell ("lissochlamys"), Burma (NHMUK 1899.4.22.77); 2 shells ("magna"), Tuonghoo, coll. Godwin-Austen ex Blanford (NHMUK 1923.2.15.5); 2 shells ("magna”), Burma, Tonghu, Theobald leg., coll. Blanford (NHMUK 1906.1.1.731); 1 shell ("magna"), Burma (NHMUK 1899.4.22.78).

\section{LOCALITY UNKNOWN: 2 shells, coll. H.E.J. Biggs, Acc. no. 2258 (NHMUK).}

\section{Description}

SHELL. Sinistral, large, thick, pale greyish-yellowish to brown, flat, only protoconch protruding slightly above dorsal surface; protoconch consists of 2.5-2.75 whorls, extremely finely granular and rather regularly, roughly ribbed, rib strength and density increases towards the end of protoconch; suture of protoconch shallow; whorls 7.25-7.5, teleoconch whorls separated by deep suture; teleoconch with rather irregular, dense, fine ribs and only fine striation; body whorl has a much weaker sculpture, ventral

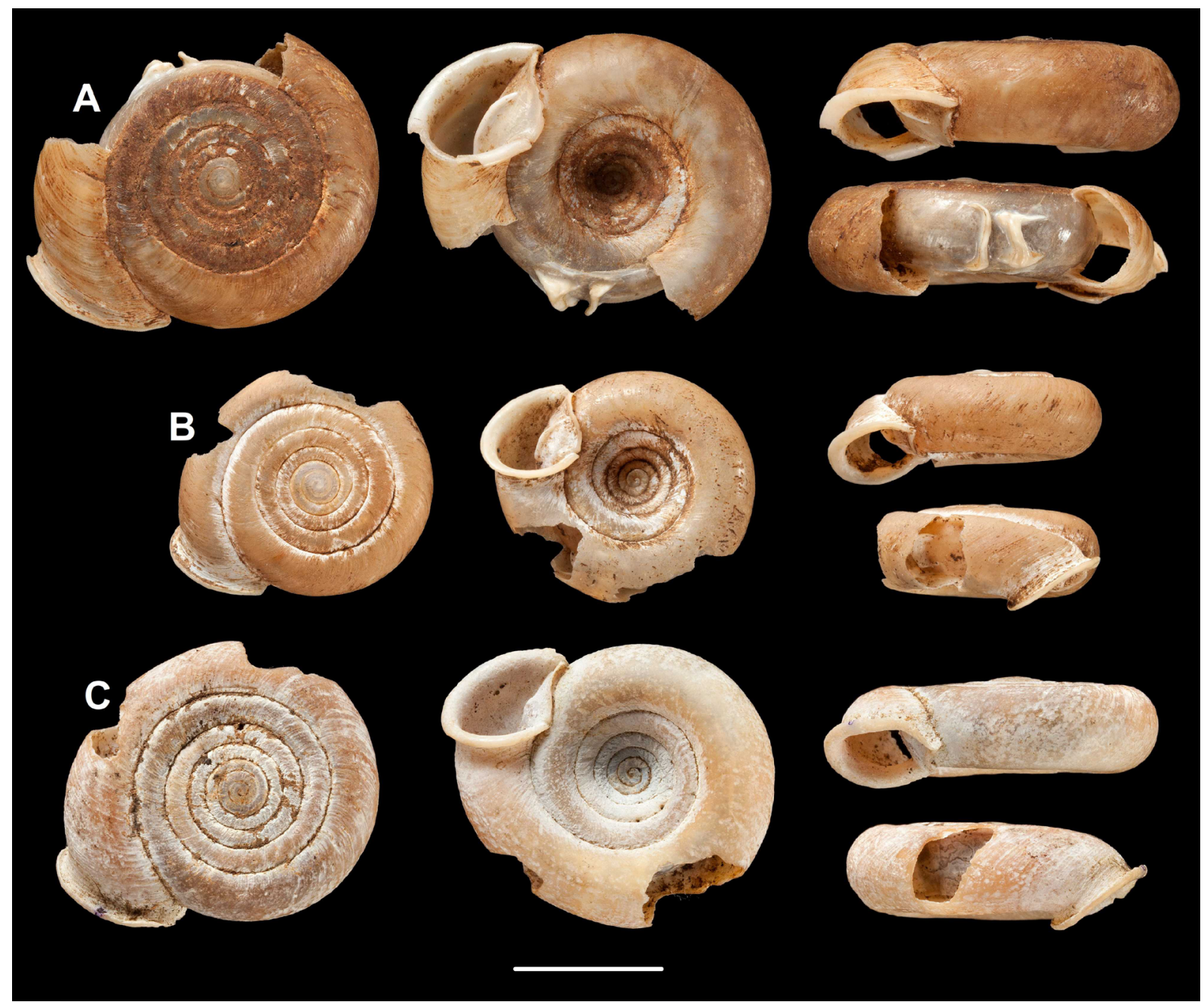

Fig. 20. Shells of species of Chersaecia Gude, 1899. A. C. magna (Gude, 1897) comb. nov., holotype (NHMUK 1922.8.29.37). B. C. magna, holotype of Plectopylis lissochlamys Gude, 1897 syn. nov. (NHMUK 1922.8.29.38). C. C. mogokensis sp. nov., holotype (NHMUK 20140787). Scale bar $=$ $10 \mathrm{~mm}$. All photos: H. Taylor. 
side nearly smooth, glossy; body whorl rounded; aperture oval; peristome whitish, expanded and reflected; parietal callus as strongly developed as peristome, rather sharp, slightly S-shaped; apertural fold free from parietal callus, very long, its end visible in oblique view into aperture; umbilicus wide, shallow, funnel-shaped.

The holotypes of Plectopylis magna and P. lissochlamys had been opened. Parietal wall with two lamellae; posterior lamella longer, slender, both ends elongated posteriorly; anterior lamella wider, slightly oblique to shell axis; lower end equally elongated both anteriorly and posteriorly, upper end elongated slightly in posterior direction, with a slightly longer elongation (= short main plica) anteriorly; lower plica slender, reaches peristome. Palatal wall with six main plicae; first situated close to upper suture, long, slightly curved; second plica strongly elongated anteriorly, straight; third short, curved; fourth and fifth join to form a vertical plate; sixth curved, of normal length, situated near lower suture; small denticles visible at posterior ends of all plicae; holotype of P. magna with an additional short horizontal plica between first and second plica.

MeAsurements (in mm). $\mathrm{D}=22.1-25.4, \mathrm{H}=7.9-8.9$ (holotype of magna, and two other shells); $\mathrm{D}=16$, $\mathrm{H}=6.7$ (holotype of lissochlamys).

\section{Differential diagnosis}

Chersaecia leucochila is smaller, has a more elevated spire, a deeper and narrower umbilicus, and its main plica is in contact with the apertural fold. See also under C. feddeni.

\section{Distribution}

This species is known from the country of Myanmar only, although the exact type locality is unknown.

\section{Remarks}

The holotype of Plectopylis magna differs from that of P. lissochlamys by the larger size, the longer anteriorly elongated lower part of the anterior lamella and the stronger lower plica, which is clearly visible only under the lamellae in P. lissochlamys, but continues only as a slight indication until the peristome in $P$. magna. All of these characters could be interpreted as intraspecific variability. Therefore, $P$. lissochlamys is assigned as a synonym of $P$. magna.

Chersaecia mogokensis sp. nov. urn:1sid:zoobank.org:act:8E2812E3-52AF-4CF9-A01D-FD01ED8396E7

Figs 20C, 21E-F

\section{Diagnosis}

Shell large, flat, widely umbilicated, parietal wall with a single lamella and a short lower plica, palatal plicae oblique, with additional denticles at their posterior ends.

\section{Etymology}

The name mogokensis refers to the type locality (Mogok). This name was written on the label of the specimen, but apparently has never been published.

\section{Material examined}

Holotype

MYANMAR: 1 shell, holotype $(\mathrm{D}=23.6 \mathrm{~mm})$, Burmah, Mogok, ruby mines, coll. Godwin-Austen (NHMUK 20140787). 


\section{Description}

SHELL. Sinistral, almost completely flat, only protoconch protrudes above dorsal surface; original colour might be reddish-brown; protoconch consists of slightly more than 2.5 whorls, separated by shallow suture; dorsal side of the protoconch irregularly, roughly wrinkled, but ventral side (i.e., inside the umbilicus) clearly tuberculated; whole teleoconch irregularly wrinkled sometimes with spiral lines especially on the apical side; whorls 6.75 ; teleoconch whorls separated by a deep suture; peristome
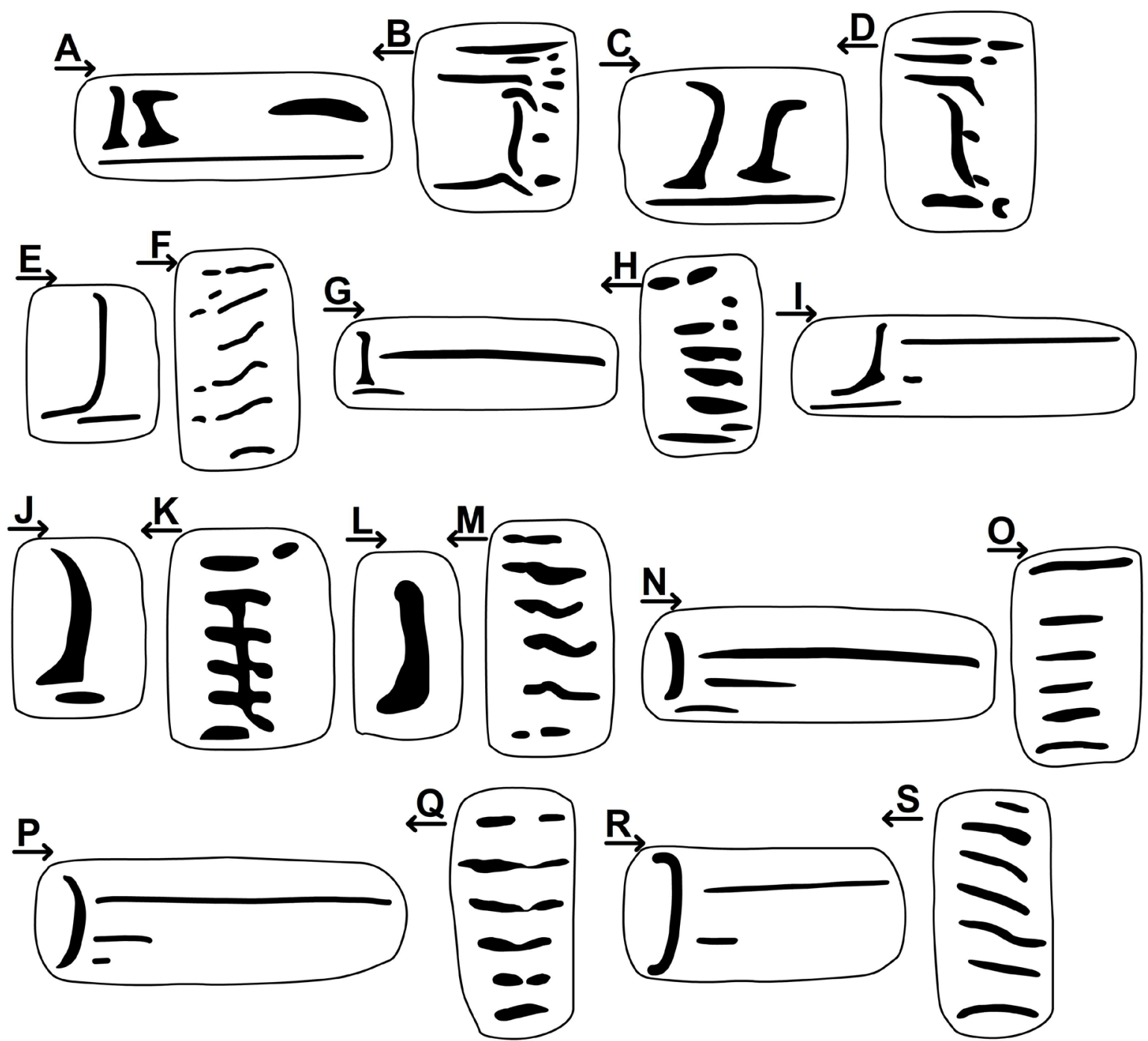

Fig. 21. Parietal (A, C, E, G, I, J, L, N, P, R) and palatal (B, D, F, H, K, M, O, Q, S) plication of species of Chersaecia Gude, 1899. A-B. C. magna (Gude, 1897) comb. nov., holotype (NHMUK 1922.8.29.37). C-D. C. magna ("P. lissochlamys", after Gude 1914b). E-F. C. mogokensis sp. nov., holotype (NHMUK 20140787). G-H. C. nagaensis (Godwin-Austen, 1875), syntypes (NHMUK 1903.7.1.753). I. C. nagaensis (NHMUK 1874.9.26.3). J-K. C. nagaensis muspratti (Gude, 1897) (after Gude 1914b). L-M. C. perarcta simplex (Solem, 1966) (after Solem 1966). N-O. C. perarcta perarcta (Blanford, 1865) (NHMUK 1906.2.2.275). P-Q. C. perarcta perarcta (UF 448575). R-S. C. perarcta perarcta, loc. "5.5 km west of Chiang Rai" (coll. PGB). Arrows below the letters indicate the direction of the aperture. Not to scale. 
strongly thickened and slightly reflected; parietal callus strongly developed, sharp, slightly S-shaped; apertural fold very short, denticle-like, free from parietal callus.

Parietal wall with a single, slightly curved lamella and a short lower plica. Palatal wall with six plicae; first and last straight, horizontal; remaining ones oblique, with additional denticles at their posterior ends.

Measurements (in mm). $\mathrm{D}=23.6, \mathrm{H}=7.7$ (holotype).

\section{Differential diagnosis}

In size and shape Chersaecia mogokensis sp. nov. resembles species of the genus Plectopylis. However, the straight, oblique palatal plicae, and the single lamella differentiates it from all species of Plectopylis. The most similar species of Chersaecia in outer shell morphology is C. shanensis, which nevertheless has strongly developed lower, main and intermediate plicae, a much stronger apertural fold, and a protoconch lacking or with a few low growth wrinkles. Chersaecia magna is also similar in outer appearance, but possesses two parietal lamellae and a very long apertural fold. All other species of Chersaecia are much smaller and/or have strongly developed main plicae.

\section{Distribution}

The only known specimen of Chersaecia mogokensis sp. nov. is from the type locality.

Chersaecia nagaensis (Godwin-Austen, 1875)

\section{Diagnosis}

Shell small, sinistral, domed or depressed-conical, dorsal side with dense reddish stripes that are often obscured by thick, brown periostracum; parietal wall with a single lamella and a short lower plica; main plica present or absent; palatal plicae horizontal, might be connected with a vertical ridge.

\section{Differential diagnosis}

Chersaecia nagaensis differs from C. leiophis in the following traits: shell smaller, spire higher, umbilicus narrower, body whorl rounded (shouldered in leiophis), periostracum denser, intermediate plica absent, or small and separated from the lamella. Chersaecia goniobathmos is similar to C. nagaensis in shell shape and sculpture, but differs from that species by possessing two lamellae, a long lower plica, and a well-developed intermediate plica, which is in contact with the anterior lamella.

Chersaecia nagaensis nagaensis (Godwin-Austen, 1875)

Figs $21 \mathrm{G}-\mathrm{I}, 22 \mathrm{~A}$

Helix (Plectopylis) nágáensis Godwin-Austen, 1875b: 609-610, 612, pl. 73, fig. 4 ["Prowi, head of the Lauier river, Nágá hills, 5000 feet”] (partim).

Helix (Plectopylis) nagaensis - Nevill 1878: 72. — Tryon 1887: 161, pl. 35, figs 78-79.

Plectopylis nagaensis - Gude 1897a: 206-207, fig. 33a-d.

Plectopylis (Chersaecia) nagaensis - Gude 1899d: 148; 1899e: 175; 1914b: 96-97, fig. 42a-d.

Chersaecia nagaensis - Páll-Gergely et al. 2015c: 10.

\section{Diagnosis}

Main plica present. 
PÁLL-GERGELY B., Systematic revision of the Plectopylinae

\section{Material examined}

Types

INDIA: 10 shells, syntypes of P. nagaensis, Naga Hills, Prowi, head of Lanier Valley, coll. GodwinAusten (NHMUK 1903.7.1.753).

\section{Additional material}

INDIA: 1 shell, Japvo Pk, Naga Hills (NHMUK 1903.7.1.3493); 2 adult shells (+ 2 juv. of questionable identity), Manipur Hills, Ogle leg. (NHMUK 1903.07.01.777); 1 shell, Naga Hills, Ogle leg., coll. Godwin-Austen (NHMUK); 9 shells, Prowi, NE Manipur, coll. Godwin-Austen (NHMUK); 1 shell, Naga Hills, Hungerford leg. (NHMUK 1891.3.17.352); 2 shells, coll. Godwin-Austen (NHMUK 1909.3.26.74); 2 shells, Naga Hills (NHMUK).

\section{Description}

SHell. Sinistral, usually with dense brownish periostracum; two shells lacking periostracum had yellowish grey colour and densely alternating reddish and yellowish stripes on the dorsal surface; below periostracum shell surface very finely reticulated as a result of fine, dense radial ribs and nearly equally strong spiral striation; spire elevated, dorsal side domed/depressed conical; protoconch consists of 2.5-2.75 whorls, very finely granular, only last ca one whorl with rough irregular, radial sculpture; whorls 6.25-6.5; teleoconch whorls separated by a shallow suture; aperture rounded; peristome whitish, expanded and reflected; parietal callus slightly S-shaped, approximately as strongly developed as peristome; apertural fold strong, connected to parietal callus; umbilicus relatively narrow and deep, funnel-shaped.

Four opened shells were examined. Parietal side with a single lamella; both ends of lamella slightly elongated posteriorly; lamella with a very slight elongation anteriorly in position of intermediate plica; an opened shell ("India", NHMUK 1874.9.26.3) with a short intermediate plica free from lamella; main plica free from lamella, reaching apertural fold; lower plica short, situated under the lamella, slightly extends beyond lamella in both anterior and posterior directions. Palatal wall with six plicae; first curved and situated near suture; second considerably elongated anteriorly, with an additional, small denticle at its posterior end; above this denticle there is another tiny denticle; third and fourth plicae shorter than second, slightly depressed Z-shaped; fifth plica shorter than fourth, divided in the middle (only visible from inside); sixth plica short, situated near suture, and positioned under the line of posterior denticles/ posterior parts of divided plicae.

Measurements (in mm). $\mathrm{D}=11.6-12.2, \mathrm{H}=6.3-6.8(\mathrm{n}=3$, type series of nagaensis).

\section{Differential diagnosis}

The main plica is long, and connected to the apertural fold (absent in Chersaecia nagaensis muspratti).

Fig. 22 (next page). A-F. Shells of species of Chersaecia Gude, 1899. A. C. nagaensis (Godwin-Austen, 1875), syntype (NHMUK 1903.7.1.753). B. C. nagaensis muspratti (Gude, 1897), syntype (NHMUK 1912.4.16.320). C. C. perarcta perarcta (Blanford, 1865), probable syntype (NHMUK 1903.7.1.753). D. C. perarcta perarcta (NHM 97458). E-F. Shell and protoconch of C. perarcta simplex (Solem, 1966), paratype (ZMUC-GAS-487). G-H. Genitalia of C. perarcta simplex (Solem, 1966) (ZMUCGAS-487). G. Male part of the genitalia. H. Opened penis (arrow shows thickened part of penial folds). Scale bars: A-E (upper scale) $=10 \mathrm{~mm} ; \mathrm{F}-\mathrm{H}=1 \mathrm{~mm}$. Photos: H. Taylor $(A-C), T$. Deli (D) and B. PállGergely (E-F). 

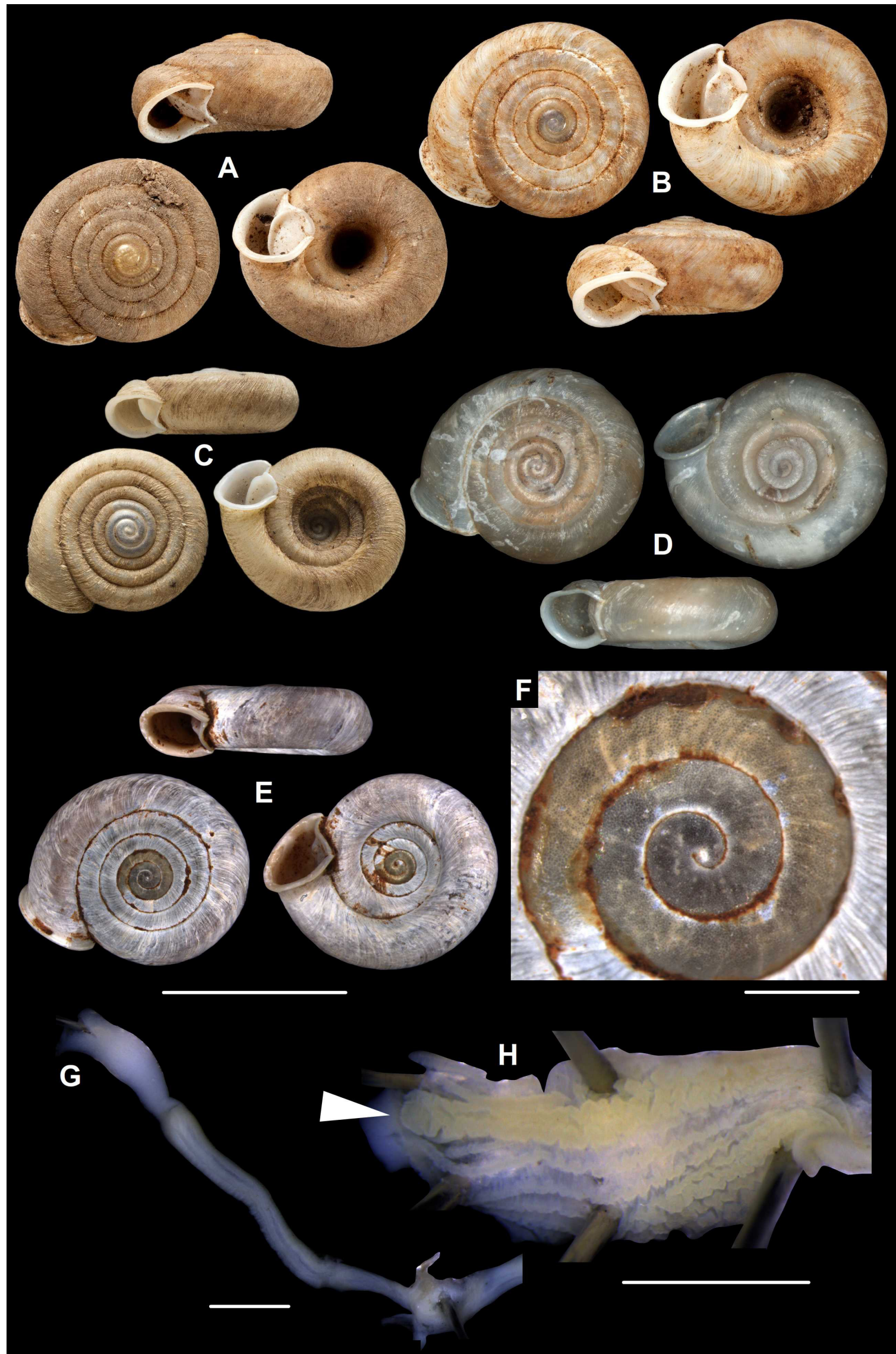
PÁLL-GERGELY B., Systematic revision of the Plectopylinae

\section{Distribution}

All known localities are within the Naga Hills and Manipur, northeastern India.

\section{Remarks}

The 'dwarfed variety' of Plectopylis nagaensis, which was mentioned in the original description of the species, is described here under the name Chersaecia shiroiensis subnagaensis subsp. nov.

Chersaecia nagaensis muspratti (Gude, 1897) comb. nov.

Figs $21 \mathrm{~J}-\mathrm{K}, 22 \mathrm{~B}$

Plectopylis muspratti Gude, 1897f: 10, fig. 45a-f ["Naga Hills, Assam"].

Plectopylis muspratti - Gude 1898h: 7-8, fig. 5a-f.

Plectopylis (Chersaecia) muspratti - Gude 1899d: 148; 1899e: 175; 1914b: 89-90, fig. 37a-f.

Chersaecia muspratti - Páll-Gergely et al. 2015c: 10.

\section{Diagnosis}

A subspecies of Chersaecia nagaensis lacking the main plica.

\section{Material examined}

\section{Syntypes}

INDIA: 2 shells, (diameter of photographed shell $=11.7 \mathrm{~mm}$ ), Naga Hills, coll. Beddome (NHMUK 1912.4.16.320).

\section{Description}

The description of the external shell is based on two syntypes deposited in the NHM. No additional material was found in that collection. Gude (1897f) described and figured the inner plicae based on the shells in Colonel Beddome's collection. Therefore, the original description of the plicae is copied from Gude (1897f).

SHELL. Sinistral, with elevated spire, dorsal side conical; one of the shells corroded, but the other has a yellowish grey basic colour with reddish stripes, which results in a mosaic-like colouration on dorsal side; protoconch matt, almost smooth or with irregular growth lines; teleoconch with fine reticular structure; whorls 6-6.5 $(n=2)$, separated by rather deep suture; whorls rounded, not angled; peristome reflected and slightly thickened, parietal callus normally developed, S-shaped; apertural fold shorter than parietal callus, connected to it.

"Parietal wall with a short entering flexuous fold united to the ridge at the aperture, becoming attenuated inwardly, and at one-third of the circumference from the aperture, with a strong, crescent-shaped vertical plate, which is suddenly deflected posteriorly at the lower extremity; below this, on the anterior side, occurs a very short, horizontal fold. Palatal folds six, horizontal, short the first free, with a small denticle posteriorly; the second, third, fourth, and fifth connected with each other by a vertical ridge, which deflects below the fifth fold posteriorly and terminates in a small, oblique denticle; the sixth again free" (Gude 1897f).

Measurements (in mm). $\mathrm{D}=11.7-12.9, \mathrm{H}=6.6-6.75$ (syntypes, $\mathrm{n}=2$ ). 


\section{Differential diagnosis}

Chersaecia nagaensis muspratti differs from the nominotypical subspecies by the absence of the main plica.

\section{Distribution}

The subspecies is known only from the type locality.

\section{Remarks}

The only notable difference between Plectopylis nagaensis muspratti and P. nagaensis nagaensis is the presence (nagaensis) or the absence (muspratti) of the main plica. Since there is no difference in the general shell or aperture shape, I assign P. muspratti as a subspecies of $P$. nagaensis.

Chersaecia perarcta (Blanford, 1865)

\section{Diagnosis}

A small, flat species with a single lamella. Parietal plicae more or less straight, horizontal or oblique, sometimes with additional denticles.

\section{Differential diagnosis}

The most similar species is $C$. perrierae, which has a longer intermediate plica, has a tendency of forming an anterior lamella, and its fourth and fifth palatal plicae form a vertical plate. See also under C. leiophis.

\section{Chersaecia perarcta perarcta (Blanford, 1865)}

Figs $21 \mathrm{~N}-\mathrm{S}, 22 \mathrm{C}-\mathrm{D}$

Helix (Plectopylis) perarcta Blanford, 1865: 75, 94 [“Mya Leit Doung, near Ava”].

Helix perarcta - Pfeiffer 1868: 397-398; 1869: 502, pl. 108, figs 13-15.

Helix (Plectopylis) perarcta - Hanley \& Theobald 1870: 7, pl. 13, fig. 3. - Godwin-Austen 1875b: 613, pl. 74, fig. 4. — Nevill 1878: 71. — Tryon 1887: 162, pl. 35, figs 91-95. — Godwin-Austen 1888: 243 ["Hlindet, 1200 feet"].

Plectopylis perarcta - Gude 1896a: 155, fig. 19a-c; 1908: 88.

Plectopylis (Chersaecia) perarcta - Gude 1899d: 148; 1899e: 175; 1914b: 106-108, fig. 50a-c.

Chersaecia perarcta - Páll-Gergely et al. 2015c: 10.

\section{Diagnosis}

Main plica present.

\section{Material examined}

Types

MYANMAR: 6 shells (probably syntypes), Burma, Myaleit doung, Ava, (NHMUK 1906.2.2.275); 3 shells (probably syntypes), Myaleit doung, near Ava (NHMUK 1888.12.4.1521-1523).

\section{Additional material}

MYANMAR: 3 shells, Burma, coll. Godwin-Austen ex Blanford (NHMUK 1909.3.15.61); 1 shell, Burma, Ava, coll. A. S. Kennard (NHMUK); 3 shells, Burma, Ava (NHMUK). 
THAILAND: 1 shell, Chiang Rae Province, limestone knoll, 4 km NE of Ban Pa Ngae, 19 $34^{\prime} 19^{\prime \prime}$ N, 9959'14" E, 410 a.s.l. m, 12 May 1988, F.G. Thompson leg. (UF 380334); 20 shells, 3 juv. shells, same data as for preceding (UF 448575); 2 shells, same data as for preceding (HNHM 97459); 8 shells, 6 juv. shells, same data as for preceding but 13 May 1988 (UF 380344); 1 shell, Wat Phra That Tham Doi Kong Kao, ca $5.5 \mathrm{~km}$ W of Chiang Rai, in clay in Temple Cave, 1954'46.34" N, 99 ${ }^{\circ} 46^{\prime} 33.64^{\prime \prime}$ E, Sep. 2007, A. Reischütz leg. (HNHM 97458); 2 shells, 2 damaged shells, same data as for preceding (coll. PGB); 2 shells, same data as for preceding (NHMW 108116); 24 shells, 10 damaged shells, same data as for preceding (coll. REI).

\section{Description of the type series}

SHELL. Sinistral, tightly coiled, flat, only protoconch protrudes above dorsal surface; colour greyish yellow to light brown; protoconch large, consists of 2.5-2.75 whorls, with large tubercles, no radial lines visible; teleoconch with very fine ribs, covered by fine periostracal folds; spiral lines absent; periostracum more prominent inside sutures; whorls 5.75-6, separated by very deep suture; umbilicus regularly shaped infundibular, only last whorl widening abruptly; body whorl rounded; peristome reflected and slightly thickened; parietal callus elevated, sharp, V-shaped.

Two shells were opened. Parietal wall with a single, strongly developed lamella, which has the lower end elongated slightly posteriorly; upper end very slightly elongated in both anterior and posterior directions; main plica long, free from lamella, reaches parietal callus; one of the shells had the main plica and the apertural fold separated (probably subadult shell); inner end of main plica situated lower (closer to the lower suture); lower plica slender, runs along and parallel with lower suture and also reaches parietal callus; there is a very short additional plica between the main and lower plica; all plica start in one vertical line anterior to lamella. Palatal plicae six; first and sixth straight, run parallel with sutures; middle plicae more or less horizontal, straight or slightly wavy; sometimes with additional posterior denticle.

Measurements (in mm). $\mathrm{D}=10.9-12.8, \mathrm{H}=4-4.5$ (UF 38344, $\mathrm{n}=5$ ); $\mathrm{D}=11.2-13, \mathrm{H}=3.7-4.5$ (loc. “5.5 km west of Chiang Rai", coll. REI); $\mathrm{D}=10.6-11.7, \mathrm{H}=3.6-4.1$ (type series, NHMUK 275.06.2.2, $\mathrm{n}=3)$.

\section{Differential diagnosis}

See under Chersaecia perarcta simplex.

\section{Distribution}

Chersaecia perarcta perarcta has been reported from the vicinity of Ava, Mandalay Region, Myanmar, and from northern Thailand (see also Fig. 17).

\section{Remarks}

Typical shells have a well-developed apertural fold, which is in contact with the parietal callus. The apertural fold of the shells collected $4 \mathrm{~km} \mathrm{NE}$ of Ban Pa Ngae is free from the parietal callus. Most of the shells (23 out of 27) from $5.5 \mathrm{~km} \mathrm{~W}$ of Chiang Rai lacked the apertural fold, and all four opened shells lacked a lower plica.

Chersaecia perarcta simplex (Solem, 1966) comb. nov.

Figs 21L-M, 22E-H

Plectopylis (Chersaecia) simplex Solem, 1966: 97-101, figs 23c-g, 24, pl. 3, figs a-c ["Chieng Dao, North Thailand at 1,200-1,300 meters elevation"]. 
Chersaecia simplex - Páll-Gergely et al. 2015c: 10.

\section{Diagnosis}

Main plica absent.

\section{Material examined}

Paratypes

THAILAND: 2 broken specimens (preserved in ethanol: PL122 used for molecular study, the other, nearly intact shell: $\mathrm{D}=12.6 \mathrm{~mm}$ ), S.E. Asien, N. Thailand, Chieng Dao, O.H., 1200-1700 m a.s.l., 1 Jul. 1960, Degerbøl leg. (nr. 979) (ZMUC-GAS-487).

\section{Description}

Measurements (in mm). $\mathrm{D}=12.6, \mathrm{H}=4.1$ ( $\mathrm{n}=1$, ZMUC-GAS-487).

ChARACters of THE GeNITAL SYSTEM. I examined the ethanol-preserved Chersaecia perarcta simplex genitalia, which were dissected out by Solem. I found an opened penis of one specimen (Fig. 22H), and the complete genitalia separated into two parts of another one (Fig. 22G). One part of the second specimen included the penis, its retractor muscle, the vagina, the distal part of the spermoviduct, and the stalk of the bursa copulatrix (the bursa itself was missing), whereas the other part contained the proximal genitalia (remaining part of spermoviduct, albumen gland, etc.). I can confirm that the diverticulum is absent, just as Solem (1966) reported. There were also some eggs in the vial, probably from the same specimen which had the complete genitalia preserved. The structure described by Solem (1966) as a "small vergic papilla" is a thickening of the folds of the penial wall, and not homologous with the penial papilla of Helicoidea, etc., which is an extended part of the epiphallus to the penis lumen.

\section{Differential diagnosis}

The shell shapes of Chersaecia perarcta and Plectopylis simplex do not differ. The nominotypical subspecies possesses the main plica, which is lacking in C. perarcta simplex.

\section{Distribution}

Chersaecia perarcta simplex is known from the type locality only (Fig. 9).

\section{Remarks}

Because of the indistinguishable outer-shell characters, Plectopylis (Chersaecia) simplex is assigned as a subspecies of $C$. perarcta. The difference between the two forms is only the presence/absence of the parietal plicae.

Chersaecia perrierae (Gude, 1898)

Figs 5C-D, 16C-D, 23A-B, 24A-B, 25

Plectopylis perrierae Gude, 1898a: 231-232, fig. 67a-f ["Thayet-Mayo, Pegu, Burma"].

Plectopylis perrierae - Gude 1898h: 14-16, fig. 10a-f.

Plectopylis (Chersaecia) perrierae - Gude 1899d: 148; 1899e: 175; 1914b: 103-105, fig. 48a-f.

Chersaecia perrierae - Páll-Gergely et al. 2015c: 10.

\section{Diagnosis}

A small, sinistral, flat species with a single lamella and rarely a second, vestigial, anterior lamella, long main, lower, and intermediate plicae on the parietal wall, and Plectopylis-like plication on the palatal wall. 


\section{PÁLL-GERGELY B., Systematic revision of the Plectopylinae}

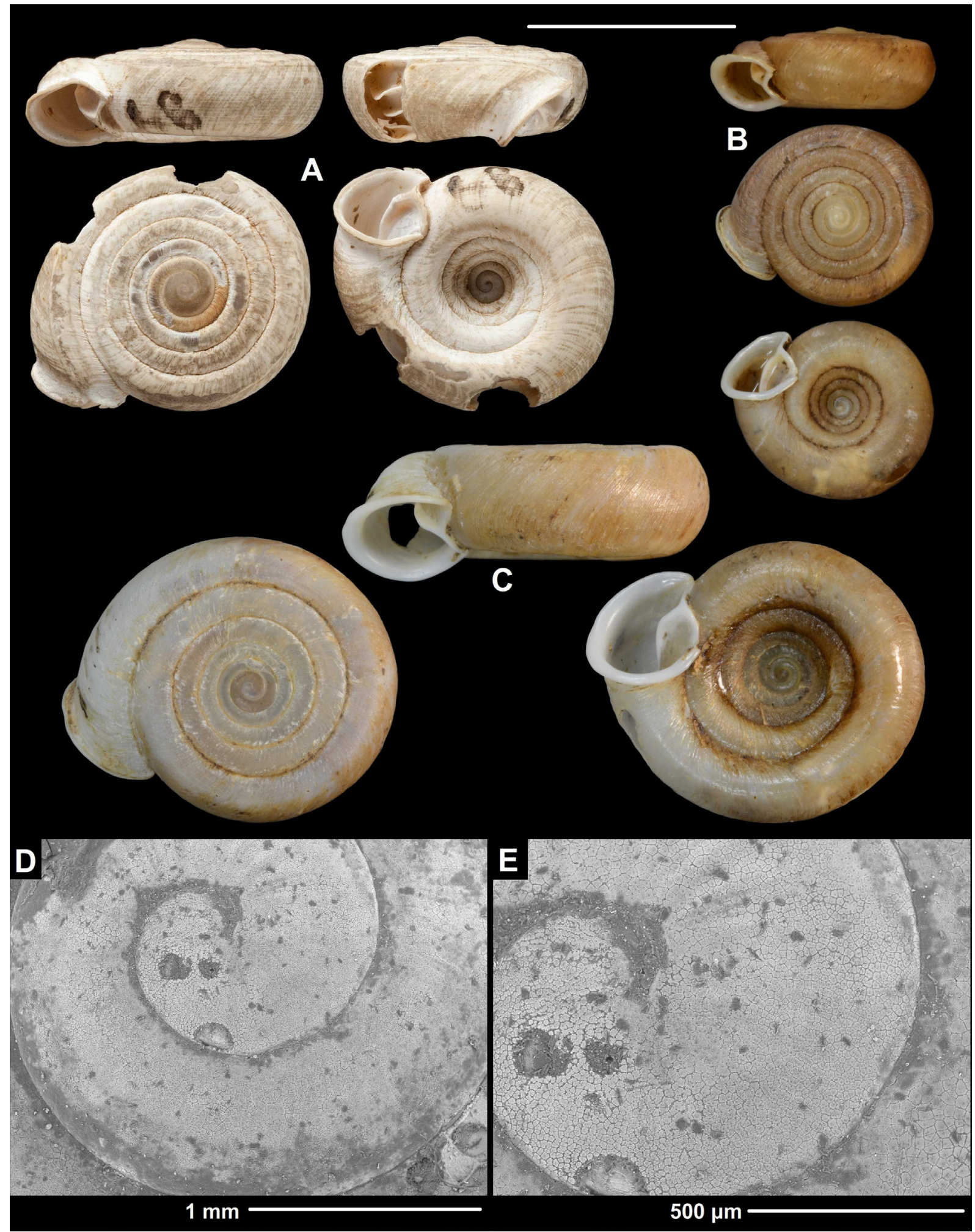

Fig. 23. Shells and protoconch of species of Chersaecia Gude, 1899. A. C. perrierae (Gude, 1898), holotype (NHMUK 1922.8.29.40). B. C. perrierae, loc. 20091019A, Specimen 2 (coll. PGB). C-E. C. refuga (Gould, 1846), lectotype (MCZ 169335). Scale bar: A-C $=10 \mathrm{~mm}$. Images: B. Páll-Gergely (B-E) and H. Taylor (A). 


\section{Material examined}

\section{Holotype}

MYANMAR: 1 shell ( $\mathrm{D}=14.8 \mathrm{~mm}$ ), Pegu [Bago], ex coll. Linter (NHMUK 1922.8.29.40).

\section{Additional material}

MYANMAR: 2 shells, Burmah, Kyengdwen Valley, Ogle leg., coll. Godwin-Austen (NHMUK 1903.7.1.776); 4 shells, Fort Stedman, coll. Godwin-Austen (NHMUK); 74 shells, Shan, Pindaya, Pindaya Cave, loc. 20091019A, 2055.409’ N, 96³9.038' E, 1294 m a.s.1., 19 Oct. 2009, K. Ohara, K. Okubo and J.U. Otani leg. (coll. OK); 5 shells, same data as for preceding (coll. PGB, ex coll. K. Ohara); 1 shell, same data as for preceding (coll. PGB, ex coll. J.U. Otani); 1 shell + ethanol-preserved body (anatomically examined), same data as for preceding (NHMUK 20170148).

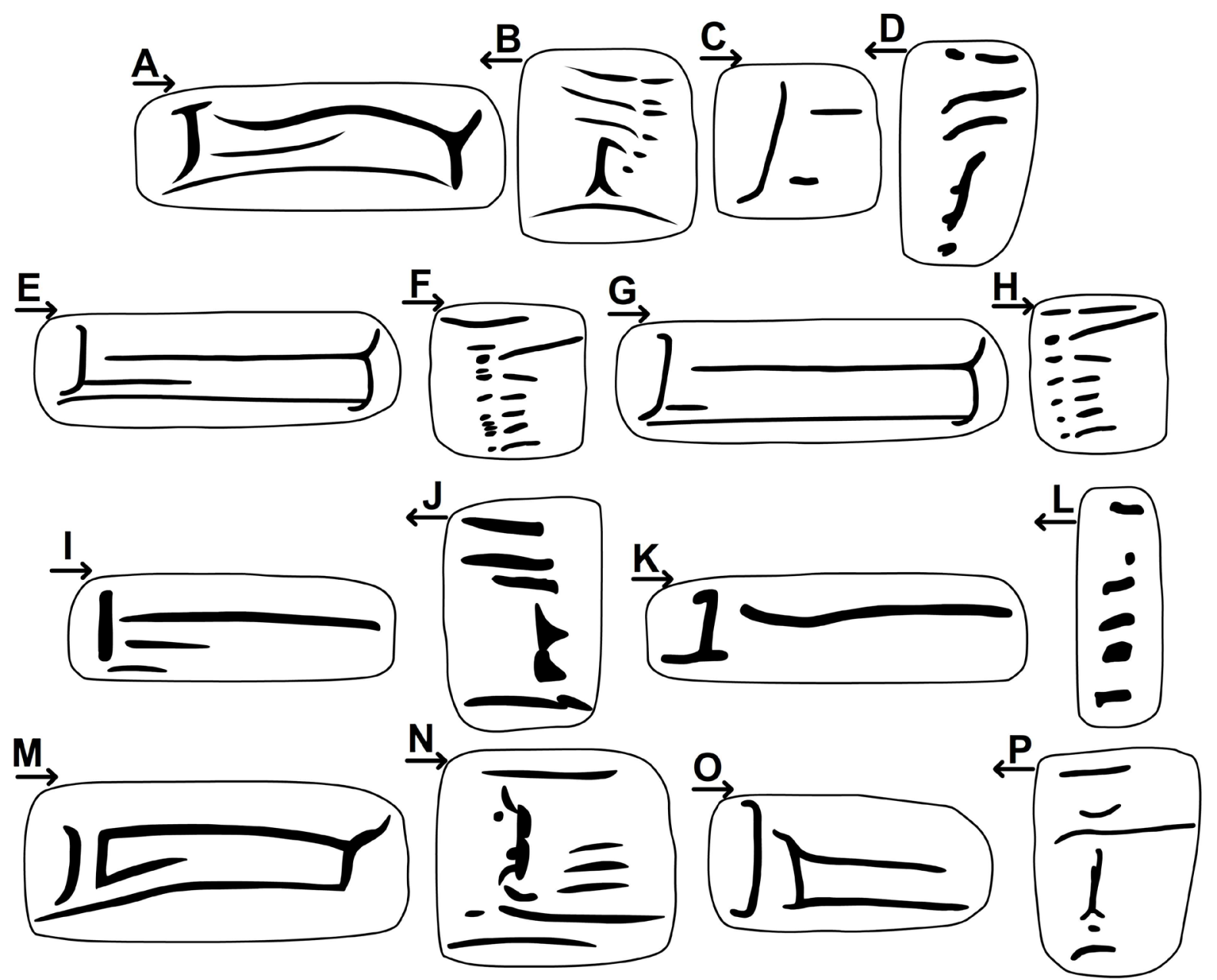

Fig. 24. Parietal (A, C, E, G, I, K, M, O) and palatal (B, D, F, H, J, L, N, P) plication of species of Chersaecia Gude, 1899. A-B. C. perrierae (Gude, 1898) (after Gude 1914b). C-D. C. refuga (Gould, 1846) (NHMUK 20170162). E-F. C. shanensis (Stoliczka, 1873), loc. 20091018B (coll. PGB). G-H. C. shanensis, loc. 20091018C (coll. PGB). I-J. C. shiroiensis shiroiensis (Godwin-Austen, 1875) (after Gude 1896a). K-L. C. shiroiensis subnagaensis subsp. nov., holotype (NHMUK 1903.7.1.753.1). M-N. C. woodthorpei (Gude, 1899) comb. nov. (after Gude 1914b). O-P. C. scabra sp. nov. (UF 380244). Arrows below the letters indicate the direction of the aperture. Not to scale. 


\section{Description}

The holotype (NHMUK 1922.8.29.40) and two additional shells from the Kyengdwen Valley (NHMUK 1903.7.1.776) are from different samples, yet they differ only in size; therefore, the shell description is based on these three specimens. The differences between those three shells and the specimens collected from locality 20091019A are mentioned in the Remarks.

SHELL. Sinistral, almost entirely flat, only protoconch protrudes above dorsal surface; all three specimens were corroded, therefore original colour could not be observed; protoconch consists of 2.75-3 whorls, finely tuberculated, last whorl irregularly, roughly wrinkled; teleoconch finely reticulated on dorsal side, elsewhere ribs dominant (holotype reticulated on entire surface); whorls 6-6.5 $(n=3)$, separated by a rather shallow (holotype) or moderately deep (other two shells) suture; body whorl rounded but angulated above (dorsal side flat); peristome slightly thickened and very slightly reflected; parietal callus elevated, sharp, V-shaped, upper (from standard apertural view) branch of V being shorter.

Two opened shells were examined (= holotype and one shell from the other sample). Parietal wall with a single, strong, curved lamella with posteriorly elongated lower end; main plica long, free from lamella, curved downwards (its posterior end situated above middle point of lamella, then runs a bit lower anteriorly, reaching middle line of lamella, and runs upwards again); lower plica very slender, starts under lamella and reaches peristome, but interrupted in its middle. Palatal plicae six; first, second and third straight and horizontal or slightly oblique; fourth and fifth form a vertical plate with a bifurcated lower end; sixth very long and divided, its anterior part much longer than the posterior.

Measurements (in mm). $\mathrm{D}=14.8, \mathrm{H}=5.9$ (holotype); $\mathrm{D}=12.6-12.9, \mathrm{H}=4.5-4.7$ (NHMUK 1903.7.1.776, $\mathrm{n}=2) ; \mathrm{D}=11.1-11.95, \mathrm{H}=3.8-5.2$ (20091019A, $\mathrm{n}=3$ ).

Characters OF THE GENITAL STRUCTURE. One specimen was anatomically examined (NHMUK 20170148). Left ommatophoral retractor passes between penis and vagina; atrium very short; penis long, slender, cylindrical; internally with longitudinal folds; epiphallic differentiation not observed; vas deferens originates from penial wall approximately at middle of penis; retractor muscle inserts on proximal end of penis, as thick as penis and slightly shorter; vas deferens derives from penial section; between middle penial section and reflected part of vagina vas deferens slender, and runs together with vagina, attached to it with weak fibres; from reflected part of vagina vas deferens gradually thickens, even exceeds diameter of penis, and becomes free from vagina (i.e., not attached to it by fibres); vagina cylindrical, slightly flattened close to atrium, internally with longitudinal folds; slightly longer than penis, and about 2-3 times thicker; several slender muscle fibres attach vagina to body wall; pedunculus short, spermoviduct strongly developed, uterus with four large embryos; bursa copulatrix approx. 2 times longer than diverticulum; diverticulum relatively thick, internally with parallel longitudinal folds; bursa slightly thickened (reaching diameter of diverticulum); both organs originate near the point where vas deferens joins pedunculus.

RADULA. Centrals with very small, triangular cusps; endocones of laterals rhomboid or slender ovoid with pointed tips; ectocones of first laterals much larger than centrals; ectocones of marginals undivided, endocones of marginals divided by shallow incision.

\section{Differential diagnosis}

Chersaecia perrierae differs from C. leiophis by the brownish shell, long lower plica which reaches the peristome (this is very short in leiophis) and the main plica, which is straight in C. leiophis, but curved downwards in C. perrierae. 
The angled body whorl resembles that of the nearby occurring Chersaecia woodthorpei. However, that species has two distinct lamellae and three short, parallel, straight palatal plicae next to the vertical plate which is formed by the fourth and fifth plicae.

\section{Distribution}

This species is known from a few localities in Myanmar. The most recent sample was collected from the eastern part of the Shan Region.

\section{Remarks}

The newly collected sample from Myanmar (20091019A) provides additional information to the old museum specimens in terms of shell colour and sculpture. The shell colour is reddish brown, and the protoconch is finely tuberculated. The shells belonging to this sample are overall smaller and flatter than the others described above and have more angulated body whorls. The main plica strongly curves down in the direction of the intermediate plica. The area between the two plicae may be covered with a white calcareous layer, which is probably homologous with the anterior lamella of other species of Chersaecia and Plectopylis (Fig. 5).
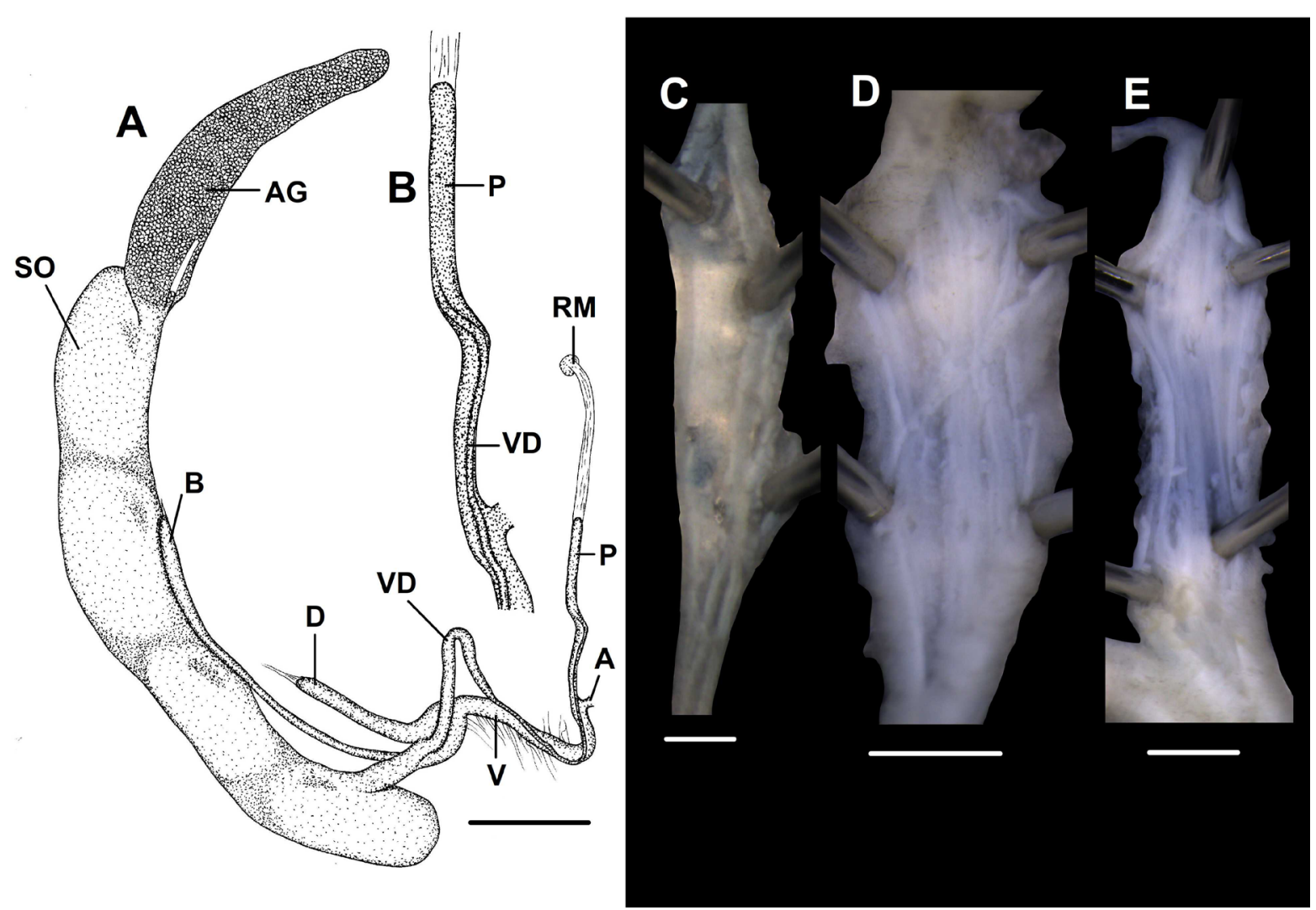

Fig. 25. Genitalia of Chersaecia perrierae (Gude, 1898) (NHMUK 20170148). A. Whole genitalia. B. Male genitalia (penis and vas deferens). $\mathbf{C}-\mathbf{E}$. Inner structure of genital organs $(\mathrm{C}=$ penis, $\mathrm{D}=$ vagina, $\mathrm{E}=$ diverticulum). Scale bars: $\mathrm{A}=2 \mathrm{~mm} ; \mathrm{C}-\mathrm{E}=0.5 \mathrm{~mm}$; B not to scale. For abbreviations see Fig. 2 . All photos: B. Páll-Gergely. 
Helix refuga Gould, 1846: 99 [“Tavoy"].

Helix refuga - Philippi 1847: 52 (=2), pl. 10, fig. 4 [“imperium Birmanorum Indiae orientalis"]. Pfeiffer 1848a: 383-384, pl. 66, figs 21-23. — Reeve 1854: species 436, pl. 82, fig. 436a-b. Theobald 1857: 249. — Pfeiffer 1868: 396.

Helix (Atopa) refuga-Albers 1850: 90.

Helix (Corilla) refugum - Adams H. \& Adams A .1855: 208.

Helix (Corilla) refuga - Gould 1862: 198.

Helix (Plectopylis) refuga - Nevill 1878: 71. — Tryon 1887: 164, pl. 35, fig. 1.

Plectopylis refuga - Gude 1898c: 15-16, fig. 75a-e.

Plectopylis (Chersaecia) refuga - Gude 1899d: 148; 1899d: 148; 1899e: 175; 1914b: 102-103, fig. $47 \mathrm{a}-\mathrm{e}$.

Plectopylis (Plectopylis) refuga - Johnson 1964: 139, pl. 38, fig. 9.

Chersaecia refuga - Páll-Gergely et al. 2015c: 10.

\section{Diagnosis}

Shell medium-sized, widely umbilicated, flat, periumbilical region glossy; parietal wall with a single lamella, short middle and main plicae; palatal wall with 6 parallel plicae.

\section{Material examined}

\section{Types}

MYANMAR: 1 shell, lectotype ( $\mathrm{D}=17.8 \mathrm{~mm}$ ), Tavoy, British Burma (MCZ 169335); 1 shell, paralectotype of refuga (photos examined), Tavoy, Burma, coll. Gould (MCZ 87871).

\section{Additional material}

MYANMAR: 1 shell (mixed sample with C. leiophis: NHMUK 20150360), Burma, ex Museum Cuming (NHMUK 20170160); 1 shell (mixed sample with C. leiophis: NHMUK 20170161), India, Thyet Myo (NHMUK 20170162).

\section{Description}

SHELL. Sinistral, entirely flat; colour off-white to pale yellowish-grey, surface overall glossy; protoconch consists of 2.5-2.75 whorls, rather glossy with very fine granular surface and irregular wrinkles; ventral part of body whorl (periumbilical region) smooth, glossy; dorsal surface and area inside umbilicus dominated by spiral striation, or spiral and radial lines of the same strength; periphery of body whorl dominated by radial lines; whorls 6-6.25, separated by comparatively shallow suture; whorls angled; aperture rounded; peristome expanded and slightly reflected; parietal callus elevated, rather sharp and V-shaped; apertural fold connected to parietal callus.

Two opened shells were examined. Parietal wall with a single curved lamella; middle and intermediate plicae short, free from lamella; lower plica absent. Palatal wall with six plicae, first short, with an additional denticle at its posterior end; second longer (but shorter than in other species of the genus), posterior end curved downwards; third short, also curved; fourth and fifth form a vertical plate, with small connecting denticles posteriorly; sixth very short.

Measurements (in mm). $\mathrm{D}=15.9-17.8, \mathrm{H}=6.6-7.4(\mathrm{n}=3$, lectotype + specimens from the NHM). 


\section{Differential diagnosis}

Chersaecia refuga has been confused with $C$. leiophis. The two species are similar, but can be easily distinguished based on the following differences: (1) refuga is entirely flat and its whorls are more strongly shouldered (both above and below) than those of C. leiophis; (2) the umbilicus of C. refuga is wider and more regularly funnel-shaped; (3) the periumbilical region, which is sharper than that of C. leiophis, is glossy (reticulated in C. leiophis); (4) the plicae anterior to the lamella are shorter than in C. leiophis; (5) the palatal plicae are shorter; (6) the protoconch and the entire shell is glossier than that of C. leiophis.

\section{Distribution}

All known shells have been collected in southern Myanmar.

\section{Remarks}

Chersaecia refuga has been confused with C. leiophis by previous authors. Godwin-Austen (1875a) claimed that the two species are identical, based on the examination of Cuming's shells, which were labelled as Plectopylis refuga. According to Gude (1914b), the same shells, which were examined by Godwin-Austen and figured by Philippi (1847), Pfeiffer (1848a) and Reeve (1854) (now NHMUK 20150360), are in fact C. leiophis. However, since Gude could not examine the type specimens of P. refuga, he was unable to recognise that the sample of Cuming contained both species. It is difficult to tell which species was figured in the mentioned literature, but the light coloured periumbilical region and the wide umbilicus characteristic for $C$. refuga suggests that they were showing $C$. refuga instead of C. leiophis.

Gude (1898c) was unable to borrow the type specimen of Plectopylis refuga, and received only drawings and photos from the curator of the New York State Museum. Dr. Merrill's drawings show one or two shells, which were opened to show the parietal plicae and lamellae. I borrowed the lectotype of $P$. refuga (MCZ 169335) and examined photos of two samples of paralectotypes (MCZ 87871, 142866). The sample MCZ 87871 contained a single shell which is very similar to the lectotype of $P$. refuga. The other sample (MCZ 142866) contained five shells, which probably belong to a different species (possibly Chersaecia feddeni) because they have rounded body whorls, which are shouldered in C. refuga. Both the lectotype (MCZ 169335) and the similar paralectotype (MCZ 87871) have a small hole on the shell ca halfway between the armature and the aperture. This hole, however, does not allow for careful examination of the parietal lamella and the adjacent plicae. Thus, it is unclear which shells were examined and figured by Dr. Merrill. Two opened shells of C. refuga were found in the NHM, which allowed the examination of the parietal plication.

Chersaecia scabra sp. nov. urn:1sid:zoobank.org:act:B6A4AF8F-9A14-4CA1-AE9D-BDF4F8A8F77A

Figs 16E-F, 24O-P, 26A-C, 27

\section{Diagnosis}

A small, sinistral, nearly-flat species with a weak apertural fold; parietal wall with two lamellae, and two equal horizontal plicae (main and intermediate) attached to anterior lamella.

\section{Etymology}

The specific epithet refers to the fact that even the live collected specimens had an eroded shell surface (scaber/scabra: erroded in Latin). 


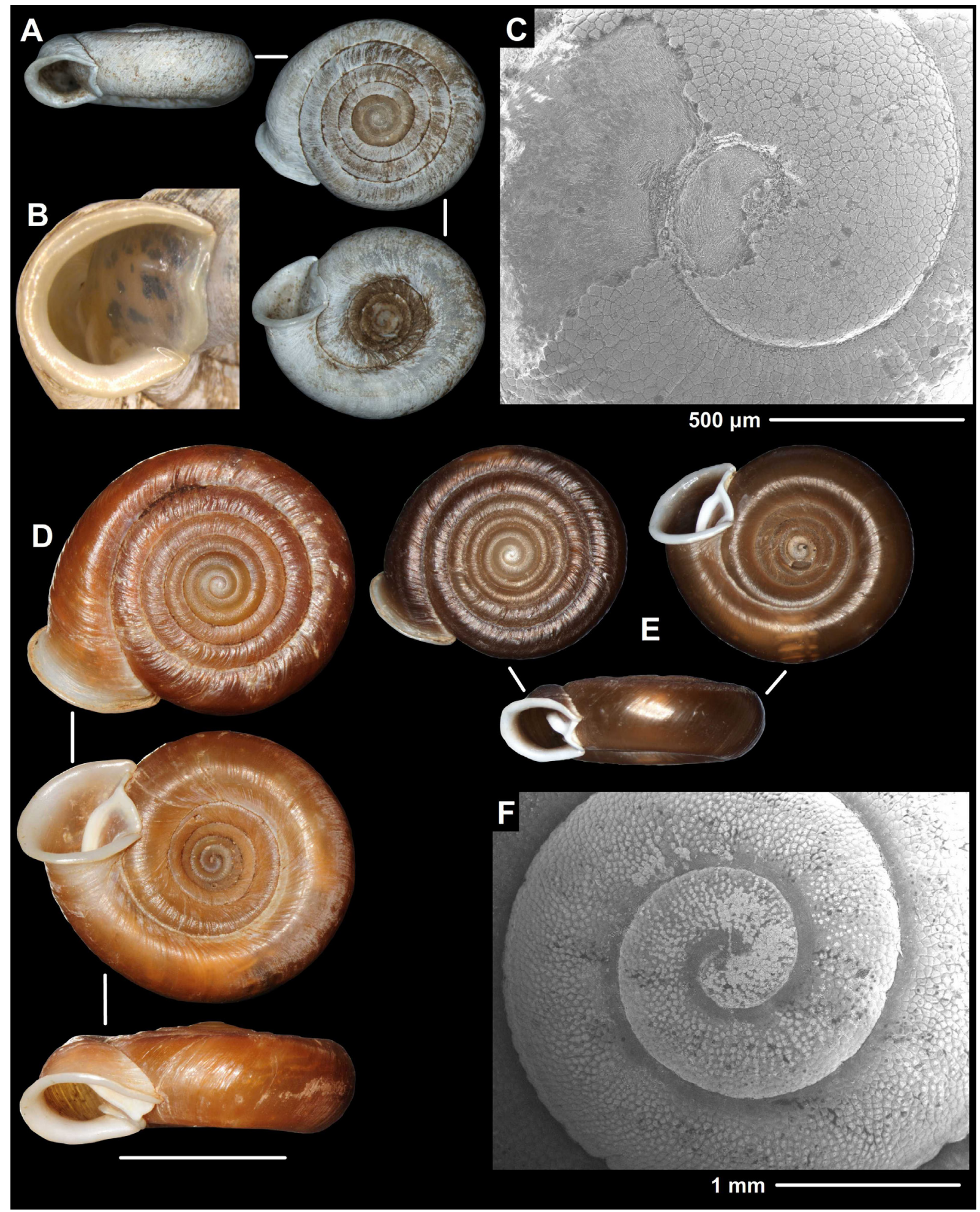

Fig. 26. Shells of species of Chersaecia Gude, 1899. A. C. scabra sp. nov., holotype (UF 380244). B. Aperture of C. scabra sp. nov., paratype (NHMUK 20170149). C. Protoconch of C. scabra sp. nov (UF 380244). D. C. shanensis (Stoliczka, 1873) (NHMUK 20170293). E. C. shanensis (NHMUK 20170292). F. Protoconch of C. shanensis, loc. 20091018B (coll. PGB). Scale bar (bottom left): A, D-E $=10 \mathrm{~mm}$; B not to scale. Images: T. Deli (A, D-E), B. Páll-Gergely (B-C, F). 


\section{Material examined}

\section{Holotype}

THAILAND: 1 shell $(\mathrm{D}=14 \mathrm{~mm})$, Chiang Rae Province, $12 \mathrm{~km} \mathrm{~S}, 5 \mathrm{~km} \mathrm{~W}$ of Mae Sai, ravine in limestone mountains, $20^{\circ} 21^{\prime} 13^{\prime \prime} \mathrm{N}, 9^{\circ} 50^{\prime} 46^{\prime \prime}$ E, $550 \mathrm{~m}$ a.s.1., 9 May 1988, F.G. Thompson leg. (UF 380244).

\section{Paratypes}

THAILAND: 3 shells, same data as for holotype (UF 448576); 1 shell, same data as for holotype (HNHM 97460); 1 shell, Chiang Rae Province, Tham Tumluang (cave), 7 km S, 2 km W of Mae Sai, 20²2'10" N, 9951'28" E, 470 m a.s.1., 8 May 1988, F.G. Thompson leg. (UF 347154); 2 shells, Chiang Rae Province, Doi Thung Mountain, 20²0'32" N, 99 50'21" E, 1320 m a.s.1., 8 May 1988, F.G. Thompson leg. (UF 347122); 50 specimens (preserved in ethanol: PL053-PL054 used for molecular study), Chiang Rai Province, Doi Tung, $50 \mathrm{~m}$ from Wat Phra That Doi Tung, $20^{\circ} 19.540^{\prime} \mathrm{N}, 99^{\circ} 49.987^{\prime}$ E, $1350 \mathrm{~m}$ a.s.1., 30 Mar. 2016, A. Hunyadi leg. (coll. HA); 1 paratype (anatomically examined: PL052 used for molecular study), same data as for preceding (NHMUK 20170149); 1 shell, Chiang Rai Province, Wat Phra That Doi Tung, 22 Oct. 2016, K. Okubo leg (coll. PGB); 3 shells, same data as for preceding (coll. OKA).

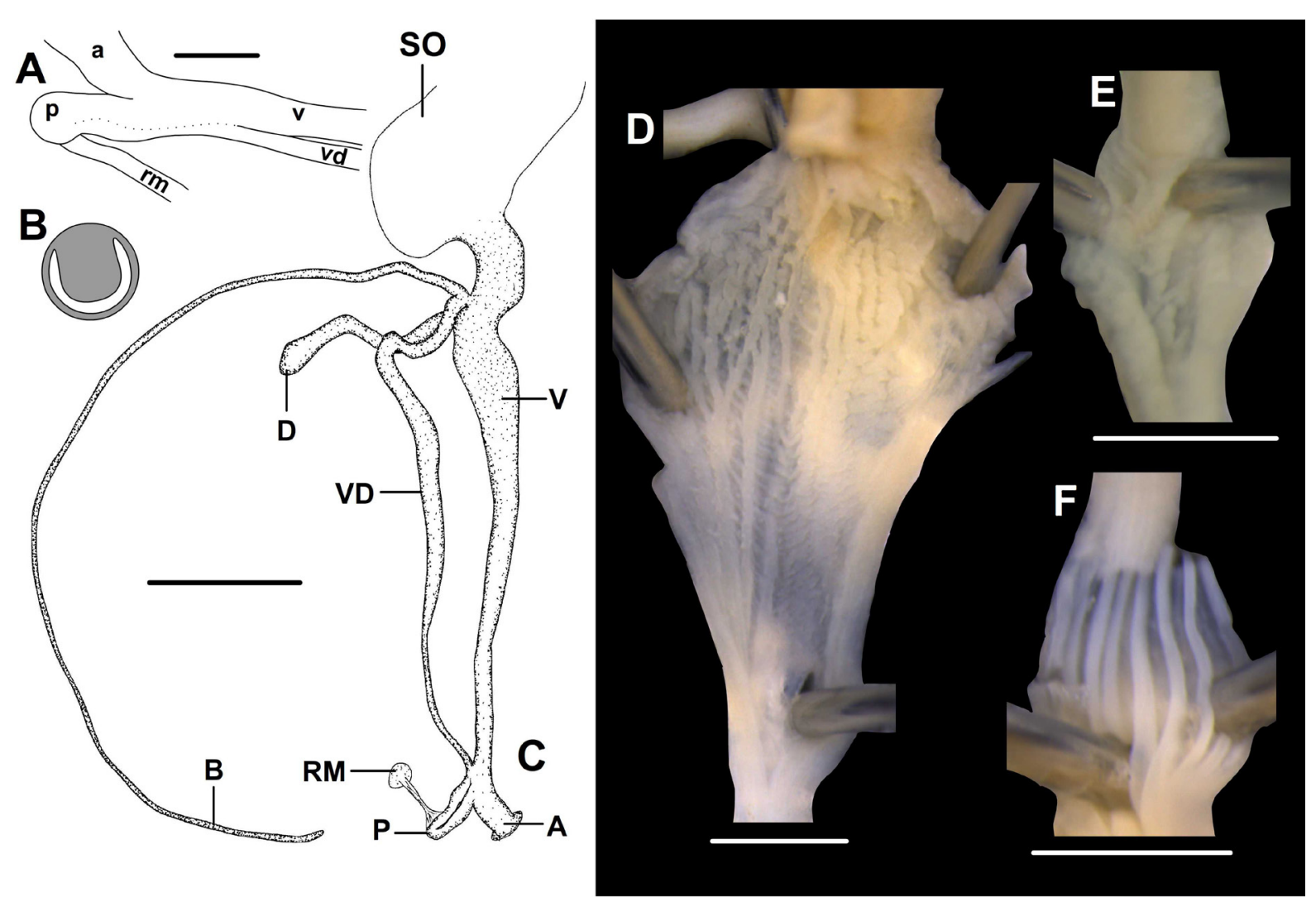

Fig. 27. Genitalia of Chersaecia scabra sp. nov. (NHMUK 20170149). A. Male genitalia. B. Cross sectional diagram of the penis. C. Distal genitalia. D-F. Inner structure of genital organs ( $\mathrm{D}=$ vagina, $\mathrm{E}=$ vas deferens, $\mathrm{F}=$ diverticulum). Scale bars: $\mathrm{A}, \mathrm{D}-\mathrm{F}=0.5 \mathrm{~mm} ; \mathrm{C}=2 \mathrm{~mm}$; $\mathrm{B}$ not to scale. For abbreviations see Fig. 2. All photos: B. Páll-Gergely. 


\section{Additional material}

THAILAND: 2 juv. specimens (preserved in ethanol), Chiang Rai Province, Doi Tung, $50 \mathrm{~m}$ from Wat Phra That Doi Tung, $20^{\circ} 19.540^{\prime}$ N, 9949.987' E, 1350 m a.s.l., 30 Mar. 2016, A. Hunyadi leg. (coll. HA).

\section{Description}

SHELL. Sinistral, light brown (although all shells, including live collected ones, were weathered), almost flat, only protoconch protrudes above dorsal surface; protoconch consists of 2.5-2.75 whorls, with fine granular structure and inconspicuous wrinkles; teleoconch with dense ribs and spiral sculpture, resulting in a reticulated structure; whorls $6-6.5$, separated by a rather shallow suture; aperture rounded; peristome only slightly thickened and reflected; parietal callus low, apertural fold very weak, free from parietal callus.

Three shells were opened. Parietal wall with two vertical lamellae, posterior one longer and C-shaped, with the arms of the ' $\mathrm{C}$ ' pointing posteriorly; anterior lamella short and connected at both ends to horizontal plicae; main and intermediate plicae of comparable length; ends of plicae visible through oblique view into aperture; main plica and apertural fold situated far from each other. Palatal wall with six plicae; first straight and parallel with upper suture; second short and curved; third longest; fourth and fifth vertical and fused to each other, forming an inverted structure similar to the letter Y; last plica short and curved downwards.

Measurements (in mm). $\mathrm{D}=11.2-13, \mathrm{H}=3.7-4.5(\mathrm{n}=5)$.

Characters of the Genital system. A single specimen was dissected (NHMUK 20170149). Right ommatophoral retractor runs between penis and vagina-vas-deferens; penis reduced, very short, blunt, ovoid, inner wall with a strongly thickened fold; retractor muscle short, inserts on proximal end of penis; vas deferens extremely long, thick proximally, slowly reduces in diameter towards penis, internally with oblique, converging longitudinal folds; vagina slender near atrium, slowly increases in width towards spermoviduct; interior of vagina with reticulated sculpture proximally, distal part of vagina with parallel longitudinal folds; diverticulum slender and relatively short, bursa copulatrix long and slender, both originate near base of spermoviduct; diverticulum internally with elevated, parallel, regular folds.

RADULA. Centrals with small, triangular cusps with pointed tips; endocones of laterals subrhomboid with pointed tip; ectocones of first laterals larger than centrals; ectocones of marginals undivided or divided to two; endocones of marginals triangular, undivided or divided by shallow incision.

\section{Differential diagnosis}

Chersaecia scabra sp. nov. largely resembles C. woodthorpei in the arrangement of the palatal and parietal plicae and lamellae, but the main plica of the latter species reaches the parietal callus, the intermediate plica is shorter, and a very long lower plica reaches the parietal callus. Moreover, C. scabra sp. nov. is larger, has less shouldered whorls and lacks the series of horizontal palatal plicae, which are characteristic in C. woodthorpei.

Chersaecia auffenbergi sp. nov. also has a similar parietal lamellation, but that species is much flatter and has Y-shaped palatal plicae.

\section{Distribution}

The new species is known from four geographically-proximate sites situated within $6 \mathrm{~km}$ of each other in northern Chiang Rae Province, north Thailand (Fig. 17). 
Chersaecia shanensis (Stoliczka, 1873)

Figs 5A-B, 24E-H, 26D-F, 28, 29A-B

Plectopylis shanensis Stoliczka, 1873: 170. ["Provinciam Burmanam 'Shan-states' dictam"].

Helix (Plectopylis) trilamellaris Godwin-Austen, 1875a: 43-44 [“Burmah”, exact locality unknown].

Helix (Plectopylis) shanensis - Hanley \& Theobald 1876: 59, pl. 149, figs 8-9. - Tryon 1887: 162-163,

pl. 36, figs 10-11 (with trilamellaris as a synonym).

Helix (Plectopylis) shawensis [sic] - Nevill 1878: 71.

Helix (Plectopylis) trilamellaris - Nevill 1878: 71 (synonym of shawensis [sic]). — Godwin-Austen

1879a: 2 (synonym of shanensis).

Plectopylis shanensis - Gude 1897g: 36, fig. 48a-c; 1899c: 77, fig. 105.

Plectopylis (Chersaecia) shanensis - Gude 1899d: 148; 1899e: 175; 1914b: 111-112, fig. 53a-d; 1920:

62-63.

Chersaecia shanensis - Páll-Gergely et al. 2015c: 10.
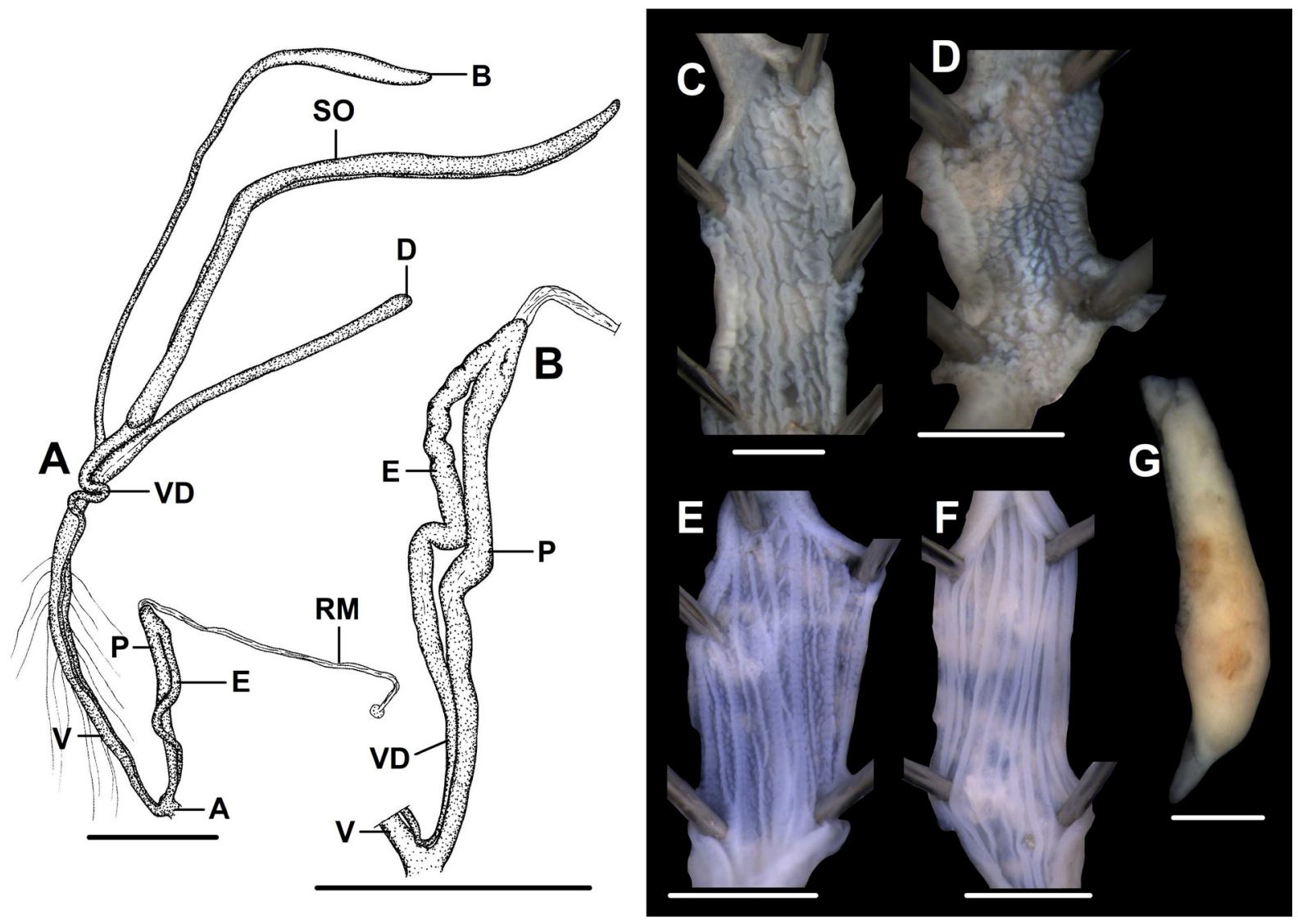

Fig. 28. Genitalia of Chersaecia shanensis (Stoliczka, 1873). A. Whole genitalia. B. Male genitalia (penis, epiphallus, vas deferens). $\mathbf{C}-\mathbf{F}$. Inner structure of genital organs $(\mathrm{C}=$ penis, $\mathrm{D}=$ epiphallus, $\mathrm{E}=$ vagina, $\mathrm{F}=$ diverticulum). G. Spermatophore found in the bursa copulatrix. Scales bars: $\mathrm{A}-\mathrm{B}=$ $2 \mathrm{~mm}$; C-G $=1 \mathrm{~mm}$. A-E show Specimen 1, PL040, loc. 20091018B, (NHMUK 20170150), F-G show Specimen 2, PL033, loc. 20091018C (NHMUK 20170151). For abbreviations see Fig. 2. All photos: B. Páll-Gergely. 


\section{Diagnosis}

A sinistral, medium-sized, brownish-corneous species with long main and lower plicae on the parietal wall; main plica connected to apertural fold; intermediate plica long, usually visible from aperture; palatal plicae parallel and straight, sometimes divided.

\section{Type material}

According to Godwin-Austen (1879a), the collection of Stoliczka was deposited in the Indian Museum (currently the Zoological Survey of India). ZSI does not loan specimens, and my request for images was not successful. Therefore, I have not examined the types of Chersaecia shanensis. According to GodwinAusten (1879a), G. Nevill compared Plectopylis trilamellaris Godwin-Austen, 1875 to Stoliczka's type specimens of $P$. shanensis, and he confirmed their identity. According to the original description of P. trilamellaris, two specimens (syntypes) are present in the collection of the Indian Museum, Calcutta.

\section{Material examined}

MYANMAR: 1 shell, Shan States (NHMUK 1906.1.1.736); 2 shells, Shan States (NHMUK 1888.12.4.1551-1552); 5 shells, Mandalay, near Yinmabin Vill., loc. 20091018A, 2049.540' N, 96 $24.830^{\prime}$ E, 289 m a.s.1., 18 Oct. 2009, K. Ohara, K. Okubo and J.U. Otani leg. (coll. PGB, ex coll. K. Ohara); 2 shells, Shan, Kalaw, Shwe U Min Cave, loc. 20091018B, 20³7.256' N, 96³3.443' E, 1340 m a.s.1., 18 Oct. 2009, K. Ohara, K. Okubo and J.U. Otani leg. (coll. PGB, ex coll. K. Ohara); 2 shells, same data as for preceding (coll. PGB, ex coll. K. Okubo); 1 shell (Fig. 26D), same data as for preceding (NHMUK 20170293); 1 specimen (preserved in ethanol with corresponding shell), same data as for preceding (NHMUK 20170150, ex coll. J.U. Otani); 2 shells, Shan, in the suburbs of Kalaw, Myin Mahti Cave, loc. 20091018C, 20³5.417' N, 96³6.720' E, 1320 m a.s.l., 18 Oct. 2009, K. Ohara, K. Okubo and J.U. Otani leg. (coll. PGB, ex coll. K. Ohara); 2 shells, same data as for preceding (coll. PGB, ex coll. K. Okubo); 1 shell (Fig. 26E), same data as for preceding (NHMUK 20170292); 1 shell + ethanol-preserved body, same data as for preceding (NHMUK 20170151, ex coll. J.U. Otani).

INDIA: 2 shells, Simla Hills, Pinagu, 8300-8700 ft a.s.1., Annandale, V.17 (NHMUK).

\section{Description}

SHELL. Sinistral, glossy, brownish-corneous or reddish, flat, only protoconch protruding above dorsal surface; protoconch consists of 2.5-3 whorls; finely granulated on both dorsal and ventral surfaces; teleoconch finely, irregularly wrinkled; entire shell consists of 6.5-7 whorls; aperture oval; peristome white, reflected and slightly thickened; parietal callus elevated, sharp and V-shaped; apertural fold strong, connected to parietal callus; umbilicus very wide and moderately deep.

Four shells belonging to two populations were opened. Parietal wall with a single, short lamella having posteriorly slightly elongated upper and lower ends; intermediate plica attached to lamella, variable in length (up to the length of lamella; in that case visible in oblique view through the aperture); in some shells (subadults?), intermediate plica free from lamella; main and lower plicae not connected to lamella and run until peristome. Palatal wall with usually seven horizontal, straight plicae; first short and runs parallel with the suture; second is longest; remaining ones of equal length; additional, denticle-like plicae visible at posterior ends of seven horizontal plicae (usually more than one denticle belongs to one plica).

Measurements (in mm). $\mathrm{D}=19.1-20.1, \mathrm{H}=6.9-7.4$ (20091018B, $\mathrm{n}=2$ ); $\mathrm{D}=14.4-15.5, \mathrm{H}=5-5.4$ $(20091018 \mathrm{C}, \mathrm{n}=2)$. 
Characters of the genital structure. Two specimens were anatomically examined. 'Specimen 1' had no embryos in its uterus (loc. 20091018B, NHMUK 20170150); 'Specimen 2' had approximately seven embryos in its uterus (loc. 20091018C, NHMUK 20170151).

Left ommatophoral retractor runs between penis and vagina; penis very long, cylindrical, internally with approximately 10 irregular, interrupted longitudinal folds, forming a rather squamous (scaly) surface; epiphallus slightly shorter than penis, although boundary between epiphallus and vas deferens not clearly visible; inner wall of epiphallus with fine tubercles; epiphallus slightly wavy, especially near its insertion to penis; retractor muscle extremely long, inserts on penial caecum; penial caecum very short; vas deferens slender, cylindrical, runs along vagina and gradually increases in diameter towards its insertion to spermoviduct; vagina extremely long, internally with parallel, converging, serrate folds; bursa copulatrix longer than diverticulum, with a slightly thickened bursa; an elongate-ovoid, fragile spermatophore was found in the bursa of one of the specimens; diverticulum relatively long, almost equally thin towards its end, internally with regular, parallel folds.

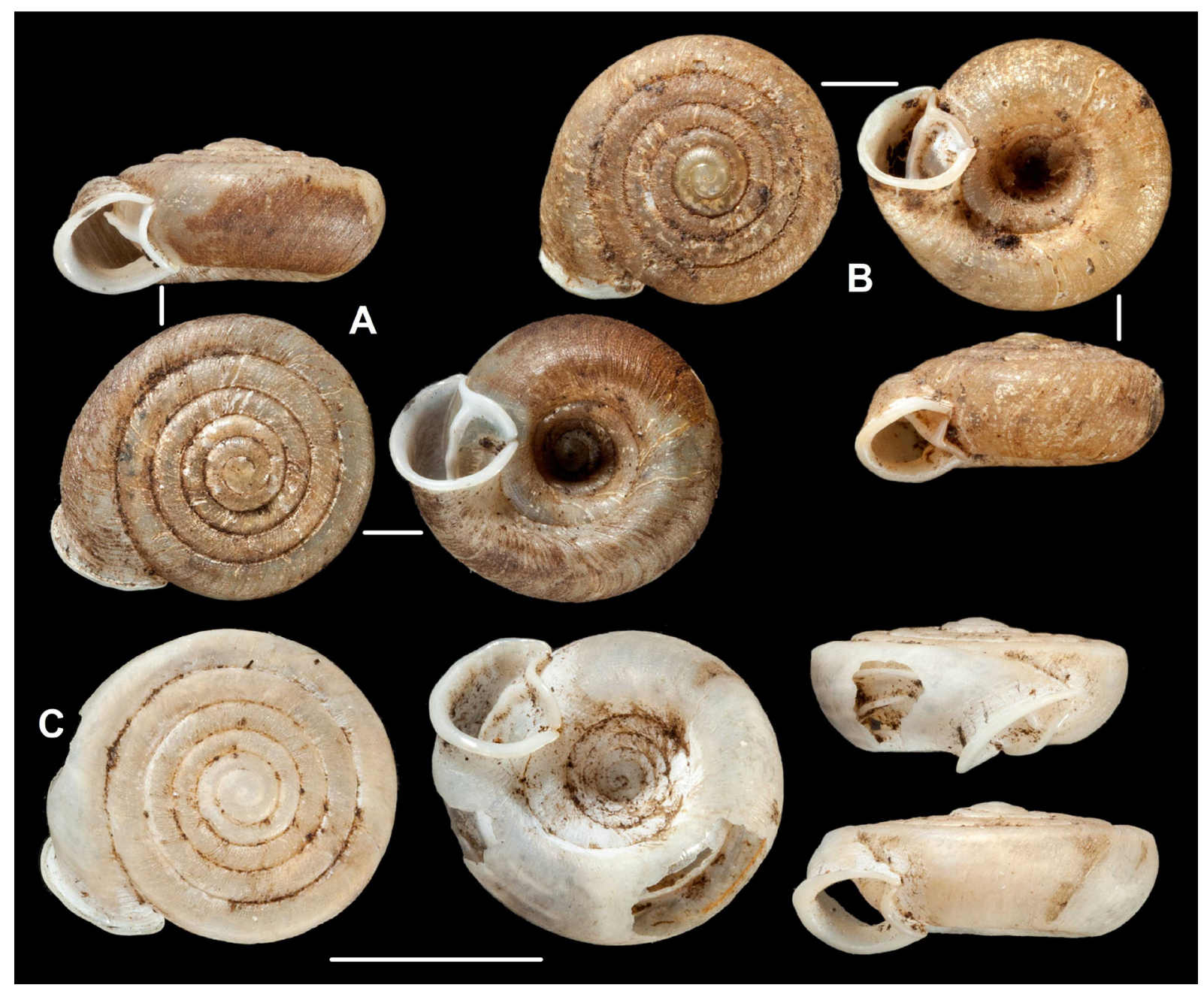

Fig. 30. Shells of species of Chersaecia Gude, 1899. A. C. shiroiensis shiroiensis (Godwin-Austen, 1875), syntype (NHMUK 1903.7.1.747). B. C. shiroiensis subnagaensis subsp. nov., holotype (NHMUK 1903.7.1.753.1). C. C. woodthorpei (Gude, 1899) comb. nov., syntype (NHMUK 1903.7.1.2100). Scale bar $=5 \mathrm{~mm}$. All photos: H. Taylor. 
RADULA. Centrals with small, triangular cusps; endocones of laterals rhomboid; ectocones of first laterals much larger than centrals; ectocones of marginals undivided, endocones of marginals undivided or divided by shallow incision.

\section{Differential diagnosis}

The large, reddish-brownish shell, the single lamella, the lower and main plica which run until the peristome, the long intermediate plica and the horizontal palatal plicae are characteristic of this species and allow separation from all congeners. See also under C. mogokensis sp. nov.

\section{Distribution}

Three precise localities are known for this species on the border of Mandalay and Shan Provinces, Myanmar (see also Fig. 12). I regard the specimen recorded from India as an erroneous label transcription.

\section{Remarks}

The species is very variable in its shell characters. The population from the Shwe U Min Cave is identical with the specimens in the NHM. The shells from the other two localities are much smaller and usually have shorter middle parietal plicae. Some specimens from Yinmabin Village have only straight palatal plicae without small plicae posteriorly.

Chersaecia shiroiensis (Godwin-Austen, 1875)

\section{Diagnosis}

Shell very small, last quarter of whorl keeled basally with a shallow groove between the suture and the keel; main parietal plica long, its posterior portion is much more elevated than the anterior, and bends downwards (in the direction of the lower suture).

\section{Differential diagnosis}

The shape of the last half/quarter whorl (groove and periumbilical keel) is characteristic for this species. See also under both subspecies.

\section{Remarks}

The two subspecies differ considerably in the parietal plication, but they are almost identical in outer shell characters, therefore they are handled as subspecies of a single species.

Chersaecia shiroiensis shiroiensis (Godwin-Austen, 1875)

Figs 24I-J, 30A

Helix (Plectopylis) shiroiensis Godwin-Austen, 1875b: 609, 613, pl. 73, fig. 3-3c ["slopes of the peak of Shiroifurar, N.E. of Munipúr, at an altitude of from 8000 to 9000 feet"].

Helix (Plectopylis) shiroiensis - Hanley \& Theobald 1876: 64, pl. 159, fig. 7. — Nevill 1878: 70. — Tryon 1887: 163, pl. 35, fig. 90.

Plectopylis shiroiensis - Gude 1896a: 155-156, fig. 20a-d.

Plectopylis (Chersaecia) shiroiensis - Gude 1899d: 148; 1899e: 175; 1914b: 105-106, fig. 49a-d.

Chersaecia shiroiensis - Páll-Gergely et al. 2015c: 10.

\section{Diagnosis}

Intermediate and lower plicae present. 


\section{Material examined}

Syntypes

INDIA: 10 shells, Naga Hills, Shiroifurar (NHMUK 1903.7.1.747).

\section{Additional material}

INDIA: 2 shells, Naga Hills, Japvo Pk, 10000 ft a.s.1., coll. Godwin-Austen (NHMUK 1903.7.1.748); 1 shell, Naga Hills, Kopamedza Pk, coll. Godwin-Austen (NHMUK 1903.7.1.775); 1 shell, Burrail, Japvo Pk., coll. Godwin-Austen (NHMUK); 1 shell, Naga Hills, Ogle leg., coll. Godwin-Austen (NHMUK 1903.7.1.232); many shells, Shiroifurar, NE Manipur, Assam, coll. Godwin-Austen (NHMUK); 1 shell, Munipur, 1875, Nevill leg. (NHMUK 1891.3.17.350-351); 3 shells, India (NHMUK 1909.1.26.74[?]); 2 adult shells, 1 juv. shell, Gazifhima, Lahupa, Naga Hills, Godwin-Austen leg. (NHMUK 1903.7.1.778).

\section{Description}

SHELL. Sinistral, light brownish or yellowish, small, spire slightly elevated; protoconch consists of 2.25 whorls, separated by shallow suture, finely, rather regularly wrinkled with extremely fine granular structure; entire shell with 5.5-6 whorls $(n=4)$; suture of teleoconch deep; teleoconch finely reticulated, radial lines usually dominant, but on dorsal side of last whorl spiral lines stronger; ventral surface also reticulated; aperture semilunar; peristome white, conspicuously thickened and strongly reflected; parietal callus V-shaped with the upper part of V being shorter; apertural fold prominent, continuous with main plica; periumbilical region slightly keeled, last half whorl slightly angulated and dorsolaterally depressed; last half whorl flares away from umbilicus; this modifies the regular infundibular shape of umbilicus (behind aperture, inside the last half whorl there is a slight canal).

Five shells were opened. Parietal wall with a vertical lamella, which has the upper end slightly, and the lower end more strongly elongated posteriorly; main plica free from lamella, in contact with apertural fold; main plica slightly curved, its middle portion situated closer to upper suture than its two ends; lower plica starts under lamella, slightly shorter than lamella; intermediate plica approximately as long as lamella, free from it. Palatal plicae six; first and second straight, third slightly oblique; fourth and fifth almost vertical; last one extremely long and rather straight, runs along periumbilical keel; there is an additional free denticle posteriorly.

Measurements (in mm). $\mathrm{D}=8-8.3, \mathrm{H}=4.4-4.5$ (NHMUK 1903.7.1.778, $\mathrm{n}=2$ ).

\section{Differential diagnosis}

See under Chersaecia shiroiensis subnagaensis subsp. nov.

\section{Distribution}

The nominotypical subspecies is known from a few localities from the Naga Hills of India.

Chersaecia shiroiensis subnagaensis subsp. nov. urn:1sid:zoobank.org:act:7DE71ACE-B30E-4569-8DE7-8CCDA15CEE03

Figs 24K-L, 30B

Helix (Plectopylis) nágáensis Godwin-Austen, 1875b: 609-610, 612, pl. 73, fig. 4 ["Prowi, head of the Lauier river, Nágá hills, 5000 feet”] (partim).

\section{Diagnosis}

Intermediate and lower plicae absent. 


\section{Etymology}

This new subspecies was mentioned as a dwarf variety of Helix (Plectopylis) nágáensis Godwin-Austen, 1875. The name subnagaensis refers to the close resemblance of this subspecies to the latter species.

\section{Material examined}

\section{Holotype}

INDIA: 1 shell, Sikhami, Lahupa, Naga Hills, coll. Godwin-Austen (NHMUK 1903.7.1.753.1).

\section{Paratypes}

INDIA: 6 shells, same data as for holotype (NHMUK 1903.7.1.753.2-7).

\section{Description}

Measurements (in mm). $\mathrm{D}=7.6-7.8, \mathrm{H}=3.5-3.7$ (type series, $\mathrm{n}=3$ ).

\section{Differential diagnosis}

Chersaecia shiroiensis subnagaensis subsp. nov. differs from the nominotypical subspecies by the fewer whorls $(5.25-5.75$ whorls; $\mathrm{n}=5$ ); a more prominent periostracum, which results in an overall darker shell; a smoother and smaller protoconch, which is conspicuously large and regularly ribbed in C. shiroiensis shiroiensis; a blunter periumbilical keel; and the absence of the intermediate and lower plicae on the parietal wall (observed in two opened shells from the type series). Chersaecia shiroiensis subnagaensis subsp. nov. differs from C. nagaensis by the smaller size, the formation of the last whorl and the absence of the lower plica.

\section{Distribution}

This new subspecies is known from the type locality only.

\section{Remarks}

Observing the palatal plicae was difficult due to the erroded shells and the thick shell walls. Two adult specimens and one juvenile had more or less transparent shells. A very long plica was visible close to the upper 'keel' in both adult shells; this long plica is situated at the position of the second plica, but in the position of the first plica (close to the suture) no plicae were found. The juvenile shell, however, had the first, short plica visible. The other plicae of the two adult shells were short, but their morphology and orientation could not be observed without breaking the shell. In the case of the juvenile shell (which was transparent), all six plicae were short and horizontal.

Chersaecia woodthorpei (Gude, 1899) comb. nov.

Figs $24 \mathrm{M}-\mathrm{N}, 30 \mathrm{C}$

Plectopylis woodthorpei Gude, 1899b: 15-16, fig. 98a-g ["Fort Stedman, Burma"].

Plectopylis (Plectopylis) woodthorpei - Gude 1899d: 148; 1899e: 175; 1914b: 124-126, fig. 61a-h. Plectopylis (Chersaecia) woodthorpei - Gude 1920: 61.

\section{Diagnosis}

A very small, sinistral species with an angulated body whorl and a very slightly elevated spire; parietal wall with two lamellae, a main and an intermediate parietal plicae, both of which are in contact with the anterior lamella; palatal wall with an overall Plectopylis-like palatal plication, with three additional horizontal plicae anterior to the vertical plate, which is formed by the fourth and fifth plicae. 


\section{Material examined}

Syntypes

MYANMAR: 3 shells, Burmah, Fort Stedman, Woodthorpe leg. (NHMUK 1903.7.1.2100).

\section{Additional material}

MYANMAR: 6 shells, E. Burmah, coll. Godwin-Austen (NHMUK).

\section{Description}

SHELL. Sinistral, small, with very slightly elevated spire; whorls shouldered, which results in a nearly flat dorsal surface; fresh shells light brown; protoconch consists of 2.5 whorls, finely tuberculated; dorsal side and area inside umbilicus dominated by reticulated sculpture; periphery of body whorl dominated by radial lines; whorls 6-6.75 $(\mathrm{n}=3)$, separated by moderately deep suture; peristome thickened and strongly reflected; parietal callus very strong, elevated, sharp, V-shaped, with the upper part of the V being shorter; apertural fold connected to parietal callus.

Two opened shells were examined. Parietal wall with a curved, long, posterior, and a shorter anterior lamella; main and intermediate plicae in contact with anterior lamella; main plica connected to apertural fold; intermediate plica about half as long as main plica; lower plica slightly extends beyond posterior lamella in posterior direction, and reaches peristome. Palatal plicae Plectopylis-like, with three additional horizontal plicae anterior to the vertical plate, which is formed by the accretion of the fourth and fifth plicae.

Measurements (in mm). $\mathrm{D}=8.8-9.9, \mathrm{H}=3.6-4.8$ (syntypes, $\mathrm{n}=2$ ).

\section{Differential diagnosis}

The carinate shell and the horizontal palatal plicae anterior to the vertical plate make the identification of the species easy. A population of Chersaecia perrierae is similar in shape, but it has a single lamella. See also under that species.

\section{Distribution}

Chersaecia woodthorpei is known from the type locality only.

Genus Hunyadiscus Páll-Gergely, 2016

Hunyadiscus Páll-Gergely in Páll-Gergely et al., 2016: 6.

\section{Type species}

Hunyadiscus saurini Páll-Gergely, 2016, by original designation.

\section{Species included}

Hunyadiscus andersoni (Blanford, 1869), H. saurini Páll-Gergely, 2016 and H. tigrina sp. nov.

\section{Diagnosis}

The discovery of Hunyadiscus tigrina sp. nov. extends our knowledge of the geographic distribution and shell morphology of the genus Hunyadiscus. Most importantly, however, it represents the first known record of the anatomy of this genus. Therefore, the diagnosis of Hunyadiscus is extended.

Shell dextral, body whorl bluntly keeled or bluntly shouldered; protoconch with strong spiral and radial lines (spiral lines stronger than or as strong as radial lines); apertural fold absent; parietal wall with only 
a single lamella, or with a lamella and some additional plicae/denticles anteriorly and/or posteriorly; palatal plicae slightly sinuate, usually horizontal. Penis short, inner penial wall with a thickened, flashy structure that is rounded in the proximal part of the penis, and divided in the middle towards the distal penial part; bursa copulatrix short with ovoid bursa; diverticulum absent.

\section{Differential diagnosis}

Hunyadiscus differs from all other plectopylid genera by the protoconch sculpture, which is characterized by both radial and spiral lines, the spirals being dominant or as strong as the radial lines. The most closely related genus is probably Naggsia Páll-Gergely \& Muratov, 2016, because of the similar dextral coiling direction, the presence of spiral striation on the protoconch, the apertural fold absent or very weak and the absence of an epiphallus and because of the close geographic proximity. The two genera differ from each other in the following shell and anatomical characters: the shape of the body whorl is keeled/shouldered in Hunyadiscus and rounded in Naggsia; the protoconch bears a strong spiral striation in Hunyadiscus, and has extremely fine spiral lines in Naggsia; the inner penial wall has parallel folds in Naggsia, but a proximally rounded and distally divided, fleshy structure in Hunyadiscus; the diverticulum is well-developed in Naggsia, and absent in Hunyadiscus.

\section{Distribution}

Northern Laos, northern Thailand, southern Kachin State of Myanmar, and the bordering Chinese region.

\section{Remarks}

Table 1 summarizes the key characters of species of Hunyadiscus.

Hunyadiscus andersoni (W. Blanford, 1869)

Helix (Plectopylis) andersoni Blanford, 1869: 448 ["Bhamo in regno Avæ et Hoetone in Yunan"].

Hunyadiscus andersoni - Páll-Gergely et al. 2016: 7-10, figs 3b-c, 4a-b, 5c-d, 11f.

\section{Remarks}

See description, figures and synonymy list in Páll-Gergely et al. (2016).

Hunyadiscus saurini Páll-Gergely, 2016

Figs $31 \mathrm{~A}-\mathrm{B}, 32 \mathrm{~A}-\mathrm{B}$

Hunyadiscus saurini Páll-Gergely in Páll-Gergely et al. 2016: 11-13, figs 3a, 4c, 5a-b, 11a.

\section{Material examined}

LAOS: 2 shells, Vientiane Province, Long Tieng $1 \mathrm{~km} \mathrm{E} \mathrm{on} \mathrm{road} \mathrm{towards} \mathrm{Sanasomboun,} \mathrm{small} \mathrm{ponor}$ cave deposits at foot of limestone cliffs right side of the road, $19.098124^{\circ} \mathrm{N}, 102.938746^{\circ} \mathrm{E}, 978 \mathrm{~m}$ a.s.1., 24 Feb. 2017, J. Grego leg. (coll. JG, inventory no. L4419).

\section{Remarks}

This species was described based on empty shells, which were collected by Edmond Saurin in the 1960s. The locality names on the labels could not be exactly located on available maps. We speculated that Saurin's "Pa Hia" may be Ban Namthong (19³.2' N, 103¹7' E) (Páll-Gergely et al. 2016). I have since had the chance to examine two shells recently collected from the above-mentioned site in Vientiane Province, Laos. This represents the first exact locality of this species, located ca $37 \mathrm{~km}$ east (in a straight line) from Pa Hia (see also Fig. 12). 


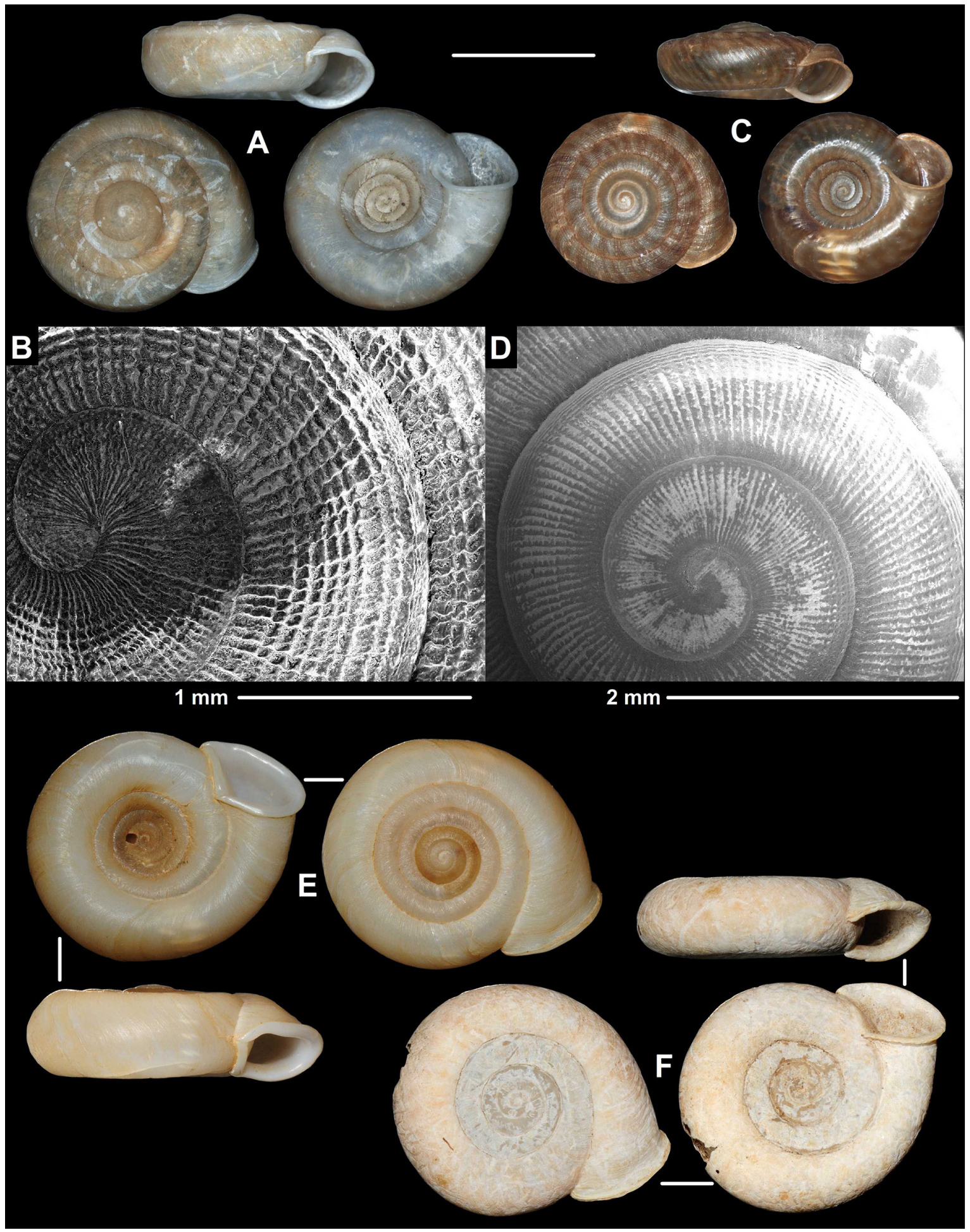

Fig. 31. Shells and protoconchs of species of Hunyadiscus Páll-Gergely, 2016 and Naggsia Páll-Gergely \& Muratov, 2016. A. Hunyadiscus saurini Páll-Gergely, 2016, holotype (MNHN IM-2000-24947). B. H. saurini, paratype (MNHN IM-2000-24949). C. Protoconch of H. tigrina sp. nov., holotype (UF 343843). D. Protoconch of $H$. tigrina sp. nov., paratype (UF 343817). E. Naggsia laomontana from Laos, Luang Praban Province, $20^{\circ} 03.48276^{\prime}$ N, $102^{\circ} 12.79912^{\prime}$ E, 364 m a.s.l., 13 Oct. 2006, K. Ohara leg. (coll. PGB). F. N. oligogyra sp. nov., holotype (UF 346781). Scale bar: A, C, E-F = 10 mm. Images: T. Deli (A, C, E-F) and B. Páll-Gergely (B, D). 


\section{Hunyadiscus tigrina sp. nov.}

urn:1sid:zoobank.org:act:563BC118-AE90-4801-8D47-9D4E78E32BDE

Figs 29C-D, 31C-D, 32C-D, 33

Plectopylis sp. - Tumpeesuwan \& Tumpeesuwan 2010: 14, fig. 2g.

\section{Diagnosis}

Shell medium-sized, dextral, thin-walled, bluntly keeled, with red and yellow stripes and a conspicuously large protoconch; parietal wall with a single curved lamella without additional plicae; palatal wall with seven parallel, horizontal plicae.

\section{Etymology}

The name 'tigrina' (used as a noun) refers to the red and yellow stripes of this species, which resemble the markings of a tiger.
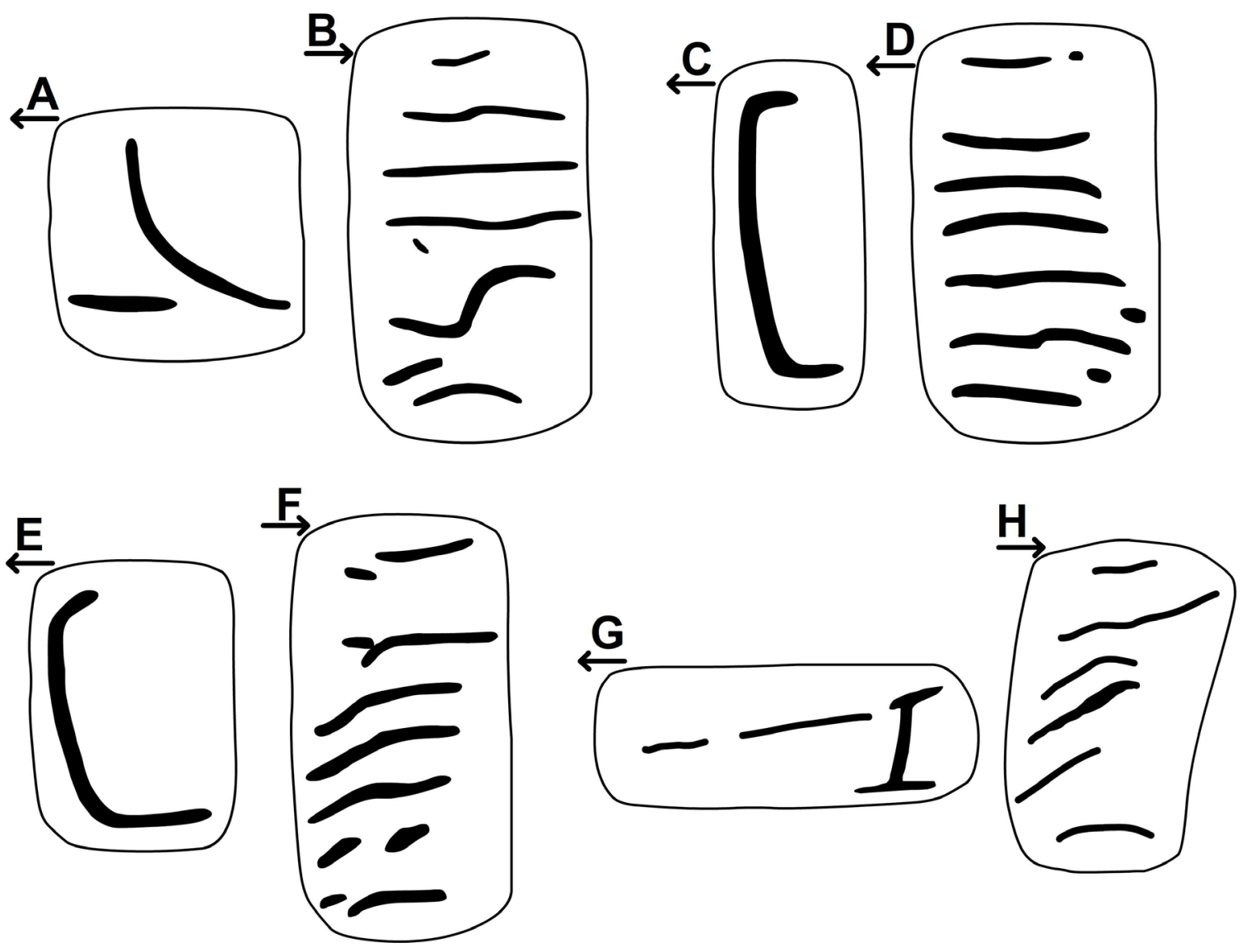

Fig. 32. Parietal (A, C, E, G) and palatal (B, D, F, H) plication of species of Hunyadiscus PállGergely, 2016 and Naggsia Páll-Gergely \& Muratov, 2016. A-B. Hunyadiscus saurini Páll-Gergely, 2016, paratypes from the type locality (UF 448579). C-D. H. tigrina sp. nov., paratype (UF 448579). E-F. Naggsia laomontana (L. Pfeiffer, 1862) from Laos, Luang Praban Province, $20^{\circ} 03.48276^{\prime}$ N, $102^{\circ} 12.79912^{\prime}$ E, 364 m a.s.l., 13 Oct. 2006, K. Ohara leg. (coll. PGB). G-H. N. oligogyra sp. nov. (UF 346781). Arrows below the letters indicate the direction of the aperture. Not to scale. 


\section{Material examined}

\section{Holotype}

THAILAND: 1 shell $(\mathrm{D}=13.9 \mathrm{~mm})$, Udon Thani Province, limestone hill, $18 \mathrm{~km} \mathrm{~W}$ of Na Klang, slope of hill, leaf litter, $17^{\circ} 19^{\prime} 30^{\prime \prime} \mathrm{N} 102^{\circ} 1^{\prime} 48^{\prime \prime}$ E, 400 m a.s.1., 23 May 1987, F.G. Thompson leg. (UF 343843).

\section{Paratypes}

THAILAND: 62 shells, same data as for holotype (UF 448579); 2 shells, same data as for holotype (HNHM 97455); 10 specimens (preserved in ethanol; 3 in separate vials used for molecular study: PL060, PL061, PL062), same data as for holotype (UF 343844); 4 shells, Loei Province, Phu Pha Ya

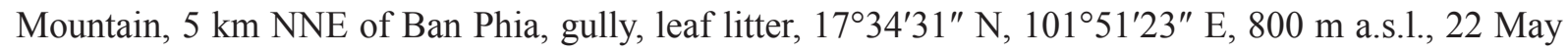
1987, F.G. Thompson leg. (UF 343809); 3 shells, Loei Province, Phu Pha Ya Mountain, 4 km NNE of Ban Phia, ravine, leaf litter, 17³4'7" N, 10151'32" E, 750 m a.s.1., 21 May 1987, F.G. Thompson leg. (UF 343782); 26 shells, Loei Province, limestone knoll, 1 km E of Ban Huai Muang, limestone dome, leaf litter, $1^{\circ} 28^{\prime} 26^{\prime \prime} \mathrm{N}, 101^{\circ} 53^{\prime 2} 20^{\prime \prime}$ E, $375 \mathrm{~m}$ a.s.1., 21 May 1987, F.G. Thompson leg. (UF 343745); 3 shells, same data as for preceding (HNHM 97473); 80 shells (incl. some juv.), Loei Province, $6 \mathrm{~km}$

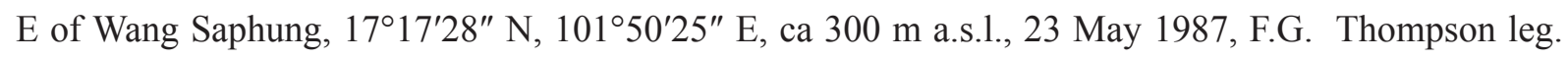
(UF 343817); 3 shells, same data as for preceding (HNHM 97474); 10 specimens (preserved in ethanol: PL022 and PL023 used for molecular study), same data as for preceding (UF 343818).
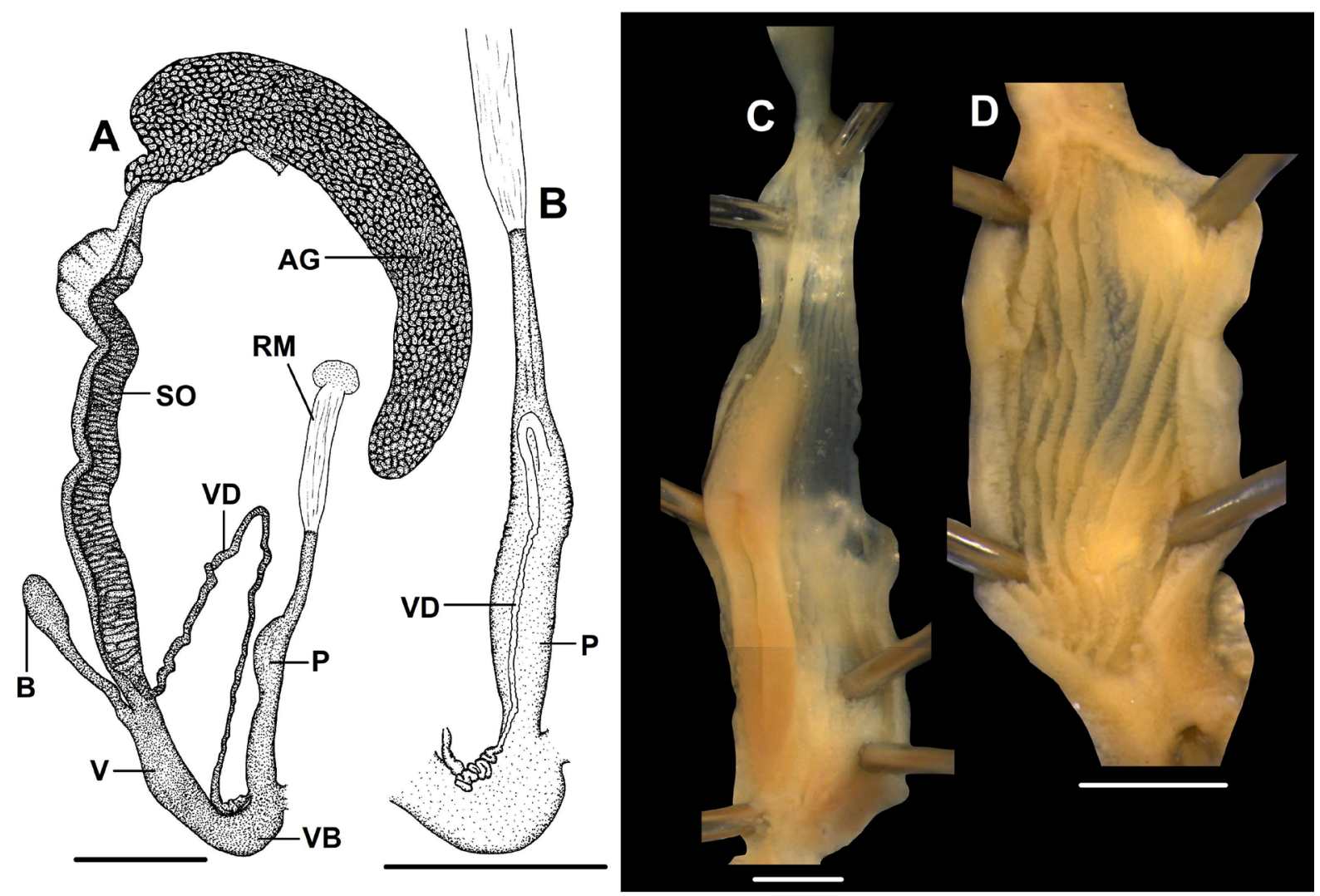

Fig. 33. Genitalia of Hunyadiscus tigrina sp. nov., Thailand (UF 343844). A. Whole genitalia. B. Male genitalia (penis and vas deferens). $\mathbf{C}-\mathbf{D}$. Inner structure of genital organs $(\mathrm{C}=$ penis, $\mathrm{D}=$ vagina). Scale bars: A-B $=2 \mathrm{~mm} ; \mathrm{C}-\mathrm{D}=1 \mathrm{~mm}$. For abbreviations see Fig. 2. All photos: B. Páll-Gergely. 


\section{Description}

SHELl. Dextral, lenticular, with bluntly keeled body whorl and conspicuously large protoconch; teleoconch with yellow and red transverse stripes, which are more prominent on ventral surface; fresh shells with periostracum with deciduous folds on keel; protoconch consists of three very finely regularly ribbed and densely spirally striated whorls; dorsal surface of teleoconch irregularly reticulate; entire shell with 5.25-6 regularly increasing whorls, separated by a rather shallow suture; ventral surface almost smooth; inner side of umbilicus irregularly finely ribbed; umbilicus moderately wide but not very deep; peristome only slightly thickened and reflected; parietal region with an additional, inconspicuous calcareous layer; apertural fold absent.

Five shells were opened. Parietal wall with a single, more-or-less vertical, curved lamella. Palatal wall with seven parallel plicae; first shortest and situated close to upper suture; second usually situated on keel, situated in comparatively large distance from first plica; last plica relatively short; middle plicae (third to sixth) usually straight, but slightly sinuate centrally; all plicae thicker anteriorly and thinner posteriorly; sometimes, additional short plicae can be seen above posterior end of last three plicae.

MeAsurements (in mm). $\mathrm{D}=12.8-17.3, \mathrm{H}=5.0-7.2(\mathrm{n}=6)$.

Characters of the genital system. Two specimens were dissected (UF 343818). Right ommatophoral retractor runs between penis and vagina; penis short, internal wall bears a complex structure that is thickened and rounded in proximal part of penis, and divides to two equal 'legs' towards atrium; no epiphallic differentiation observed; retractor muscle thick, inserts on proximal end of penis; proximal part of penis contains very small, conical calcareous granules; distal end of vas deferens hidden, it derives near insertion of retractor muscle and becomes a free tube near proximal end of penis; free part of vas deferens very long, thickened near proximal end; vagina about as long as penis, internally with rather irregular, converging longitudinal folds; vaginal bulb slightly developed; bursa copulatrix short, with oval bursa; diverticulum absent.

RADULA. Centrals nearly entirely reduced; endocones of laterals rhomboid; ectocones of marginals undivided or divided to two; endocones of marginals mostly undivided, or divided by shallow incision.

\section{Differential diagnosis}

Hunyadiscus saurini has a shouldered body whorl, stronger spiral striation on the protoconch, a horizontal lower plica anterior to the lamella, and the fifth main palatal plica is strongly Z-shaped. In contrast, H. tigrina sp. nov. usually has a smaller, keeled shell, weaker spiral striation on the protoconch, possesses only a single lamella on the parietal wall, and all its palatal plicae are horizontal.

\section{Distribution}

The species is known from Loei and Udon Provinces, northern Thailand (Fig. 12).

Genus Naggsia Páll-Gergely \& Muratov, 2016

Hunyadiscus Páll-Gergely \& Muratov in Páll-Gergely et al., 2016: 13.

\section{Type species}

Helix laomontana L. Pfeiffer, 1862, by original designation.

\section{Species included}

Naggsia laomontana (L. Pfeiffer, 1862) and N. oligogyra sp. nov. 


\title{
Distribution
}

The genus Naggsia is known from a few localities in northern Laos and northern Thailand (Fig. 4).

\section{Remarks}

Table 1 summarizes the key characters of species of Naggsia.

Naggsia laomontana (L. Pfeiffer, 1862)

Figs 31E, 32E-F

Helix laomontana L. Pfeiffer, 1862: 272, pl. 36, figs 9-10 [“Lao Mountains, Camboja”].

Naggsia laomontana - Páll-Gergely et al. 2016: 14-23, figs 1a-b, 2a, 4d, 5e-f, 7-8, 9a-c, 10.

\section{Remarks}

See description, figures and synonymy list in Páll-Gergely et al. (2016), and Fig. 12.

\author{
Naggsia oligogyra sp. nov. \\ urn:1sid:zoobank.org:act:13CE6536-3C26-421E-ACA1-270750697E3A
}

Figs $31 \mathrm{~F}, 32 \mathrm{G}-\mathrm{H}$

\section{Diagnosis}

A large, flat, dextral species with few (5) whorls; parietal wall with a single lamella, and a main plica free from the deeply situated apertural fold.

\section{Differential diagnosis}

The shell of the new species resembles $N$. laomontana, which has about a whorl more and only a single lamella on the parietal wall.

\section{Etymology}

The species is named after its few whorls, from the Greek 'oligos', meaning few and 'gyros', meaning whorl.

\section{Material examined}

\section{Holotype}

THAILAND: 1 shell $(\mathrm{D}=21.0 \mathrm{~mm})$, Chiang Mae Province, Doi Pha San Sao Mountain, $1 \mathrm{~km} \mathrm{~W}$ of Ban Prang Ma-o, $19^{\circ} 25^{\prime} 58.26^{\prime \prime}$ N, 994'14.02" E, 500 m a.s.1., 19 Jun. 1987, F.G. Thompson leg. (UF 346781).

\section{Paratypes}

THAILAND: 2 broken shells, same data as for holotype (UF 448574); 1 broken shell, same data as for holotype (HNHM 97457).

\section{Description}

SHELl. Dextral, flat, with five rapidly increasing whorls, separated by a rather shallow suture; only strongly weathered shells were available for study, and therefore the sculpture could not be observed in detail; protoconch with fine ribs; teleoconch with inconspicuous, irregular riblets and paler reddish transverse stripes; peristome relatively thin, only slightly reflected and thickened; parietal callus low and blunt; apertural fold weak, situated far from parietal callus. 
One shell was opened. Parietal wall with a single, straight lamella having slight horizontal extensions above and below in both anterior and posterior directions; main plica free from lamella, starts near upper end of lamella, and does not reach apertural fold. Palatal wall with six plicae; first situated close to upper suture, short; second to fifth oblique, second being the longest; sixth curved, concave.

Measurements (in mm). $\mathrm{D}=21.0, \mathrm{H}=6.3$ (holotype).

\section{Distribution}

The new species is known from the type locality only, where it occurs together with C. leiophis (Fig. 17).

Genus Plectopylis Benson, 1860

Plectopylis Benson, 1860: 244.

\section{Type species}

Helix achatina Pfeiffer, 1845 by subsequent designation (Pilsbry 1894). Helix achatina Pfeiffer, 1845 is a junior homonym of Helix achatina Gmelin, 1791. The valid name of the species is Plectopylis bensoni Gude, 1914.

\section{Species included}

Plectopylis anguina (Gould, 1847), P. bensoni Gude, 1914, P. cairnsi Gude, 1898, P. crassilabris sp. nov., P. cyclaspis Benson, 1859, P. karenorum W. Blanford, 1865, P. linterae Möllendorff, 1897, P. malayana sp. nov. and $P$. thompsoni sp. nov.

\section{Diagnosis}

Shell sinistral, flat, widely umbilicated, usually thick; protoconch smooth (matt) or with small tubercles, usually with irregular, low growth ridges (wrinkles); apertural fold present; parietal wall with two vertical lamellae, which are fused at their upper ends forming a structure resembling the Greek letter lambda $(\lambda)$; palatal side with a vertical plate formed by the accretion of two plicae (the fourth and the fifth), and three horizontal plicae above and one below that plate.

Inner wall of penis sculptured with multiple, usually serrate parallel folds, and sometimes calcareous crystals; penial caecum usually absent, or a vestigial caecum might be discernible; retractor muscle inserts on penis-epiphallus transition (or on caecum); attached to penis with weak muscle fibres, it is shorter than penis, internally with a few parallel folds; vas deferens slender, usually thickened near its proximal end; vagina mostly short; bursa copulatrix with a slender stalk and a bursa of variable length; diverticulum short and thick, ovoid.

\section{Differential diagnosis}

See differential diagnosis and remarks under Chersaecia.

\section{Distribution}

Southern Myanmar, northern Malaysia and north-eastern India.

\section{Remarks}

Table 3 summarizes the key characters of species of Plectopylis. 
Plectopylis anguina (Gould, 1847)

Figs 34A, 35A

Helix anguina Gould, 1847: 218-219 [“Manko, near Newville, Province of Tavoy"].

Helix (Plectopylis) anguina - Hanley \& Theobald 1870: 7, pl. 13, fig. 7. — Godwin-Austen 1875b: 613. - Nevill 1878: 72. — Tryon 1887: 165, pl. 35, fig. 6.

Plectopylis anguina - Gude 1898d: 76, fig. 79a-f (on page 75).

Plectopylis (Plectopylis) anguina - Gude 1899d: 148; 1899e: 175; 1914b: 136-138, fig. 69a-f. Johnson 1964: 40, pl. 41, fig. 5. (fig. caption before pl. 38, shell photo mixed up with Cyclostoma (Cyclophorus) cucullata).

\section{Diagnosis}

A very large, sinistral species with conspicuously flattened shell, and bluntly keeled body whorl.

\section{Material examined}

Types

MYANMAR: 2 shells, paralectotypes, Tavoy (NHMUK 20140812); 1 shell, paralectotype, Manko, Tavoy, coll. Gould (MCZ 147595); 1 shell, lectotype, Burmah, Manko, near Newville, Tavoy, Mrs Vinton leg., coll. Gould (MCZ 169042); 1 shell, paralectotype, same data as for preceding (MCZ 169043).

I examined the paralectotypes in the NHM, and received photographs of specimens deposited in the MCZ.

\section{Additional material}

MYANMAR: 1 shell, Burmah, Moulmein, 1908, coll. C.R. Boettger (SMF 102815); 1 shell (mixed sample with Plectopylis bensoni) (SMF 172059); 1 shell, Burma, coll. Bosch ex Rolle (SMF 345109); 3 shells, Mergui (NHMUK); 1 shell, Rangoon, Moulmein, coll. Godwin-Austen (NHMUK 1903.7.1.739); 1 shell, Rangoon, Moulmein, coll. Blanford (NHMUK 1906.1.1.732); 1 shell, Molmein (NHMUK); 2 shells, Damathat Hill (NHMUK 1888.12.4.1553-1554).

\section{Description of the type series}

SHELL. Sinistral, strongly depressed, dorsal surface slightly concave, but protoconch protrudes to reach level of dorsal surface; whorls 5-5.75 $(\mathrm{n}=2)$; body whorl bluntly keeled; whole shell brownish with yellowish stripes, dorsal side seems to be darker than ventral; one specimen was almost completely brown above and striped below, whereas other shells were striped above and almost completely pale on their ventral side; protoconch matt, almost smooth, with irregular, inconspicuous growth lines and extremely small granular structure; teleoconch dominated by irregular growth lines, and some reticulated parts on dorsal surface (between end of protoconch and beginning of last whorl); periphery of body whorl almost smooth; aperture almost completely facing downwards; peristome strongly thickened and slightly reflected; parietal callus quite low, slightly depressed V-shaped; apertural fold starts at some distance from parietal callus.

One opened shell was examined. Lambda-complex complete; both legs with slight elongations anteriorly and posteriorly; upper branch slightly longer than elongation of left leg; main plica connected to the right leg. Palatal plicae typical of Plectopylis.

MeAsurements (in mm). $\mathrm{D}=26.2-30.4, \mathrm{H}=7.1-7.9$ (paralectotypes, NHMUK 20140812, $\mathrm{n}=2$ ). 
Table 3. Key characters, most similar species and distribution of species of Plectopylis.

\begin{tabular}{|c|c|c|c|}
\hline Species & Key traits & Most similar species & Distribution \\
\hline P. anguina & $\begin{array}{l}\text { flat shell, strongly oblique } \\
\text { aperture, bluntly keeled body } \\
\text { whorl }\end{array}$ & P. bensoni & southern Myanmar \\
\hline P. bensoni & $\begin{array}{l}\text { robust shell, rounded body } \\
\text { whorl }\end{array}$ & P. anguina, $P$. cairnsi & southern Myanmar \\
\hline P. cairnsi & $\begin{array}{l}\text { main plica free from lambda- } \\
\text { complex }\end{array}$ & $\begin{array}{l}\text { P. bensoni, } \\
\text { P. thompsoni sp. nov. }\end{array}$ & $\begin{array}{l}\text { southern Thailand (Krabi } \\
\text { Province }\end{array}$ \\
\hline P. crassilabris sp. nov. & $\begin{array}{l}\text { robust shell, thickened } \\
\text { peristome, main plica absent }\end{array}$ & P. linterae & $\begin{array}{l}\text { southern Thailand (Chon } \\
\text { Buri, Chachoengsao, } \\
\text { Chantaburi, Rayong } \\
\text { provinces) }\end{array}$ \\
\hline P. cyclaspis & keeled body whorl & - & $\begin{array}{l}\text { southern Myanmar (around } \\
\text { Mawlamyine) }\end{array}$ \\
\hline P. karenorum & $\begin{array}{l}\text { flat, thin-walled shell, tiger } \\
\text { stripes }\end{array}$ & - & Myanmar (Bago) \\
\hline P. linterae & $\begin{array}{l}\text { small, robust shell, main } \\
\text { plica present }\end{array}$ & P. crassilabris sp. nov. & Myanmar (Bago) \\
\hline P. malayana sp. nov. & $\begin{array}{l}\text { brown shell with periostracal } \\
\text { folds, short plica attaches to } \\
\text { right leg of lambda-complex }\end{array}$ & P. cairnsi & $\begin{array}{l}\text { border region of Thailand } \\
\text { and Malaysia }\end{array}$ \\
\hline P. thompsoni sp. nov. & $\begin{array}{l}\text { large, flat shell, right leg of } \\
\text { lambda-complex absent }\end{array}$ & P. cairnsi & $\begin{array}{l}\text { southern Thailand (Krabi } \\
\text { and Trang provinces) }\end{array}$ \\
\hline
\end{tabular}

\section{Differential diagnosis}

Plectopylis anguina differs from P. bensoni by the lighter, flatter shell, the bluntly keeled body whorl, the more elongated aperture and the overall more elongated (ovate) shell outline.

\section{Distribution}

The species has been reported from a few southern Burmese localities.

\section{Remarks}

Gude (1914b) mentioned that Plectopylis anguina differs from P. repercussa in features of the parietal plication. Namely, "the lower arm of the bifurcation" is longer than the upper, whereas the reverse is true in $P$. repercussa. In the opened paralectotype in the NHM this was not the case, because the upper arm was very slightly longer then the lower leg. The other difference mentioned by Gude is that the lower plica does not extend beyond the left leg in $P$. anguina, but does so in P. repercussa. My observations do not match those of Gude, because the lower plica does not exceed the left leg in the opened paralectotype of $P$. repercussa. Therefore, this character does not distinguish the two species. Based on this evidence, $P$. anguina is a valid species, different from $P$. bensoni (of which $P$. repercussa is a synonym) because of its characteristic flat shell, strongly oblique aperture and bluntly keeled body whorl. 


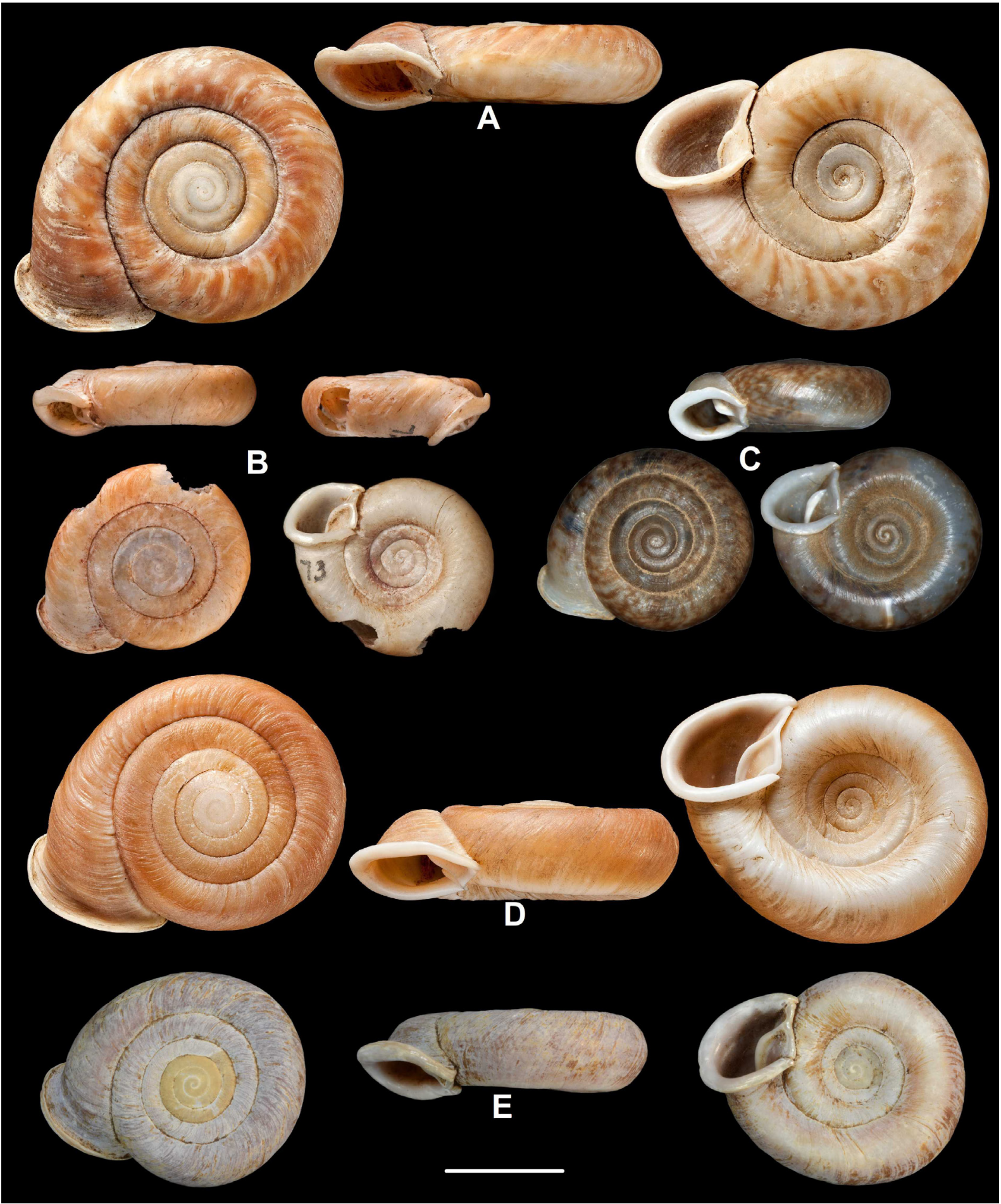

Fig. 34. Shells of species of Plectopylis Benson, 1860. A. P. anguina (Gould, 1847), paralectotype (NHMUK 20140812). B. P. cairnsi Gude, 1898, holotype (NHMUK 1922.8.29.47). C. P. cairnsi (UF 76761). D. P. bensoni Gude, 1914, paralectotype of Helix repercussa Gould, 1856 (NHMUK 20140813). E. Neotype of P. bensoni (NHMUK 20170143). Scale bar $=10 \mathrm{~mm}$. Photos: T. Deli (C), B. Páll-Gergely (E) and H. Taylor (A-B, D). 
Plectopylis bensoni Gude, 1914

Figs 2, 34E, 35C, 36A-F, 37, 38A-B

Helix achatina Pfeiffer, 1845: 86 ["Südamerika"].

Helix repercussa Gould, 1856: 11 ["Tavoy and Mergui”]. Syn. nov.

Plectopylis achatina var. obesa Gude, 1898e: 115, fig. 83a-c. Syn. nov.

Plectopylis achatina var. infrafasciata Gude, 1898f: 133, fig. 84a-f. Syn. nov.

Plectopylis achatina var. venusta Gude, 1898f: 133, fig. 85a-c. Syn. nov.

Plectopylis achatina var. castanea Gude, 1898f: 133-134, fig. 86a-c. Syn. nov.

Plectopylis achatina var. breviplica Gude, 1898f: 134, fig. 87a-c. Syn. nov.

Plectopylis achatina var. repercussoides Gude, 1899a: 333. Syn. nov.

Plectopylis (Plectopylis) bensoni, Gude 1914b: 138-141, figs 70-72.

Helix (Atopa) achatina - Albers 1850: 90.

Helix (Corilla) achatinum - Adams \& Adams 1855: 208.

Helix achatina - Benson 1859c: 95 ["near Moulmein"]. — Pfeiffer 1868: 395.

Helix (Plectopylis) achatina - Benson 1860: 244, 245. - Hanley \& Theobald 1870: 7, pl. 13, fig. 1. — Godwin-Austen 1875b: 613, pl. 74, fig. 6-6a. - Nevill 1878: 71. — Kobelt 1879: 236, pl. 71, fig. 9. - Tryon 1887: 165, pl. 35, figs 3-5, 7-8. — Tapparone Canefri 1889: 47 (=323). — GodwinAusten 1895: 155. pl. 7, fig. 5.

Helix repercussa - Pfeiffer 1868: 396. — Gude 1898d: 74, fig. 78a-i.

Plectopylis achatina - Stoliczka 1871: 221-222, pl. 15, figs 1-3. - Pilsbry 1894: 145, pl. 40, figs 5-8. - Gude 1898e: 114-115, figs 80-82.

Helix (Plectopylis) repercussa - Hanley \& Theobald 1870: 7, pl. 13, fig. 4. — Nevill 1878: 72. — Tryon 1887: 165 (synonym achatina).

Plectopylis (Plectopylis) achatina (var. repercussoides, var. infrafasciata, var. castanea, var. obesa, var. venusta, var. pachystoma Theob. M.S., var. breviplica) - Gude 1899d: 148.

Plectopylis (Plectopylis) repercussa - Gude 1899d: 148; 1899e: 175; 1914b: 146-149, fig. 78a-i. Johnson 1964: 139, pl. 37, fig. 3.

Plectopylis (Plectopylis) achatina - Gude 1899e: 175.

Plectopylis achatina var. obesa-Gude 1900a: 35-36, fig. 13a-c.

Plectopylis achatina var. infrafasciata - Gude 1900a: 36-37, fig. 14a-c.

Plectopylis achatina var. venusta - Gude 1900a: 37-38, fig. 15a-c.

Plectopylis bensoni var. repercussoides - Gude 1900b: 91.

Plectopylis repercussa - Gude 1900b: 91.

Plectopylis (Plectopylis) bensoni var. repercussoides - Gude 1914b: 141-142.

Plectopylis (Plectopylis) bensoni var. infrafasciata - Gude 1914b: 142-143, fig. 73a-c.

Plectopylis (Plectopylis) bensoni var. castanea - Gude 1914b: 143, fig. 74a-c.

Plectopylis (Plectopylis) bensoni var. obesa - Gude 1914b: 143-144, fig. 75a-c.

Plectopylis (Plectopylis) bensoni var. venusta - Gude 1914b: 144-145, fig. 76a-c.

Plectopylis (Plectopylis) bensoni var. breviplica - Gude 1914b: 145-146, fig. 77a-c.

Plectopylis (Plectopylis) bensoni - Zilch 1960: 595, fig. 2095.

\section{Diagnosis}

A very variable species with medium-sized to very large, flat shell, shouldered body whorl due to flat dorsal side (although edge of body whorl rounded), strong main plica, which is connected to both the anterior lamella and the apertural fold, lower plica usually reaches the peristome. 


\section{Type material}

The original description (Pfeiffer 1845) was based on a single specimen from the private collection of J.E. Gray, and was said to be collected in South America ("soll aus Südamerika herstammen"). This locality was questioned later (Pfeiffer 1848b: 406), and in the $5^{\text {th }}$ edition of the Monographiae Heliceorum Viventium, Pfeiffer (1868) designated "Farm Caves, prope Moulmein" as the locality of the species. The location of the single shell (holotype) is unknown, and it is most probably lost. Pfeiffer's collection was destroyed during WWII (Dance 1986). If not destroyed, there are two possibilities where the holotype could be: either in the collection of Cuming, or the shells could have remained in the collection of Gray. Both collections are deposited in the NHM (Dance 1986). I have been unable to locate the holotype there. Since this is the type species of Plectopylis, which is the type genus of the family Plectopylidae, I found it necessary to select a neotype. The shell detailed below, collected at the type locality, is therefore designated as the neotype.

\section{Material examined}

Neotype (here designated)

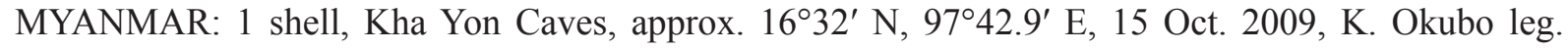
(NHMUK 20170143, ex coll. K. Okubo).

\section{Other types}

MYANMAR: 1 shell, lectotype of P. repercussa, Burmah, Tavoy and Mergui, coll. Gould (MCZ 169336); 3 shells, paralectotypes of P. repercussa, Burmah, Tavoy (NHMUK 20140813); 1 shell, holotype of P. bensoni var. castanea, Moulmein, coll. Linter (NHMUK 1922.8.29.45); 1 shell, holotype of $P$. bensoni var. infrafasciata, Moulmein, coll. Linter (NHMUK 1922.8.29.43); 1 shell, holotype of P. bensoni var. obesa, Moulmein, coll. Linter (NHMUK 1922.8.29.42); 1 shell, holotype of P. bensoni var. repercussoides, Moulmein, coll. Linter (NHMUK 1922.8.29.46); 1 shell, holotype of $P$. bensoni var. venusta Moulmein, coll. Linter (NHMUK 1922.8.29.44).

The lectotype of $P$. repercussa was selected by Johnson (1964). According to the original description of P. bensoni var. breviplica, the holotype is in the collection of Mr Ponsonby, but it was not found in the NHM.

\section{Additional material}

MYANMAR: 1 shell, Birmanie, coll. Denis (MNHN IM-2012-2516); 7 shells, Birmanie, Moulmein, Mission L. Fea, 1885-1889 (MNHN-IM-2012-2517); 2 shells, Birmanie, coll. Jousseaume (MNHNIM-2012-2518); 8 shells, Indien, Moulmein (NHMS 122182-122189); 1 shell, Moulmein (NHMS 122180); 1 shell, Ost-Indien, ex coll. Dr. Holub 1896 (NHMS 4923); 1 shell, Mergui, Fulton leg., coll. Möllendorff (SMF 150096); 2 shells, ("var. infrafasciata"), Burma, coll. Bosch ex Rolle (SMF 172061); 1 shell, Barma, coll. Möllendorff (SMF 150094); 2 shells ("achatina obesa"), Burma, coll. Bosch, ex Rolle (SMF 172060); 1 shell ("v. castanea", mixed sample with P. anguina), Burma, coll. Bosch ex Rolle (SMF 172059); 2 shells, Indien, Moulmein, coll. Jaeckel ex Edlauer (SMF 212737); 2 shells, Indien, Moulmein, coll. Bosch, ex Rolle (SMF 172057); 1 shell, Moulmein, coll. Pfeiffer ex Staudinger (SMF 102813); 3 shells, Moulmein, coll. Jetschin ex Linter 1893 (SMF 102822); 2 shells, Moulmein, coll. Kobelt 1876, ex-exhibition coll. "alte Schau-Slg." (photographed in Zilch 1960) (SMF 150088); 3 shells, Birma, coll. Möllendorff ex Beddome (SMF 150091); 3 shells (not typical form with elevated spire), Attaram-Tal, coll. Möllendorff (SMF 150092); 2 shells, Moulmein, coll. Ehrmann ex Staudinger (SMF 150093); 1 shell, Burma, coll. Reinhardt (SMF 150098); 3 shells, Burma, Moulmein, coll. Möllendorff (SMF 150090); 2 shells, Burma, Moulmein, coll. C. Boettger, 1908 (SMF 102814); 3 shells (labelled as "anguina"), Burmah, Mergui (NHMUK); 2 shells (under the name anguina), Burmah, Moulmein, coll. A. S. Kennard, coll. Gude (NHMUK); 1 shell, Birma, coll. Bosch, ex Rolle (SMF 172063); 1 shell, Moulmein (ZMUC-GAS-1802); 1 shell, Moulmein, coll. Steenberg (ZMUC-GAS-1803); 1 shell, Indien, 
Linter leg., 1906, coll. Steenberg (ZMUC-GAS-1801); 1 shell, Moulmein, Bostre Indien, coll. Steenberg ex Dr. Stoliczka (ZMUC-GAS-1815); 4 specimens (ethanol-preserved bodies + corresponding shells), Kayin, West foot of Zwegabin Mt., Pha-an, loc. 20091014A, 16²49.676' N, 9740.504' E, $31 \mathrm{~m}$ a.s.1., 14 Oct. 2009, K. Ohara, K. Okubo and J.U. Otani leg. (coll. PGB); 1 specimen (shell + anatomically examined body), same data as for preceding (NHMUK 20170152); 6 shells, Kayin, West foot of Zwegabin Mt., $16^{\circ} 49.552^{\prime}$ N, 97 $40.603^{\prime}$ E, 24 m a.s.l., 14 Oct. 2009, K. Ohara, K. Okubo and J.U. Otani leg. (coll. PGB, ex coll. K. Ohara); 2 shells, Kayin, Pha-an, east foot of Mt. Zwegabin, loc. 20091014C, $16^{\circ} 48.783^{\prime}$ N, $97^{\circ} 40.395^{\prime}$ E, 14 Oct. 2009, K. Ohara, K. Okubo and J.U. Otani leg. (coll. PGB, ex coll. K. Okubo); 1 shell (protoconch examined by SEM), same data as for preceding (coll. PGB); 4 shells, same data as for preceding (coll. PGB, ex coll. K. Ohara); 1 shell, Kayin, [rubber plantation] Pha-an, opposite side of point C, $16^{\circ} 48.693^{\prime}$ N, 97 39.809' E, 32 m a.s.1., 14 Oct. 2009, K. Ohara, K. Okubo and J.U. Otani leg. (coll. PGB, ex coll. J.U. Otani); 1 shell, Pha An, Bayin Nyi Cave, ca $16^{\circ} 58.225^{\prime}$ N, 97²9.614' E, 13. Oct. 2009, K. Ohara, K. Okubo and J.U. Otani leg. (coll. PGB, ex coll. K. Okubo); 1 shell, Kayin, Sadsar [Saddan] Cave, Pha-an, $16^{\circ} 44.414^{\prime}$ N, 97 43.114' E, 50 m a.s.1., 14. Oct. 2009, K. Ohara, K. Okubo and J.U. Otani leg. (coll. PGB, ex coll. K. Okubo).

SRI LANKA: 1 shell, Tinter [probably Linter] leg. (HNHM 62599); 2 shells, Ceylon, coll. Kovács, Gy. (HNHM 67067); 4 shells, Ceylon, ex coll. Oberwimmer (NHMS 122190-122193); 3 shells, Ceylon(?), coll. Krüper ex Oberwimmer (SMF 102809); 1 shell, Ceylon, Colombo, coll. Jetschin ex Oberwimmer (SMF 102810); 2 shells, Ceylon, coll. Bosch, ex Rolle (SMF 172058); 1 shell, Ceylon, coll. Jetschin ex Oberwimmer (SMF 102812).

LOCALITY UNKNOWN: 2 shells (SMF 150087); 2 shells (labelled as anguina) (NHMUK).

\section{Description}

SHELl. Sinistral, flat, but protoconch usually protrudes above dorsal surface; colour variable, from yellowish to blue and flesh-coloured/reddish (usual); shells usually not monochrome, but with lighter stripes of variable thickness; ventral shell surface usually much lighter than dorsal side; protoconch large, consists of 3.25-3.75 whorls, very finely, irregularly wrinkled; ca first whorl of teleoconch with reticulated sculpture; following ca 1.5 whorls rather glossy, with rough, irregular wrinkles; body whorl rounded or slightly, bluntly keeled, above and below shouldered; aperture oblique, oval; peristome strongly expanded and reflected; parietal callus strongly developed, blunt, slightly S-shaped; apertural fold usually strong, connected to parietal callus; umbilicus wide, without periumbilical keel.

Four opened shells were examined. Lambda-complex complete; upper branch does not extend beyond left leg; right leg long or very long; main plica connected to lambda-complex, continuous with apertural fold; lower plica starts below lambda-complex and runs until peristome, or in some populations stops in the middle. Palatal plicae six; first relatively short, situated close to suture; second strongly elongated anteriorly, with a dichotomous posterior end; third shorter, its posterior end descends in direction of lower suture; fourth and fifth form a vertical plate, with one or two additional denticles on posterior side, near its lower end; sixth short, curved.

MeAsurements (in mm). D = 17.7-31.3, $\mathrm{H}=7-9.1$ (smallest and largest specimens found in the NHM); $\mathrm{D}=26.2-28.8, \mathrm{H}=8.6-9.1$ (repercussa, NHMUK paralectotypes); $\mathrm{D}=23.8, \mathrm{H}=8.1$ (holotype of achatina var. castanea); $\mathrm{D}=17.7, \mathrm{H}=7$ (holotype of achatina var. venusta); $\mathrm{D}=27.3, \mathrm{H}=8.8$ (holotype of achatina var. repercussoides); $\mathrm{D}=21.8, \mathrm{H}=8.6$ (holotype of achatina var. infrafasciata); $\mathrm{D}=19.3$, $\mathrm{H}=7.5$ (holotype of achatina var. obesa). Stoliczka (1871) mentioned that the largest shell was $35 \mathrm{~mm}$ in width.

Characters of the genital structure. Two specimens were anatomically examined (NHMUK 20170152). 


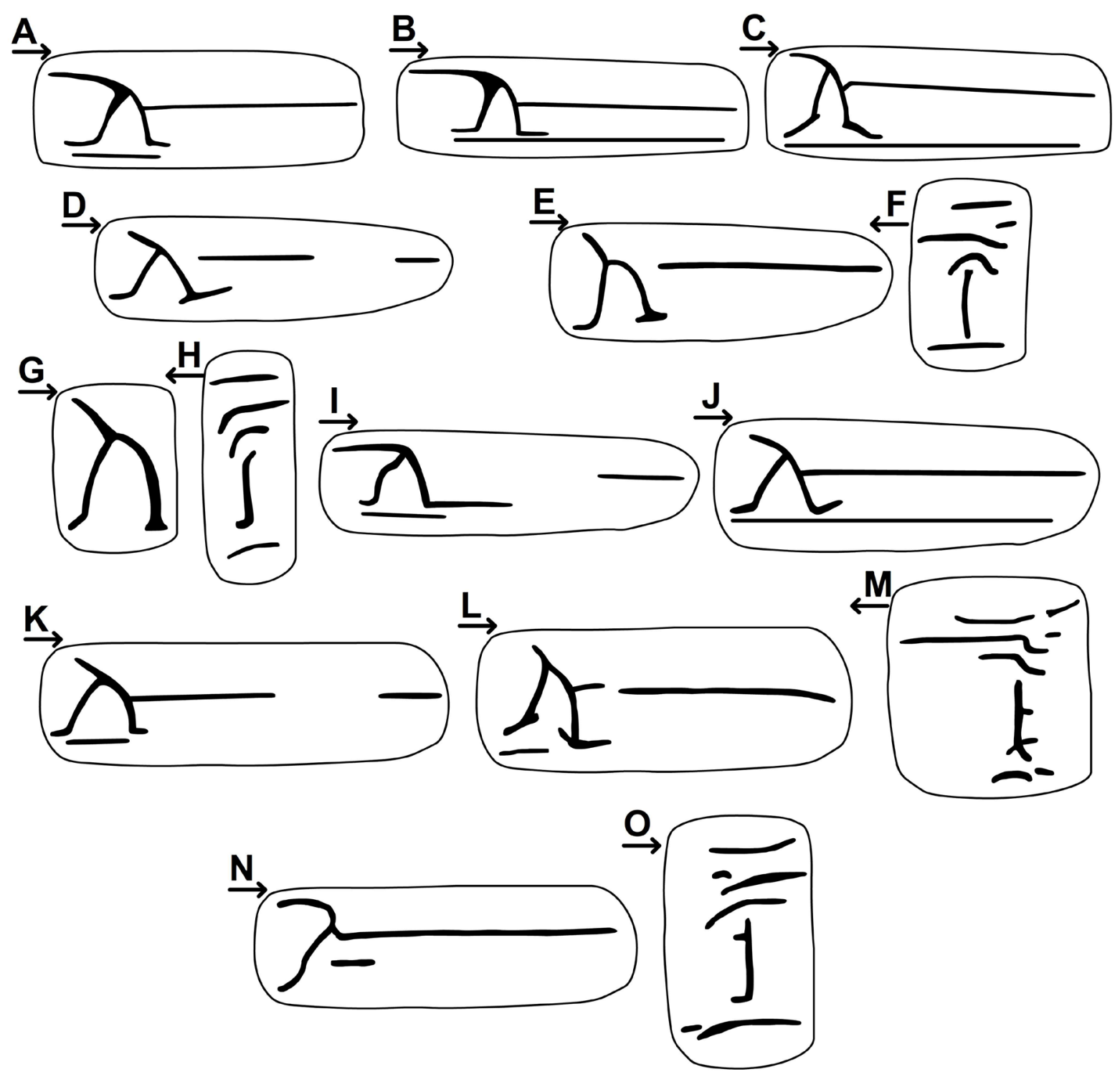

Fig. 35. Parietal (A-E, G, I-L, N) and palatal (F, H, M, O) plication of species of Plectopylis Benson, 1860. A. P. anguina Gould, 1847, paralectotype (NHMUK 20140812). B. P. repercussa Gould, 1856, lectotype (MCZ 169336). C. P. bensoni var. repercussoides Gude, 1899, holotype (NHMUK 1922.8.29.46). D. P. cairnsi Gude, 1898, holotype (NHMUK 1922.8.29.47). E-F. P. cairnsi (UF 76761). G-H. P. crassilabris sp. nov., paratype (UF 448577). I. P. cyclaspis Benson, 1859 (NHMUK 1906.02.02.148). J. P. karenorum (W. Blanford, 1865) from "Pegu", Myanmar (NHMUK). K. P. linterae var. fusca Gude, 1898 (NHMUK 1888.12.04.1541-3). L-M. P. malayana sp. nov., paratypes from the type locality (coll PGB). N-O. P. thompsoni sp. nov., paratype (UF 448578). Arrows below the letters indicate the direction of the aperture. Not to scale. 


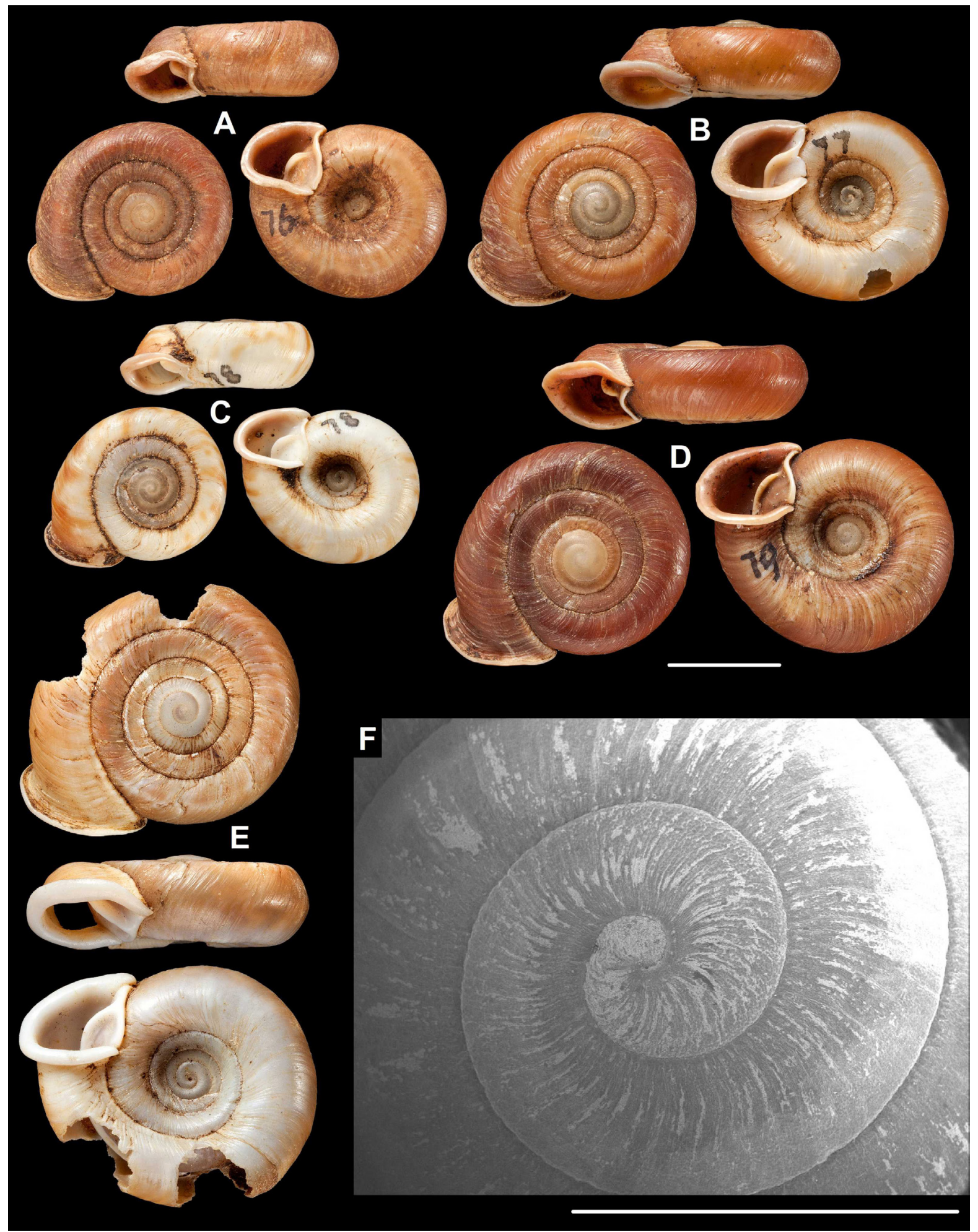

Fig. 36. Shells of Plectopylis bensoni Gude, 1914. A. Holotype of var. obesa Gude, 1898 (NHMUK 1922.8.29.42). B. Holotype of var. infrafasciata Gude, 1898 (NHMUK 1922.8.29.43). C. Holotype of var. venusta Gude, 1898 (NHMUK 1922.8.29.44). D. Holotype of var. castanea Gude, 1898 (NHMUK 1922.8.29.45). E. Holotype of var. repercussoides Gude, 1899 (NHMUK 1922.8.29.46). F. Protoconch of Plectopylis bensoni, loc. 20091014C (coll. PGB). Scale bars: A-E (upper scale) $=10 \mathrm{~mm}$; F (lower scale) $=2 \mathrm{~mm}$. Images: H. Taylor (A-E) and B. Páll-Gergely (F). 
Left ommatophoral retractor crosses penis and vagina; atrium very short; penis with a longer, cylindrical proximal, and a shorter, also cylindrical but slightly thicker distal portion; penis internally with approx. 10 longitudinal, serrate folds without calcareous granules; epiphallus slightly shorter than distal part of penis; internally with 4-5 strong, longitudinal folds; distal part of penis and epiphallus bound together with weak muscle fibres; a short, blunt penial caecum discernible; retractor muscle slender, flat, and inserts on penial caecum; vas deferens slender, even near its insertion to pedunculus; it is bound to distal part of penis and vagina by weak membrane; vagina approximately as long as penis, flattened at its curving point (this is the point where vaginal bulb is developed in some specimens), otherwise rather cylindrical; uterus with three large, elongated embryos in one specimen; diverticulum triangular, robust, short, bursa copulatrix with very long, slender stalk, bursa elongate oval; a long, club-like, easily weathering spermatophore was found in bursa; slender end of spermatophore curly; whole surface of spermatophore finely wrinkled; spermatophore internally not structured.

Radula. Centrals with small, triangular cusps; endocones of laterals wide ovoid with pointed tips; ectocones of first laterals much larger than centrals; ectocones of marginals undivided, endocones of marginals mostly undivided or divided by shallow incision. See also under radula of Plectopylis cyclaspis.

\section{Differential diagnosis}

See under $P$. anguina, $P$. cairnsi and $P$. linterae.
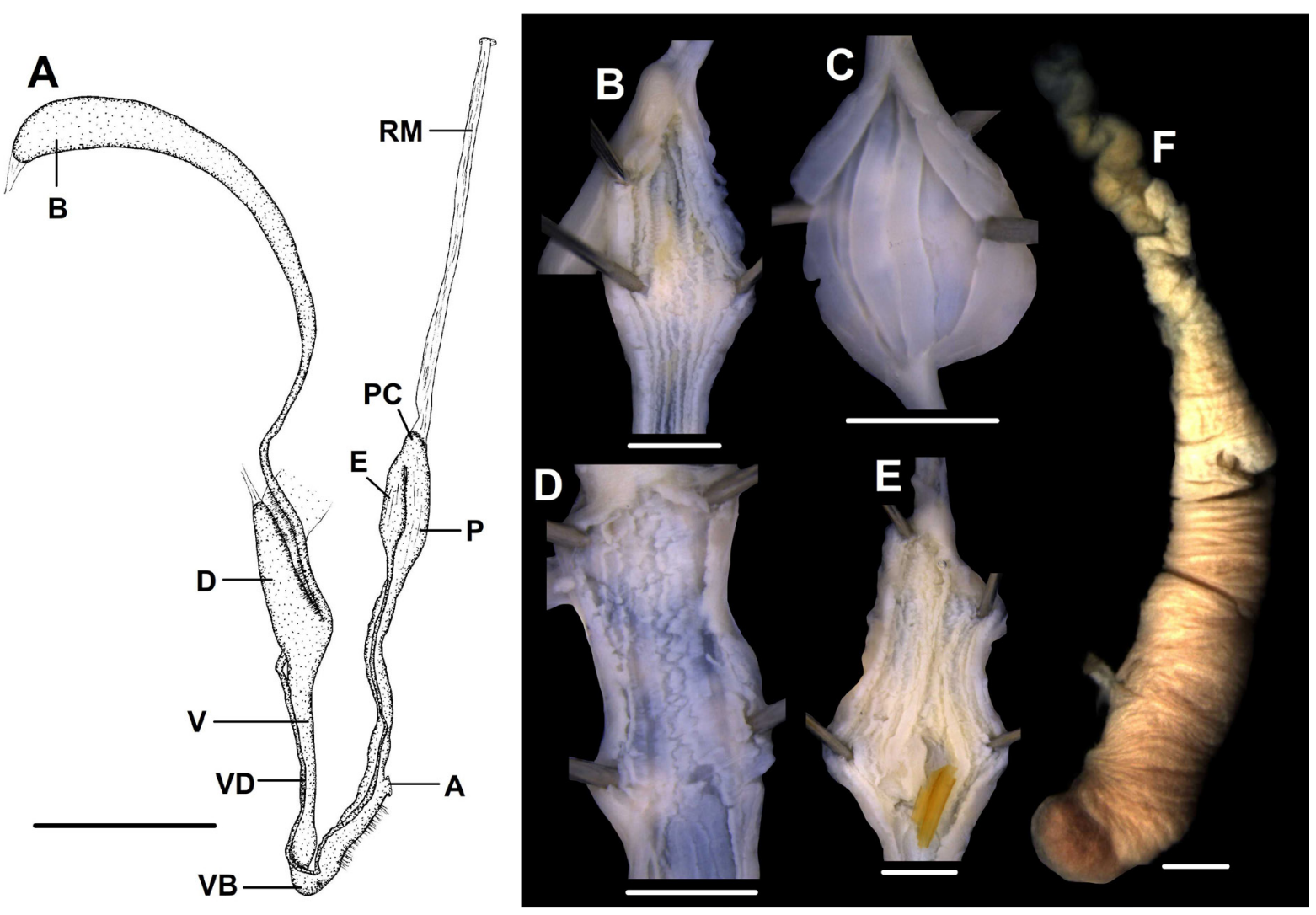

Fig. 37. Genitalia of Plectopylis bensoni Gude, 1914(NHMUK 20170152). A. Distal genitalia. B-E. Inner structure of genital organs $(\mathrm{B}=$ penis, $\mathrm{C}=$ epiphallus, $\mathrm{D}=$ vagina, $\mathrm{E}=$ diverticulum $)$. F. Spermatophore found in the bursa copulatrix. A and $\mathrm{F}$ show one specimen, whereas B-E show another specimen. Scales bars: A $=5 \mathrm{~mm}$; B-F $=1 \mathrm{~mm}$. For abbreviations see Fig. 2. All photos: B. Páll-Gergely. 


\section{Distribution}

The species has been reported from several southern localities in Myanmar. Georeferenced sites are known from the limestone hills of the Kayin and Mon States. Although many historical samples are recorded as from from Sri Lanka or Ceylon, these probably all represent erroneous localities on the labels (see also Fig. 12), because no plectopylid has been found in Sri Lanka recently (D. Raheem, pers. comm., 2017 January), and this distribution type is highly unlikely from a biogeographical point of view.

\section{Remarks}

Plectopylis achatina was described by L. Pfeiffer (1845) as "Helix achatina Gray". However, Gray never described this taxon, so the author should be considered as Pfeiffer. For a long time this species was called Plectopylis achatina Pfeiffer, 1845. That name, however, was already occupied by Helix achatina Gmelin, 1791 (see Gmelin 1791). Therefore, Gude proposed the replacement name Plectopylis bensoni.

The only remarkable difference between Plectopylis repercussa and P. bensoni is the strongly elongated upper branch of the lambda-complex in $P$. repercussa, which differs from the shorter upper branch of $P$. bensoni. This, however, does not allow the distinction of the two species, which otherwise do not differ in general shell shape. Moreover, $P$. bensoni var. repercussoides is described as an "intermediate between typical $P$. bensoni and $P$. repercussa" (Gude 1914b). I therefore treat $P$. repercussa as a synonym of $P$. bensoni.

One sample ("Attaram-Tal”, coll. Möllendorff, SMF 150092) had three shells with a somewhat elevated spire and a slightly keeled body whorl (similar to that of Plectopylis anguina). This sample might be a locally isolated form with peculiar shell characters.

Plectopylis cairnsi Gude, 1898

Figs 34B-C, 35D-F, 38C-D, 39

Plectopylis cairnsi Gude 1898g: 171. fig. 90 a-g ["possibly Burma"].

Plectopylis (Plectopylis) cairnsi - Gude 1899d: 148; 1899e: 175; 1914b: 129-130, fig. 64a-g.

Plectopylis achatina - Boonngam et al. 2008: 259, fig. 2.

\section{Diagnosis}

A large, sinistral species with an apertural fold that is not in contact with the lambda-complex.

\section{Material examined}

Holotype

MYANMAR: 1 shell, holotype, Burma? (NHMUK 1922.8.29.47).

\section{Additional material}

THAILAND: 14 shells, Krabi Province, Limestone Ridge on E side of Highway 4.9 km NW of Krabi, $8^{\circ} 11^{\prime} \mathrm{N}, 98^{\circ} 51^{\prime} \mathrm{E}, 40 \mathrm{~m}$ a.s.1., 25 Sept. 1985, F.G. Thompson leg. (UF 76744); 3 shells, same data as for preceding (HNHM 97479); 16 specimens (preserved in ethanol), same data as for preceding (UF 76457); 7 shells, Krabi Province, S side of Limestone Ridge, $6.4 \mathrm{~km}$ ENE of Ban Chong Phli, 805' N, 98 $51^{\circ}{ }^{\prime} \mathrm{E}$, 26 Sep. 1985, F.G. Thompson leg. (UF 76787); 197 shells, Krabi Province, Limestone Ridge 6 km Ne, $2.5 \mathrm{~km} \mathrm{~N}$ of Krabi, $8^{\circ} 07^{\prime} \mathrm{N}, 98^{\circ} 56^{\prime} \mathrm{E}, 100 \mathrm{~m}$ a.s.1., 26 Sep. 1985, F.G. Thompson leg. (UF 76761); 20 specimens (preserved in ethanol: two of them, PL011 and PL012, used for molecular study) (UF 76467); 6 shells (mixed sample with P. thompsoni sp. nov.), Krabi Province, $10 \mathrm{~km}$ NE of Ao Luk, 8²9' N, 

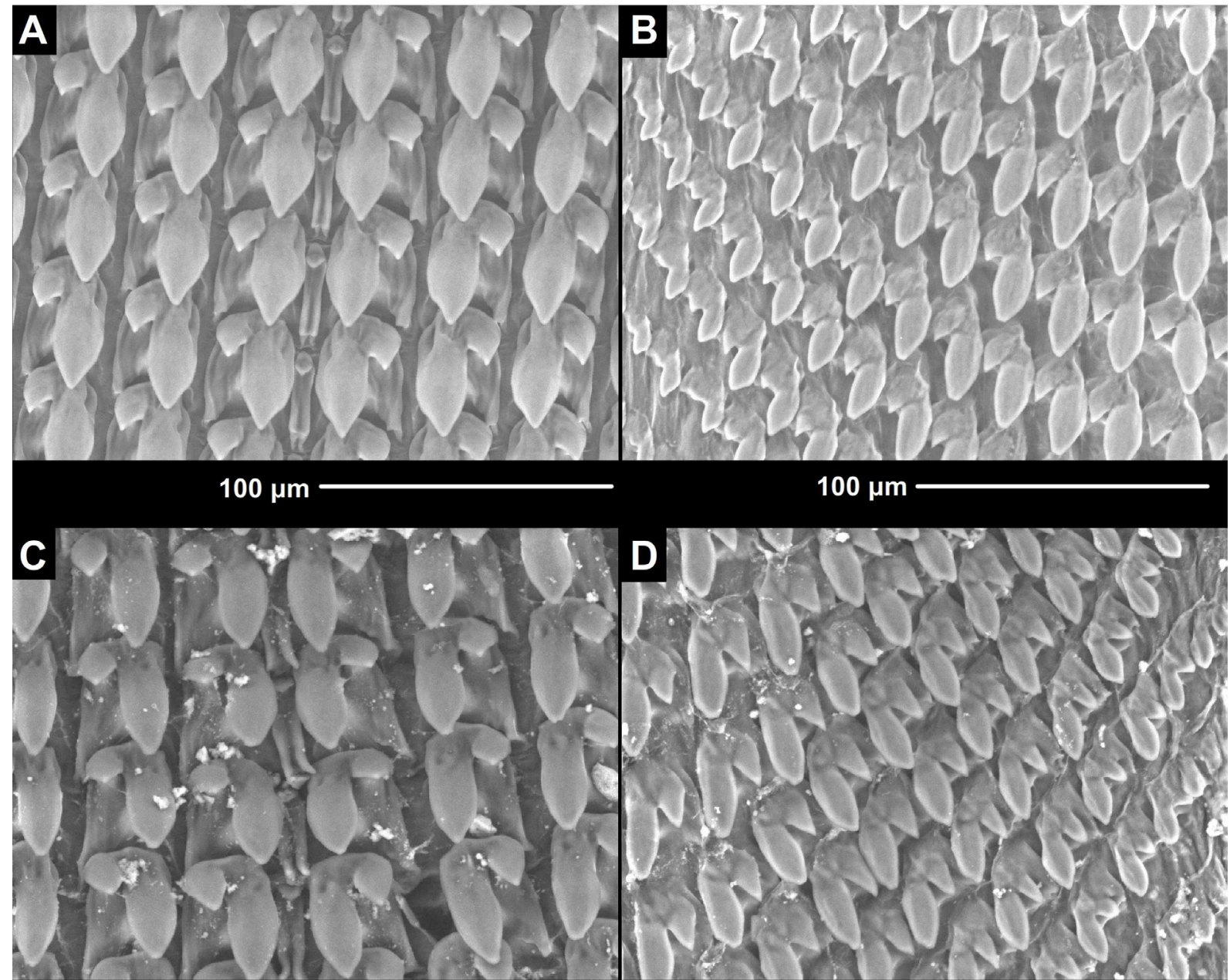

\section{$100 \mu \mathrm{m}$}

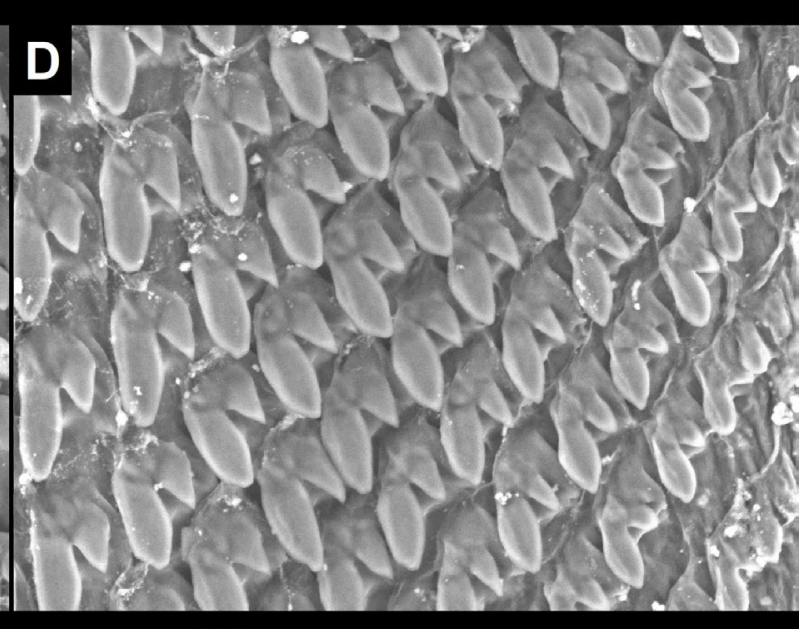

$100 \mu \mathrm{m}$

$100 \mu \mathrm{m}$

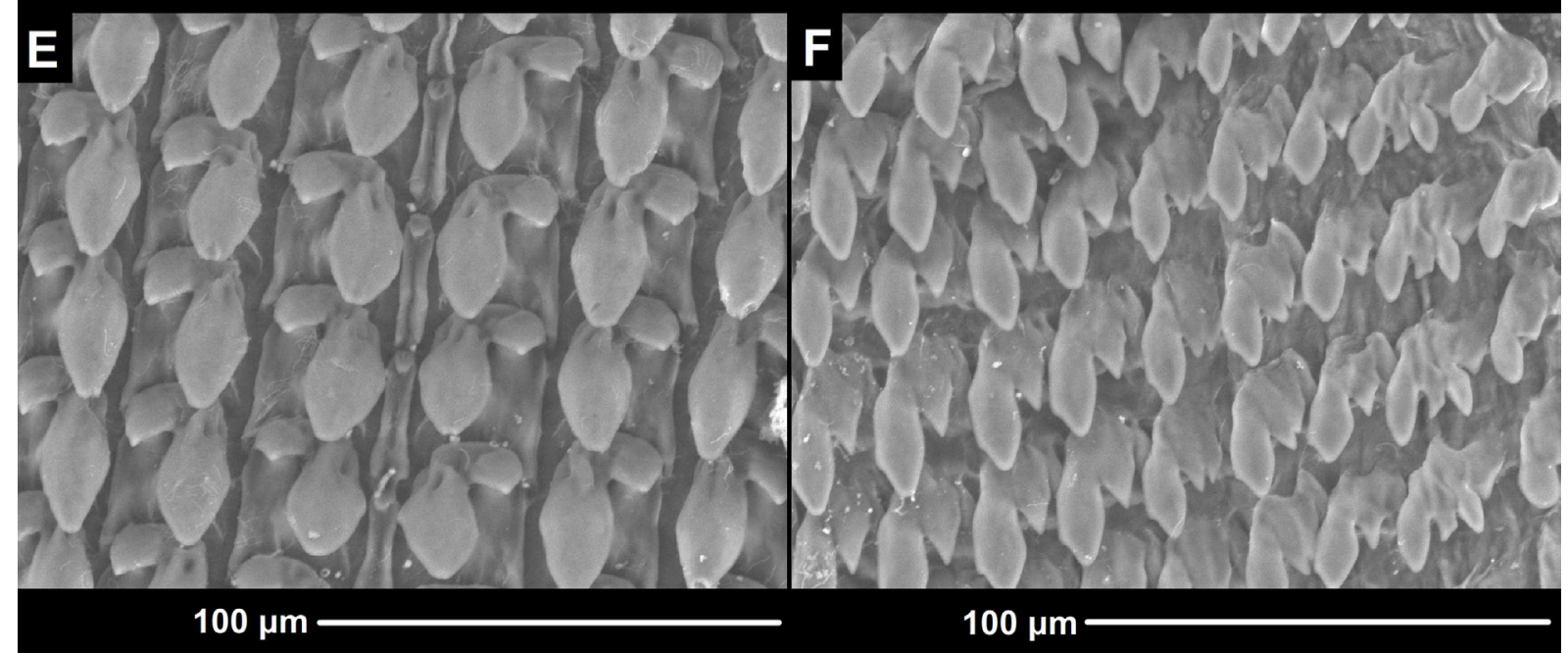

Fig. 38. Radula of species of Plectopylis Benson, 1860. A, C and E show central and first lateral teeth; B, D and F show marginal teeth. A-B. P. bensoni Gude, 1914. C-D. P. cairnsi Gude, 1898 (UF 76467). E-F. P. crassilabris sp. nov. (UF 343899). All images: B. Páll-Gergely. 
9849’ E, 30 Sep. 1985, F.G. Thompson leg. (UF 77252); 2 specimens (preserved in ethanol: PL015 and PL016 used for molecular study), same data as for preceding (UF 77252); 2 shells, Krabi Province, limestone knoll on the $\mathrm{W}$ side of Highway 401, $2.2 \mathrm{~km} \mathrm{~N}$ of Ban Ao Luk Nua, 8²5' N, 98 $44^{\prime}$ E, 25 Sep. 1985, F.G. Thompson leg. (UF 76723); 3 shells, Krabi Province, Wat Tham Sua, Nation Valley, Mar. 2000, J. and Ch. Hemmen leg. (coll. PGB); 3 shells, Krabi Province, ca $2.5 \mathrm{~km} \mathrm{~W}$ of Nong Khon, road nr 4033 (NW of Krabi), Oct. 1999, J. and Ch. Hemmen leg. (HNHM 97480); 12 shells, same data as for preceding (coll. PGB); 3 shells, Krabi Province, ca $0.3 \mathrm{~km}$ SE of Bau Chong Phili (NW of Krabi), Oct. 1999, J. and Ch. Hemmen leg. (coll. PGB); 5 shells, Krabi Province, off Km 117.6, road \# 4 (Phang Nga-Krabi), $1.5 \mathrm{~km}$ on unpaved road, $8^{\circ} 09.574^{\prime} \mathrm{N}, 98^{\circ} 51.761^{\prime}$ E, Sep. 2000, J. and Ch. Hemmen leg. (coll. PGB); 5 shells, Krabi Province, Khao Phung Cave Forest Park (ca 20 km N of Krabi), 3 Mar. 2000, J. and Ch. Hemmen leg. (coll. PGB); 2 shells, Krabi Province, left side off Km 23, \# no. 4, Phang NgaKrabi, Mar. 2000, J. and Ch. Hemmen leg.(coll. PGB); 10 shells, Krabi Province, WNW of Amphoe Khao Phanom (from rd \# 4037 to rd \# 4) limestone hill at left side, $8^{\circ} 22.711^{\prime}$ N, 98 $96.183^{\prime}$ E, J. and Ch. Hemmen leg. (coll. PGB); 6 shells, Krabi Province, ca 6 km N of Ban Nai Sa (NW of Krabi), Mar. 2000, J. and Ch. Hemmen leg. (coll. PGB); 3 shells, Krabi Province, Kao Klom, (NW of Krabi), Oct. 1999, J. and Ch. Hemmen leg. (coll. PGB); 2 shells, Krabi Province, canyon ca $1.3 \mathrm{~km} \mathrm{~W}$ of road \# 4, direction to old town of Ao Luk (Krabi to Phang Nga), $8^{\circ} 22.382^{\prime}$ N, $98^{\circ} 44.043^{\prime}$ E, J. and Ch. Hemmen leg. (coll. PGB); 6 shells, Krabi Province, limestone hill, left side off Km 112 road \# 4 (Krabi-Phang Nga), $8^{\circ} 05.758^{\prime}$ N, 98 $52.106^{\prime}$ E, 22 Oct. 2000, J. and Ch. Hemmen leg. (coll. PGB); 7 shells, Krabi Province, Wat Tham Sua, Nation Valley (near Krabi), $8^{\circ} 07.691^{\prime}$ N, $98^{\circ} 55.678^{\prime}$ E, Oct. 2000, J. and Ch.
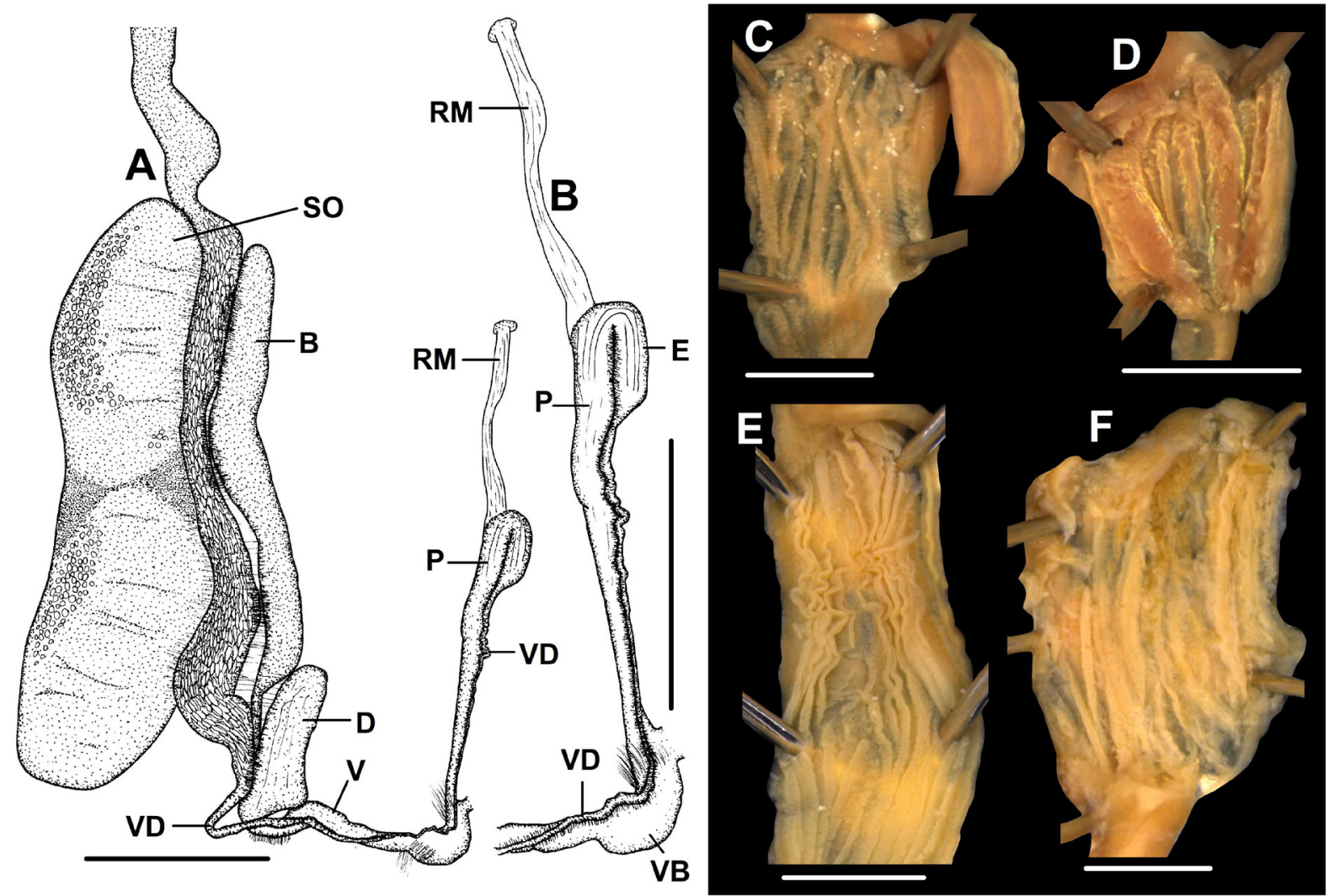

Fig. 39. Genitalia of Plectopylis cairnsi Gude, 1898, PL012 (UF 76467). A. Distal genitalia. B. Male genitalia (penis, epiphallus, vas deferens). $\mathbf{C}-\mathbf{F}$. Inner structure of genital organs $(\mathrm{C}=$ penis, $\mathrm{D}=$ epiphallus, $\mathrm{E}=$ vagina, $\mathrm{F}=$ diverticulum). Scale bars: $\mathrm{A}-\mathrm{B}=5 \mathrm{~mm} ; \mathrm{C}-\mathrm{F}=1 \mathrm{~mm}$. For abbreviations see Fig. 2. All photos: B. Páll-Gergely. 
Hemmen leg. (coll. PGB); 7 shells, Krabi Province, North of Krabi, Tiger Cave Temple, Wort Tham Sena, $8^{\circ} 07^{\prime} 36.15^{\prime \prime}$ N, 98 55'26.65" E, Sep. 2007, A. Reischütz leg. (coll. REI); 1 shell, 1 damaged shell, (coll. PGB); 2 shells, Tiger Cave, Krabi (coll. PGB) (ex coll. K. Okubo); 9 shells, 4 tissue samples, 4 specimens in ethanol, Phangnga, Ao Nang, $\mathrm{N}$ side of cliff, $8^{\circ} 1.93^{\prime} \mathrm{N}, 98^{\circ} 50.28^{\prime} \mathrm{E}, 70 \mathrm{~m}$ a.s.1., $26 \mathrm{Jul}$. 2010, B. Hausdorf leg. (ZMH 51951); 4 shells, 2 tissue samples, 3 specimens in ethanol, Krabi, Ban Chong Mai Kaeow, $\mathrm{N}$ of Ao Luek Nuea, calcareous rocks, $8^{\circ} 24.87^{\prime} \mathrm{N}, 98^{\circ} 44.22^{\prime}$ E, $60 \mathrm{~m}$ a.s.1., $31 \mathrm{Jul}$. 2010, B. Hausdorf leg. (ZMH 51964); 1 shell, Krabi, Phanom Benja National Park, Huai To waterfall and surrounding forest, $8^{\circ} 14.35^{\prime} \mathrm{N}, 98^{\circ} 54.87^{\prime} \mathrm{E}, 120 \mathrm{~m}$ a.s.1., 28 Jul. 2010, B. Hausdorf leg. (ZMH 51992); 3 shells, Krabi, Thap Prik, calcareous rocks N of, $8^{\circ} 10.75^{\prime}$ N, $98^{\circ} 52.45^{\prime}$ E, 60 m a.s.1., 28 Jul. 2010, B. Hausdorf leg. (ZMH 79010); 3 shells, Southern Thailand, Andaman Sea side, Krabi Province, Phnom Mountain, donated by Mr Somnuek Patamakanthin and Mr Samwang Patamakanthin, 31 Jul. 2006 (NHMUK 2006.03.29).

\section{Description}

SHELL. Sinistral, almost flat, spire only slightly elevated; whorls 5.5; basal colour yellowish to greyish, dorsal surface with brownish-red and paler stripes; protoconch consists of 2.5-2.75 whorls, extremely finely granular with fine, irregular growth wrinkles; teleoconch very finely, regularly ribbed and decussated with fine spiral lines; sculpture less prominent on ventral side; peristome thickened and slightly reflected, with a rather weak, blunt parietal callus; apertural fold continuous with main plica, usually free from parietal callus (or reaches with a thinner projection).

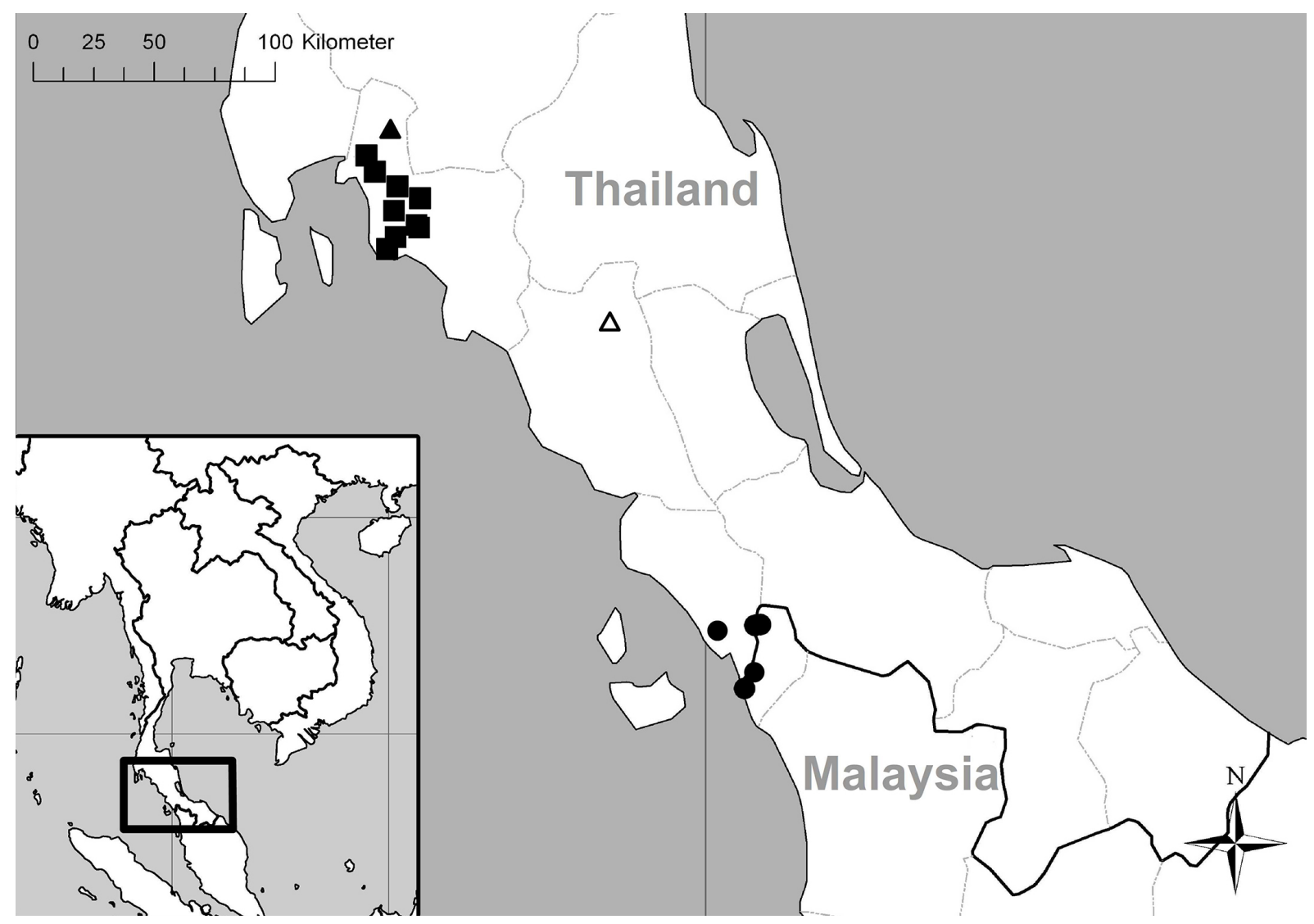

Fig. 40. Distribution of species of Plectopylis Benson, 1860 in Southern Thailand and northern Malaysia. Legends: empty triangle $=P$. thompsoni sp. nov.; square $=P$. cairnsi Gude, 1898; filled triangle $=$ sympatric locality of $P$. thompsoni sp. nov. and $P$. cairnsi; circle $=$ P. malayana sp. nov. 
Lambda-complex complete; upper branch and left leg elongated; main plica free from lambda-complex; short horizontal plica may be present under lambda-complex. Palatal wall typical of Plectopylis.

Measurements (in mm). $\mathrm{D}=18.9, \mathrm{H}=6.5$ (holotype); $\mathrm{D}=18.4-21.1, \mathrm{H}=6.3-7.4(\mathrm{n}=3$, shells from Thailand).

Characters of the genital system. One specimen from sample UF 76467 was examined. Left ommatophoral retractor runs between penis and vagina; penis relatively long, internally with parallel, serrate folds and tiny calcareous crystals; epiphallus and vas deferens attached to penis with weak muscle fibres; no penial caecum observed; epiphallus internally with three main, and some minor longitudinal folds; retractor muscle thick and inserts on proximal part of penis; vagina approx. half of length of penis, and of comparable diameter; bursa copulatrix with a very short, slender stalk, and a very long, elongate, thick bursa; diverticulum ovate, slightly shorter than stalk of bursa copulatrix; diverticulum contained a spermatophore, which is long, fragile, reddish brown tube folded multiple times, forming an ovate mass having pointed ends.

RADULA. Centrals with small, triangular cusps; endocones of laterals ovoid with pointed tip; ectocones of first laterals much larger than centrals; ectocones of marginals undivided, endocones of marginals mostly undivided.

\section{Differential diagnosis}

Plectopylis thompsoni sp. nov. is larger and flatter, the right leg of its lambda-complex is absent, and the main plica is connected to the lambda-complex. Plectopylis bensoni is usually larger, has a shouldered body whorl (more rounded in cairnsi), and the main plica is connected to the lambda-complex (not connected in cairnsi). For the differences with P. malayana sp. nov., see under that species.

\section{Distribution}

This species is known from Krabi Province in Thailand only. In one of the localities, Plectopylis cairnsi co-occurs with $P$. thompsoni sp. nov. (Fig. 40).

\section{Remarks}

Most examined shells had the main plica and the apertural fold connected. In contrast, they are free from each other in the holotype of $P$. cairnsi. Furthermore, the main plica reaches the parietal callus in the holotype and only in the minority of the Thai shells. In view of these differences, which I consider minor, I do not find it necessary to treat the Thai populations as a distinct taxon.

\section{Plectopylis crassilabris sp. nov. urn:1sid:zoobank.org:act:4CA2A554-40F3-4F82-91E2-A83C03DBD696}

Figs $35 \mathrm{G}-\mathrm{H}, 38 \mathrm{E}-\mathrm{F}, 41 \mathrm{~A}-\mathrm{D}, 42$

\section{Diagnosis}

A large, sinistral species with few (5.25-5.5) whorls, narrow umbilicus and conspicuously thickened peristome; apertural fold short, main plica absent.

\section{Etymology}

The name of the new species is derived from its conspicuously thickened lip, from the latin 'crassus', meaning 'strong' and 'labris', meaning 'lip'. 


\section{Material examined}

\section{Holotype}

THAILAND: 1 shell $(\mathrm{D}=22.5 \mathrm{~mm})$, Chon Buri Province, Khao Cha Ang, ca $17 \mathrm{~km} \mathrm{ESE} / 4 \mathrm{~km} \mathrm{~S}$ of Om Phanom, 13¹0'57" N, 101³5'16" E, 150 m a.s.1., 26 Apr. 1987, F.G. Thompson leg. (UF 279203).

\section{Paratypes}

THAILAND: 89 shells, same data as for holotype (UF 448577); 15 specimens (preserved in ethanol: PL006 used for molecular study), same data as for holotype (UF 279204); 2 shells, same data as for holotype (HNHM 97461); 53 shells, on the border of Rayong and Chantaburi Provinces, Khao Wangse, $13 \mathrm{~km}$ N of Ban Na Yai Aun, 1253'13" N, 101²9'2" E, 100 m a.s.1., 12 May 1987, F.G. Thompson leg. (UF 346377); 2 shells, same data as for preceding (HNHM 97475); 16 specimens (preserved in ethanol: PL088 and PL089 used for molecular study), same data as for preceding (UF 343899); 93 shells, Chachoengsao Province, Khao Tham Raet, $5 \mathrm{~km}$ ENE of Ban Non Khok, $13^{\circ} 26^{\prime} 6^{\prime \prime} \mathrm{N}, 101^{\circ} 44^{\prime} 10^{\prime \prime} \mathrm{E}, 100 \mathrm{~m}$ a.s.l., 11 May 1987, F.G. Thompson leg. (UF 346364); 5 shells, same data as for preceding (UF 346374); 3 shells, same data as for preceding (HNHM 97462); 10 specimens (preserved in ethanol: PL074 and PL075 used for molecular study), same data as for preceding (UF 376790); 5 shells, Eastern Thailand, Rayong Province, Khaochamao District, Wat Khao Pratun, 13.124312 ${ }^{\circ}$ N, 101.596876 E, 15 Jun. 2007, P. Dumrongrojwattana leg. (coll. PGB); 1 shell, same data as for preceding (SMF 349028); 1 paratype, same data as for preceding (NHMB 551276); 6 shells, eastern Thailand, Chonburi Province, Bathong District, Kangkhaw Cave, 13.199314 N 101.579334º E, 22 Aug. 2008, P. Dumrongrojwattana leg. (coll. PGB); 12 shells, eastern Thailand, Chantaburi Province, Kanghangmaen District, Khaowongkot, $12.883881^{\circ} \mathrm{N}, 101.818037^{\circ}$ E, 13 Jun. 2007, P. Dumrongrojwattana leg. (coll. PGB); 2 shells, eastern Thailand, Chantaburi Province, Kanghaenhmaew District, Khaowonggot Temple, 13 Jan. 2009 (coll. HGL 0000728385).

\section{Additional material}

THAILAND: 4 juv. shells, same data as for holotype (UF 448577); 1 juv. shell, Chom Buri Province,

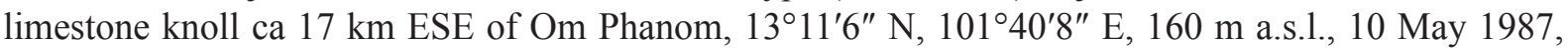
F.G. Thompson leg. (UF 346464); 3 juv. shells, on the border of Rayong and Chantaburi Provinces,

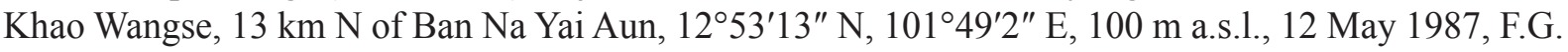
Thompson leg. (UF 346377); 19 juv. shells, Chachoengsao Province, Khao Tham Raet, 5 km ENE of Ban Non Khok, 1326 $6^{\prime} 6^{\prime \prime}$ N, 101 ${ }^{\circ} 44^{\prime} 10^{\prime \prime}$ E, 100 m a.s.1., 11 May 1987, F.G. Thompson leg. (UF 346364).

\section{Description}

SHeLl. Sinistral, strongly built, brownish corneous (most examined shells were heavily weathered); ventral side with reddish and paler mosaic-like structure; protoconch with fine wrinkles, teleoconch with very fine, irregular growth lines and weak spiral structure; whorls 5.25-5.5; umbilicus conspicuously narrow; peristome strongly thickened and slightly reflected with a parietal callus of the same thickness; apertural fold short, in contact with parietal callus.

Five shells were opened. Lambda-complex complete; upper branch long, main plica absent. Palatal plicae typical of Plectopylis.

Measurements (in mm). $\mathrm{D}=17.3-20.1, \mathrm{H}=6.6-8.0$ (UF 346364, $\mathrm{n}=4$ ); $\mathrm{D}=20.4-23.7, \mathrm{H}=7.7-8.7$ (UF 448577, $\mathrm{n}=4$ ).

Characters of the Genital system. Two specimens were examined (one from sample UF 279204, one from UF 343899). Left ommatophoral retractor runs between penis and vagina; penis relatively long, proximally sculptured with parallel, longitudinal, serrate folds, distally sculptured with transverse folds; calcareous crystals were found in penis lumen; epiphallus and vas deferens attached to penis with weak 
muscle fibres; no penial caecum observed; retractor muscle thick, inserted on penis proximally; vagina slightly shorter and thicker than penis, internally with parallel wrinkled folds and calcareous crystals; bursa copulatrix with a short, relatively slender stalk and an elongate ovate bursa; diverticulum ovate, approx. as long as stalk of bursa copulatrix; diverticulum of specimen from sample UF 343899 contained a spermatophore, which is a long, fragile, reddish brown thread-like tube folded multiple times, forming an ovate mass with pointed ends.

RADULA. Centrals with small, triangular cusps; endocones of laterals rhomboid or ovoid with pointed tip; ectocones of first laterals much larger than centrals; ectocones of marginals undivided, endocones of marginals divided by shallow incision.

\section{Differential diagnosis}

Plectopylis crassilabris sp. nov. is easily distinguished from its relatives by the narrow umbilicus, thickened peristome and the absence of a long plica on the parietal wall. The most similar species in terms of shell characters is $P$. linterae; for comparisons see under that species.

\section{Distribution}

The species is known from southern Thailand (Chon Buri, Rayong and Chachoengsao Provinces) (Fig. 12).

\section{Remarks}

The specimens from Chachoengsao Province (UF 346364) are smaller and have a much thicker peristome than the individuals from the other two provinces. The traits of the genital anatomy (absence of penial caecum, short, ovoid diverticulum) suggest that the closest related species to Plectopylis crassilabris sp. nov. is $P$. cairnsi.

\section{Plectopylis cyclaspis (Benson, 1859)}

Figs 35I, 41E

Helix catinus Benson, 1859a: 185 [“prope Moulmein, provinciæ Tenasserim"].

Helix cyclaspis Benson, 1859b: 273 (nom. nov. pro Helix catinus Benson, 1859, non Helix catinus Pfeiffer, 1857: 64).

Helix revoluta Pfeiffer, 1867: 64 [“in insulis Andamanicis”].

Helix (Plectopylis) cyclaspis - Benson 1860: 245-246 ["Farm Caves near Moulmein"]. - Hanley \&

Theobald 1870: 7, pl. 13, fig. 10. — Godwin-Austen 1875b: 613, pl. 74, fig. 10. — Nevill 1878: 72.

— Tryon 1887: 164-165, pl. 35, fig. 9.

Plectopylis cyclaspis - Stoliczka 1871: 222-223, pl. 15, figs 4-6. — Gude 1897b: 244, fig. 34a-d.

Plectopylis (Plectopylis) cyclaspis - Gude 1899d: 148; 1899e: 175; 1914b: 130-132, fig. 65a-d; 1920:

63.

\section{Diagnosis}

A medium-sized, sinistral species with brownish purple shell and very conspicuous, sharp keel.

\section{Type material}

Benson (1859a) wrote the following in the original description of Helix catinus: "The single specimen transmitted for examination is in such a corroded state, that the true nature of the sculpture can merely be guessed at." In the type collection of the NHM there are three shells having an intact sculpture with the following data: Damalthat, NHMUK 1898.12.04.1520-22, 3 syntypes. These three shells surely do not represent type specimens of $P$. cyclaspis. 


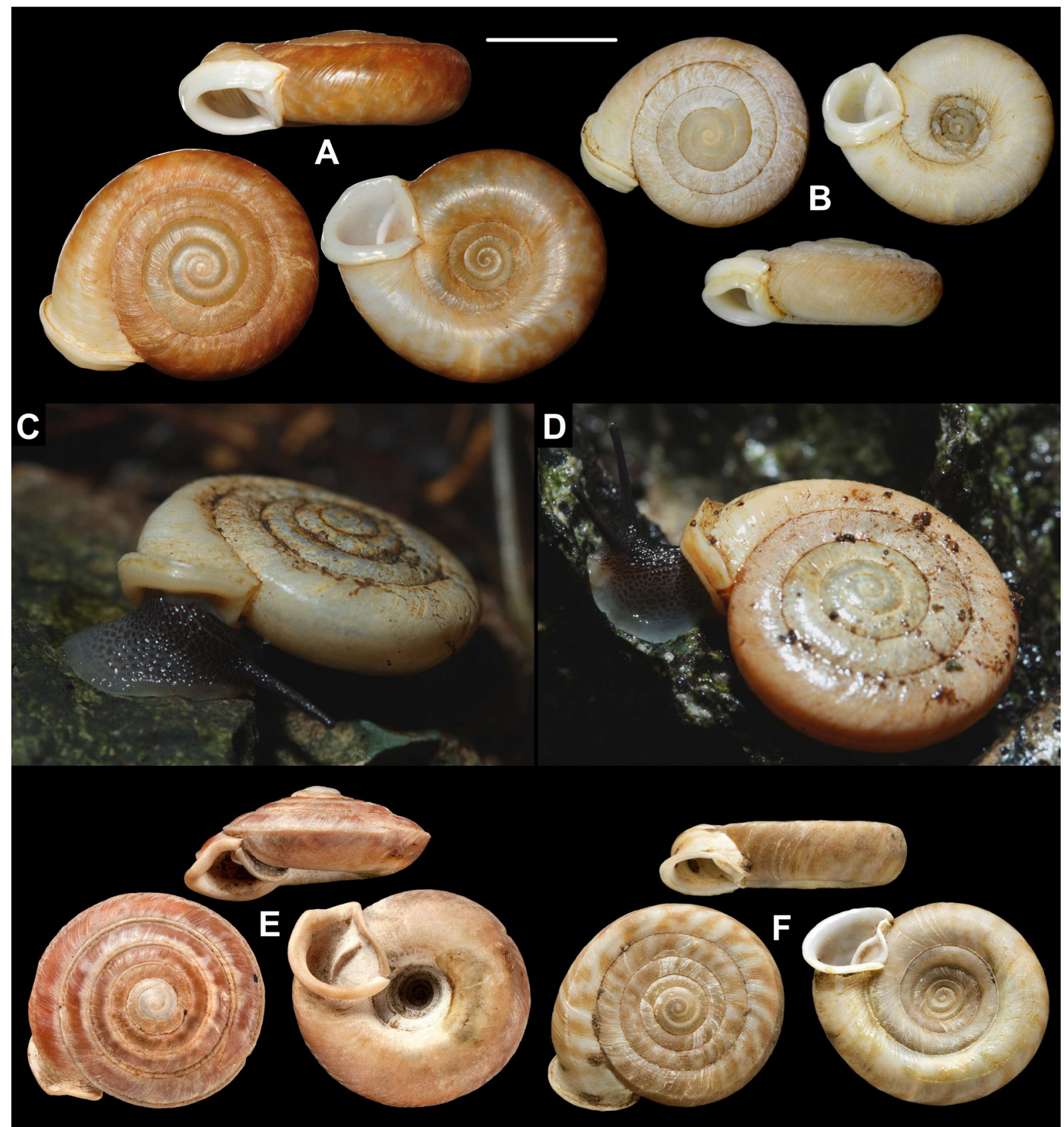

Fig. 41. Shells and living specimens of species of Plectopylis Benson, 1860. A. P. crassilabris sp. nov., holotype (UF 279203). B. P. crassilabris sp. nov. (UF 346364). C-D. Living specimens photographed in the Khao Wong National Park, Aug.-Sep. 2010. E. P. cyclaspis (Benson, 1859) (NHMUK 1888.12.4.1520-1522). F. P. karenorum (W. Blanford, 1865), probable syntype (NHMUK 1906.2.2.263). Scale bar: A-B, E-F $=10 \mathrm{~mm}$; C-D not to scale. Photos: T. Deli (A), B. Páll-Gergely (B), S. Damrongsiri (C-D) and H. Taylor (E-F). 


\section{Material examined}

MYANMAR: 3 shells, Burma, Moulmein, coll. Oldham, Pres. 1951 (NHMUK); 2 shells, Moulmein (NHMUK); 2 juv. shells, Moulmain, coll. Godwin-Austen (NHMUK); 4 shells, Molmein (NHMUK); 2 shells, Burma (NHMUK 1871.9.23.48); 2 juv. shells, Moulmain, coll. Godwin-Austen (NHMUK); 2 shells, Tenasserim, Moulmein, coll. Godwin-Austen, ("P.Z.S., 1874") (NHMUK); 4 shells, Moulmein (NHMUK 1906.2.2.148); 2 shells, Burma, Moulmein, coll. J.S. Hawkins (NHMUK 1954.6.2.270-271); 3 shells, Burmah, Moulmein, coll. Salisbury ex Beddome (NHMUK).

\section{Description}

SHELL. Sinistral, strongly built, brownish purple, basal side lighter; protoconch consists of 2.75-3 whorls, matt, almost smooth or sometimes extremely finely granulated and roughly wrinkled; teleoconch irregularly wrinkled, without spiral lines; fresh shells with flat periostracal folds on keel; whorls 6.256.5 , strongly, sharply keeled, suture not conspicuous, an additional groove runs above suture; umbilicus narrow; aperture strongly facing downwards (in direction of ventral side); peristome conspicuously protruding in elongation of keel, which results in a concave bay between the parieto-palatal edge of peristome and the position of keel; peristome strongly thickened and reflected; parietal callus almost straight or very slightly S-shaped; apertural fold strong, free from parietal callus; umbilicus relatively narrow and deep.
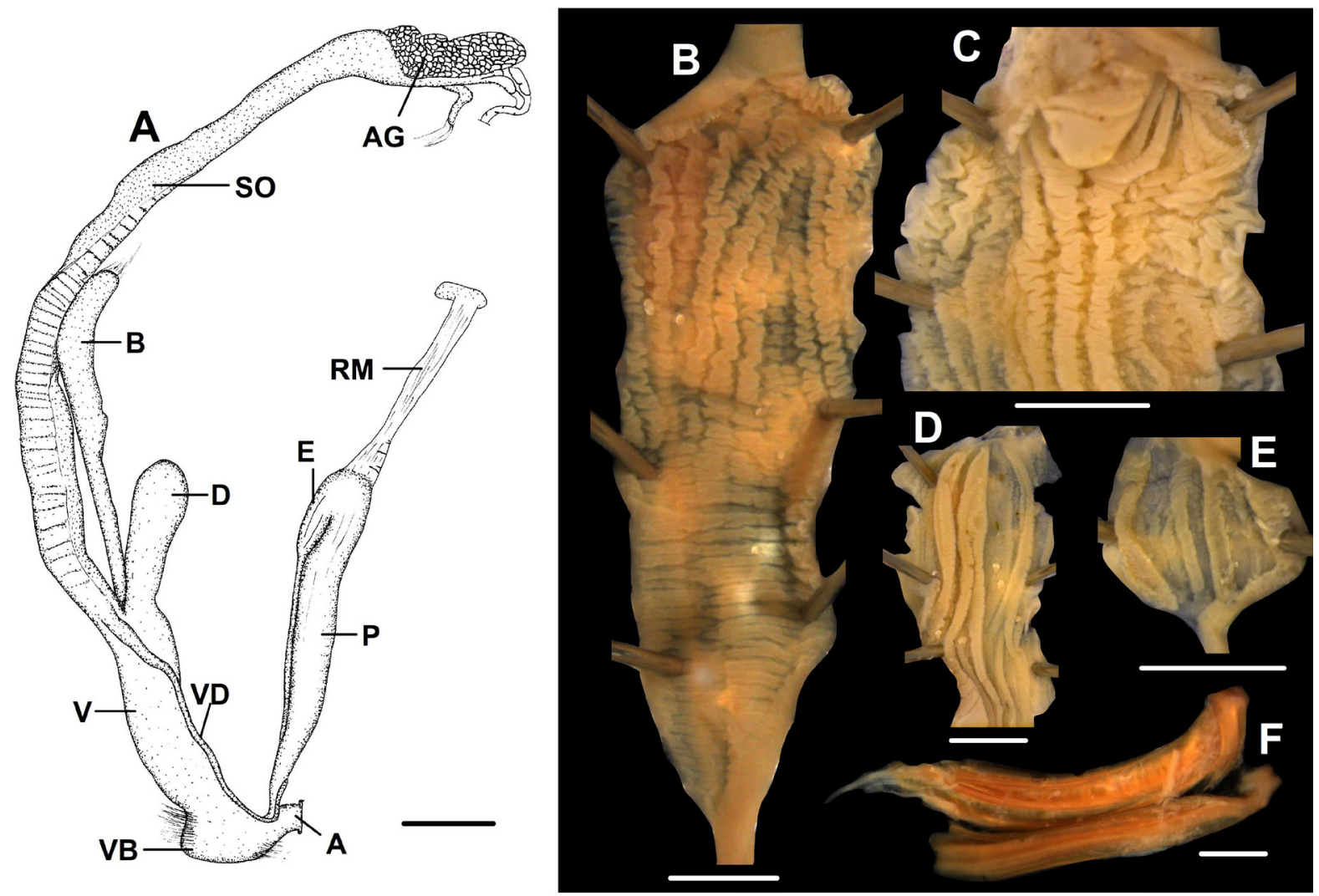

Fig. 42. Genitalia of Plectopylis crassilabris sp. nov. A. Whole genitalia (UF 376790). B-E. Inner structure of genital organs ( $\mathrm{B}=$ penis, $\mathrm{C}=$ vagina, $\mathrm{D}=$ diverticulum, $\mathrm{E}=$ epiphallus) (UF 376790). F. Spermatophore, PL088 (UF 343899). Scale bars: A $=5 \mathrm{~mm}$; B-F $=1 \mathrm{~mm}$. For abbreviations see Fig. 2. All photos: B. Páll-Gergely. 
Two opened shells were examined. Lambda-complex complete; left leg weak, right leg much stronger, has a very long anterior elongation; upper branch very long, parallel with upper suture; lower plica short, does not extend beyond lambda-complex; main plica absent. Palatal plicae typical of Plectopylis.

MeAsurements (in mm). $\mathrm{D}=18.9-19, \mathrm{H}=8.4-8.5$ (NHMUK 148.06.2.2, $\mathrm{n}=3$ ).

Characters of the genial structure. Stoliczka (1871) published a description and drawings of the genitalia of this species.

RADULA. The characters of the radula of $P$. cyclaspis and P. bensoni (under the name achatina) were described by Stoliczka (1871). According to him, the central tooth is very small, and the laterals have a large main cusp, and an ectocone with two or three cusps. This shape is unusual in the family Plectopylidae. Lateral teeth in all species of Plectopylis examined so far have a single large endocone, and a smaller ectocone with a single cusp. Therefore, the description of the radular teeth by Stoliczka (1871) is considered as inaccurate, probably due to insufficient instruments.

\section{Differential diagnosis}

Plectopylis cyclaspis cannot be confused with any other plectopylid species due to its conspicuous keeled whorls.

\section{Distribution}

All known samples were collected in the vicinity of Moulmein (Myanmar). See also Remarks.

\section{Remarks}

Stoliczka (1871) claimed that the type locality of $P$. revoluta (Andaman Islands) is probably incorrect, because he received thousands of other shells from those islands, but none of them were plectopylids. Gude (1914b) concluded that Plectopylis revoluta (Pfeiffer, 1867) is probably a synonym of $P$. cyclaspis. The species called $P$. revoluta in the recent literature is described here as $P$. malayana sp. nov.

Plectopylis karenorum (W. Blanford, 1865)

Figs 35J, 41E

Helix (Plectopylis) karenorum Blanford, 1865: 73-75, 94. ["Banks of Tsanda Khyoung, near Kaintha village, in Henzada district, Pegu", "on the banks of the Nungatho Khyoung, Henzada district"].

Helix karenorum - Pfeiffer 1868: 397; 1869: 503, pl. 108, figs 16-18.

Helix (Plectopylis) karenorum - Hanley \& Theobald 1870: 7, pl. 13, fig. 6. — Godwin-Austen 1875b:

613, pl. 74, fig. 5a. — Nevill 1878: 72. — Tryon 1887: 164, pl. 35, figs 96-100.

Plectopylis karenorum - Gude 1897b: 244-245, fig. 35a-d.

Plectopylis (Plectopylis) karenorum - Gude 1899d: 148; 1899e: 175; 1914b: 132-134, fig. 66a-d.

\section{Diagnosis}

A small to medium-sized, fragile species having lighter and darker stripes on the dorsal side; the angled body whorl and concomitantly entirely flat dorsal surface is characteristic for this species.

\section{Type material}

No specimens of Plectopylis karenorum were found in the type collection of the NHM. However, I found samples collected by Blanford and labelled as being collected from one of the type localities. Therefore, the samples detailed below probably represent syntypes. 


\section{Material examined}

\section{Syntypes}

MYANMAR: 2 shells, Pegu, Nungathokhyoung, Henzadah, coll. Blanford (NHMUK 1906.2.2.263); 5 shells, Pegu, Henzadah, coll. Blanford (NHMUK 1906.2.2.146).

\section{Additional material}

MYANMAR: 1 shell, Pegu, coll. Möllendorff (SMF 150097); 7 shells, Herizadah (NHMUK); 1 shell, Burmah, Pegu, coll. A. S. Kennard (NHMUK); 1 shell, Moulmain?, coll. Godwin-Austen (NHMUK 1903.7.1.735); 3 shells, Burma, Pegu, ex coll. Museum Cuming (NHMUK); 3 shells, Burmah, coll. Godwin-Austen (NHMUK 1903.7.1.737); 3 shells, Henzada District (NHMUK 1888.12.04.15481550); 1 shell, Pegu, ex coll. H. Adams (NHMUK 1878.1.28.283).

LOCALITY UNKNOWN: 2 juv. shells, no data, coll. H.F./W.T. Blanford, acc. 1944 (NHMUK).

\section{Description}

SHeLl. Sinistral, completely flat, unusually thin-walled for Plectopylis; colour basically greyish with brownish-corneous stripes; protoconch consists of 2.75-3 whorls, extremely finely tuberculated and roughly, irregularly wrinkled; whorls 5.5-6, separated by relatively shallow suture; whorls strongly angled, which results in an entirely flat dorsal surface; whole shell with fine reticulated sculpture; dorsal side and area inside umbilicus dominated by spiral lines (or spiral and radial lines are of comparable strength); periphery of body whorl dominated by radial wrinkles; aperture small, rather rounded, peristome slightly thickened and reflected; parietal callus strongly developed but blunt, slightly S-shaped, upper part of ' $\mathrm{S}$ ' shorter; apertural fold in contact with parietal callus.

Three opened shells were examined. Lambda-complex complete; left leg with a posteriorly elongated end; upper branch approximately as long as elongated part of left leg; right leg with anteriorly and somewhat obliquely elongated end; main plica in contact with right leg. Palatal plicae typical of Plectopylis.

Measurements (in mm). $\mathrm{D}=12-14.1, \mathrm{H}=3.9-5.1$ (NHMUK 1906.2.2.146, $\mathrm{n}=4$ ); $\mathrm{D}=18.4-19.7$, $\mathrm{H}=5.6-5.9$ (NHMUK 1906.2.2.263, $\mathrm{n}=2$ ).

\section{Differential diagnosis}

Plectopylis karenorum can be distinguished from all congeners by the flat, solid, thin-walled shell with shouldered body whorl and striped colouration.

\section{Distribution}

This species has been reported from several Burmese localities.

Plectopylis linterae Möllendorff, 1897

Figs $35 \mathrm{~K}, 43$

Plectopylis linterae Möllendorff, 1897: 28-29 [“Pegu”].

Plectopylis linterae var. fusca Gude, 1898g: 170-171, fig. 89a-f. Syn. nov.

Plectopylis linterae - Gude 1898g: 170, fig. 88a-c.

Plectopylis (Plectopylis) linterae - Gude 1914b: 134-136, fig. 67a-c; 1899d: 148; 1899e: 175.

Plectopylis (Plectopylis) linterae var. fusca - Gude 1914b: 136, fig. 68a-f; 1899d: 148; 1899e: 175. 


\section{Diagnosis}

SHELL. Small, sinistral, thick with slightly elevated spire, strongly thickened peristome, and a main plica, which is weak, and sometimes free from the apertural fold.

\section{Material examined}

\section{Types}

MYANMAR: 1 shell, probably holotype (labelled as lectotype) of $P$. linterae $(\mathrm{D}=15.7 \mathrm{~mm})$, Pegu, coll. Möllendorff (SMF 9280).

The type sample of $P$. linterae var. fusca Gude, 1898 could not be located in the NHM.

\section{Additional material}

MYANMAR: 2 shells, Pegu, coll. Bosch, ex Rolle (SMF 172062); 3 shells (labelled as "var. fusca"), Pathung-Thoung, Attaram R. (NHMUK 1888.12.4.1541-1543); 1 shell, Burma (NHMUK 1916.3.16.5); 2 shells (labelled as "pachystoma"), Burmah, Theobald leg. (NHMUK 1903.07.01.736); 1 opened shell (labelled as "karenorum"), Moulmain(?), coll. Godwin-Austen (NHMUK 1903.07.01.735); 1 shell (labelled as "pachystoma"), Molmein (NHMUK 1906.01.01.741); 5 shells (photos of one shell examined, see Fig. 43A), India, coll. Linter (RAME 1720/1909/D7.48a-e).

\section{Description}

SHELL. Sinistral, strongly built, spire somewhat elevated, dorsal surface slightly conical, shell outline slightly oval; colour dark yellowish-greyish to brownish and reddish; protoconch consists of 2.5-

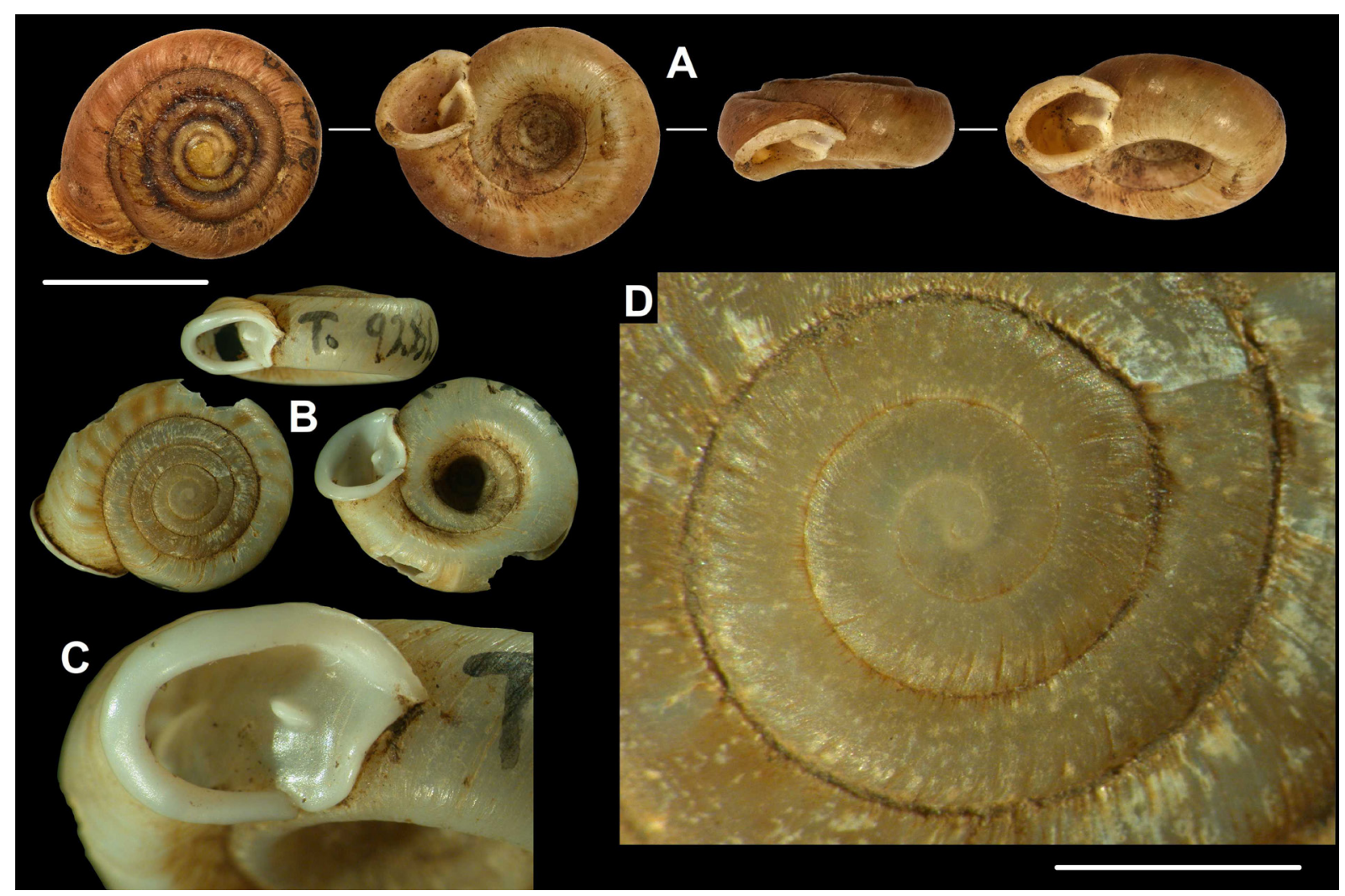

Fig. 43. Photos of Plectopylis linterae Möllendorff, 1897. A. Shell from Myanmar (RAME 1720/1909/ D7.48a). B-D. Holotype (SMF 9280). Scale bars: D (protoconch) $=2 \mathrm{~mm}$; A-B (shells) $=10 \mathrm{~mm}$; C not to scale. Photos: G. Oliver (A) and B. Páll-Gergely (B-D). 
2.75 whorls, matt, very finely, irregularly wrinkled with extremely fine granular structure; whole shell dominated by irregular, fine wrinkles; dorsal side and area inside umbilicus finely reticulated; periumbilical area smooth, although rather roughly wrinkled near aperture; whorls 5.25-5.75 $(n=4)$, body whorl rounded; aperture rounded or oval; peristome strongly thickened and slightly reflected; parietal callus elevated, strong, S-shaped; apertural fold strong, free from the parietal callus or slightly connected to it; umbilicus funnel-shaped, relatively narrow, with a blunt periumbilical keel.

One opened shell was examined. Lambda-complex complete; both legs with slightly elongated ends anteriorly and posteriorly; upper branch as long as extension of left leg; main plica in contact with right leg, free from apertural fold or connected to it; main plica always much weaker than apertural fold. Palatal plicae typical to Plectopylis.

MeAsurements (in mm). $\mathrm{D}=15.7-16.2, \mathrm{H}=5.6-6.6$ (lectotype and paralectotypes, $\mathrm{n}=3$ ); $\mathrm{D}=16-16.9$, $\mathrm{H}=5.4-5.5$ ("var. fusca", NHMUK 1888.12.4.1541-43, $\mathrm{n}=3$ ).

\section{Differential diagnosis}

In shell shape Plectopylis linterae is most similar to P. crassilabris sp. nov., which is larger, lacks the main plica and has a stronger spiral sculpture. Typical specimens of $P$. linterae are much smaller than $P$. bensoni, have a more elevated spire and a more rounded body whorl. Although in some (probably very old) specimens of $P$. linterae the apertural fold is connected to the main plica, the apertural fold is always much stronger (more elevated) than the main plica. The apertural fold and the main plica are always connected in $P$. bensoni, and their boundary is not visible.

\section{Distribution}

Plectopylis linterae is known from Pegu only. The exact geographic position of the other locality (Pathung-Thoung) is unknown.

\section{Remarks}

The species is sometimes named as "Plectopylis pachystoma Theobald" on museum labels, but this name has never been published. Although the types of Plectopylis linterae var. fusca could not be found in the NHM, I found non-type shells labelled "var. fusca". Those specimens differ from typical $P$. linterae in the uniformly brown dorsal surface, which is not sufficient for distinction on any taxonomic levels, meaning Plectopylis linterae var. fusca is a synonym of $P$. linterae.

Plectopylis malayana sp. nov. urn:lsid:zoobank.org:act:987C6622-4318-4E5E-AE9C-097C21DC546F

Figs 35L-M, 44A-E, 45, 46A-B

Plectopylis revoluta - van Benthem Jutting 1960: 17 ["Limestone hill Kaki Bukit, near kampong Wang Tangga, Perlis"]. - Berry 1963: 13, fig. 51 ["abundant in limestone hills in North Malaya"]. Maassen 2001: 78.

\section{Diagnosis}

A medium-sized, sinistral, brown-shelled species having periostracal filaments along the upper keel of the body whorl; apertural fold not in contact with parietal callus; lambda-complex with a short connecting plica anteriorly.

\section{Etymology}

The species is named for Malaysia, where most of the samples were collected. 


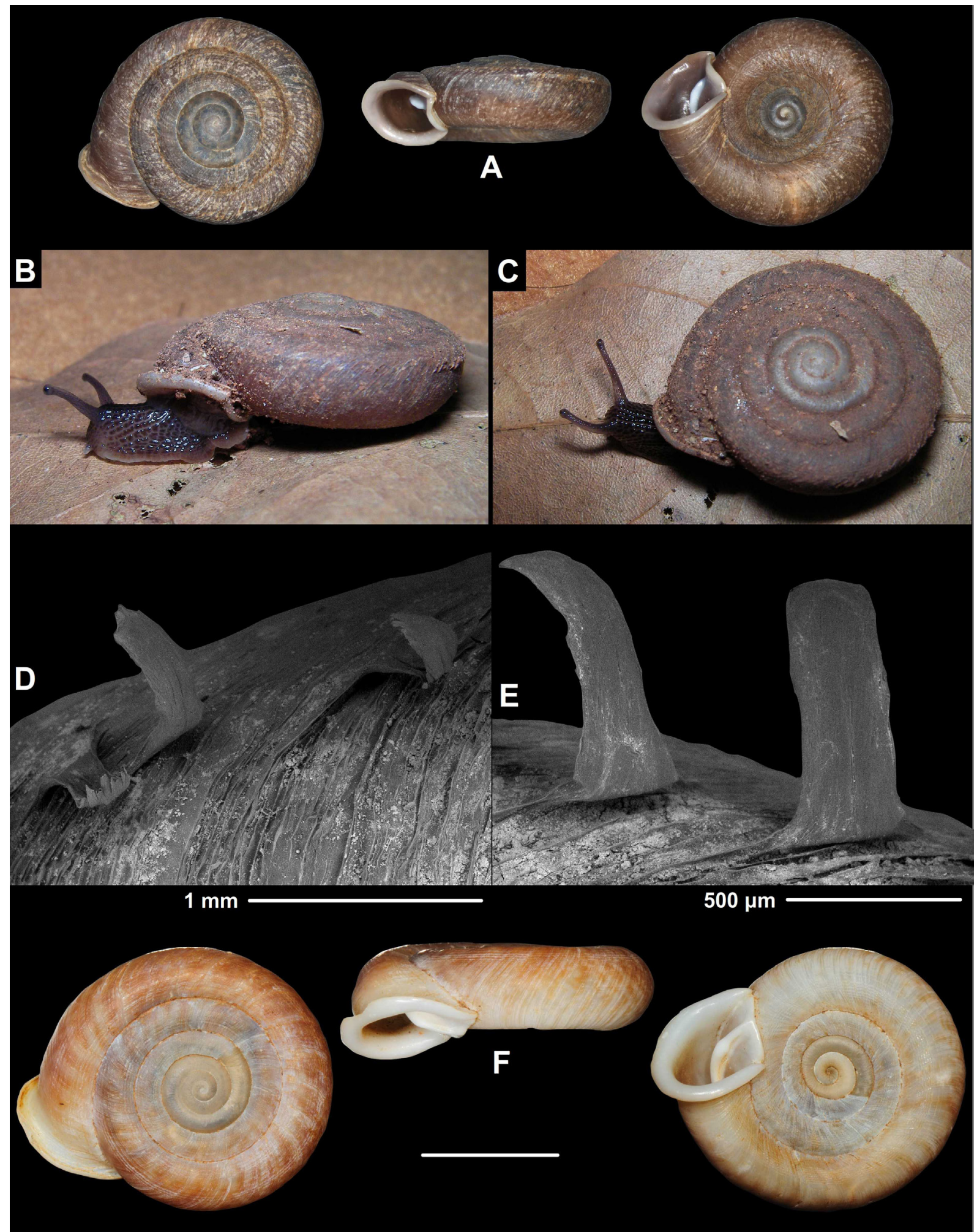

Fig. 44. Shells of species of Plectopylis Benson, 1860. A. P. malayana sp. nov., holotype (HNHM 97469). B-C. Living specimen of P. malayana sp. nov. D-E. SEM images of the periostracal folds of P. malayana sp. nov., specimens from loc. 2013/14. F. P. thompsoni sp. nov., holotype (UF 77249). Scale bars: A, F (lower scale) $=10$ mm. Images: T. Deli (A, F), T.-S. Liew (B-C) and B. Páll-Gergely (D-E). 
PÁLL-GERGELY B., Systematic revision of the Plectopylinae

\section{Material examined}

Holotype

MALAYSIA: 1 shell $(\mathrm{D}=18.1 \mathrm{~mm})$, Perlis, Kaki Bukit (N of Kangar), Oct. 1998, J. and Ch. Hemmen leg. (HNHM 97469).

\section{Paratypes}

MALAYSIA: 11 shells, same data as for holotype (coll. JG); 9 shells, same data as for holotype (coll. PGB); 20 shells, same data as for holotype (coll. HE); 2 shells, same data as for holotype (NHMW 108117); 5 shells, Perlis, Bukit Kubu (NE of Kuala Perlis), 21 Mar. 1998, J. and Ch. Hemmen leg. (coll. JG); 4 shells, same data as for preceding (coll. PGB); 1 shell, Perlis, Wangga Tangga Valley, near Kaki Bukit, 23 Mar. 1998, J. and Ch. Hemmen leg. (coll. HA); 10 shells, same data as for preceding (coll. JG); 9 shells, same data as for preceding (coll. PGB); 3 shells, Nha-Krabi, south, Apr. 2003, Dieter Hörner leg. (coll. JG); 1 shell, Perlis, about $21 \mathrm{~km} \mathrm{~N}$ of Kangar, max. $3 \mathrm{~km}$ from the Thai border, Kaki Bukit, near Kampung Wang Tangga, $6^{\circ} 38^{\prime} 28^{\prime \prime} \mathrm{N}, 100^{\circ} 12^{\prime} 08^{\prime \prime} \mathrm{E}$, in leaf litter in a secondary forest, base of limestone hill, 17 Mar.1995, V. Kessner leg. (coll. PGB); 3 shells, same data as for preceding (coll. REI); 2 shells, Perlis, Titi Tinggi Mukim, Kaki Bukit, Gua Kelam, towards Wang Tangga, near fossil locality site, live/dead collected among disturbed limestone rocks and litters near exit of cave, 26 Apr. 1996, Chan Sow-Yan and Leo Nguang leg., ex Chan 1997 (SMF 311305); 35 shells, Perlis, Kaki Bukit, Gua Kelam, 06³8.68' N, 100¹2.23' E, 9 Jul. 1999, W. Maassen leg. (coll. WM); 4 shells (preserved in ethanol: PL009, PL010, PL019, PL020 used for molecular study), Perlis, Kaki Bukit, around Gua Kelam, $06^{\circ} 38^{\prime} \mathrm{N}, 100^{\circ} 11^{\prime} \mathrm{E}, 50 \mathrm{~m}$ a.s.l., $11 \mathrm{Jan} .2013$, A. Hunyadi leg. (coll. HA); 1 paratype (preserved in ethanol, anatomically examined), same data as for preceding (NHMUK 20170153); 44 shells, West Malaysia, Perlis, Wang Kelian State Park near Thai Border, 06²41.98' N, $100^{\circ} 11.80^{\prime}$ E, 10 Jul. 1999, W. Maassen leg. (coll. WM); 10 shells, West Malaysia, Perlis, limestone hill, $30 \mathrm{~km} \mathrm{~N}$ of Kangar, 06² 41.00' N, 100¹1.21' E, 10 Jul. 1999, W. Maassen leg. (coll. WM); 5 shells, West Malaysia, Perlis, Bukit Air Park, N of Kangar, 11 Jul. 1999, W. Maassen leg. (coll. WM); 4 shells, West Malaysia, Perlis, Kaki Bukit, near Kampung Wang Tangga, 11 Jul. 1995, V. Kessner leg. (coll. WM); 1 shell, Perlis, Kaki Bukit, near Kampung Wang Tangga, in leaf litter, secondary forest at the base of limestone hill, 17 Mar. 1995, V. Kessner leg. (HNHM 42264); 2 shells, Perlis, Kaki Bukit, Kampunk, Wang Tangga, coll. L. Drimmer (MMGY 69644); 1 shell, Perlis, Kampung Tebing Tinggi, $3.5 \mathrm{~km} \mathrm{~W}$ of Kangar, $06^{\circ} 26.707^{\prime} \mathrm{N}, 100^{\circ} 09.1931^{\prime}$ E, 20 m a.s.1., 12 Jan. 2013, A. Hunyadi leg. (coll. HA); 46 shells, Perlis, Kaki Bukit, around Gua Kelam, loc. 2013/14, 06 38.674' N, 100¹2.170' E, 45-55 m a.s.1., 13 Jan. 2013, A. Hunyadi leg. (coll. HA).

THAILAND: 3 shells, Satun Province, Ban Rae, coll. Brandt, 1966 (MNHN); 4 shells, Satun Province, Ban Rae, 4 Jan. 1966, Brandt leg. (ZMH 45914); 3 shells, same data as for preceding (SMF 207667); 2 shells, same data as for preceding except coll. Klemm (nr. 54168) (NHMW 108223); 3 shells, same data as for preceding except coll. Oberwimmer (NHMW 108224); 4 shells, same data as for preceding except coll. Biggs (NHMUK 20170159); 3 shells, same data as for preceding except coll. Brand 1966 (MNHN IM-2012-2519); 1 paratype (preserved in ethanol), Satun Province, Thale Ban Nat. Park, lowland rain forest, $6^{\circ} 42^{\prime} \mathrm{N}, 100^{\circ} 10^{\prime} \mathrm{E}$, ca $400 \mathrm{~m}, 20$ Oct. 1991, M. Andersen, O. Martin and N. Scharff leg. (ZMUC-GAS-1834).

\section{Additional material}

MALAYSIA: 1 juv. shell, Perlis, about $21 \mathrm{~km} \mathrm{~N}$ of Kangar, max. $3 \mathrm{~km}$ from the Thai border, Kaki Bukit near Kampung Wang Tangga, $6^{\circ} 38^{\prime} 28^{\prime \prime} \mathrm{N}, 100^{\circ} 12^{\prime} 08^{\prime \prime} \mathrm{E}$, in leaf litter in a secondary forest, base of limestone hill, 17 Mar.1995, V. Kessner leg. (coll. PGB). 


\section{Description}

SHELL. Sinistral, chocolate brown (or yellowish, if weathered), nearly flat, strongly depressed conical or flat with protoconch slightly protruding above dorsal surface; protoconch consists of 3.25-3.5 whorls, very finely granular, with inconspicuous growth lines on last 1.5-2 whorls; ventral surface of protoconch roughly ribbed; teleoconch with a reticulated surface consisting of very fine, dense ribs and widely-spaced spiral lines; periostracum of fresh specimens with deciduous folds on upper keel of body whorl; whorls 6-6.5, separated by a relatively shallow suture; aperture rounded; peristome thickened and expanded; parietal callus sharp; apertural fold usually short, white and never in contact with parietal callus.

Four shells were opened. Lambda-complex compete; left leg and upper branch relatively short; middle portion of right leg with a short horizontal, attached plica, which is rarely in contact with main plica; short lower plica situated below lambda-complex; in some specimens main plica connected to apertural fold, whereas in others they are free (this trait is probably age-dependent). Palatal wall with six plicae; first three straight with sinuate (S-shaped) posterior ends; last plica slightly curved with its convex side pointing upwards; additional short plica visible above posterior end of last plica; fourth and fifth plicae vertical and fused together, forming a single, vertical plate, which is usually bifurcated below and possesses 1-2 additional horizontal plicae posteriorly.

MeAsurements (in mm). $\mathrm{D}=17.6-19.0, \mathrm{H}=6.6-7.2(\mathrm{n}=4)$.
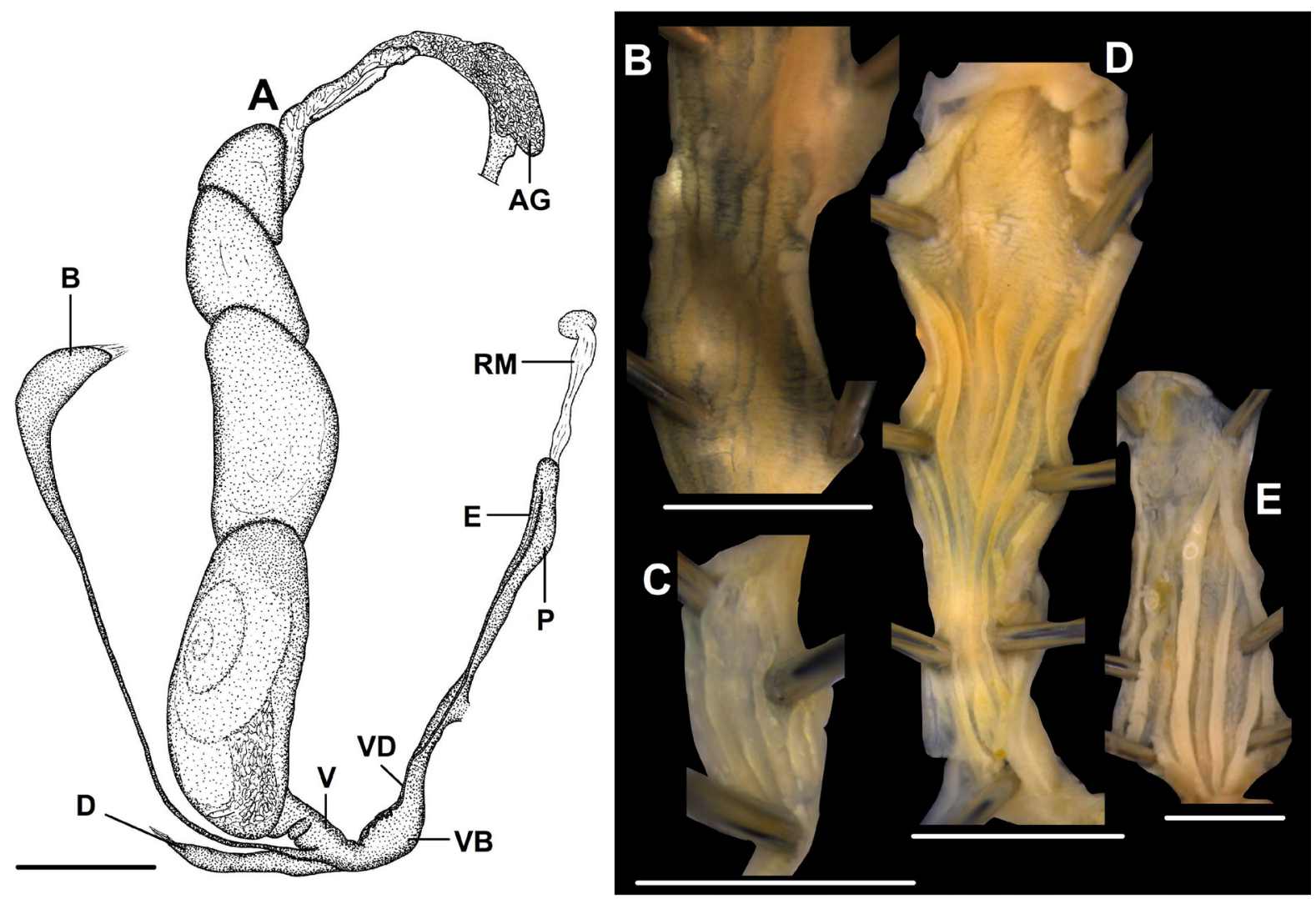

Fig. 45. Genitalia of Plectopylis malayana sp. nov., PL010 (NHMUK 20170153). A. Whole genitalia. B-E. Inner structure of genital organs $(\mathrm{B}=$ penis, $\mathrm{C}=$ epiphallus, $\mathrm{D}=$ vagina, $\mathrm{E}=$ diverticulum). Scale bars: $A=5 \mathrm{~mm}$; $B-E=1 \mathrm{~mm}$. For abbreviations see Fig. 2. All photos: B. Páll-Gergely. 
Characters of the genital system. One specimen was examined. Locality information: Malaysia, Perlis, Kaki Bukit, around Gua Kelam, 06 $38^{\circ}$ N, 100¹1' E, 50 m a.s.l., A. Hunyadi leg., 11 Jan. 2013 (NHMUK 20170153). Left ommatophoral retractor runs between penis and vagina; penis relatively long and slender, internally with parallel, serrate folds; epiphallus and vas deferens attached to penis with weak muscle fibres; no penial caecum observed; retractor muscle thick and short, inserts on proximal part of penis; vagina approx. as long as penis, but thicker; bursa copulatrix with a very long, slender stalk, bursa elongate ovoid; diverticulum short, blunt, ovoid; four developing embryos were found in uterus, the most distal one was the most well-developed, with a shell of 3 whorls.

RADULA. Centrals with small, triangular cusps; endocones of laterals rhomboid; ectocones of first laterals larger than centrals; ectocones of marginals undivided, endocones of marginals mostly undivided, or divided by shallow incision.
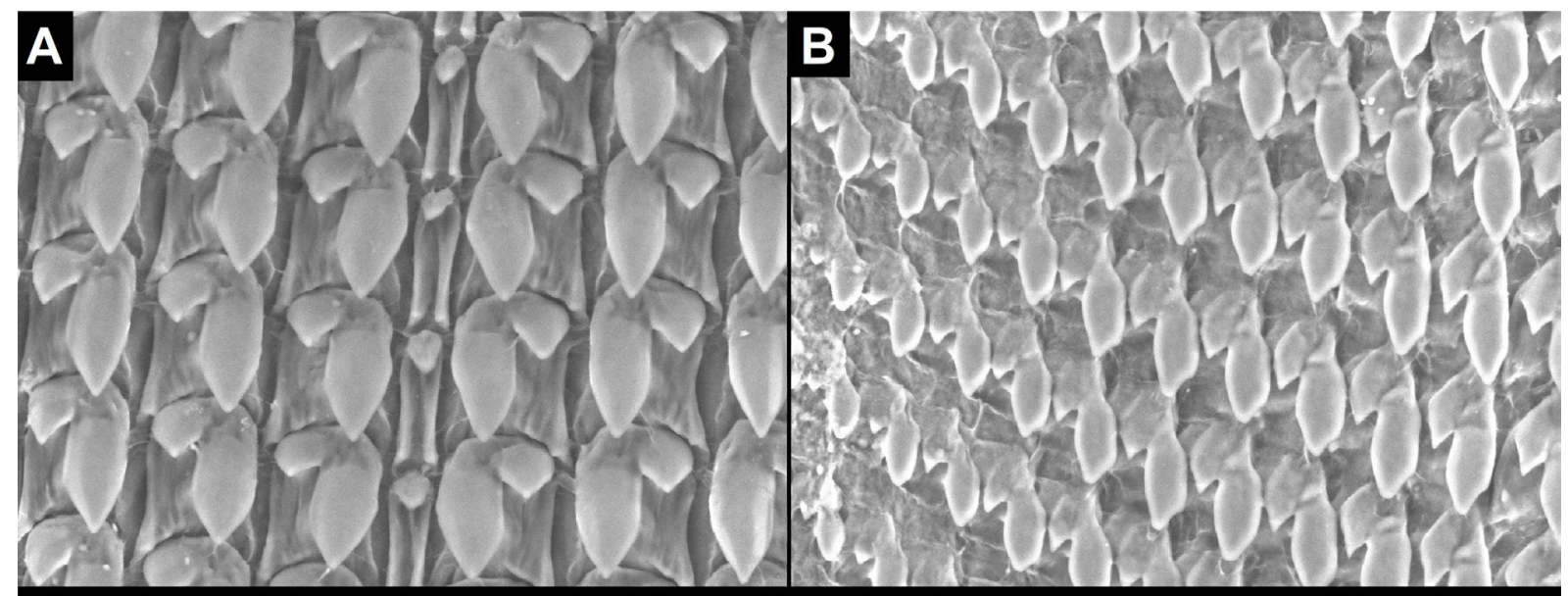

$100 \mu \mathrm{m}$

$100 \mu \mathrm{m}$

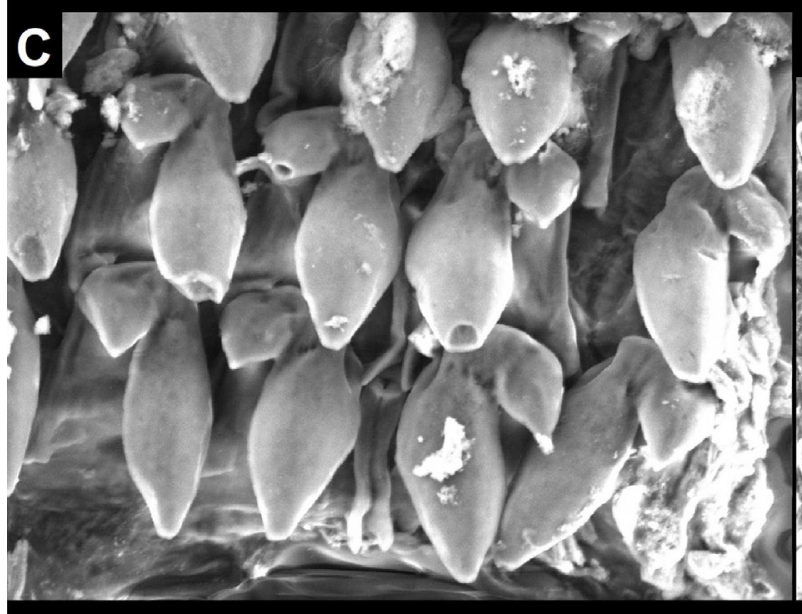

$50 \mu \mathrm{m}$

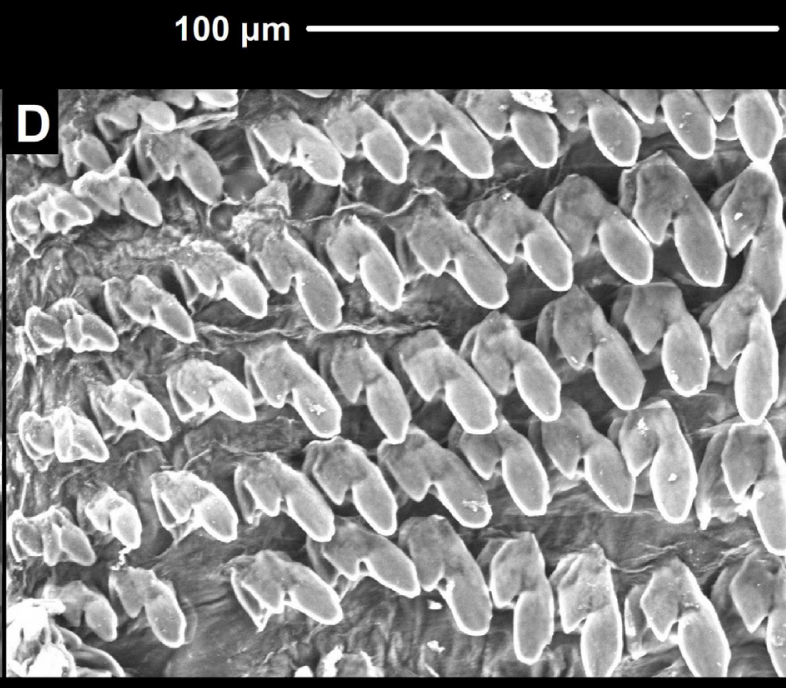

$100 \mu \mathrm{m}$

Fig. 46. Radula of Plectopylis Benson, 1860 species. A, C. Central and first lateral teeth. B, D. Marginal teeth. A-B. Plectopylis malayana sp. nov. (loc. 2013/14, coll. HA). C-D. Plectopylis thompsoni sp. nov. (UF 76482). All images: B. Páll-Gergely. 


\section{Differential diagnosis}

Plectopylis malayana sp. nov. differs from P. cairnsi by its darker shell, thinner lip, less rounded body whorl, several additional plicae on the palatal wall, shorter left leg, and shorter upper branch of the lambda-complex. Furthermore, the lambda-complex of $P$. cairnsi is never fused to the main plica (sometimes fused in P. malayana sp. nov.), and P. malayana sp. nov. has a small fold that is attached to the central part of the right leg. Plectopylis bensoni is usually larger than P. malayana sp. nov. and has a rounded body whorl, whereas the body whorl of P. malayana sp. nov. is angled. Moreover, P. malayana sp. nov. has a finely reticulated shell surface, which is nearly smooth in $P$. bensoni with irregular growth lines.

\section{Distribution}

Plectopylis malayana sp. nov. is known from Perlis Province (near the Thai border) in northern Malaysia and the Satun Province in southern Thailand only. See also Remarks and Fig. 40.

\section{Remarks}

The species collected from northern Malaysia was mentioned as Plectopylis revoluta (Pfeiffer, 1867) in the literature (see above). Plectopylis revoluta, however, was originally described from the Andaman Islands. Gude (1914b) discussed the taxonomic status of $P$. revoluta in detail, and concluded that revoluta is possibly a synonym of $P$. cyclaspis. The absence of the types of $P$. revoluta does not allow clarification of this question, but the original description of $P$. revoluta (e.g., body whorl acutely keeled) certainly does not fit the Malaysian species. Therefore, a new name must be given to this species.

The sample collected by Brandt in 1966 was distributed to several museums (ZMH, NHMW, SMF, MNHN). According to the label the locality is "Satun: Ban Rae". The locality name "Ban Rae" probably refers to Ban Rae Kot, northwest of Mueang Satun.

Plectopylis thompsoni sp. nov. urn:1sid:zoobank.org:act:21175C88-45BD-4DFE-9EAD-A16FCB9B623E

Figs 35N-O, 44F, 46C-D, 47

\section{Diagnosis}

A large, sinistral, flat species with a strongly developed lip and a long apertural fold that is in contact with the peristome; right leg of lambda-complex absent.

\section{Etymology}

The new species is dedicated to and named after Fred Gilbert Thompson (1934-2016), who collected most of the material examined for this publication.

\section{Material examined}

\section{Holotype}

THAILAND: 1 shell $(\mathrm{D}=23 \mathrm{~mm})$, Trang Province, limestone mountain, $7 \mathrm{~km} \mathrm{~S} / 2 \mathrm{~km}$ E of Huai Yot, $7^{\circ} 44^{\prime} \mathrm{N}$ 99³8'E, 40 m a.s.1., 28 Sep. 1985, F.G. Thompson leg. (UF 77249).

\section{Paratypes}

THAILAND: 14 shells, same data as for holotype (UF 448578); 13 specimens (preserved in ethanol: PL069 and PL070 used for molecular study), same data as for holotype (UF 76482); 2 shells, same data as for holotype (HNHM 97463); 1 shell, Krabi Province, $10 \mathrm{~km}$ NE of Ao Luk, 8²9' N, 98 $8^{\circ} 49^{\prime}$ E, 30 Sep. 1985, F.G. Thompson leg. (mixed sample with P. cairnsi) (UF 507377); 1 shell, same data as for preceding (HNHM 97476); 17 shells, Trang Province, limestone mountain, 7 km S/2 km E of Huai Yot, 
$40 \mathrm{~m}$ a.s.1., 28 Sep. 1985, F.G. Thompson leg. (UF 77250); 2 shells, same data as for preceding (HNHM 97477).

\section{Description}

SHELl. Sinistral, flat, fresh shells with yellowish- and reddish-corneous markings resembling tigerstripes, or with a mosaic-like pattern; protoconch consists of 3.25-3.5 whorls, very fine granulose with fine growth wrinkles near suture; last whorl of protoconch irregularly, finely ribbed; teleoconch with irregular growth lines and rather regular spiral striation; entire shell consists of 5.25-6 whorls; aperture oval; peristome conspicuously thickened and slightly reflected; parietal callus also thickened; apertural fold in contact with parietal callus.

Six shells were opened. Lambda-complex incomplete (right leg absent); upper branch strongly elongated posteriorly; main plica connected to lambda-complex, starts from just below meeting point of left leg and upper branch; a short lower plica also present below main plica; lower plica usually free but can be in contact with left leg. Palatal wall typical of Plectopylis.

Measurements (in mm). $\mathrm{D}=18.3-23.3, \mathrm{H}=6.3-7.4(\mathrm{n}=4)$.

Characters of the Genital system. Two specimens of sample UF 76482 were examined (Fig. 47). One of the specimens was aphallic (PL069), its male genitalia consisted of a small wart-like structure, which was connected to the vas deferens. The female parts of that specimen appeared normal. Moreover, a spermatophore (long, fragile, reddish brown tube-like thread folded multiple times and forming an ovate mass with pointed ends) was found in the diverticulum. The description of the traits of the genital structure of the other specimen are as follows: left ommatophoral retractor runs between penis and vagina; penis relatively long, with slender distal, and thickened proximal part, internally with parallel, serrate folds; epiphallus and vas deferens attached to penis with weak muscle fibres; no penial caecum observed; retractor muscle thick, slightly shorter than penis, inserts on proximal part of penis; vagina slightly shorter than penis, but thicker; bursa copulatrix with a very long, slender stalk, bursa strongly elongate ovoid, only slightly thickened; diverticulum small, oval; three developing embryos found in uterus, covered by fine calcareous powder-like crystals.

RADUla. Centrals nearly entirely reduced; endocones of laterals rhomboid or elongate-ovoid with pointed tip; ectocones of marginals undivided; endocones of marginals mostly undivided, or divided by shallow incision.

\section{Differential diagnosis}

Plectopylis thompsoni sp. nov. can be distinguished from all other species of Plectopylis by the reduced right leg of the lambda-complex. In shape, $P$. thompsoni sp. nov. resembles $P$. anguina, but that species is larger, its aperture is more oblique to the shell axis, has a bluntly keeled body whorl and lacks the spiral lines, which are prominent in P. thompsoni sp. nov. Plectopylis thompsoni sp. nov. is larger than P. malayana sp. nov. and its apertural fold reaches the parietal callus. Plectopylis cairnsi, which also occurs sympatrically with $P$. thompsoni sp. nov., is usually smaller than the new species, has a thinner apertural fold and peristome, a less descending aperture, and usually has a more elevated spire. Shells of $P$. bensoni of the same diameter as $P$. thompsoni sp. nov. are higher, their protoconch protrudes above the dorsal surface and they lack spiral lines on the body whorl.

\section{Distribution}

Two localities are known from the limestone hills of northern Trang Province. One additional shell was found in a sample of Plectopylis cairnsi from northern Krabi Province. I cannot rule out the possibility that the shell of $P$. thompsoni sp. nov. was mistakenly included in that sample. Therefore, the presence of this new species in Krabi Province needs confirmation (Fig. 40). 


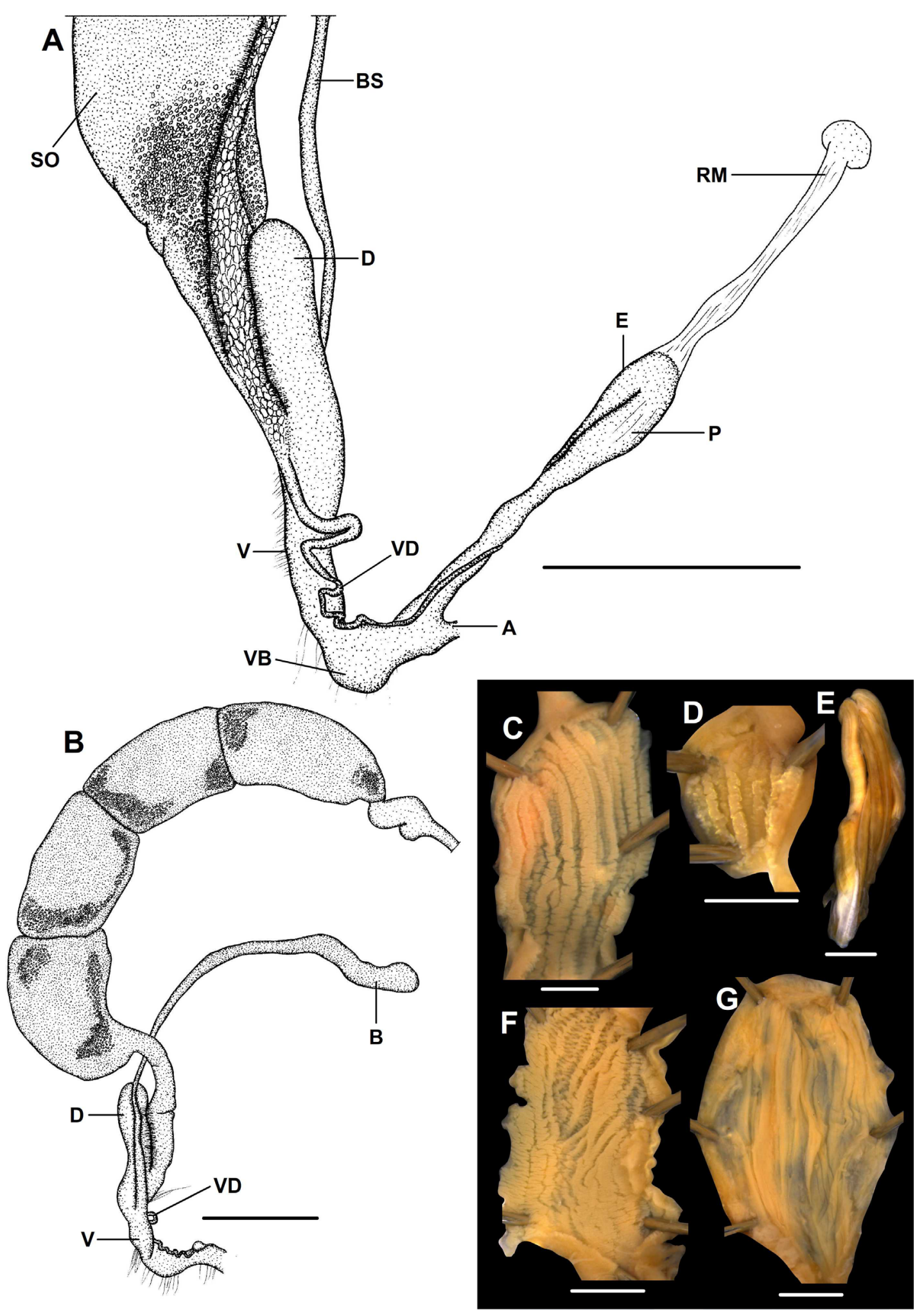

Fig. 47. Genitalia of Plectopylis thompsoni sp. nov. A. Distal genitalia, PL070 (UF 76482). B. Genitalia of an aphallic specimen, PL069 (UF 76482). C-D, F-G. Inner structure of genital organs (C = penis, $\mathrm{D}=$ epiphallus, $\mathrm{F}=$ vagina, $\mathrm{G}=$ diverticulum), PL070 (UF 76482). E. Spermatophore, PL070 (UF 76482). Scale bars: $A-B=5 \mathrm{~mm} ; C-G=1 \mathrm{~mm}$. For abbreviations see Fig. 2. All photos: B. Páll-Gergely. 


\section{Discussion}

Currently, 109 extant species and 13 subspecies of Plectopylidae are recognized, but several new species probably await description, especially from the southern Himalaya region and southern China. With this paper all members of the Plectopylidae are revised and figured (Páll-Gergely \& Hunyadi 2013; PállGergely \& Asami 2014, 2016; Páll-Gergely et al. 2015b, 2015c, 2016; Páll-Gergely 2018), with the exception of the Taiwanese Sicradiscus ishizakii (Kuroda, 1941) and the Japanese S. hirasei (Pilsbry, 1904). The large amount of morphological and unpublished molecular phylogenetic information made the subdivision of the family into two subfamilies possible. Plectopylinae includes the genera Chersaecia, Hunyadiscus, Naggsia and Plectopylis, whereas Sinicolinae subfam. nov. includes Gudeodiscus (with the subgenus Veludiscus), Endothyrella, Halongella, Sicradiscus, Sinicola and the Eocene fossil Plectopyloides. Table 4 summarizes all names of Plectopylinae with their current generic placement. Our knowledge on the anatomy of Sinicolinae subfam. nov. is much more complete than that of the Plectopylinae. For example, the recognition of the genera Halongella and the subgenus Veludiscus was possible only on the basis of anatomical traits. Consequently, new anatomical information will probably redraw generic boundaries, especially in the conchologically and anatomically diverse genus Chersaecia. Similarly, most samples of the Plectopylinae are known from historical museum collections with usually imprecise locality information. In contrast, for Sinicolinae subfam. nov., we have much more accurate information on the distribution of certain species, especially in southern China and northern Vietnam.

The Plectopylidae is widely distributed from Nepal to southern Japan and from middle China (Sichuan, Chongqing, Hubei, Zhejiang Provinces) to Peninsular Malaysia. The only fossils that can certainly be classified in the Plectopylidae have been reported from Henan and Shangdong Provinces, not far north of the distribution of extant plectopylids (Yen 1969; Li 1986; Páll-Gergely \& Asami 2014). The current centre of diversity, inferred from the number of extant genera, is in southern China and northern Vietnam for Sinicolinae subfam. nov., and northern Thailand and eastern Myanmar for Plectopylinae.

Our knowledge on the habitat preference and life history of the Plectopylidae is limited. Most (all?) species are known to prefer limestone habitats, and occur on bases of rocks, under stones and decaying logs, and among leaf litter. The sculpture of the dorsal shell surface of most species is reticulated, which enables the living snails to camouflage themselves by encrusting their shells with mud. Judging from the number of shells in collections, some species of the Plectopylinae occur in dense populations in Myanmar and Thailand. Our present knowledge is insufficient to apply conservational categories to each species, especially to those inhabiting Myanmar. Overall, as for most southeast Asian land snails, the main threat to plectopylids is probably limestone mining (quarrying) (Clements et al. 2006). Therefore, protecting as many limestone hills as possible is paramount to save these species.

The life histories of plectopylids can be inferred from the traits of their genital apparatus. It seems that all species are ovoviviparous. The embryos developing in the uterus possess soft shells, and are found in capsules that bear tiny calcareous crystals. These crystals probably serve as a calcium source for the new-born snails. Having soft embryonic shells is important, because the armature of the parent would prevent the birth of hard-shelled embryos. The reproductive biology of Plectopylidae is interesting and deserves further study. For example, the genus Halongella is known to possess calcareous thorns on the inner surface of the vagina. Furthermore, several species of Gudeodiscus, Sinicola and Sicradiscus are known to have disposable calcareous crystals of usually claw-like shape in pockets formed by the penial wall (Páll-Gergely et al. 2015b). The diverticulum of plectopylids is unique in terms of its position. Namely, it originates from the wall of the proximal vagina, usually near the branching point of the bursa copulatrix. Spermatophores are found in both organs, although in Sinicolinae subfam. nov. they were most frequent in the bursa copulatrix, whereas in the Plectopylinae in the diverticulum. In both subfamilies spermatophores found in the diverticulum consisted of fragile, folded threads, whereas the ones found in the bursa were compact masses of soft material. 
Table 4 (continued on next page). Species and subspecies of the Plectopylinae. Synonyms are marked with an asterisk.

\begin{tabular}{|c|c|}
\hline (sub)species name & Current name \\
\hline andersoni & Hunyadiscus andersoni (W. Blanford, 1869) \\
\hline anguina & Plectopylis anguina (Gould, 1847) \\
\hline auffenbergi sp. nov. & Chersaecia auffenbergi Páll-Gergely sp. nov. \\
\hline austeni & Chersaecia austeni (Gude, 1899) \\
\hline bensoni & Plectopylis bensoni Gude, 1914 \\
\hline brachydiscus Godwin-Austen, 1879* & Chersaecia dextrorsa \\
\hline brachyplecta & Chersaecia brachyplecta (Benson, 1863) comb. nov. \\
\hline breviplica Gude, 1898* & Plectopylis bensoni \\
\hline cairnsi & Plectopylis cairnsi Gude, 1898 \\
\hline castanea Gude, 1898* & Plectopylis bensoni \\
\hline crassilabris sp. nov. & Plectopylis crassilabris Páll-Gergely sp. nov. \\
\hline cyclaspis & Plectopylis cyclaspis (Benson, 1859) \\
\hline degerbolae Solem, 1966* & Chersaecia leiophis \\
\hline densegyrata sp. nov. & Chersaecia densegyrata Páll-Gergely sp. nov. \\
\hline dextrorsa & Chersaecia dextrorsa (Benson, 1860) \\
\hline feddeni & Chersaecia feddeni (W. Blanford, 1865) comb. nov. \\
\hline goniobathmos & Chersaecia goniobathmos (Ehrmann, 1922) comb. nov. \\
\hline infrafasciata Gude, 1898* & Plectopylis bensoni \\
\hline karenorum & Plectopylis karenorum W. Blanford, 1865 \\
\hline kengtungensis Gude, 1914* & Chersaecia leiophis \\
\hline laomontana & Naggsia laomontana (Pfeiffer, 1863) \\
\hline leiophis & Chersaecia leiophis (Benson, 1860) \\
\hline leucochila & Chersaecia leucochila (Gude, 1897) comb. nov. \\
\hline linterae & Plectopylis linterae Möllendorff, 1897 \\
\hline lissochlamys Gude, 1897* & Chersaecia magna \\
\hline magna & Chersaecia magna (Gude, 1897) comb. nov. \\
\hline malayana sp. nov. & Plectopylis malayana Páll-Gergely sp. nov. \\
\hline mogokensis sp. nov. & Chersaecia mogokensis Páll-Gergely sp. nov. \\
\hline muspratti & Chersaecia nagaensis muspratti (Gude, 1897) \\
\hline nagaensis & Chersaecia nagaensis nagaensis (Godwin-Austen, 1875) \\
\hline obesa Gude, 1898* & Plectopylis bensoni \\
\hline oligogyra sp. nov. & Naggsia oligogyra Páll-Gergely sp. nov. \\
\hline perarcta & Chersaecia perarcta perarcta (Blanford, 1865) \\
\hline perrierae & Chersaecia perrierae (Gude, 1897) \\
\hline ponsonbyi Godwin-Austen, 1888* & Chersaecia feddeni \\
\hline pseudophis Godwin-Austen, 1875* & Chersaecia leiophis \\
\hline refuga & Chersaecia refuga (Gould, 1846) \\
\hline repercussa Gould, $1856^{*}$ & Plectopylis bensoni \\
\hline repercussoides Gude, $1899^{*}$ & Plectopylis bensoni \\
\hline
\end{tabular}


Table 4 (continued). Species and subspecies of the Plectopylinae. Synonyms are marked with an asterisk.

\begin{tabular}{ll}
\hline (sub)species name & Current name \\
\hline reversalis sp. nov. & Chersaecia reversalis Páll-Gergely sp. nov. \\
saurini & Hunyadiscus saurini Páll-Gergely, 2016 \\
scabra sp. nov. & Chersaecia scabra Páll-Gergely sp. nov. \\
shanensis & Chersaecia shanensis (Stoliczka, 1873) \\
shiroiensis & Chersaecia shiroiensis shiroiensis (Godwin-Austen, 1875) \\
simplex & Chersaecia perarcta simplex (Solem, 1966) \\
smithiana & Chersaecia smithiana (Gude, 1896) comb. nov. \\
subnagaensis subsp. nov. & Chersaecia shiroiensis subnagaensis Páll-Gergely subsp. nov. \\
thompsoni sp. nov. & Plectopylis thompsoni Páll-Gergely sp. nov. \\
tigrina sp. nov. & Hunyadiscus tigrina Páll-Gergely sp. nov. \\
trilamellaris Godwin-Austen, 1875* & Chersaecia shanensis \\
venusta Gude, 1898* & Plectopylis bensoni \\
woodthorpei & Chersaecia woodthorpei (Gude, 1899) comb. nov. \\
\hline
\end{tabular}

\section{Acknowledgements}

I am grateful to Jonathan Ablett (NHM), Anita Eschner (NHMW), Zoltán Fehér (HNHM), Virginie Héros and Philippe Maestrati (MNHN), Ronald Janssen (SMF), Ana-Maria Păpureanu (NHMS), and András Varga (MMGY) for granting access to the museum collections under their care, to Adam Baldinger (MCZ), Seelawut Damrongsiri, Tamás Deli, Pongrat Dumrongrojwattana, Jozef Grego, Bernhard Hausdorf (ZMH), Christa Hemmen, András Hunyadi, Harry J. Lee, Thor-Seng Liew, Wim J.M. Maassen, Kenji Ohara, Kanji Okubo, Graham Oliver, Jamen Uiriamu Otani, Alexander Reischütz, Tom Schiøtte (ZMUC), John Slapcinsky (UF) and Harold Taylor (NHM) for providing specimens and sending images for study, to Liz Price for identifying historical localities, to Dinarzarde Raheem and Thierry Backeljau for commenting on the first draft of the manuscript, to Chloë Chester for professional proof editing and to Kurt Auffenberg for discussions and correcting the English. I am indebted to The Biodiversity Heritage Library for the multitude of rare literature made available to us (www.biodiversitylibrary.org). This study was supported by the Japan Society for the Promotion of Science and the MTA (Hungarian Academy of Sciences) Premium Post Doctorate Research Program.

\section{References}

Adams H. \& Adams A. 1855. The Genera of Recent Mollusca; Arranged According to their Organization. Vol. II. Van Voorst, London. https://doi.org/10.5962/bhl.title.4772

Albers J.C. 1850. Die Heliceen nach natürlicher Verwandtschaft systematisch geordnet. Th. Chr. Fr. Enslin, Berlin. https://doi.org/10.5962/bhl.title.11507

Benson W.H. 1859a. Descriptions of new species of Helix, Streptaxis, and Vitrina, collected by Mr. W. Theobald, jun. in Burmah, the Khasia Hills, and Hindustan. The Annals and Magazine of Natural History 3 (3): 184-188. Available from https://biodiversitylibrary.org/page/2317905 [accessed 4 Jul. 2018].

Benson W.H. 1859b. Descriptions of new Helicidae contained in the Darjiling collections of Messrs. W. T. and H. F. Blanford. The Annals and Magazine of Natural History 3 (3): 265-273. Available from https://biodiversitylibrary.org/page/2317971 [accessed 4 Jul. 2018]. 
Benson W.H. 1859c. Notes on the Animals of Rhaphaulus Chrysalis, Pupina artata, Otopoma clausum, Helix Achatina, and H. pylaïca. The Annals and Magazine of Natural History 3 (4): 93-96. Available from https://biodiversitylibrary.org/page/2356222 [accessed 4 Jul. 2018].

Benson W.H. 1860. Notes on Plectopylis, a group a Helicidae distinguished by several internal plicate Ephiphragms; with the Characters of a new Species. The Annals and Magazine of Natural History 3 (5): 243-247. Available from https://biodiversitylibrary.org/page/18658580 [accessed 30 Jul. 2018].

Benson W.H. 1863. Characters of new Land-Shells from the Andaman Islands, Burmah, and Ceylon, and of the Animal of Sophina. The Annals and Magazine of Natural History 3 (11): 318-323. Available from https://biodiversitylibrary.org/page/22221772 [accessed 30 Jul. 2018].

Benthem-Jutting van W.S.S. 1960. Some notes on land and freshwater Mollusca of Malaya. Basteria 24: $10-20$.

Berry A.J. 1963. An introduction to the non-marine molluscs of Malaya. Malayan Nature Journal 17: $1-17$.

Blanford W.T. 1865. Contributions to Indian Malacology, No. V. Descriptions of new land shells from Arakan, Pegu, and Ava; with notes on the distribution of described species. Journal of the Asiatic Society of Bengal 34 (2): 66-105. Available from https://biodiversitylibrary.org/page/37191013 [accessed 30 Jul. 2018].

Blanford W.T. 1869. Descriptions of new Land and Freshwater Mollusc Species collected by Dr. John Anderson in Upper Burma and Yunan. Proceedings of the Zoological Society of London 37: 444-450. https://doi.org/10.1111/j.1469-7998.1869.tb07354.x

Boonngam P., Dumrongrojwattana P. \& Matchacheep S. 2008. The Diversity of Land Snail Fauna in Chonburi Province, Eastern Thailand. Kasetsart Journal (Natural Science) 42: 256-263.

Bouchet P., Rocroi J.-P., Frýda J., Hausdorf B., Ponder W., Valdes A. \& Warén A. 2005. Classification and nomenclator of gastropod families. Malacologia: International Journal of Malacology 47 (1-2): 1-397. Available from https://biodiversitylibrary.org/page/25127194 [accessed 30 Jul. 2018].

Bouchet P., Rocroi J-P., Hausdorf B., Kaim A., Kano Y., Nützel A., Parkhaev P., Schrödl M. \& Strong E.E. 2017. Revised classification, nomenclator and typification of gastropod and monoplacophoran families. Malacologia 61 (1-2): 1-526. https://doi.org/10.4002/040.061.0201

Clements R., Sodhi N.S., Schilthuizen M. \& Ng P. 2006. Karsts of Southeast Asia: neglected and imperiled arks of biodiversity. BioScience 56: 733-742.

https://doi.org/10.1641/0006-3568(2006)56[733:LKOSAI]2.0.CO;2

Dance S.P. 1986. A History of Shell Collecting. E.J. Brill, Leiden.

Degner E. 1923. Zur Anatomie und systematischen Stellung von Sculptaria Pfeiffer. Archiv für Molluskenkunde 55 (4): 146-160.

Ehrmann P. 1922. Land- und Süßwasserschnecken aus den südl. Schan-Staaten, Hinterindien. Sitzungsberichte der naturforschenden Gesellschaft zu Leipzig 45-48: 1-28.

Gmelin J.F. 1791. Caroli a Linné, systema naturae. Tom. I. Pars VI.: 3021-3910. Beer, Leipzig. Available from https://biodiversitylibrary.org/page/25743606 [accessed 30 Jul. 2018].

Godwin-Austen H.H. 1875a. Supplementary Notes on the Species of Helicidce of the subgenus Plectopylis. Proceedings of the Zoological Society of London 1875: 43-44. Available from https://biodiversitylibrary.org/page/28501196 [accessed 30 Jul. 2018]. 
PÁLL-GERGELY B., Systematic revision of the Plectopylinae

Godwin-Austen H.H. 1875b. Descriptions of five new Species of Helicidae of the Subgenus Plectopylis, with remarks on all the other known forms. Proceedings of the Zoological Society of London 1874: 608-613. Available from https://biodiversitylibrary.org/page/28502797 [accessed 30 Jul. 2018].

Godwin-Austen H.H. 1879. On new species of the Genus Plectopylis of the Family Helicidae. Journal of the Asiatic Society of Bengal 48 (2): 1-4. Available from https://biodiversitylibrary.org/page/41375567 [accessed 30 Jul. 2018].

Godwin-Austen H.H. 1888. On some land-mollusks from Burmah, with descriptions of some new species. Proceedings of the Zoological Society of London 1888: 240-245. Available from https://biodiversitylibrary.org/page/28690913 [accessed 30 Jul. 2018].

Godwin-Austen H.H. 1895. Notes on, and drawings of, the animals of various Indian Land Mollusca (Pulmonifera). Journal of the Asiatic Society of Bengal 64 (2): 151-156. Available from https://biodiversitylibrary.org/page/39373651 [accessed 30 Jul. 2018].

Gould A.A. 1846. [Dr. Gould exhibited a collection of shells, sent from Tavoy, in Burmah, by the Rev. Mr. Mason. Among them he distinguished and characterized the following undescribed species]. Proceedings of the Boston Society of Natural History 2: 98-100. Available from https://biodiversitylibrary.org/page/9490782 [accessed 30 Jul. 2018].

Gould A.A. 1847. [Dr. Gould described new shells, received from Rev. Mr. Mason, of Burmah, several of which had been furnished...]. Proceedings of the Boston Society of Natural History 2: 218-221. Available from https://biodiversitylibrary.org/page/9490902 [accessed 30 Jul. 2018].

Gould A.A. 1856. [Dr. A.A. Gould presented the following descriptions of shells]. Proceedings of the Boston Society of Natural History 6: 11-16. Available from https://biodiversitylibrary.org/page/9493210 [accessed 30 Jul. 2018].

Gould A.A. 1862. Otia Conchologica: Descriptions of shells and molluscs from 1839 to 1862. Boston. Gould and Lincoln, Boston. Available from https://biodiversitylibrary.org/page/12900173 [accessed 30 Jul. 2018].

Gude G.K. 1896a. Armature of Helicoid landshells. Science Gossip 3 (30): 154-156. Available from https://biodiversitylibrary.org/page/33878774 [accessed 30 Jul. 2018].

Gude G.K. 1896b. Armature of Helicoid landshells. Science Gossip 3 (31): 178-181. Available from https://biodiversitylibrary.org/page/33878798 [accessed 30 Jul. 2018].

Gude G.K. 1897a. Armature of Helicoid landshells. Science Gossip 3 (32): 204-207. Available from https://biodiversitylibrary.org/page/33878824 [accessed 30 Jul. 2018].

Gude G.K. 1897b. Armature of Helicoid landshells. Science Gossip 3 (33): 244-246. Available from https://biodiversitylibrary.org/page/33878864 [accessed 30 Jul. 2018].

Gude G.K. 1897c. Armature of Helicoid landshells and new forms of Plectopylis. Science Gossip 3 (34): 274-276. Available from https://biodiversitylibrary.org/page/33878894 [accessed 30 Jul. 2018].

Gude G.K. 1897d. Armature of Helicoid landshells and new forms of Plectopylis. Science Gossip 3 (35): 300-301. Available from https://biodiversitylibrary.org/page/33878920 [accessed 30 Jul. 2018].

Gude G.K. 1897e. Armature of Helicoid landshells and new forms of Plectopylis. Science Gossip 3 (36): 332. Available from https://biodiversitylibrary.org/page/33878952 [accessed 30 Jul. 2018].

Gude G.K. 1897f. Armature of Helicoid landshells, with a new species of Plectopylis. Science Gossip 4 (37): 10-11. Available from https://biodiversitylibrary.org/page/33861365 [accessed 30 Jul. 2018].

Gude G.K. 1897g. Armature of Helicoid landshells, with a new form of Plectopylis. Science Gossip 4 (38): 36-37. Available from https://biodiversitylibrary.org/page/33861391 [accessed 30 Jul. 2018]. 
Gude G.K. 1897h. Armature of Helicoid landshells, with new species of Plectopylis. Science Gossip 4 (39): 70-71. Available from https://biodiversitylibrary.org/page/33861425 [accessed 30 Jul. 2018].

Gude G.K. 1897i. Armature of Helicoid landshells, with new species of Plectopylis. Science Gossip 4 (42): 170-171. Available from https://biodiversitylibrary.org/page/33861525 [accessed 30 Jul. 2018].

Gude G.K. 1897j. Species of Plectopylis recently described in "Science Gossip". The Journal of Malacology 6: 44-48. Available from https://biodiversitylibrary.org/page/16100004 [accessed $30 \mathrm{Jul}$. 2018].

Gude G.K. 1898a. Armature of Helicoid landshells with new species of Plectopylis. Science Gossip 4 (44): 231-232. Available from https://biodiversitylibrary.org/page/33861586 [accessed 30 Jul. 2018].

Gude G.K. 1898b. Armature of Helicoid landshells, with a new species of Plectopylis. Science Gossip 4 (45): 263-264. Available from https://biodiversitylibrary.org/page/33861618 [accessed 20 jul. 2018].

Gude G.K. 1898c. Armature of Helicoid landshells. Science Gossip 5 (49): 15-17. Available from https://biodiversitylibrary.org/page/34016951 [accessed 30 Jul. 2018].

Gude G.K. 1898d. Armature of Helicoid landshells. Science Gossip 5 (51): 74-76. Available from https://biodiversitylibrary.org/page/41951035 [accessed 30 Jul. 2018].

Gude G.K. 1898e. Armature of Helicoid landshells and new forms of Plectopylis. Science Gossip 5 (52): 114-115. Available from https://biodiversitylibrary.org/page/34017026 [accessed 30 Jul. 2018].

Gude G.K. 1898f. Armature of Helicoid landshells and new forms of Plectopylis. Science Gossip 5 (53): 133-134. Available from https://biodiversitylibrary.org/page/34017049 [accessed 30 Jul. 2018].

Gude G.K. 1898g. Armature of Helicoid landshells and new forms of Plectopylis. Science Gossip 5 (54): 170-172. Available from https://biodiversitylibrary.org/page/34017090 [accessed 30 Jul. 2018].

Gude G.K. 1898h. Species of Plectopylis recently described in "Science Gossip". The Journal of Malacology 7: 7-16. Available from https://biodiversitylibrary.org/page/16100061 [accessed $30 \mathrm{Jul}$. 2018].

Gude G.K. 1899a. Armature of Helicoid landshells and new forms of Plectopylis. Science Gossip 5 (59): 332-333. Available from https://biodiversitylibrary.org/page/34029472 [accessed $30 \mathrm{Jul}$. 2018].

Gude G.K. 1899b. Armature of Helicoid landshells and a new species of Plectopylis. Science Gossip 6 (61): 15-17. Available from https://biodiversitylibrary.org/page/34012896 [accessed 30 Jul. 2018].

Gude G.K. 1899c. Armature of Helicoid landshells and new species of Plectopylis. Science Gossip 6 (63): 75-77. Available from https://biodiversitylibrary.org/page/34036959 [accessed 30 Jul. 2018].

Gude G.K. 1899d. Armature of Helicoid landshells and new sections of Plectopylis. Science Gossip 6 (65): 147-149. Available from https://biodiversitylibrary.org/page/34012981 [accessed 30 Jul. 2018].

Gude G.K. 1899e. Armature of Helicoid landshells. Science Gossip 6 (66): 174-177. Available from https://biodiversitylibrary.org/page/34123273 [accessed 30 Jul. 2018].

Gude G.K. 1900a. Species of Plectopylis recently described in "Science Gossip". The Journal of Malacology 7: 34-38. Available from https://biodiversitylibrary.org/page/16100090 [accessed $30 \mathrm{Jul}$. 2018].

Gude G.K. 1900b. Notes on some specimens of Plectopylis. The Journal of Malacology 7: 91. Available from https://biodiversitylibrary.org/page/16100151 [accessed 30 Jul. 2018].

Gude G.K. 1908. On the identity of Plectopylis leiophis and P. pseudophis. Proceedings of the Malacological Society of London 8: 88-89. Available from https://biodiversitylibrary.org/page/32058281 [accessed 30 Jul. 2018]. 
PÁLL-GERGELY B., Systematic revision of the Plectopylinae

Gude G.K. 1911. Note on some preoccupied Molluscan generic names and proposed new genera of the family Zonitidae. Proceedings of the Malacological Society of London 9: 269-273. Available from https://biodiversitylibrary.org/page/30825115 [accessed 30 Jul. 2018].

Gude G.K. 1914a. Descriptions of new species of helicoids from the Indian Region. Proceedings of the Malacological Society of London 11 (1): 52-57.

Available from https://biodiversitylibrary.org/page/15715573 [accessed 30 Jul. 2018].

Gude G.K. 1914b. The Fauna of British India including Ceylon and Burma. Mollusca.-II. (Trochomorphidae--Janellidae). Taylor \& Francis, London.

Available from https://biodiversitylibrary.org/page/12910698 [accessed 30 Jul. 2018].

Gude G.K. 1920. Presidential address. The armature of land Mollusca. Proceedings of the Malacological Society of London 14 (2-3): 52-73. Available from https://biodiversitylibrary.org/page/30346763 [accessed 30 Jul. 2018].

Hanley S.C.T. \& Theobald W. 1870-1876. Conchologia Indica; Being Illustrations of the Land and Freshwater Shells of British India. L. Reeve \& Co., London. Available from https://biodiversitylibrary.org/page/14402372 [accessed 30 Jul. 2018].

Johnson R.I. 1964. The Recent Mollusca of Augustus Addison Gould. Smithsonian Institution, Washington. Available from https://biodiversitylibrary.org/page/7892487 [accessed 30 Jul. 2018].

Kerney M.P. \& Cameron R.A.D. 1979. A Field Guide to the Land Snails of Britain and North-west Europe. Collins, London.

Kobelt W. 1879. Illustrirtes Conchylienbuch. Bauer \& Raspe, Nürnberg. Available from https://biodiversitylibrary.org/page/33654358 [accessed 30 Jul. 2018].

Li Y.-T. 1986. The correction of diagnosis and classification of the gastropod Plectopyloides Yen. Professional Papers of Stratigraphy and Palaeontology 14: 241-252.

Maassen W.J.M. 2001. A preliminary checklist of the non-marine Molluscs of West-Malaysia. "A handlist". De Kreukel, Extra Editie [for 2001]: 1-155.

Möllendorff O. von 1897. Drei neue Arten. Nachrichtsblatt der Deutschen Malakozoologischen Gesellschaft 29: 28-31. Available from https://biodiversitylibrary.org/page/28228258 [accessed $30 \mathrm{Jul}$. 2018].

Möllendorff O.F. von 1898. Verzeichniss der auf den Philippinen lebenden Landmollusken. Abhandlungen der Naturforschenden Gesellschaft zu Görlitz 22: 25-208.

Nevill G. 1878. Hand list of Mollusca in the Indian Museum, Calcutta. Part I. Gastropoda. Pulmonata and Prosobranchia-Neurobranchia. Order of the Trustees, Calcutta. Available from https://biodiversitylibrary.org/page/19872326 [accessed 30 Jul. 2018].

Páll-Gergely B. 2018. Redescription of the reproductive anatomy and the plication of Sicradiscus hirasei (Pilsbry, 1904) (Gastropoda: Pulmonata: Plectopylidae). Venus 76 (1-4): 86-89.

https://doi.org/10.18941/venus.76.1-4_86

Páll-Gergely B. \& Asami T. 2014. Additional information on the distribution, anatomy and systematics of living and fossil Chinese Plectopylidae (Gastropoda: Pulmonata). Genus 25 (3): 527-564.

Páll-Gergely B. \& Asami T. 2016. A new species of Gudeodiscus Páll-Gergely, 2013 from China, with extraordinary conchological and anatomical features (Gastropoda, Pulmonata, Plectopylidae). ZooKeys 564: 1-19. https://doi.org/10.3897/zookeys.564.6560

Páll-Gergely B. \& Hunyadi A. 2013. The family Plectopylidae Möllendorff 1898 in China (Gastropoda, Pulmonata). Archiv für Molluskenkunde 142 (1): 1-66. 
Páll-Gergely B., Hunyadi A. \& Asami T. 2015a. A new Chinese species of Eostrobilops Pilsbry, 1927 with a checklist of Eostrobilops and Enteroplax Gude, 1897 species (Gastropoda, Pulmonata, Strobilopsidae). ZooKeys 508: 85-95. https://doi.org/10.3897/zookeys.508.10004

Páll-Gergely B., Hunyadi A., Ablett J., Luong Van H., Naggs F. \& Asami T. 2015b. Systematics of the family Plectopylidae in Vietnam with additional information on Chinese taxa (Gastropoda, Pulmonata, Stylommatophora). ZooKeys 473: 1-118. https://doi.org/10.3897/zookeys.473.8659

Páll-Gergely B., Budha P.B., Naggs F., Backeljau T. \& Asami T. 2015c. Review of the genus Endothyrella Zilch, 1960 with description of five new species (Gastropoda, Pulmonata, Plectopylidae). ZooKeys 529: 1-70. https://doi.org/10.3897/zookeys.529.6139

Páll-Gergely B., Muratov I.V. \& Asami T. 2016. The family Plectopylidae (Gastropoda, Pulmonata) in Laos with the description of two new genera and a new species. ZooKeys 592: 1-26. https://doi.org/10.3897/zookeys.592.8118

Pfeiffer L. 1845. Uebersicht der mit inneren Lamellen versehenen Helix-Arten. Zeitschrift füt Malakozoologie 2: 81-87. Available from https://biodiversitylibrary.org/page/16291669 [accessed 30 Jul. 2018].

Pfeiffer L. 1848a. Die Schnirkelschnecken (Gattung Helix) in Abbildungen nach der Natur mit Beschreibungen. In: Martini F.H.W. \& Chemnitz J.H. (eds) Systematisches Conchylien-Cabinet. Bauer \& Raspe Nürnberg. Available from https://biodiversitylibrary.org/page/51354164 [accessed $30 \mathrm{Jul}$. 2018].

Pfeiffer L. 1848b. Monographia Heliceorum Viventium: Sistens Descriptiones Systematicas et Criticas Omnium Huius Familiae Generum et Specierum Hodie Cognitarum. Volumen Primum. Brockhaus, Leipzig. Available from https://biodiversitylibrary.org/page/13130589 [accessed 30 Jul. 2018].

Pfeiffer L. 1857. Zur Fauna der Admiralitäts-Inseln. Malakozoologische Blätter 3: 237-248. Available from https://biodiversitylibrary.org/page/15865204 [accessed 30 Jul. 2018].

Pfeiffer L. 1862. Description of thirty-six new land shells, from the collection of H. Cuming, Esq. Proceedings of the Zoological Society of London 30: 268-278.

https://doi.org/10.1111/j.1469-7998.1862.tb06529.x

Pfeiffer L. 1867. Eine neue Helix. Malakologische Blätter 14: 64.

Available from https://biodiversitylibrary.org/page/15855865 [accessed 30 Jul. 2018].

Pfeiffer L. 1868. Monographia Heliceorum Viventium: Sistens Descriptiones Systematicas et Criticas Omnium Huius Familiae Generum et Specierum Hodie Cognitarum. Brockhaus, Leipzig. Available from https://biodiversitylibrary.org/page/12932069 [accessed 30 Jul. 2018].

Pfeiffer L. 1869. Novitates Conchologicae. Series Prima. Mollusca extramarina. Beschreibung und Abbildung, neuer oder kritischer Land-und Süsswasser-Mollusken. (Mit Einschluss der Auricularceen). Band 3. Theodor Fischer, Cassel.

Philippi R.A. 1847. Abbildungen und Beschreibungen neuer oder wenig gekannter Conchylien. Band 2. Theodor Fischer, Cassel. https://doi.org/10.5962/bhl.title.10589

Pilsbry H.A. 1893-1895. Manual of Conchology. Ser. 2, vol. 9. (Helicidae, vol. 7): Guide to the Study of Helices. Conchological Section, Academy of Natural Sciences of Philadelphia, Philadelphia. https://doi.org/10.5962/bhl.title.6534

Pilsbry H.A. 1905. Anatomical and systematic notes on Dorcasia, Trigonephrus, n. gen., Corilla, Thersites, and Chloritis. Proceedings of the Malacological Society of London 6: 286-291. Available from https://biodiversitylibrary.org/page/15176417 [accessed 30 Jul. 2018]. 
Raheem D.C., Breugelmans K., Wade C.M., Naggs F.C. \& Backeljau T. 2017. Exploring the shell-based taxonomy of the Sri Lankan land snail Corilla H. and A. Adams, 1855 (Pulmonata: Corillidae) using mitochondrial DNA. Molecular Phylogenetics and Evolution 107: 609-618. https://doi.org/10.1016/j.ympev.2016.12.020

Reeve L.A. 1854. Conchologia Iconica, or, Illustrations of the Shells of Molluscous Animals. Vol 7, (1495 species). Lovell Reeve, London. Available from https://biodiversitylibrary.org/page/11120877 [accessed 30 Jul. 2018].

Schileyko A.A. 1998. Treatise on Recent Terrestrial Pulmonate Molluscs, Part 1. Achatinellidae, Amastridae, Orculidae, Strobilopsidae, Spelaeodiscidae, Valloniidae, Cochlicopidae, Pupillidae, Chondrinidae, Pyramidulidae. Ruthenica Supplement 2 (1): 1-127.

Schileyko A.A. 1999. Treatise on Recent Terrestrial Pulmonate Molluscs, Part 4. Draparnaudiidae, Caryodidae, Macrocyclidae, Acavidae, Clavatoridae, Dorcasiidae, Sculptariidae, Corillidae, Plectopylidae, Megalobulimulidae, Strophocheilidae, Cerionidae, Achatinidae, Subulinidae, Glessulidae, Micractaeonidae, Ferrussaciidae. Ruthenica Supplement 2: 435-564.

Schileyko A.A. 2001. Treatise on Recent Terrestrial Pulmonate Molluscs, Part 7. Endodontidae, Thyrophorellidae, Charopidae. Ruthenica Supplement 2: 881-1034.

Solem A. 1966. Some non-marine mollusks from Thailand, with notes on classification of the Helicarionidae. Spolia Zoologica Musei Hauniensis 24: 1-110.

Solem A. 1968. "Ptychodon" misoolensis Adam and Van Benthem Jutting, 1939, a New Guinea Strobilopsid land snail and review of the genus Enteroplax. Veliger 11: 24-30. Available from https://biodiversitylibrary.org/page/42397797 [accessed 30 Jul. 2018].

Stoliczka F. 1871. Notes on terrestrial Mollusca from the neighbourhood of Moulmein (Tenasserim Provinces), with descriptions of new species. Journal of the Asiatic Society of Bengal 40 (2): 217-259. Available from https://biodiversitylibrary.org/page/35631081 [accessed 30 Jul. 2018].

Stoliczka F. 1873. Descriptions of two new species of Indian Landshells. Journal of the Asiatic Society of Bengal 42 (2): 169-171. Available from https://biodiversitylibrary.org/page/35546066 [accessed 30 Jul. 2018].

Tapparone Canefri T. 1889. Viaggio di Leonardo Fea in Birmania e regioni vicine. XVIII. - Molluschi terrestri e d'Acqua dolce. Annali del Museo Civico di Storia Naturale di Genova 2a (7): 295-359. Available from https://biodiversitylibrary.org/page/35995965 [accessed 30 Jul. 2018].

Theobald W. 1857. Notes on the distribution of some land and freshwater shells of India: Part I. Journal of the Asiatic Society of Bengal 26: 245-254. Available from https://biodiversitylibrary.org/page/35546066 [accessed 30 Jul. 2018].

Tumpeesuwan C. \& Tumpeesuwan S. 2010. Species diversity and abundance of Land Snails in limestone and sandstone hills in Nong Bua Lamphu Province. Burapha Science Journal 2: 10-19. [In Thai.]

Tryon G.W. 1887. Manual of Conchology; Structural and Systematic. With Illustrations of the Species. Ser. 2, vol. 3. Helicidae, Volume I. Published by the Author, Philadelphia. Available from https://biodiversitylibrary.org/page/1287540 [accessed 30 Jul. 2018].

Yen T.-C. 1969. Fossile nicht-marine Mollusken-Faunen aus Nordchina. Sitzungsberichte der Österreichischen Akademie der Wissenschaften 177: 55-57.

Zilch A. 1959-1960. Handbuch der Paleozoologie, 6 (2) Euthyneura: 481-834. Gebrüder Borntraeger, Berlin. 
Manuscript received: 8 June 2017

Manuscript accepted: 9 February 2018

Published on: 16 August 2018

Topic editor: Rudy Jocqué

Section editor: Kurt Jordaens

Desk editor: Chloë Chester

Printed versions of all papers are also deposited in the libraries of the institutes that are members of the EJT consortium: Muséum national d'Histoire naturelle, Paris, France; Botanic Garden Meise, Belgium; Royal Museum for Central Africa, Tervuren, Belgium; Natural History Museum, London, United Kingdom; Royal Belgian Institute of Natural Sciences, Brussels, Belgium; Natural History Museum of Denmark, Copenhagen, Denmark; Naturalis Biodiversity Center, Leiden, the Netherlands; Museo Nacional de Ciencias Naturales-CSIC, Madrid, Spain; Real Jardín Botánico de Madrid CSIC, Spain; Zoological Research Museum Alexander Koenig, Bonn, Germany. 